\title{
Characterizing the Fish Passage Environment at The Dalles Dam Spillway: 2001-2004
}

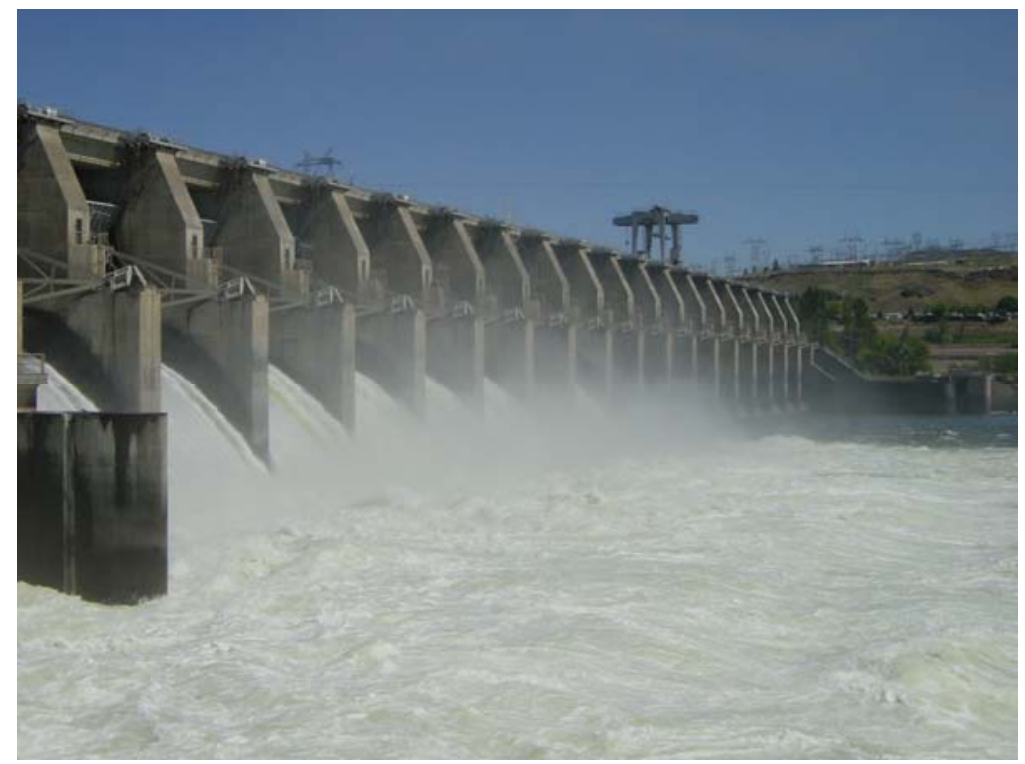

M. C. Richmond

T. J. Carlson

J. A. Serkowski

C. B. Cook

J. P. Duncan

W. A. Perkins

Final Report

May 2007

Prepared for the U.S. Army Corps of Engineers

Portland District, Portland, Oregon

Under a Related Services Agreement with the U.S. Department of Energy

Contract DE-AC05-76RL01830

\section{Pacific Northwest National Laboratory}




\title{
DISCLAIMER
}

This report was prepared as an account of work sponsored by an agency of the United States Government. Neither the United States Government nor any agency thereof, nor Battelle Memorial Institute, nor any of their employees, makes any warranty, express or implied, or assumes any legal liability or responsibility for the accuracy, completeness, or usefulness of any information, apparatus, product, or process disclosed, or represents that its use would not infringe privately owned rights. Reference herein to any specific commercial product, process, or service by trade name, trademark, manufacturer, or otherwise does not necessarily constitute or imply its endorsement, recommendation, or favoring by the United States Government or any agency thereof, or Battelle Memorial Institute. The views and opinions of authors expressed herein do not necessarily state or reflect those of the United States Government or any agency thereof.

\author{
PACIFIC NORTHWEST NATIONAL LABORATORY \\ operated by \\ BATTELLE \\ for the \\ UNITED STATES DEPARTMENT OF ENERGY \\ under Contract DE-AC05-76RL01830
}

Printed in the United States of America

Available to DOE and DOE contactors from the

Office of Scientific and Technical Information,

P.O. Box 62, Oak Ridge, TN 37831-0062;

ph: (865) 576-8401

fax: (865) 576-5728

email: reports@adonis.osti.gov

\author{
Available to the public from the National Technical Information Service, \\ U.S. Department of Commerce, 5285 Port Royal Rd., Springfield, VA 22161 \\ ph: (800) 553-6847$$
\text { fax: (703) 605-6900 }
$$ \\ email: orders@ntis.fedworld.gov \\ online ordering: http://www.ntis.gov/ordering.htm
}

This document was printed on recycled paper.

$(9 / 2003)$ 


\title{
Characterizing the Fish Passage Environment at The Dalles Dam Spillway: 2001-2004
}

\author{
M. C. Richmond \\ T. J. Carlson \\ J. A. Serkowski \\ C. B. Cook \\ J. P. Duncan \\ W. A. Perkins
}

Final Report

May 2007

Prepared for the U.S. Army Corps of Engineers

Portland District, Portland, Oregon

Under a Related Services Agreement

with the U.S. Department of Energy

Contract DE-AC05-76RL01830

Pacific Northwest National Laboratory

Richland, Washington 99352 



\section{Summary}

Fish are injured and/or killed during passage through high-energy dissipation and energy extraction environments such as spillway stilling basins, sluiceway outfalls, and hydropower turbines. The hydraulic conditions in these environments that pose a risk to fish health are a function of many factors. In the case of spillways and stilling basins, important factors include the design of the stilling basin (dimensions, presence or absence of baffle blocks, presence or absence of deflectors), spillway discharge, and tailwater elevation.

At The Dalles Dam, located between Oregon and Washington states on the Columbia River, fish passing over the spillway and exposed to the severe hydraulic environment in the stilling basin have a survival rate that is below acceptable levels. The objective of this study was to identify conditions within The Dalles Dam spill environment that are dangerous to fish and identify and compare choices between different operational and structural alternatives.

The spill environment at The Dalles Dam in 2001-2004 was characterized using a field-deployed autonomous sensor (the Sensor Fish), live-fish balloon tag tests, computational fluid dynamics (CFD) modeling, and Lagrangian particle tracking. The sensor fish has a self-contained capability to digitally record the pressure and triaxial accelerations during is exposure history after release into the spillway. After recovery downstream of the tailrace, the data stored in the memory of the sensor are downloaded and stored for analysis. The spillway, stilling basin, and tailrace hydrodynamics were simulated using an unsteady, free-surface, three-dimensional CFD code that solved the Reynolds-averaged Navier-Stokes equations in conjunction with a two-equation turbulence model. The results from the CFD simulations were then used in a Lagrangian particle tracking model that included the effects of mass, drag, and buoyancy in the particle equation of motion. A random walk method was used to simulate the effects of small-scale turbulence on the particle motion.

Several operational and structural conditions were evaluated using data from Sensor Fish, live-fish balloon tag tests, CFD, and particle tracking. Quantifying events such as strike and stilling basin retention time characterized exposure conditions in the spill environment. The key study results were:

- The use of unsteady CFD and Lagrangian tracking of particles with inertia was an effective means of quantifying stilling basin flow-related characteristics using the retention time and collision count metrics.

- A relational database system (using Microsoft Access) was implemented to facilitate the analysis of the large amount of Sensor Fish, CFD-based Lagrangian particle-tracking, and live fish data. The database was found to be an efficient means for accessing and analyzing data from disparate sources.

- Particles with mass (inertia) follow different paths through the stilling basin compared to massless particles (as represented by streamlines in steady flow). Therefore, it is important to use inertial particles when computing metrics such as retention time and collision count. 
- Median stilling basin retention time ranged from 6 to 10 seconds, but exceeded 100 seconds in some cases. Retention time decreased with increasing spillway discharge. This trend was consistent between the Sensor Fish and particles.

- Sensor Fish and particles both showed that construction of the spillwall between bays 6 and 7 reduced the lateral flow component (towards the North) in the stilling basin.

- Vertical release location (shallow or deep) did not have a consistent effect on live fish survival, Sensor Fish collision count, or particle collision count.

- The majority of particles passed directly through the stilling basin with no recirculation.

- Particle tracking showed that the majority of high-intensity collisions occurred on baffle blocks.

- Even for particles that did not collide with the baffle blocks, many showed rapid pressure changes that could be harmful to fish.

- In a simulation with the baffle blocks removed, many more collisions occurred on the face of the endsill as compared to the existing conditions with baffle blocks in place.

- The incidence of Sensor Fish collisions was higher at low (4 Kcfs) and high (20 Kcfs) discharges and lower at moderate (10-15 Kcfs) discharges when the data were pooled by discharge across all treatments. Live fish also tended to have higher survival at moderate discharge. However, no consistent trends were observed within individual treatments (release bay, release depth/offset, and discharge). The greater variability in collisions per deployment may be due to the small number of Sensor Fish released (about 15 samples) in an specific treatment.

- Particles showed that severe collision was maximum at moderate discharge (13 to $18 \mathrm{Kcfs}$ ) when the data were pooled by discharge. This trend was the inverse of that observed in the live fish and sensor fish data. When individual treatments were considered, confounding trends in particle severe collision counts were observed.

- Particle metrics showed a strong influence of horizontal release location on retention time and collision count. This effect was not observed in the Sensor Fish or live fish data, but only two horizontal locations were used in the field tests.

The following are recommendations for future work:

- The prototype relational database system implemented in this work is specific to The Dalles Dam spillway studies. The functionality of this database can be expanded for use in assessments of fish passage conditions at turbines, spillways and bypass facilities for other hydroelectric projects. In addition to overall survival estimates, the database should contain live fish injury mechanism classifications that are consistent with laboratory investigations of fish injury. 
- A Sensor Fish statistical study design and data analysis methodology should be developed that can be used to estimate necessary sample sizes to meet a specified precision level in analysis metrics such as collision count. The methodology should also include presentation of standard error or confidence limits for each analysis metric including a definition of sample size requirements.

- Laboratory tests with Sensor Fish and live fish collisions are needed to determine the relationship between sensor collision intensity and live fish injury rates. The tests should be representative of collision mechanisms for different hydraulic structures such as baffle blocks, deflectors, and turbine blades.

- The overall methodology using Sensor Fish, CFD, particle tracking, and the database system developed in this study could be used to perform a synthesis of spillway passage studies conducted at different Columbia and Snake River Dams. The effects of different spillway elevation profiles and configurations with and without baffle blocks, flow deflectors, and RSWs (removable spillway weirs) could be analyzed. 



\section{Acknowledgments}

This study was funded by the U.S. Army Corps of Engineers, Portland District, Portland Oregon under a Related Services Agreement with the U.S. Department of Energy under Contract DE-AC05-76RL01830.

We would like to thank the following individuals for their contributions to this project:

- US Army Corps of Engineers, Portland District

- Mike Langeslay

- Laurie Ebner

- Natalie Richards

- Paul Williams

- US Army Corps of Engineers, ERDC

- Winston Glenn Davis (1:80 general model data)

- William Preslan (1:40 sectional model data)

- Steven Wilhelms (1:40 sectional model data)

- Normandeau Associates

- Paul Heisy

- Dilip Mathur

- Pacific Northwest National Laboratory

- $\mathrm{Tao} \mathrm{Fu}$

- Dennis Dauble

- Cindy Rakowski

- Mark Weiland

This document was prepared using the LTEX typesetting system (http://www.tug.org). We thank Scott Waichler and the PNNL-IATEX project (http://latex.pnl.gov) for providing the Laboratory standard document style files. 



\section{Abbreviations and Acronyms}

$\begin{array}{ll}\text { 3DOF } & \text { three-degree-of-freedom } \\ \text { 6DOF } & \text { six-degree-of-freedom } \\ \text { CENWP } & \text { Portland District, U.S. Army Corps of Engineers } \\ \text { CFD } & \text { computational fluid dynamics } \\ \text { cfs } & \text { cubic feet per second } \\ \text { ERDC } & \text { Engineer Research and Development Center, U.S. Army Corps of Engineers } \\ \text { Hz } & \text { Hertz or samples/second } \\ \text { Kcfs } & \text { thousand cubic feet per second } \\ \text { LPT } & \text { Lagrangian particle tracking } \\ \text { MAE } & \text { Mean absolute error } \\ \text { PNNL } & \text { Pacific Northwest National Laboratory } \\ \text { RMS } & \text { Root mean square error } \\ \text { STL } & \text { StereoLithography } \\ \text { USACE } & \text { U.S. Army Corps of Engineers }\end{array}$





\section{Contents}

Executive Summary . . . . . . . . . . . . . . . . . iii

Acknowledgments ..................................... vii

Abbreviations and Acronyms ................... ix

1.0 Introduction . . . . . . . . . . . . . . . . . . . 1.1

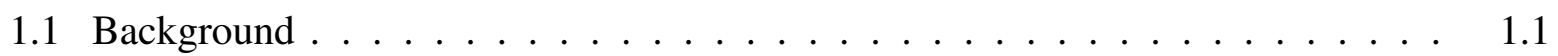

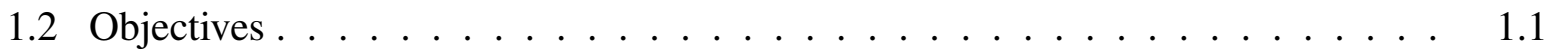

1.3 The Dalles Dam . . . . . . . . . . . . . . . . . . . . 1.1

1.4 Report Organization . . . . . . . . . . . . . . . . . . . 1.7

2.0 Methods .............................. . . . . . . . . .

2.1 Sensor Fish Devices $\ldots \ldots \ldots \ldots \ldots$

2.1.1 Sensor Fish Deployment and Recovery . . . . . . . . . . . . . . . . 2.2

2.1.2 Treatment Releases . . . . . . . . . . . . . . 2.3

2.2 Computational Fluid Dynamics (CFD) . . . . . . . . . . . . . . 2.3

2.3 Lagrangian Particle Tracking (LPT) . . . . . . . . . . . . . . . . 2.4

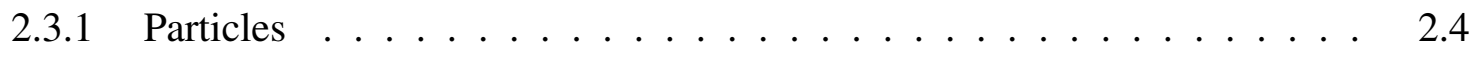

2.3.1.1 Spherical Particles . . . . . . . . . . . . . 2.5

2.3.1.2 Massless Particles ................ 2.6

2.3.2 Effects of Turbulence . . . . . . . . . . . . . . . 2.6

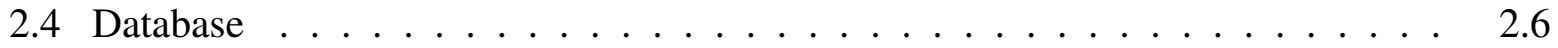

2.4.1 Design Objectives . . . . . . . . . . . . . . . 2.7

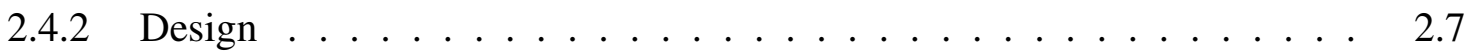

2.4.2.1 Data Storage . . . . . . . . . . . . . 2.7 
2.4.2.2 Query Interface $\ldots \ldots \ldots \ldots \ldots$

2.4.2.3 Data Analysis Capability . . . . . . . . . . . . . . . 2.11

2.4 .3 Data Entry . . . . . . . . . . . . . . . . . 2.13

2.5 Analysis Metrics . . . . . . . . . . . . . . . . 2.13

2.5 .1 Sensor Fish . . . . . . . . . . . . . . . . . . . . . . 2.15

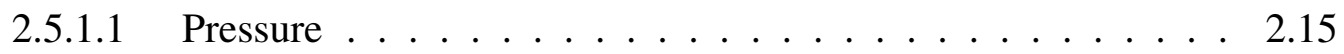

2.5.1.2 Acceleration and Collision $\ldots \ldots \ldots \ldots \ldots$

2.5.1.3 Residence Time . . . . . . . . . . . . . . . . . . . 2.16

2.5.2 Computational Fluid Dynamics and Lagrangian Particle Tracking . . . . 2.16

2.5.2.1 Particle Collisions . . . . . . . . . . . . . 2.16

2.5.2.2 Particle Residence Time . . . . . . . . . . . . . . 2.17

2.6 Limitations . . . . . . . . . . . . . . . . . . . . 2.17

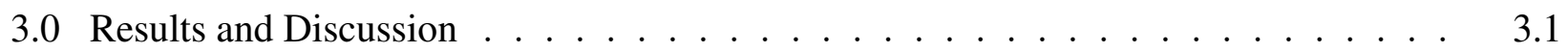

3.1 Sensor Fish $\ldots \ldots \ldots \ldots . \ldots \ldots$

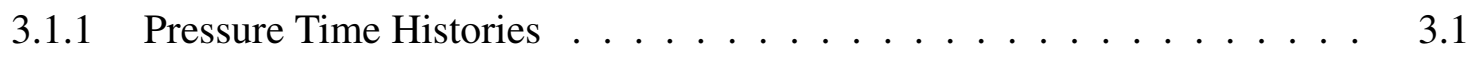

3.1 .2 Residence Time . . . . . . . . . . . . . . . . . 3.3

3.1 .3 Collision Count . . . . . . . . . . . . . . . . . . . 3.4

3.2 Tainter Gate Approach Conditions Near Release Pipe Locations . . . . . . . 3.6

3.3 Lagrangian Particle Tracking . . . . . . . . . . . . . . . . . 3.11

$3.3 .1 \quad$ Trajectories . . . . . . . . . . . . . . . . 3.12

3.3.2 Collision Locations $\ldots \ldots \ldots \ldots . \ldots \ldots$

3.3.3 Residence Times . . . . . . . . . . . . . . . . . . . 3.18

3.3 .4 Release Location . . . . . . . . . . . . . . . . . . . . . . . . . 3.22 
3.3.5 Baffle Block Removal . . . . . . . . . . . . . . . . . . . . 3.27

3.3.6 Inertial Versus Fluid Particles _ . . . . . . . . . . . . . . . . 3.29

3.4 Comparison of Live Fish Test, Sensor Fish, and Particle Tracking Results . . 3.29

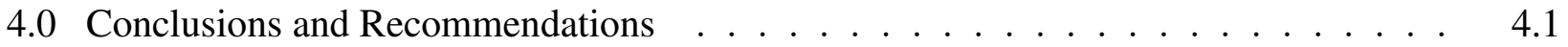

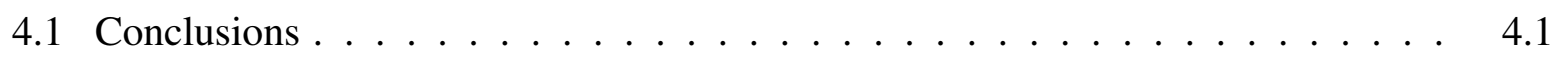

4.2 Recommendations . . . . . . . . . . . . . . . . . . 4.2

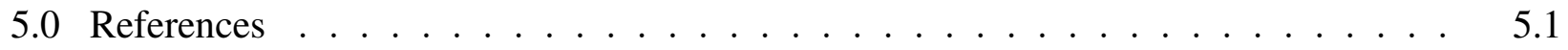

Appendix A - Summary Tables $\ldots \ldots \ldots \ldots \ldots \ldots$ A.1 . . . . . . . . . .

Appendix B - Geometry for The Dalles Tailrace CFD Models . . . . . . . . . . . B.1

Appendix $\mathrm{C}-\mathrm{CFD}$ Model $\ldots \ldots \ldots \ldots \ldots \ldots \ldots \ldots \ldots$

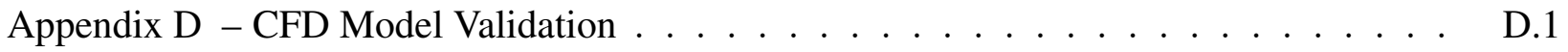




\section{Figures}

1.1 Location of The Dalles Dam on the Columbia River . . . . . . . . . . . . . . . . . 1.2

1.2 Plan view of The Dalles Dam showing the primary structures, including the powerhouse, navigation lock, and spillway. . . . . . . . . . . . . . . 1.3

1.3 Columbia River bathymetery downstream of the The Dalles Dam. . . . . . . . . . . 1.4

1.4 Aerial view of The Dalles Lock and Dam with all spillway bays operating. . . . . . 1.4

1.5 Geometry of The Dalles spillway, stilling basin, and end sill. . . . . . . . . . . 1.5

1.6 Photograph taken during the construction of The Dalles Dam. The photo shows the guide walls on each side of Bay 2 on the right hand side. . . . . . . . . . . . 1.6

1.7 Photograph taken during the construction of The Dalles Dam. The photo shows the stilling basin, baffle blocks and endsill. . . . . . . . . . . . . . . . . .

2.1 Sensor Fish body fixed coordinate system. The 3DOF version used in this study only measures the three linear accelerations $\left(a_{x}, a_{y}, a_{z}\right)$ which are shown as red arrows. The $6 \mathrm{DOF}$ version measures the angular velocities $\left(\omega_{x}, \omega_{y}, \omega_{z}\right)$ in addition to the linear accelerations.

2.2 Large version of the Sensor Fish device used in 2001 and 2002. This version was used in 423 releases. . . . . . . . . . . . . . . . . . . . . . . . . . .

2.3 3DOF version of the Sensor Fish device used in 2003 and 2004. This version was used in 464 releases.

2.4 Sensor fish sample table relationships. . . . . . . . . . . . . .

2.5 Live fish sample table relationships. . . . . . . . . . . . . . . . 2.10

2.6 Access 2003 query interface form. . . . . . . . . . . . . . . 2.11

$2.7 \quad$ An Matlab-based sensor fish graphing application screen. . . . . . . . . . . . . . 2.12

2.8 A MatLab sensor fish graphing application screen. . . . . . . . . . . . . . . 2.13

2.9 A MatLab sensor fish graphing application screen. . . . . . . . . . . . . . . . . 2.14

2.10 Sample pressure profiles from a sensor fish and CFD particle. . . . . . . . . . . . 2.17

3.1 Features of a typical sensor fish pressure time history during a spillway passage release. . . . . . . . . . . . . . . . . . . . . 
3.2 Common sensor fish pressure time histories for spillway passage releases. . . . . . 3.2

3.3 Sensor fish pressure record indicating recirculation in the stilling basin. . . . . . . 3.3

3.4 Histogram of sensor fish stilling basin residence time. All releases were pooled together. . . . . . . . . . . . . . . . . . 3.4

3.5 Average sensor fish residence time for different ranges of bay discharge. . . . . . 3.5

3.6 Sensor fish average collision rates as a function of bay discharge rate. . . . . . . . 3.6

3.7 Tainter gate flows $\ldots \ldots \ldots \ldots \ldots \ldots$

3.8 Tainter gate pressure $\ldots \ldots \ldots \ldots \ldots$

3.9 Tainter gate pressure error . . . . . . . . . . . . . . . . . . 3.10

3.10 Particle release locations. . . . . . . . . . . . . . . . 3.11

3.11 Relationship between computed metrics and number of particles. . . . . . . . . . 3.12

3.12 Particle tracks in Bay 4 at 17kcfs with the spillway in place between Bays 6 and 7. . 3.13

3.13 Common particle trajectories through the stilling basin. . . . . . . . . . . . 3.14

3.14 Side view of particle distributions at different times in Bay 4 at $17 \mathrm{kcfs}$. Red and blue particles were released at the higher and lower spillway face elevations, respectively.

3.15 Recirculation zone in upper section of flow of Bay 2 at 12 Kcfs. . . . . . . . . 3.15

3.16 Plan view of particles shown in Figure 3.14 from time $=0$ to $2 \mathrm{~s} . \ldots . . . . .3 .16$

3.17 Plan view of particles shown in Figure 3.14 from time $=3$ to $5 \mathrm{~s} . \ldots . . . . . .3 .16$

3.18 Particles released from Bay 13 caught in lateral flow. . . . . . . . . . . . . . 3.17

3.19 Particle tracks in Bay 4 without and with the Bay $6 / 7$ training wall. . . . . . . . . 3.17

3.20 Particle wall collisions colored and sized by impact velocity in Bay 4 at 10kcfs. . . 3.18

3.21 Trajectories of particle colliding with baffle block. . . . . . . . . . . . . . 3.19

3.22 Collision count as function of bay discharge rate . . . . . . . . . . . . . . 3.20

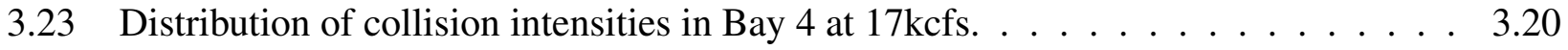


3.24 Residence time as a function of bay discharge rate . . . . . . . . . . . . 3.21

3.25 Distribution of residence times in Bay 2 at 4 Kcfs. . . . . . . . . . 3.21

3.26 Collision count metric distribution by release location in Bay 2 at 12 Kcfs. . . . . 3.22

3.27 Lateral flow offsets particles released at center of Bay $2 \ldots \ldots$. . . . . . . . 3.23

3.28 Residence time in Bay 2 at $10 \mathrm{Kcfs}$ as a function of release location across the spillway face. . . . . . . . . . . . . . . . . . 3.23

3.29 Interaction with flow separation area behind pier extension leads to longer residence times. . . . . . . . . . . . . . . . . . . . . . . . 3.24

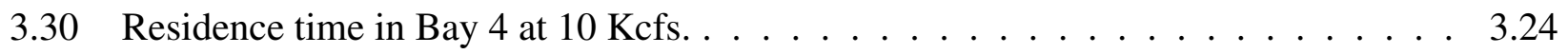

3.31 Effect on residence time of $4 \mathrm{ft}$ lateral shift in release location in Bay 2. . . . . . . . 3.25

3.32 Relationship between total collision count rate and release depth. . . . . . . . 3.26

3.33 Relationship between residence time and release depth. . . . . . . . . . . 3.26

3.34 Effects of removing baffle blocks in front of Bay $2 \ldots \ldots \ldots . .2 \ldots$

3.35 Particle wall collisions colored and sized by collision velocity in Bay 2 at $21 \mathrm{Kcfs}$ with no baffle blocks. . . . . . . . . . . . . . . . . . . . . 3.28

3.36 Comparison of streamlines to inertial particles used in this study. . . . . . . . . . 3.29

3.37 Live fish statistics 2003 and $2004 \ldots \ldots \ldots . \ldots \ldots . \ldots \ldots$

3.38 Sensor Fish metrics 2003 and $2004 \ldots \ldots \ldots \ldots$. . . . . . . . . . . . . . . . .

3.39 Particle metrics 2003 and $2004 \ldots \ldots \ldots \ldots \ldots . \ldots \ldots \ldots$

B.1 Spatial distribution of bathymetry data $\ldots \ldots \ldots \ldots \ldots \ldots$

B.2 Anomalous bathymetry features between the powerhouse and tailrace bathymetry . B.4

B.3 Three-dimensional representation of the bathymetry $\ldots \ldots \ldots \ldots \ldots \ldots \ldots$

C.1 Three-dimensional representation of the bathymetry $\ldots \ldots \ldots \ldots \ldots$ C.4 . . . . . .

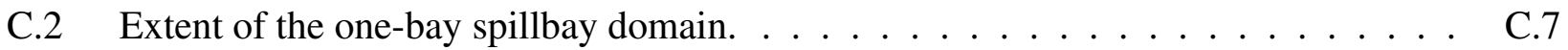

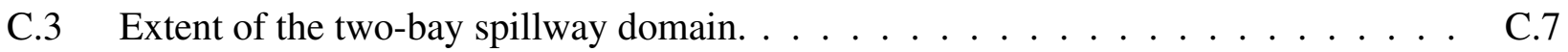


C.4 Plan view of the 12 -bay spillway domain $\ldots \ldots \ldots \ldots$. . . . . . . . .

C.5 Plan view of the 19 -bay spillway domain $\ldots \ldots \ldots \ldots \ldots \ldots$

C.6 Plan view of the 19-bay May02T2 simulation . . . . . . . . . . . . . C.10

D.1 Plan View: Baffle Block Details and Piezometer Locations . . . . . . . . . . . . . D.1

D.2 Side View: Baffle Block Details and Piezometer Locations . . . . . . . . . . . . . D.4

D.3 End Sill and Elevation $68 \mathrm{ft}$ Shelf Piezometer Locations . . . . . . . . . . . . . . D.4

D.4 Sketch of water surface elevation and velocity vectors from the $5 \mathrm{kcfs}$ per bay physical model simulation. Source: BHL (1964) . . . . . . . . . . . . . D.5

D.5 Velocity magnitude shaded cross section generated by the CFD model for the $5 \mathrm{kcfs}$ simulation. The cross section passes through the model centerline baffle. . . . . . D.5

D.6 Comparison of physical model versus CFD model pressures around the baffle block D.5

D.7 Comparison of physical model versus CFD model pressures around the end sill . . D.6

D.8 Sketch of water surface elevation and velocity vectors from the $20 \mathrm{kcfs}$ per bay physical model simulation. Source: BHL (1964) . . . . . . . . . . . D.6

D.9 Velocity magnitude shaded cross section generated by the CFD model for the 20 kcfs simulation. The cross section passes through the model centerline baffle. . . . D.6

D.10 Comparison of physical model versus CFD model pressures around the baffle block D.7

D.11 Comparison of physical model versus CFD model pressures around the end sill $\quad$. D.7

D.12 1:40 scale physical model of The Dalles Spillway at ERDC. . . . . . . . . . . . . D.8

D.13 3-D perspective of the CFD 1:40 scale numerical flume. . . . . . . . . . . D.9

D.14 Plan view of the physical model flume and measurement sites . . . . . . . . . . D.9

D.15 1:40 scale physical model versus CFD model comparison . . . . . . . . . . D.11

D.16 ADV measurements locations in front of a TDA spillbay . . . . . . . . . . . D.14

D.17 Tainter gate validation . . . . . . . . . . . . . . . D.15 


\section{Tables}

B.1 Document sources for TDA structures $\ldots \ldots \ldots \ldots \ldots \ldots$ B.1

B.2 Document sources for bathymetry data . . . . . . . . . . B.2

C.1 CENWP Rating Curve for TDA at Forebay Elevation $160 \mathrm{ft}$. . . . . . . . . . . . C.6

D.1 Model parameters for the 1:36 model simulations _ . . . . . . . . . . D.2

D.2 Comparison of horizontal velocity data for the 1:40 scale TDA model. . . . . . . . D.12

D.3 Summary of velocity magnitude error statistics for the tainter gate validation simulation cases. . . . . . . . . . . . . . . . . . . . D.13

D.4 Comparison of computed discharge and discharge obtained from CENWP rating curve. . . . . . . . . . . . . . . . . . . D 13 


\subsection{Introduction}

This report presents the results from a series of studies of spillway passage conditions at The Dalles Dam during 2001 through 2004. The work was conducted by Pacific Northwest National Laboratory (PNNL) for the U.S. Army Corps of Engineers (USACE), Portland District.

\subsection{Background}

Fish are injured and/or killed during passage through high-energy dissipation and energy extraction environments such as spillway stilling basins, sluiceway outfalls, and hydropower turbines. The hydraulic conditions in these environments that pose a risk to fish health are a function of many factors. In the case of spillways and stilling basins, important factors include the design of the stilling basin (dimensions, presence or absence of baffle blocks, presence or absence of deflectors), spillway discharge, and tailwater elevation.

The Dalles Dam (TDA) was constructed during 1952-1957, and is located at River Mile 191.5 (Figure 1.1). When The Dalles Dam was constructed, passage facilities for downstream migranting juvenile salmonids were not included. Presently, the only means to pass downstream migranting salmonids at The Dalles Dam through non-turbine routes are spillway and sluiceway operations where they are exposed to a severe hydraulic environment. Using these routes, fish passage efficiency (FPE; the proportion of fish passing the dam through non-turbine routes) is about $80-90 \%$. Survival estimates of $92-96 \%$ for spill and $81-86 \%$ for turbine passage are among the lowest in the Columbia River Basin (Ploskey et al. 2001). Thus, there is a definite need to improve passage conditions for juvenile salmon at The Dalles Dam.

\subsection{Objectives}

The overall goal of this study was to identify hydraulic conditions within The Dalles Dam spill environment that are dangerous to fish and could be reduced when making choices between different operational and structural alternatives. Specific objectives were to:

- Describe spillway passage conditions using the Sensor Fish device (a self-contained autonomous three-degree-of-freedom sensor), computational fluid dynamics (CFD), and Lagrangian tracking of particles with mass.

- Use a combination of sensor fish, CFD, particle tracking, and live fish data to evaluate stilling basin conditions that may be related to increased risk of direct injury to fish.

- Investigate alternative structural configurations such as a training wall (or spillwall) and baffle block removal.

\subsection{The Dalles Dam}

The Dalles Dam is located approximately 192 miles upstream of the mouth of the Columbia River (see Figure 1.1). The main features of the project are shown in Figure 1.2. The bathymetry of the 
Columbia River near the The Dalles is very complex with extreme changes in elevation in several locations (Figure 1.3).

Construction of The Dalles Dam began in 1952, and water was first impounded in 1957 (USACE 2000). As shown in Figure 1.4, the spillway contains 23 spillway bays. Each $50 \mathrm{ft}$ wide bay is controlled with a tainter gate ( $47 \mathrm{ft}$ radius) and is separated from adjoining bays with a $10 \mathrm{ft}$ wide pier. The overall length of the spillway is $1447 \mathrm{ft}$, with its crest elevation at $121 \mathrm{ft}$ (m.s.l.) and top deck elevation at $185 \mathrm{ft}$ (m.s.l.) The bottom of the stilling basin is at $55 \mathrm{ft} \mathrm{m}$.s.l. and the downstream shelf rises up to $68 \mathrm{ft}$ m.s.l. (Figure 1.5). Baffle blocks were constructed approximately $197 \mathrm{ft}$ downstream of the spillway crest to dissipate energy and force a hydraulic jump in the stilling basin (Figures 1.6 and 1.7). These are $9 \mathrm{ft}$ high by $10.5 \mathrm{ft}$ wide sloping blocks that are uniformly separated with a gap of $6.2 \mathrm{ft}$. A $13 \mathrm{ft}$ high vertical end sill marks the downstream end of the stilling basin. A concrete apron then extends $52 \mathrm{ft}$ downstream from the end sill.

Downstream of Bays 1 through 15, the basalt shelf extends for approximately $700 \mathrm{ft}$ before a very steep drop-off leading to the thalweg is reached. Downstream of Bays 15 through 23, the basalt shelf tapers back towards the spillway, and the length of the basalt shelf is much less (approximately 200 feet downstream of Bay 23).

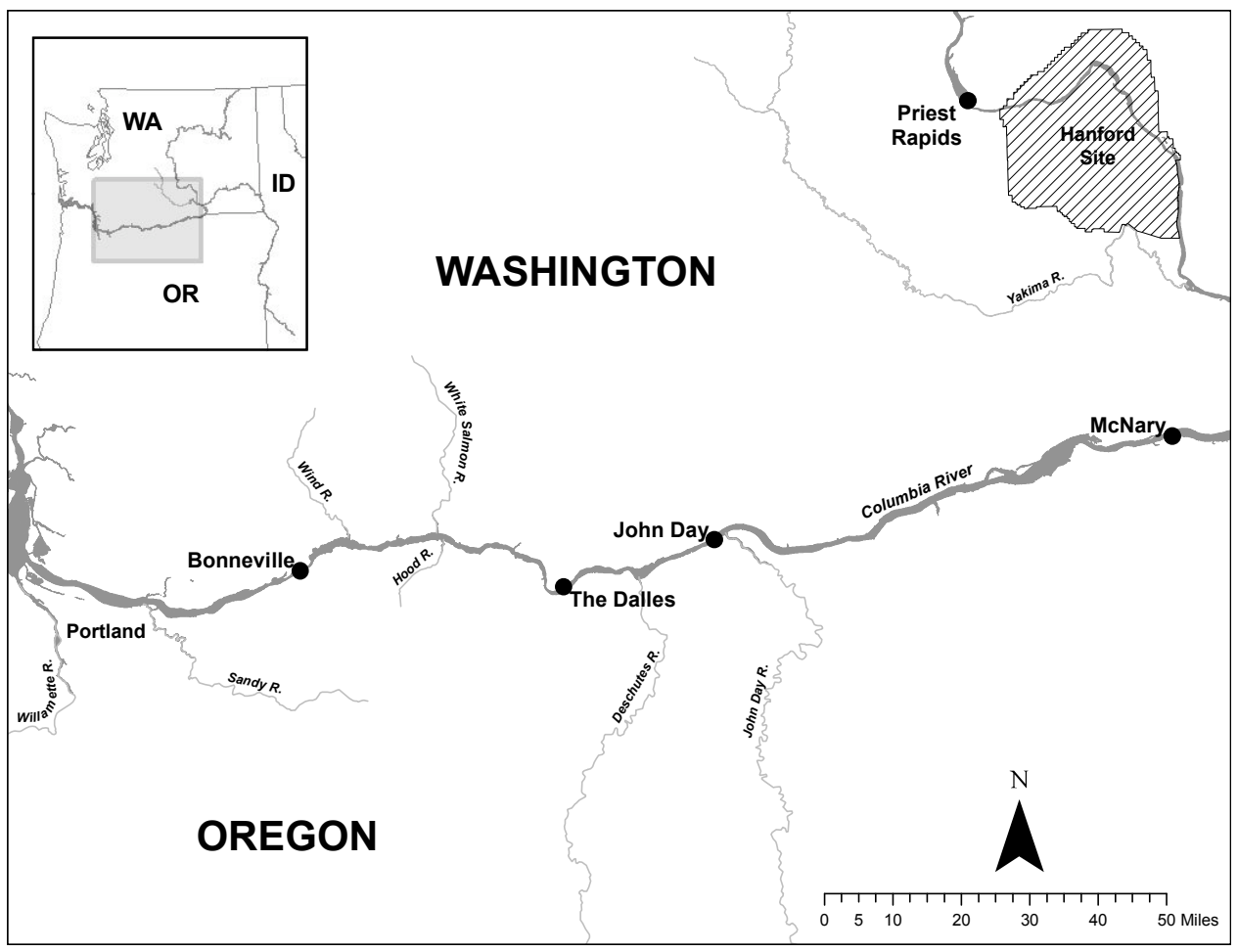

Figure 1.1. Location of The Dalles Dam on the Columbia River 


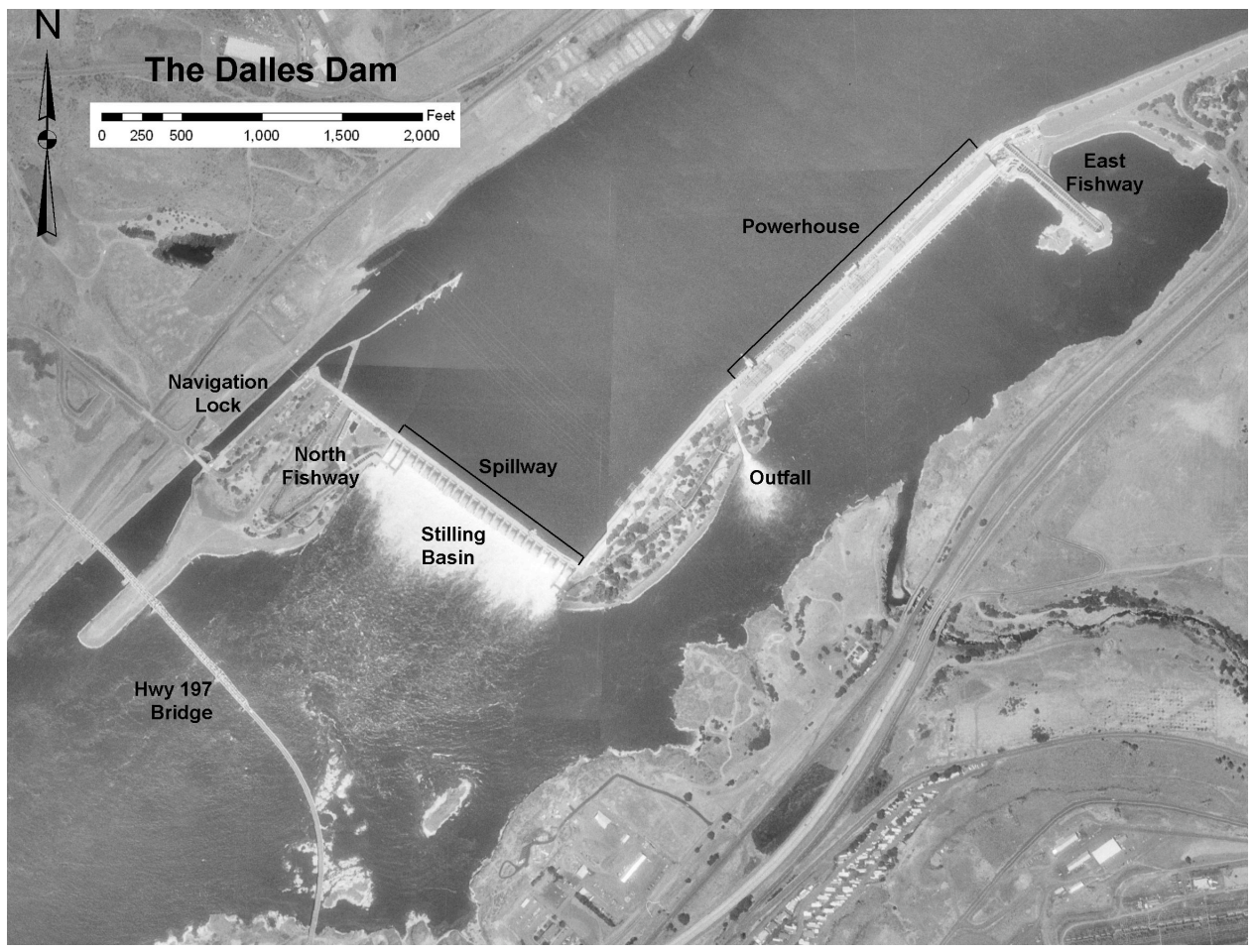

Figure 1.2. Plan view of The Dalles Dam showing the primary structures, including the powerhouse, navigation lock, and spillway. 


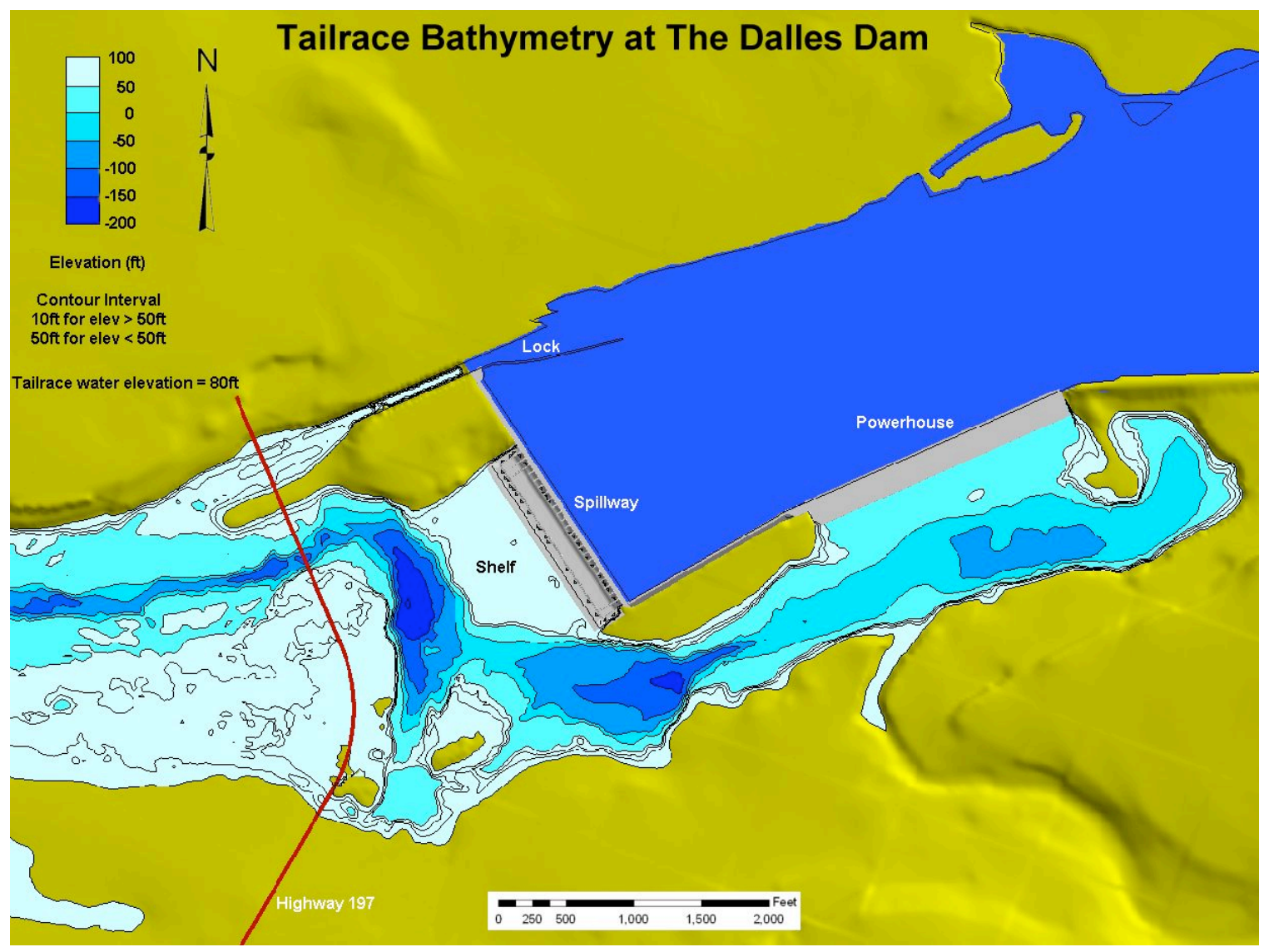

Figure 1.3. Columbia River bathymetery downstream of the The Dalles Dam.

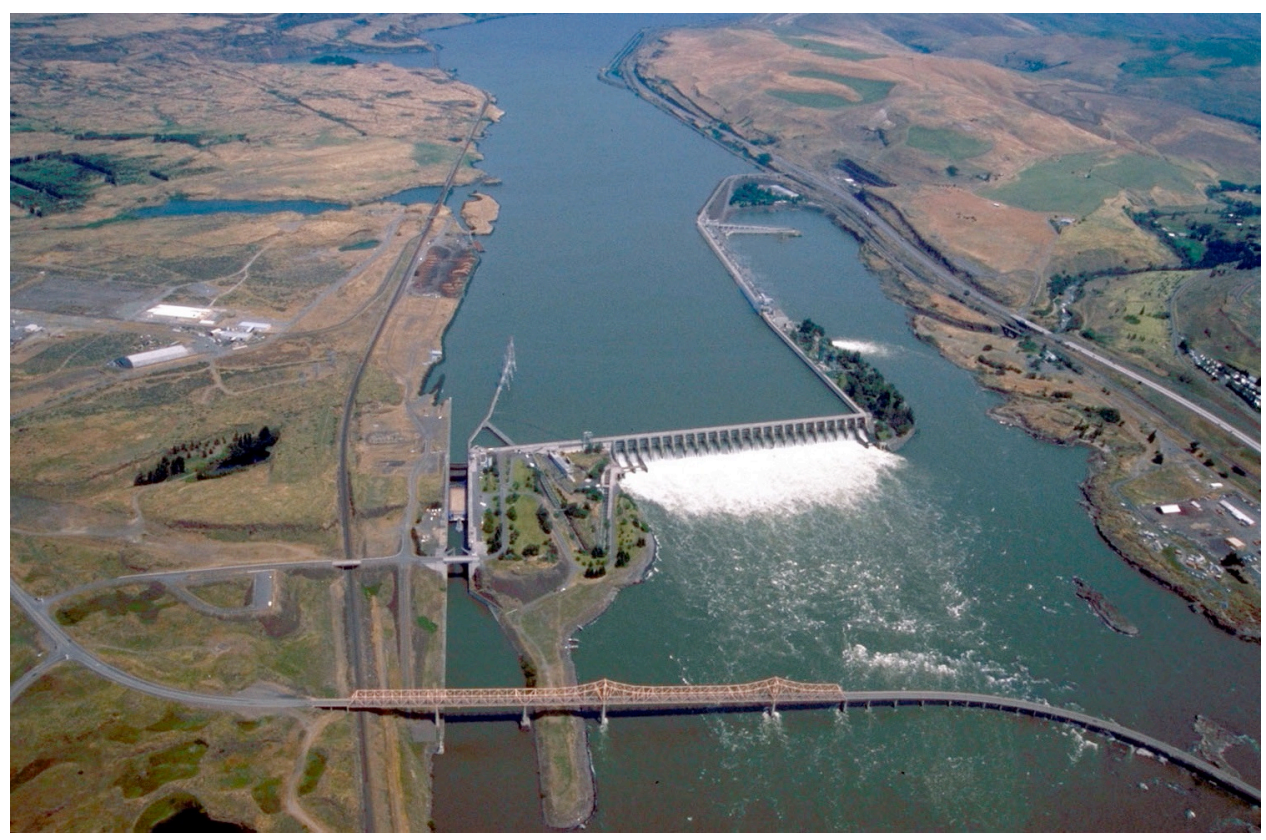

Figure 1.4. Aerial view of The Dalles Lock and Dam with all spillway bays operating. 

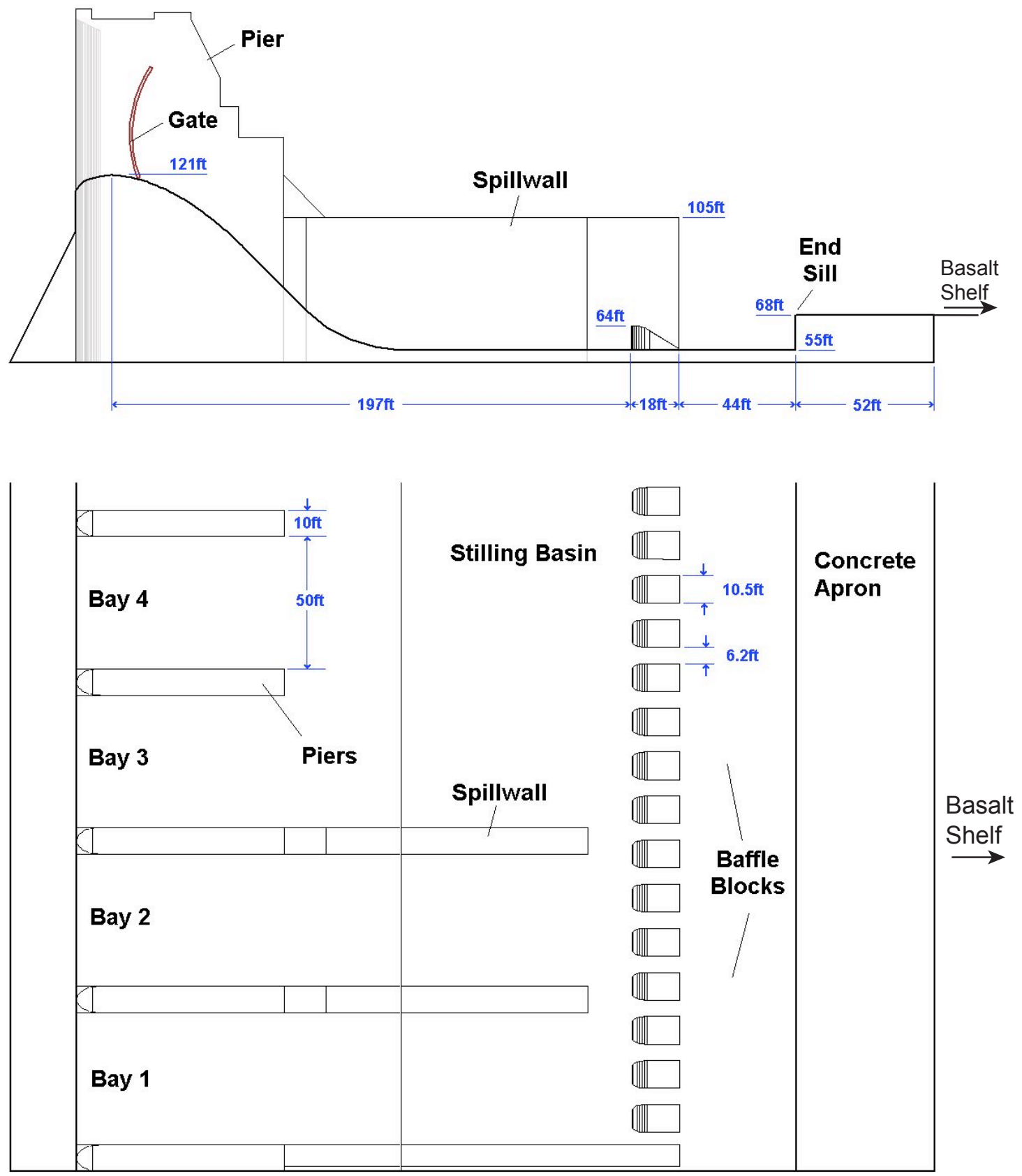

Figure 1.5. Geometry of The Dalles spillway, stilling basin, and end sill. 


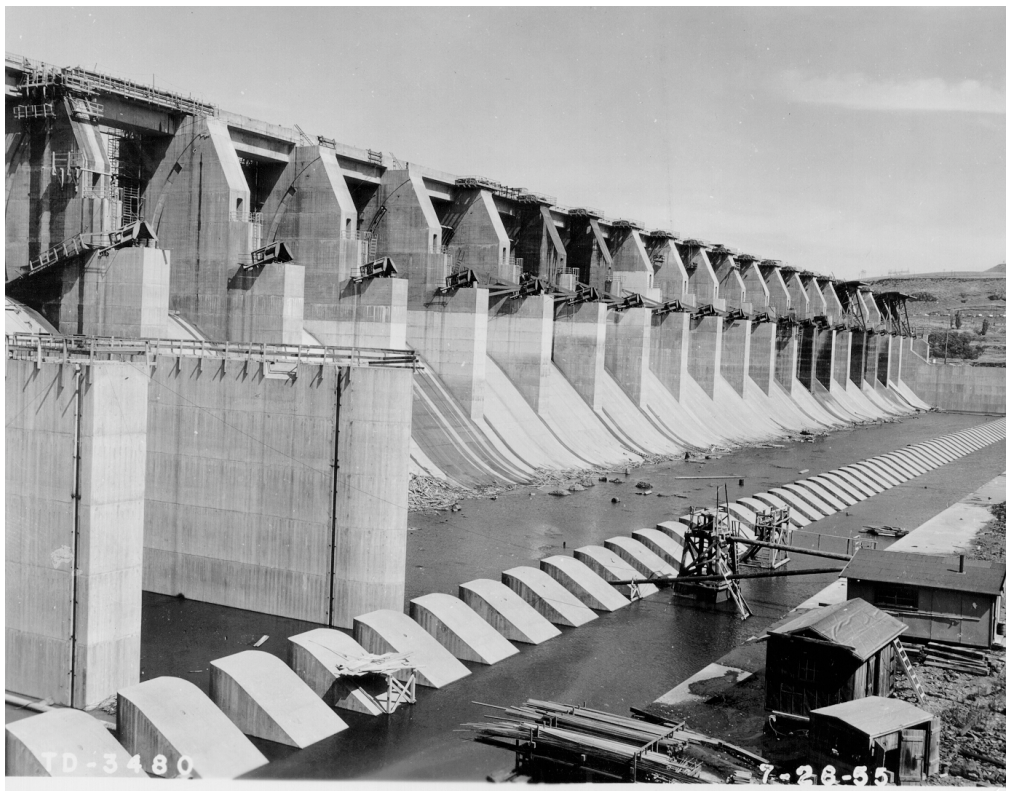

Figure 1.6. Photograph taken during the construction of The Dalles Dam. The photo shows the guide walls on each side of Bay 2 on the right hand side.

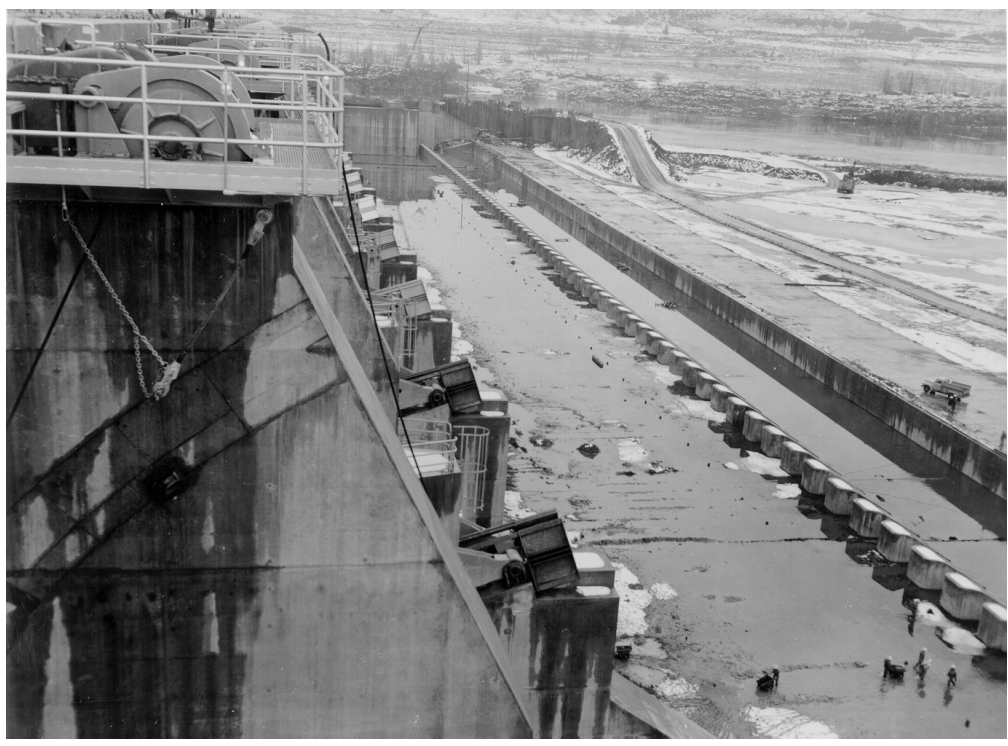

Figure 1.7. Photograph taken during the construction of The Dalles Dam. The photo shows the stilling basin, baffle blocks and endsill. 


\section{$1 \quad 1.4$ Report Organization}

2 Chapter 2 describes the Sensor Fish devices, a brief overview of the CFD model, the Lagrangian 3 particle tracking model, and methods used to store and analyze the data. In Chapter 3, Sensor 4 Fish and particle tracking results are presented togther with a summary of live fish test results. 5 Conclusions and recommendations are given in Chapter 4. Appendices A through D summarize 6 the analysis metrics for the Sensor Fish and particle tracking, geometry used to construct the CFD 7 model, the CFD model, and CFD model validation, respectively. 



\subsection{Methods}

The primary analysis tools used in this study were the sensor fish device, computational fluid dynamics (CFD), and Lagrangian particle tracking (LPT) of particles with mass.

\subsection{Sensor Fish Devices}

The Sensor Fish device (Sensor Fish) is an autonomous device being used to better understand the physical conditions fish experience during passage through hydroturbines and other dam bypass alternatives. Sensor Fish development was initiated at Pacific Northwest National Laboratory in 1997 as an internal development initiative. The product of the initiative was a functional prototype that was field tested in spring 1999 and extensively used during winter 1999-2000 as part of an evaluation of the first minimum gap runner installed at Bonneville Dams first powerhouse on the Columbia River. Since this initial use, PNNL has undertaken further development of the Sensor Fish with funding from the U.S. Department of Energys Advanced Hydropower Turbine System Program (Carlson and Duncan 2003). These efforts have led to numerous design changes to improve function of the Sensor Fish and extend the range of its use (Carlson et al. 2003).

Although not available for use in this study, the most recent extension of the Sensor Fish has been to add rate gyros in addition to the linear accelerometers (Deng et al. 2004). Addition of the rate gyros permits all six possible motions of the Sensor Fish (three components of linear acceleration plus pitch, roll, and yaw angles) to be measured. The new sensor package became available in 2005. It is a significant improvement because it measures the six-degree-of-freedom (6DOF) components required to describe the motion of the Sensor Fish during transit through a spillway, hydroturbine or other dam passage route.

The Sensor Fish used in these spillway studies at The Dalles are three-degree-of-freedom (3DOF) devices and only measure linear acceleration in the three principle axes of the sensor body (Figure 2.1). The Sensor Fish are waterproof, nearly neutrally buoyant sensor packages that measure pressure and tri-axial acceleration as the sensor is carried with flow through a hydraulic environment. Two versions of the Sensor Fish were used in these studies: a large $355 \mathrm{~g}$ version in 2001-2002 and a smaller $42 \mathrm{~g}$ version in 2003-2004.

The large version of the Sensor Fish Device used in this study is constructed of clear polycarbonate plastic and is 7.5 inches (in.) long and a diameter of 2 in (Figure 2.2). Digital samples of the sensors analog output are taken every $0.005 \mathrm{sec}$ over a period of two minutes as the sensor passes through the passage environment. The large Sensor Fish Devices used at The Dalles Dam have a mass of $355 \mathrm{gm}$, an average displacement of $363.8 \mathrm{ml}$, and a mean density of $0.977 \mathrm{gm} / \mathrm{ml}$.

The so-called 3DOF version of the Sensor Fish housing (Figure 2.3) is constructed of clear polycarbonate plastic and is approximately $3.5 \mathrm{in}$. long and $0.75 \mathrm{in}$. in diameter. Digital samples of the sensors analog outputs are taken every $0.005 \mathrm{sec}$ over a period of up to 5.45 minutes as the sensor is carried with flow through the passage environment. The small Sensor Fish devices have an average mass of $42 \mathrm{~g} \pm 0.20 \mathrm{~g}$ (including buoyancy adjustment weight), a displacement of 43 $\mathrm{ml} \pm 0.56 \mathrm{ml}$, and a density of $0.98 \mathrm{~g} / \mathrm{ml} \pm 0.01 \mathrm{~g} / \mathrm{ml}$. 


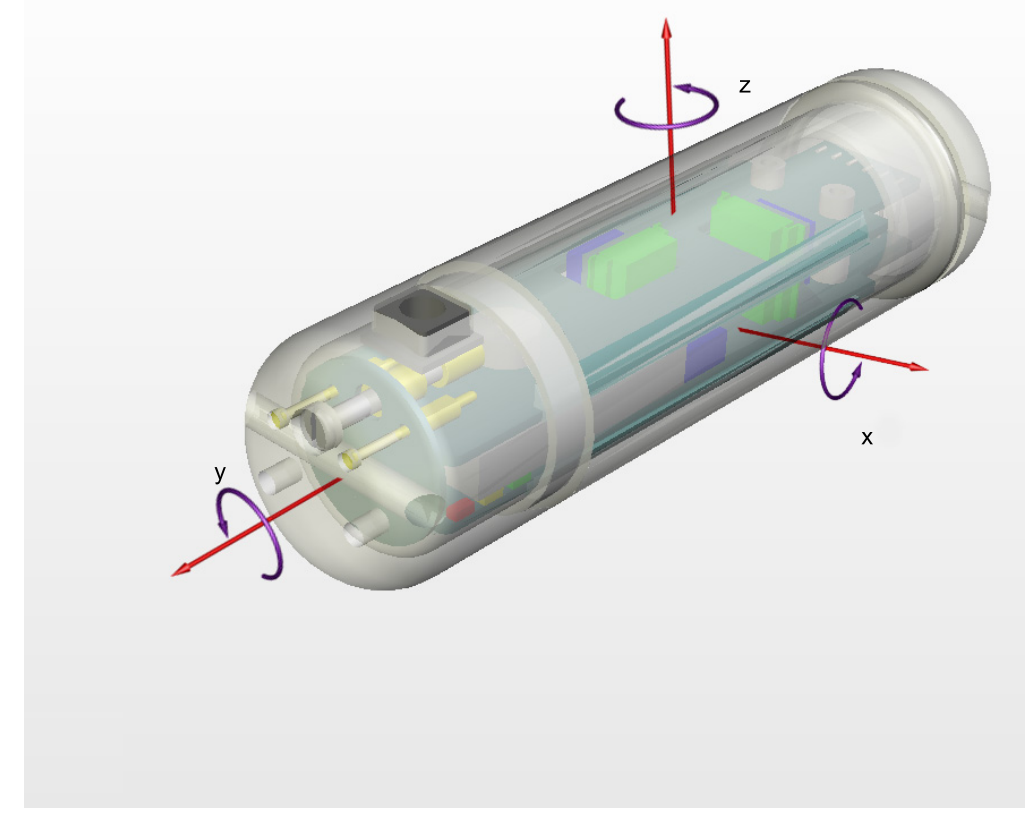

Figure 2.1. Sensor Fish body fixed coordinate system. The 3DOF version used in this study only measures the three linear accelerations $\left(a_{x}, a_{y}, a_{z}\right)$ which are shown as red arrows. The 6DOF version measures the angular velocities $\left(\omega_{x}, \omega_{y}, \omega_{z}\right)$ in addition to the linear accelerations.

Both versions of the Sensor Fish Device are designed to be slightly positively buoyant in fresh water so that it slowly returns to the surface in the event all recovery balloons are lost during passage through a turbulent environment but not so buoyant that buoyancy forces would have a significant influence on acceleration observations during passage with turbulent flow.

Pressure samples are used to estimate the depth of the sensor (when hydrostatic pressure conditions can be assumed) and other hydraulic phenomena, while accelerometer output is used to characterize the Sensor Fish response to turbulence, strike, and scraping. The remainder of the Sensor Fish electronics consists of rechargeable batteries, a power supply, an analog-to-digital converter, memory, and communication components. The digital samples acquired during passage are stored in a nonvolatile memory. The sensor memory is accessed after the Sensor Fish is recovered and acquired data are downloaded to a computer for processing and analysis.

\subsubsection{Sensor Fish Deployment and Recovery}

Sensor Fish were equipped with HiZ balloon tags and a micro-radio transmitter and placed into the live fish injection system using the same methods as those used for live test fish (Normandeau Associates 2004). The balloon tags, which were identical to those used to tag live fish, contain a capsule filled with a chemical that produces gas when activated with hot water. The balloons inflate within a few minutes of release and bring the Sensor Fish to the surface for recovery. Location of the Sensor Fish in the tailrace is aided by use of a directional radio receiver antenna to locate the radio transmitter attached to the Sensor Fish. 


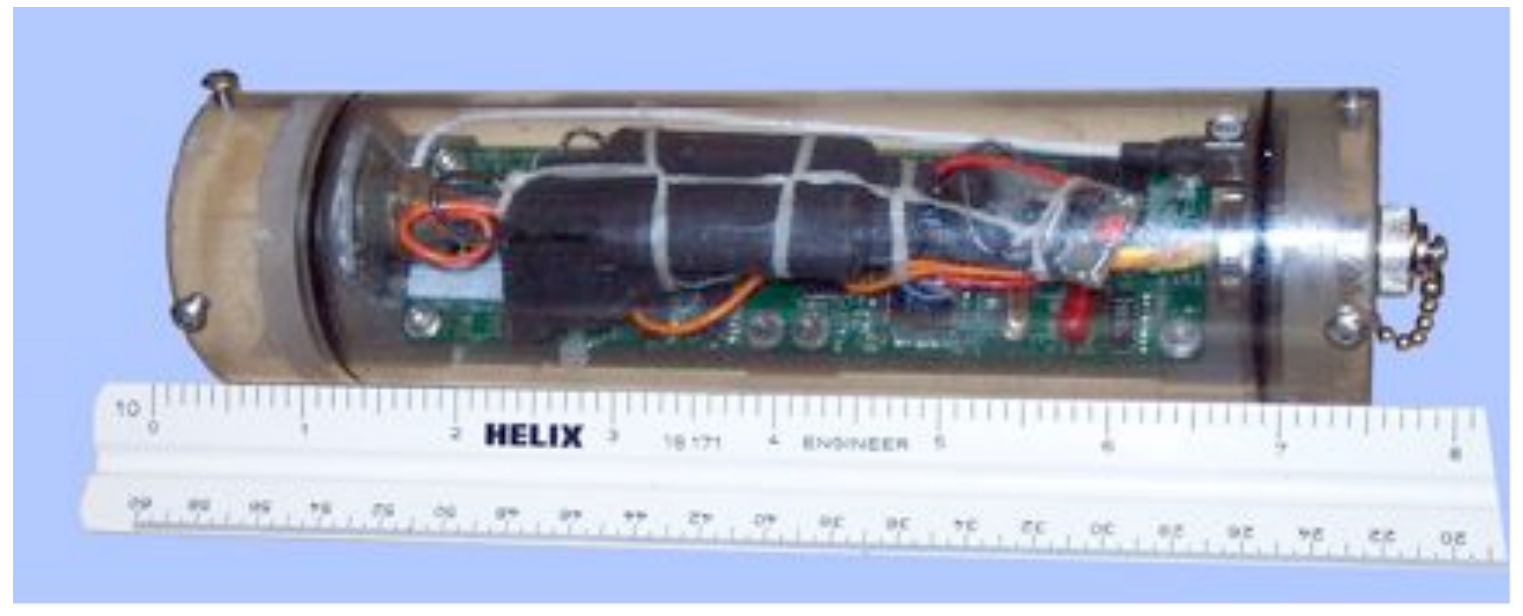

Figure 2.2. Large version of the Sensor Fish device used in 2001 and 2002. This version was used in 423 releases.

\subsubsection{Treatment Releases}

Sensor Fish and live fish releases were made into an induction system consisting of flexible 4 in diameter hoses that extended from the forebay deck to the spill discharge. Portions of the pipe located in the flow of the spill were routed through 6 in diameter steel pipes that enabled the flexible pipe to be held in position through the forces of the flowing water.

A single release elevation was used in the Spring and Summer 2002 studies. The exit of the release pipe was $8 \mathrm{ft}$ above the spillbay crest in Spillbays 4 and 9. In spillbays 11 and 13 the exit elevation was $4 \mathrm{ft}$ above the crest.

In 2003 and 2004, pipe exit elevations were $10 \mathrm{ft}$ (deep release) and $15 \mathrm{ft}$ (shallow release) above the spillbay crest (elevation $121 \mathrm{ft}$ ). Some treatments also had release locations that were offset approximately $8.5 \mathrm{ft}$ from the centerline of the spillbay.

Sensor Fish were released through Spillbays 2, 4, 9, 11, and 13. The location and number of Sensor Fish released are summarized in the tables presentated in Appendix A. The number of Sensor Fish released for a particular treatment condition ranged from 4 to 39 . However, most treatments had between 10 and 20 Sensor Fish releases.

\subsection{Computational Fluid Dynamics (CFD)}

The spillway, stilling basin, and tailrace hydrodynamics at The Dalles were simulated using an unsteady, free-surface, three-dimensional CFD code that solved the Reynolds-averaged NavierStokes equations in conjunction with a two-equation turbulence model. The geometric data (bathymetry and engineered structures) used to construct the CFD model are presented in Appendix B. A summary of the FLOW-3D CFD model is provided in Appendix C. The results from the CFD simulations were then used in a Lagrangian particle tracking model (Section 2.3) that included the effects of mass, drag, and buoyancy in the particle equation of motion. 


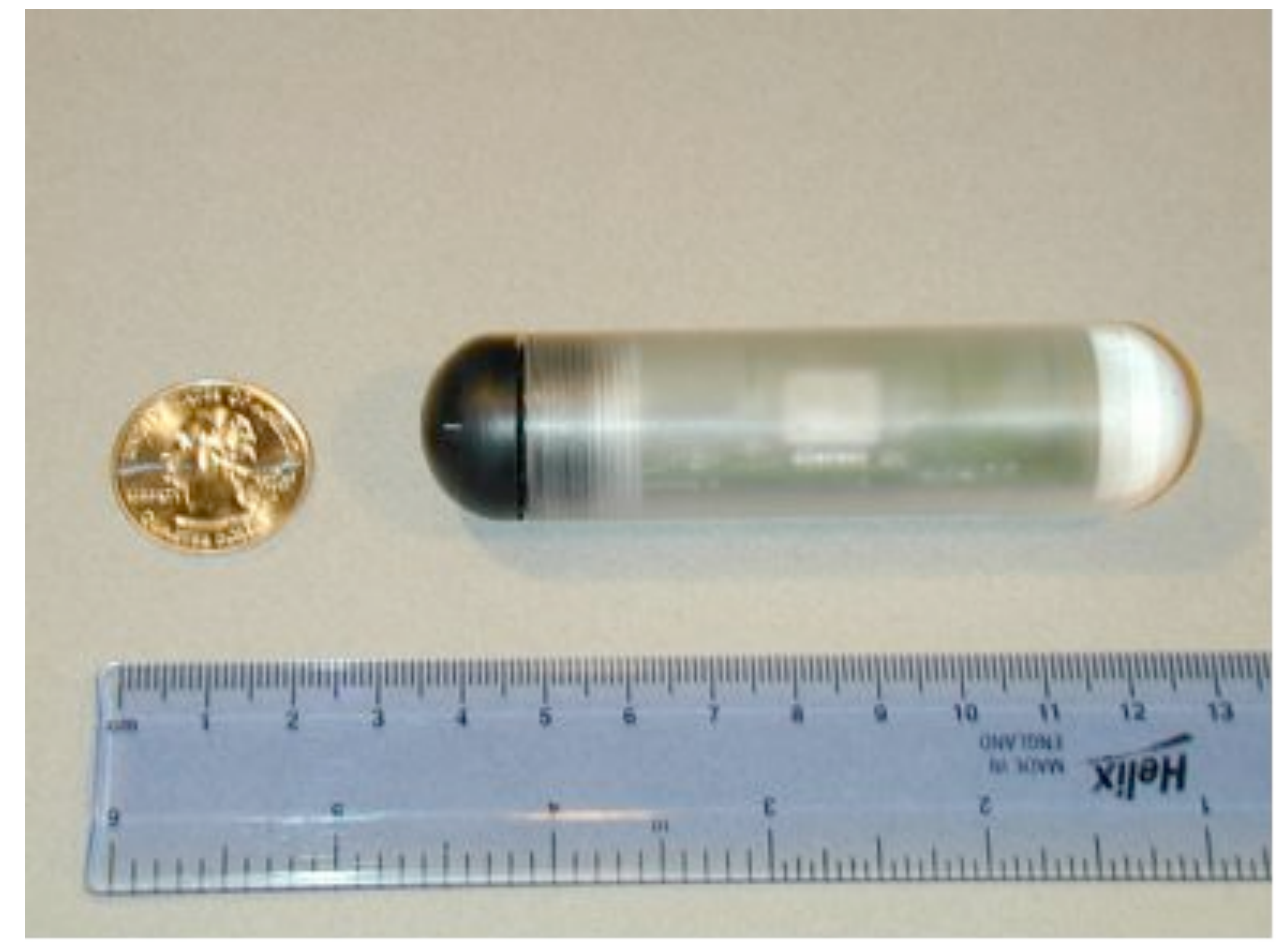

Figure 2.3. 3DOF version of the Sensor Fish device used in 2003 and 2004. This version was used in 464 releases.

Before the Flow-3D CFD model was used at The Dalles, the model was tested to understand how it would perform under a range of hydraulic conditions. The model was configured to simulate the geometry and test conditions for which data sets from physical models were available. Comparison of results between the simulations and measurements show that the model is capable of providing reliable information both upstream of the tainter gates and downstream in the turbulent high-velocity flow field downstream of the spillway face. Because this study is focused on the stilling basin, only validation results specific to this area are presented in this report and those are summarized in Appendix D. Additional validation test cases, and the supporting comparisons of results, are presented in Cook et al. (2006).

\subsection{Lagrangian Particle Tracking (LPT)}

Particle motion in a fluid is represented by Newton's second law of motion:

$$
\sum \mathbf{F}=m \mathbf{a}=\frac{d \mathbf{v}}{d t}
$$


where $\sum \mathbf{F}$ is the sum of forces acting on the particle, $m$ is the particle mass, $\mathbf{a}$ is the particle acceleration, $\mathbf{v}$ is the particle velocity, and $t$ is time. The forces considered to act on particles in this work are gravity $\left(\mathbf{F}_{g}\right)$, drag $\left(\mathbf{F}_{d}\right)$, and added mass $\left(\mathbf{F}_{a}\right)$. This leads to a simple set of ordinary differential equations (ODE) describing particle motion:

$$
\begin{aligned}
& \frac{d \mathbf{x}}{d t}=\mathbf{v} \\
& \frac{d \mathbf{v}}{d t}=\mathbf{a}=\frac{1}{m}\left(\mathbf{F}_{g}+\mathbf{F}_{d}+\mathbf{F}_{a}\right)
\end{aligned}
$$

where $\mathbf{x}$ is the particle location. The ODE system is solved using the methods available in the GNU Scientific Library (www.gnu.org).

3

\subsubsection{Spherical Particles}

The gravitational force acting on a spherical particle is computed as (Gondret et al. 2002)

$$
\mathbf{F}_{\mathrm{g}}=\frac{4}{3} \pi r^{3}\left(\rho_{p}-\rho_{f}\right) \mathbf{g}
$$

4

The drag force acting on a spherical particle in the $i$ direction is computed as (Gondret et al. 2002)

$$
F_{\mathrm{d}_{i}}=-\frac{1}{2} \pi r^{2} \rho_{f} C_{D_{i}}\left(v_{i}-v_{f_{i}}\right)
$$

where $v_{i}$ and $v_{f_{i}}$ are the particle and fluid velocities in the $i$ direction and $C_{D_{i}}$ is

$$
C_{D_{i}}=\left\{\begin{array}{cl}
0.0 & \text { for } \mathrm{Re}_{i}=0 \\
\frac{24}{\operatorname{Re}_{i}}\left(1+0.15 \mathrm{Re}_{i}^{0.687}\right) & \text { for } 0<\mathrm{Re}_{i}<1300 \\
0.4 & \text { for } \mathrm{Re}_{i} \geq 1300
\end{array}\right.
$$

where

$$
\operatorname{Re}_{i}=\frac{\left|v_{i}-v_{f_{i}}\right| d \rho_{f}}{\mu}
$$

and $\mu$ is the fluid kinematic viscosity.

The added mass force acting on a spherical particle is computed as (Gondret et al. 2002)

$$
\mathbf{F}_{a}=-\frac{2}{3} \pi r^{3} \rho \frac{d \mathbf{u}}{d t}
$$

For this work, particles are assumed to be neutrally buoyant spheres with approximately the same volume as a sensor fish device: $d=0.03915 \mathrm{~m}$ and $\rho=997.775 \mathrm{~kg} / \mathrm{m}^{3}$, so $m=0.03135 \mathrm{~kg}$. 


\subsubsection{Massless Particles}

When particles have no mass, the particle velocity is assumed equal to the fluid velocity. So, the ODE system (2.1) is simplified to

$$
\begin{aligned}
& \frac{d \mathbf{x}}{d t}=\mathbf{v}=\mathbf{v}_{f} \\
& \frac{d \mathbf{v}}{d t}=0
\end{aligned}
$$

2

The particle velocity is augmented with a random component based on the random displacement proposed by Dimou and Adams (1990) and Brickman and Smith (2002). The random displacement in the $i$ direction is given by

$$
\Delta x_{i}=\left[\frac{\partial D_{i i}}{\partial x_{i}}\right] \Delta t+\sqrt{2 D_{i i} \Delta t} \varphi_{i}
$$

where $\varphi_{i}$ is a Gaussian random number and $D_{i i}$ is the turbulent diffusion coefficient in the $i$ direction, given by

$$
D_{i i}=K_{d} v_{t}=K_{d} \frac{\mu_{t}}{\rho_{f}}
$$

where $K_{d}$ is a positive scale factor, normally $1.0, v_{t}$ is the turbulent fluid dynamic eddy viscosity, $\mu_{t}$ is the turbulent fluid kinematic eddy viscosity computed by the CFD model. The velocity component used to augment particle velocity is then

$$
u_{f_{i}}^{\prime}=\frac{\Delta x_{i}}{\Delta t}=\left[\frac{\partial D_{i i}}{\partial x_{i}}\right]+\sqrt{\frac{2 D_{i i}}{\Delta t}} \varphi_{i}
$$

7 Equation 2.5 is evaluated at each particle time step using local fluid conditions.

8

\subsection{Database}

The large amounts of live-fish, sensor-fish, and CFD particle-tracking data were collected during numerous spillway survival studies at The Dalles Dam were dispersed among several parties, stored 
in separate formats, and proved difficult to analyze together. A key objective of this project was to synthesize this information into a database that could eventually become a single repository for spillway survival data collected at The Dalles. The database and associated analysis components are generally purpose and can be used to support studies at other hydroelectric projects. The result of this effort is the Fish Passage Analysis System (FishPAS).

\subsubsection{Design Objectives}

The FishPAS design objectives were to:

- Preserve existing live-fish, sensor-fish, and CFD particle-tracking data in a single, secure repository

- Structure the data to accommodate similar data sets from future studies at The Dalles and other hydroelectric projects

- Structure the data to provide maximum versatility in how the data can be grouped and retrieved

- Provide an efficient means for accessing these data by researchers

- Develop tools for analyzing these data

\subsubsection{Design}

We implemented FishPAS using Microsoft Access® 2003, a widely-available relational database management system (RDBMS), and MathWorks MatLab® , a scientific analysis application. These applications exist in a networked Windows XP® environment.

The basic components of the system are a data storage structure, a query interface, and an analysis toolkit. At the present, the sensor fish component of the system is functional. Structures exist for the handling of live-fish data. The system will continue to evolve as analysis needs develop. The following description focuses on the sensor fish portion of FishPAS.

\subsubsection{Data Storage}

\section{Sensor Fish Data}

Sensor fish data consist of the primary time-history records from the sensor fish itself and secondary metadata describing sensor fish deployment details and dam operational conditions. We handle these two data types differently within FishPAS as discussed below.

Raw output generated by the sensor fish is the source for the primary data sets. Due to the large size of the accumulated primary data sets (about 1GB), the anticipated growth in this portion of the database (in the 10s of GBs), and the limitations of the Access file structure (2GB), FishPAS stores the primary data in separate external binary files. This allows the data to be distributed among multiple fileservers across the network. These binary files contain the following fields: 
- measurement time (s)

- gauge pressure (psi)

- X acceleration component (g)

- Y acceleration component (g)

- $\mathrm{Z}$ acceleration component (g)

- Acceleration magnitude (g)

- $\mathrm{X}$ rotational velocity (deg/s)

- Y rotational velocity (deg/s)

- $\mathrm{Z}$ rotational velocity (deg/s)

- rotational velocity magnitude (deg/s)

The binary file stores each measurement as ten sequential 4-byte values with no separator between records. This format is efficient for rapid loading into the MatLab analysis package (see Section 2.4.2.3).

Secondary sensor fish data includes information relating to the conditions associated with each deployment event. This information includes:

- sensor fish study name and general location

- specific release location (bay, pipe, elevation, etc.)

- release and recovery times

- recovery location (XY coordinate)

- project operations during deployment (flow, water elevation, etc.)

- reference to primary data file location (full path)

- miscellaneous comments

The reference to the primary data file is the key to linking the secondary data to the primary data.

FishPAS stores secondary data within the Access RDBMS structure in a group of related tables centered around a main sample table. The sample table consists a single record for each sensor fish deployment event and includes codes that link the sample to the study description, release 
location details, and operational conditions (see Figure 2.4)

\section{Live Fish Data}

Live fish data include fish release and injury information. As there is less of a distinction between primary and secondary live-fish data, FishPAS stores most of this information within the Access RDBMS. Photos of fish, if available, reside in external files that are referenced by the database. The data are distributed among a number of related tables centering around a main sample table.

The sample table contains a single record for each live fish release. Sample information includes a physical description of the fish, the deployment time, and several fields summarizing injuries. The table also includes codes that link the sample to the study description, release location details, operational conditions, and detailed injury classifications (see Figure 2.5). Each sample fish may have one or more injuries. The injuries are classified according to their type (e.g., loss of equilibrium, hemorrhage, etc.), location (e.g., head, fin, etc.), and severity (low, medium, or high). The sample may also be associated with one or more digital photographs that are referenced through fileserver locations stored in the database.

Note that although the database was designed to use detailed injury data those data were not available for this study, but could be included in the future.

\section{Particle Tracking Data}

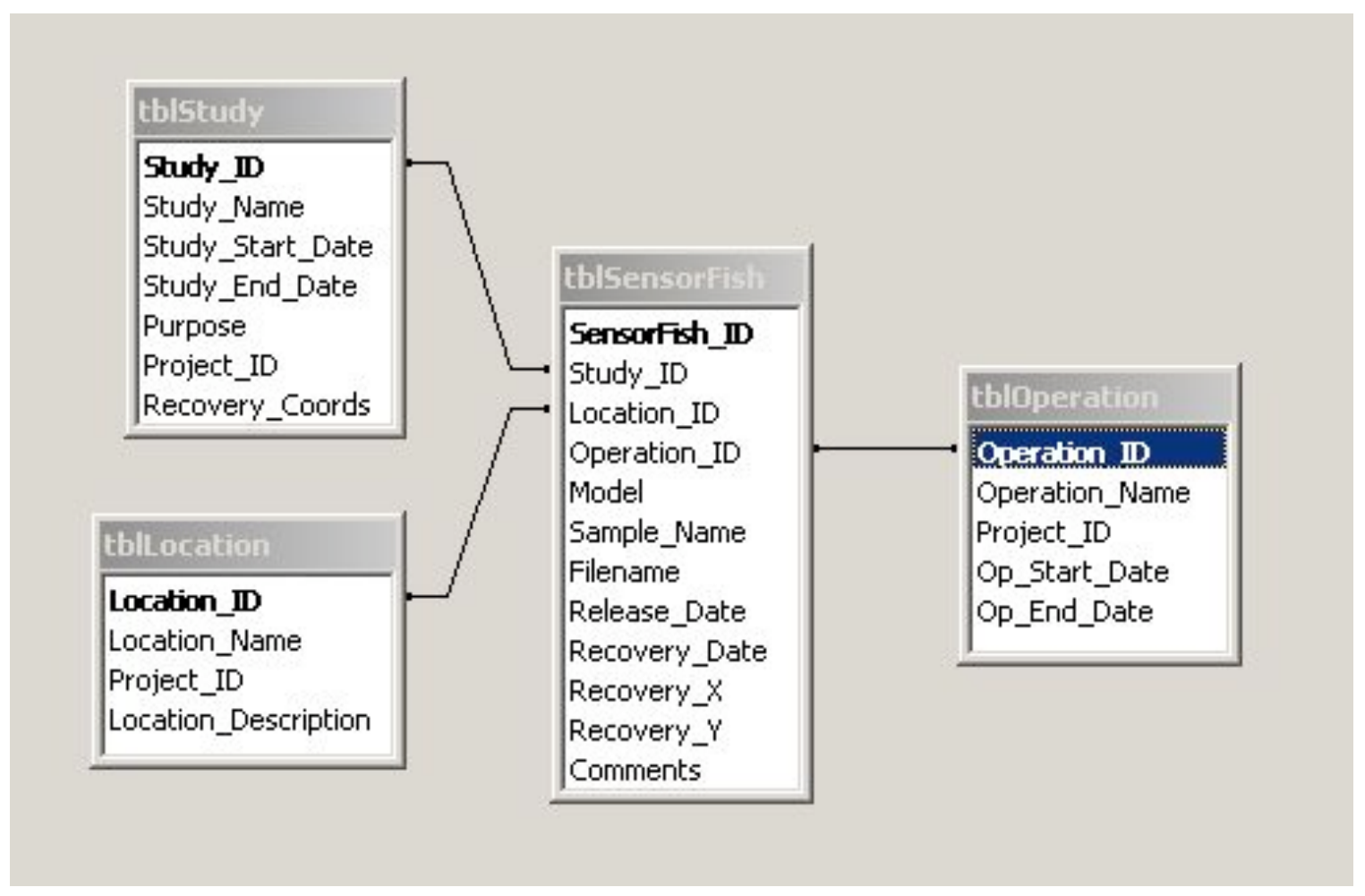

Figure 2.4. Sensor fish sample table relationships. 


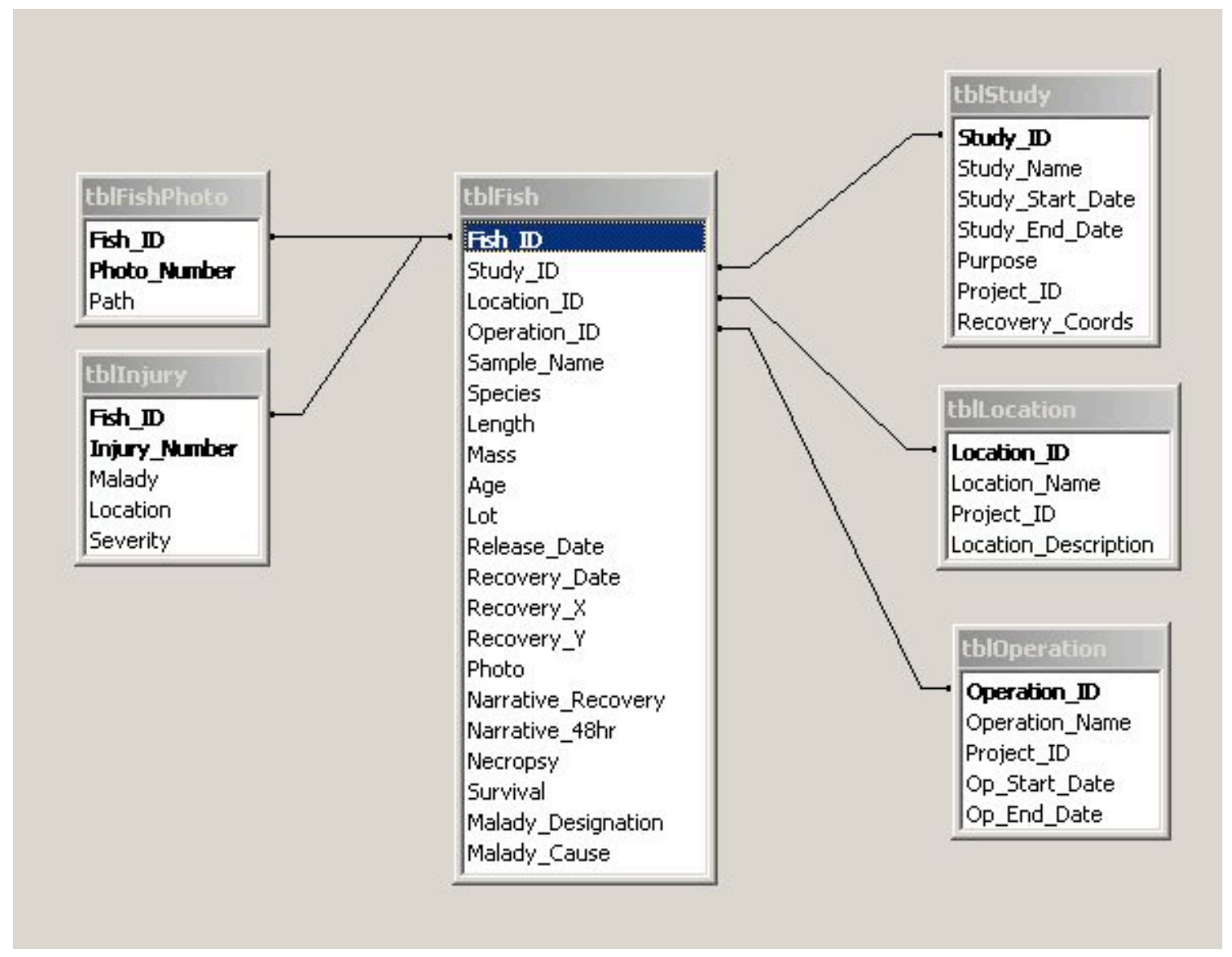

Figure 2.5. Live fish sample table relationships.

In the future, FishPAS will also store trajectories of particles propagated through CFD models. Since these particles are intended to simulate the passage of sensor fish through a flow system, the generated data share many of the same characteristics of sensor fish data. Although this part of FishPAS is not currently designed, we anticipate that, as with sensor fish records, the primary time-history data will reside in external files that are referenced by the Access database containing secondary data about the runs.

\subsubsection{Query Interface}

The second basic component of FishPAS is a user interface for querying data from the database. This interface provides a link between the primary records and the analysis tools provided by MatLab. The interface consists of an Access 2003 form (Figure 2.6) that is linked to the underlying secondary data tables. The function of the form is to generate a list of sample numbers that meet the users selection criteria and pass them on to MatLab for analysis. Users define the criteria either with a query-building tool, or by writing their own custom query. The query-building tool is a set of standard filters for automatically constructing a structured query language (SQL) command based on lists of available studies, release locations, operational conditions, and release dates. The user may edit the generated SQL command or create a custom query. Users may save queries for future use. 


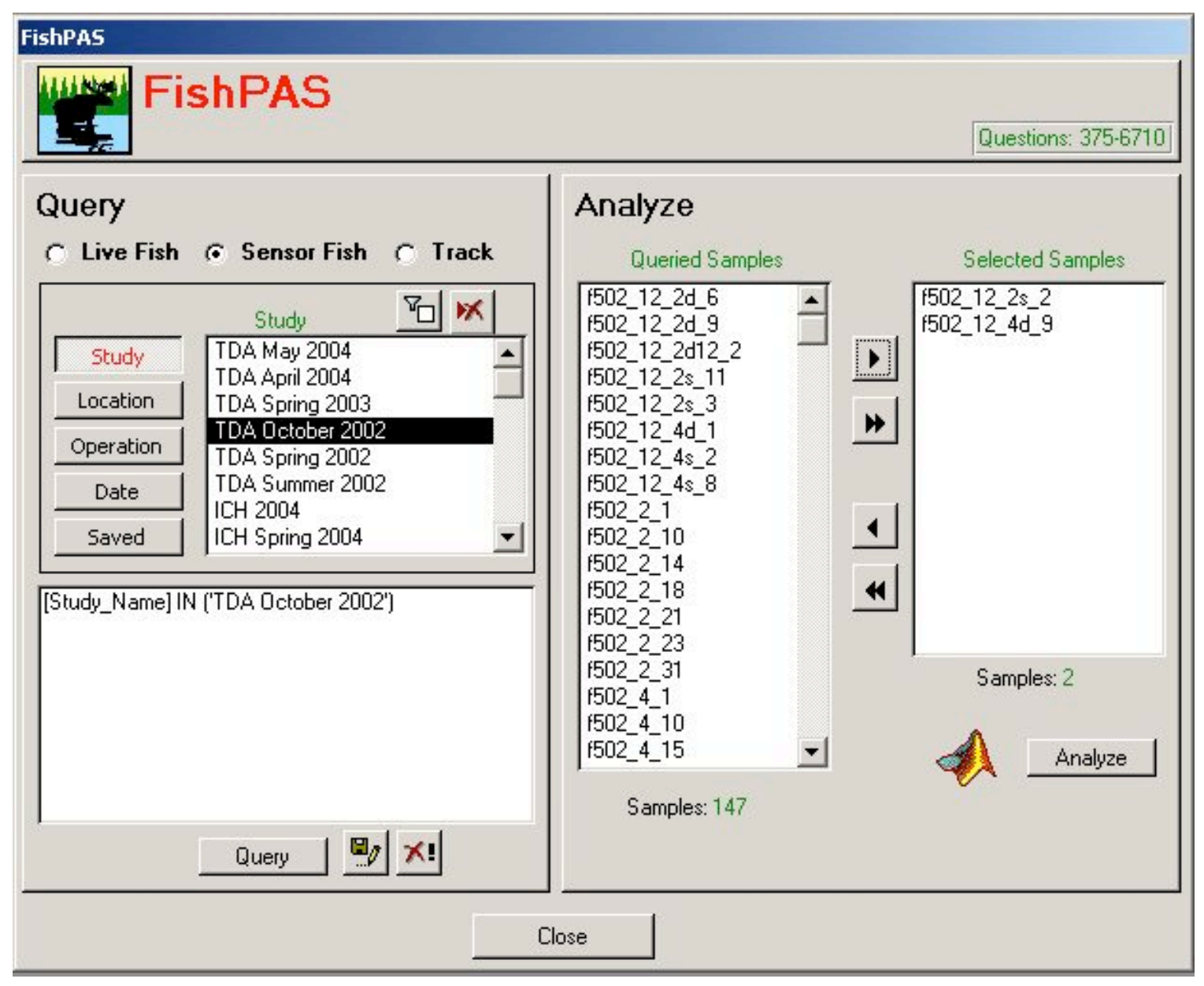

Figure 2.6. Access 2003 query interface form.

As an example, the user might select TDA October 2002 from the study list for sensor fish. This action results in 147 samples appearing in the Queried Samples list on the right side of the form. The user may further reduce this list by selecting a release location of TDA Bay 4 Middle Deep from the list of locations associated with the TDA October 2002 study. The sample list now decreases to just 10 samples. Finally, the user may transfer any or all of these Queried Samples to the Selected Samples list and deliver them to the MatLab analysis application by pressing the Analyze button. The actual output of the form is a command to MatLab that includes references to the binary files containing the primary data.

\subsubsection{Data Analysis Capability}

Analysis of live-fish, sensor-fish, and particle data currently includes capabilities for creating timeseries graphs, computing basic metrics, and displaying these metrics graphically. We chose MatLab as the ultimate application for developing analysis tools because of the programs rich set of routines for plotting and processing numeric data. The current MatLab application plots multiple sets of sensor fish data and allows the user to perform some basic operations including frequency filtration, time shifting, and point probes (Figure 2.7). 
However, most of the analysis functionality used in this report is currently implemented using Microsoft Access 2003. The Access application consists of a table structure for storing metrics data and an interface for plotting this data. Metrics values are loaded into a master table (Figure 2.8) that contains references to the study and conditions associated with the metrics. Ancillary tables store further details associated with the metrics, including study description, dates, metrics units, and operation conditions. Metrics data are either loaded manually, or, in the case of particle data, imported directly from the 3DData database.

The user interface for analyzing the metrics is an Access form (Figure 2.9). With this form, the user can select criteria for retrieving metrics desired for analysis, create groupings on which to compute statistics, and then plot the results as a bar chart. For example, the user may wish to compare live-fish mortality to sensor-fish residence time in Bay 2 under a variety of flow conditions. Because data at a discharge rate of $4.5 \mathrm{Kcfs}$ may be available from several studies the application would average the available metrics and present pairs of bars for each available discharge rate in Bay 2. By this method, relationships and trends in metrics can be conveniently visualized.

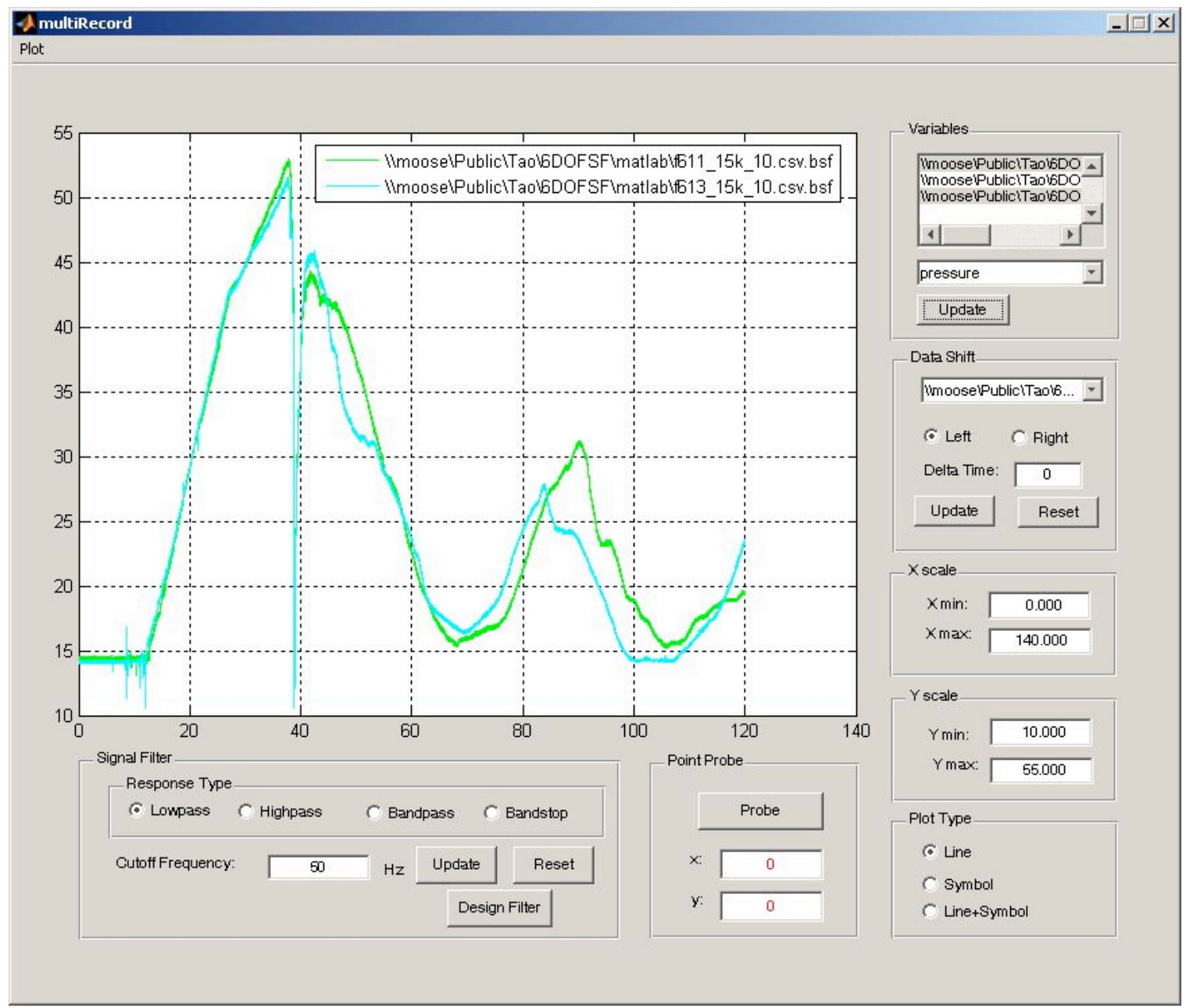

Figure 2.7. An Matlab-based sensor fish graphing application screen. 


\begin{tabular}{|c|c|c|c|}
\hline \multicolumn{4}{|c|}{ 面 tblMetrics : Table } \\
\hline & Field Name & Data Type & \\
\hline F & Type & Text & Live fish, sensor fish, or particle metric \\
\hline 8 & Study & Text & Name of study for which metric was obtained \\
\hline ? & Metric & Text & Abbreviation for metric name \\
\hline P & Bay & Number & Spill bay associated with metric \\
\hline ? & Release & Text & Release location of data collection device \\
\hline & Flow & Number & Bay discharge rate in kcfs \\
\hline & FlowGroup & Text & Discharge rate grouping for lumping similar data \\
\hline & ReleaseGroup1 & Text & Release location grouping 1 for lumping similar data \\
\hline & ReleaseGroup2 & Text & Release location grouping 2 for lumping similar data \\
\hline & Value & Number & Metric value (units vary) \\
\hline & Excluded & Yesino & Flag to exclude data from analysis \\
\hline
\end{tabular}

Figure 2.8. A MatLab sensor fish graphing application screen.

\subsubsection{Data Entry}

The method of data entry into FishPAS depends on the type of data being loaded. With primary data, the sensor fish data, we start with a raw data file. Next, a program provided by the sensor fish manufacturer converts it to a human-readable comma separated value (CSV) file. The FishPAS data loader converts the CSV file to the binary format described in Section 2.4.2.1. We record the location and name of this binary file in the sensor fish sample table.

With secondary data, the study investigator typically records the information relating to each deployment in a Microsoft Excel spreadsheet. To load these data into FishPAS, we parse the spreadsheet for the necessary information and modify the format as necessary before importing the data set into an Access table. From this Access table, we distribute the data to the appropriate FishPAS tables using a series of queries. We must enter certain data, such as study names, location names, and their associated descriptions manually into the database.

To load existing live-fish data, we will need to parse narrative injury descriptions into the FishPAS injury classification scheme. In the future, we anticipate that the data will arrive in a form that we can load directly into the database.

Loading of CFD particle-track data will follow a method similar to that used for sensor-fish data. We will convert the primary data generated by the particle tracking program into external binary files and load secondary data based on model run information.

\subsection{Analysis Metrics}

In order to assess the relative risk to fish of various hydraulic conditions within the stilling basin, we have developed a variety of metrics to quantify certain characteristics of the passage environment. These metrics are based on physical conditions that are believed to correlate with fish injury and mortality. Such conditions include exposure to high shear, rapid pressure changes, and collisions with solid objects. While several recent studies such as Abernethy et al. (2001), Neitzel et al. (2004), Deng et al. (2005) have begun to explore quantitatively the relationship between severe 


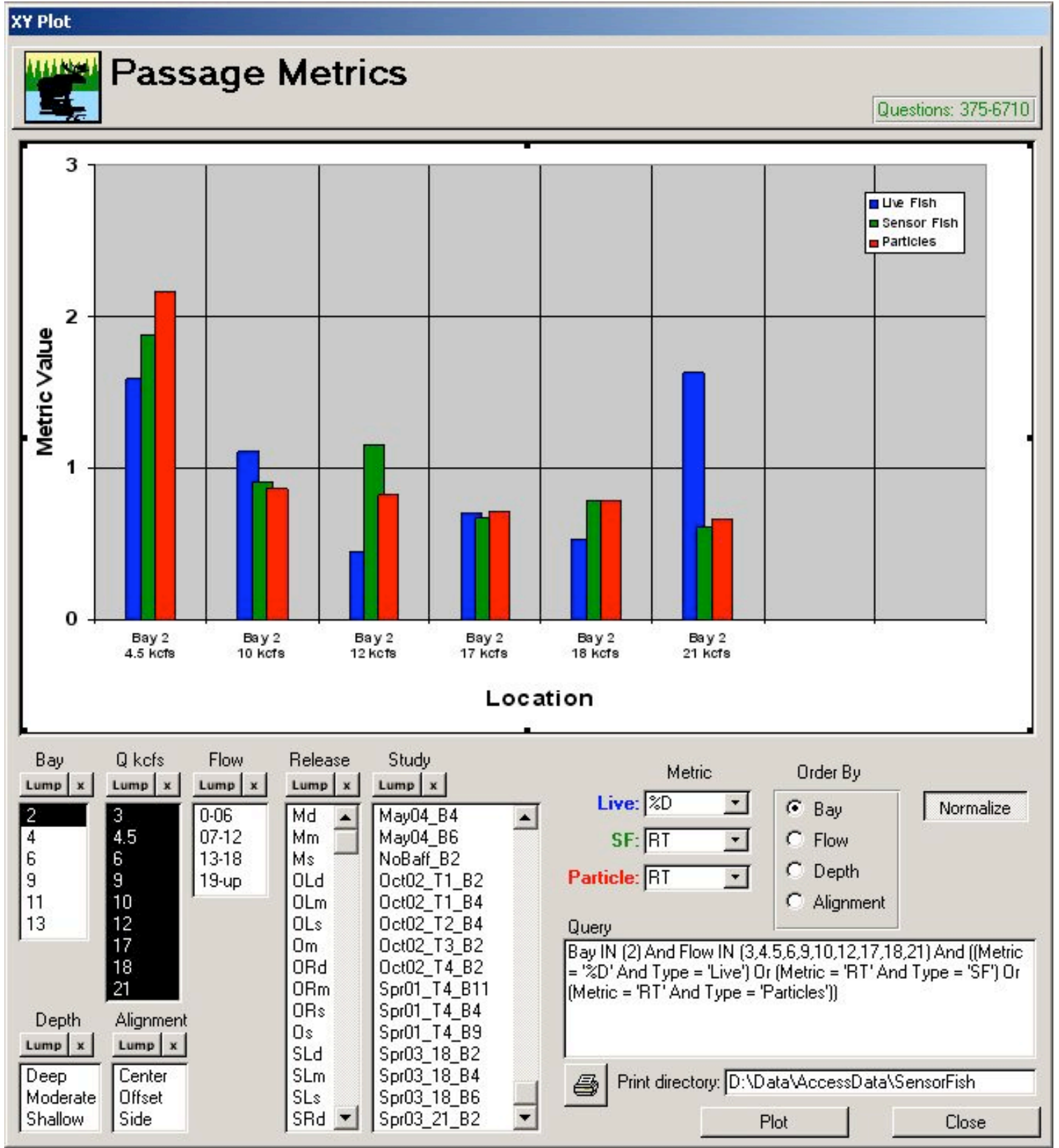

Figure 2.9. A MatLab sensor fish graphing application screen.

hydraulic conditions and fish injury, applicable information in this area is sparse. Therefore, our 2 metrics are best used for relative risk comparisons between various flow scenarios; they are not 3 intended to be predictors of actual fish injury or mortality rates.

4 To compare metrics, we first compute the metric value for a single sensor fish deployment or 5 particle track. All of the values associated with a particular study scenario are averaged to obtain a 6 final score for that condition. We can then compare this final score to the scores of other conditions 7 to determine which result in lower risks of injury. 
All of the metrics described below apply only to conditions found in the spillway and stilling basin. We have further divided the region into two zones. The spillway zone is the area between the release pipe exit and a point halfway down the spillway ( $55 \mathrm{ft}$ horizontally downstream of the spillway crest). The stilling basin zone begins at the end of the spillway zone and continues to a point $10 \mathrm{ft}$ beyond the stilling basin end sill.

\subsubsection{Sensor Fish}

The raw data downloaded from the Sensor Fish consists of sets of four time histories extending from the time the sensor is placed in the injection pipe through its recovery in the tailrace. One time history is for pressure, the other three are for tri-axial acceleration. The time histories are incremented in 0.005 -second intervals corresponding to the $200-\mathrm{Hz}$ sampling rate of the sensor analog-to-digital converter. These data were loaded in the database application (Section 2.4.3).

\subsubsection{Pressure}

Pressure measurements obtained from the Sensor Fish are adjusted to zero at atmospheric pressure to estimate gage pressure. The adjustment pressure is obtained for each Sensor Fish release by computing the average recorded pressure when the sensor is at atmospheric pressure prior to placement into the fish injection system. This estimate of mean pressure offset is subtracted from recorded pressure to obtain estimates of gage pressure. When the Sensor Fish does not have a large relative motion compared to the carrier fluid (a small slip velocity) the pressure sensor will record the local static pressure in the fluid. When the slip velocity is small and if hydrostatic pressure conditions exist (small vertical fluid acceleration) water depth in feet can be estimated from gage pressure in engineering units by dividing gage pressure by 0.4335 , which is the pressure in psi of 12 inches of fresh water at a temperature of $39.2 \mathrm{~F}$. Non-hydrostatic conditions would be expected in the zones immediately under the tainter gate and near the baffle blocks. Large slip velocities would be expected immediately after a collision event.

Experience with Sensor Fish Device data sets to date has shown that pressure time histories are useful to indicate the location of the sensor relative to the surface and bottom. While keeping in mind the limitations noted above, the pressure records are also helpful in identifying sensor movements, indicating entrainment in large-scale turbulent events such as rollers. Since most pressure sensors are also sensitive to the high accelerations associated with collision and scraping, such events are frequently detectable as sharp impulses in pressure time histories that cannot represent a realistic change in sensor depth. A key use of the CFD and LPT data is to improve the estimated location and motion of the Sensor Fish by comparing the pressure records from each method.

\subsubsection{Acceleration and Collision}

The development version of sensor fish used in these studies did not always provide consistent acceleration values due to flex in the circuit board on which the accelerometers were mounted. Thus, based on laboratory testing, acceleration patterns were used to identify collision events in the data sets. We therefore chose to focus analysis on identifying likely severe collision events. Note that the circuit board flex issue has been corrected in the current 6DOF generation of the sensor fish. 
To identify likely collision and intense acceleration events in sensor fish records, a routine was written that searches for and counts these acceleration signatures. The routine looks for occurrences of the following sequence of three adjacent acceleration magnitude readings:

- Value 1: any value

- Value 2: a value greater than Value 1 by a specified threshold amount

- Value 3: a value less than Value 2

The threshold value must be set high enough to exclude accelerations due to relatively low intensity collisions or shear.

\subsubsection{Residence Time}

An important measure of injury potential is the duration of exposure by the fish to harmful conditions. Assuming that the majority of direct spillway passage injuries occur in the stilling basin, the longer a fish remains in this environment, the greater its chances of sustaining damage. A metric called residence time (RT) is defined as the time spent by a fish, sensor fish, or particle in the stilling basin.

Residence time can be computed for a sensor fish if we estimate the time at which it enters and leaves the stilling basin. By comparing the pressure profiles of sensor fish to those of CFD particles under similar flow conditions, we have identified distinct signatures for certain locations within the stilling basin (see Figure 2.10). These pressure signatures are present in most sensorfish records. Using these signatures, we can estimate the time of the stilling basin entry and exit points of a sensor fish and compute its estimated residence time.

\subsubsection{Computational Fluid Dynamics and Lagrangian Particle Tracking}

\subsubsection{Particle Collisions}

The Lagrangian particle tracking program records the time, location, and intensity of each particle collision with a wall. The collision intensity (CI) is defined as the velocity component of the particle normal to the wall immediately before the collision, or

$$
\mathrm{CI}=v \cdot \mathbf{n}
$$

where $v$ is the particle velocity and $\mathbf{n}$ is the unit normal vector of the wall. Given the same particle velocity, a low-angle glancing contact will have a lower intensity than a head-on collision.

Several metrics that may correlate to fish injury potential are possible using this collision data. This study uses a collision count (CC) metric that is simply the number of wall strikes sustained by a particle during its travel through the stilling basin. Since low-intensity collisions are less likely to be detrimental to a fish, a CC metric that uses a threshold collision intensity, below which the collisions are not counted, was used as well. Though lacking quantitative data about damage to fish from collisions, we set this threshold to a value of $20 \mathrm{ft} / \mathrm{s}$, which is an estimated lower limit for injury to occur. This is called the CC20 metric. Some experimental evidence for this value 

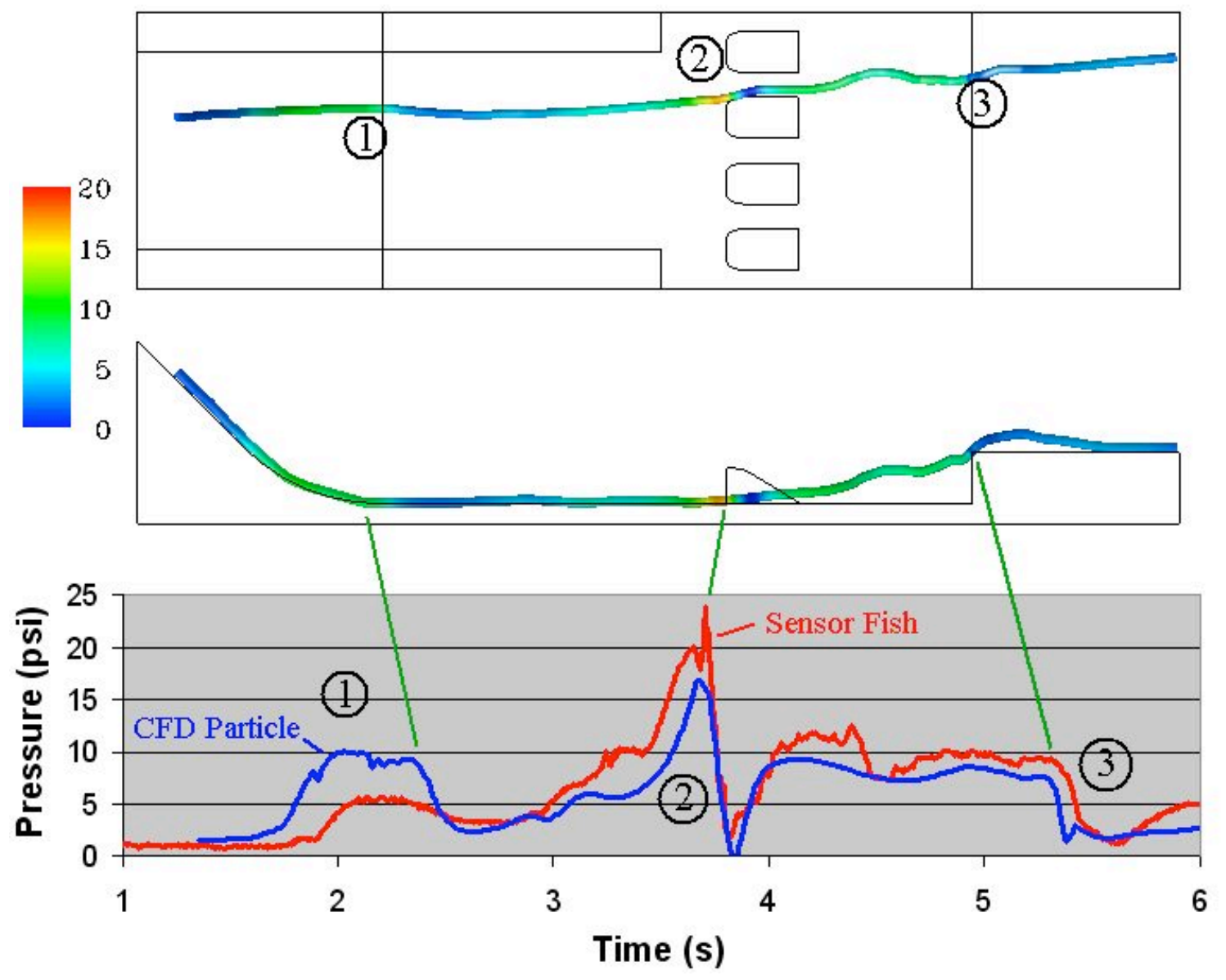

Figure 2.10. Sample pressure profiles from a sensor fish and CFD particle.

is provided by Turnpenny et al. (1992) who exposed fish to a simulated turbine blade strike. For a blunt blade profile corresponding to the near-hub fish were not injured for a collision velocity of $17.3 \mathrm{ft} / \mathrm{s}$. Here we assume that collision with a baffle block face would be similar to the blunt profile blade.

\subsubsection{Particle Residence Time}

Particle residence time is very similar to the RT metric for sensor fish. The difference is that with particle tracks, the stilling basin entry and exit points can be precisely determined from the simulated path coordinates.

\subsection{Limitations}

The Sensor Fish Device is designed to pass passively as a near neutrally buoyant object through severe hydraulic environments. The Sensor Fish does not behave like a live fish nor does it have structures that emulate the more sensitive features of live fish, such as eyes; therefore, linkage between the output of the Sensor Fish and injuries to live fish requires concurrent observations of injury to live test fish or some other means to interpret accelerometer output within the context of 
fish injury. The location of the Sensor Fish in space is not measured directly by the instrument, but can only be inferred using supplemental physical information that can be obtained from theory, physical models, and/or CFD models.

The mass of the large version of the Sensor Fish compared to that of juvenile fish is quite important and affects how acquired data should be interpreted. The mass of the Sensor Fish is approximately 10 times greater than that of yearling Chinook salmon smolt (35 gm) and approximately 70 times greater than that of a sub-yearling Chinook (5 gm). In this sense, the larger Sensor Fish output most likely underestimates the acceleration response of juvenile fish to changes in flow and underestimates response to turbulence encountered during spill passage.

In zones where hydrostatic pressure conditions exist (where vertical fluid accelerations are small) water depth, and hence Sensor Fish depth, can be estimated from Sensor Fish gage pressure. Nonhydrostatic conditions occur in the zones immediately under the tainter gate and near the baffle blocks. Estimation of depth from Sensor Fish gage pressure is not possible when the Sensor Fish is in relative motion compared to the carrier fluid (a so-called slip velocity). In these conditions the pressure sensor will not record the local static pressure in the fluid. Large slip velocities would be expected immediately after a collision event.

Presently, all Sensor Fish studies have been conducted concurrently with live fish studies. As a consequence, while the response of the Sensor Fish to turbulence, strike, and other turbine passage events may not exactly mimic that of juvenile fish, exposure metrics obtained using the device can be analyzed in reference to survival and injury observations obtained for live test fish under the same spill operating conditions. During a spill study, release of Sensor Fish is conducted concurrent with live fish releases so that samples of the spill passage environment are obtained over the range of conditions experienced during the passage survival study.

Simulated inertial particle trajectories and collisions can differ from those of live fish and Sensor Fish because of a number of factors. Like the Sensor Fish, the inertial particles are not fish and have no behavioral response. The simulated particles are spherical in shape and not cylindrical like the Sensor Fish. Air entrainment and intense, time-varying surface waves were not captured in the simulation. Therefore, differences between simulated and prototype velocities and turbulence would be expected. The inertial particle tracking did include CFD-computed estimates of turbulence effects, but the RNG turbulence model might under represent the actual turbulence intensities. Many of these shortcomings could be addressed using advanced, high-resolution unsteady CFD to further clarify the interaction between the hydrodynamics (velocity, pressure) and inertial particle tracks. CFD modeling capability exists that includes air entrainment and a suitable turbulence component capable of resolving the unsteady large eddies generated by the shear layers near the spillway surface and in the immediate wake of the deflector. However, such models are computationally intensive and could only be applied to a smaller region of interest, such as the spillway face or around a small number of baffle blocks. Application of an advanced CFD model to capture these small-scale processes was beyond the scope of the current study. In addition, a capability to track cylindrical shaped particles is under development at PNNL and could be used in future studies. 


\title{
3.0 Results and Discussion
}

\subsection{Sensor Fish}

\begin{abstract}
Nearly 1000 Sensor Fish deployments were made over the course of fish passage studies at The Dalles spillway during 2001 to 2004 . Between 5 and $10 \%$ of the recovered data sets were unsuitable for analysis due to malfunctions in the units. The most common cause was failure of the pressure transducer. This was usually identified by obviously anomalous records where pressures would remain flat or spike to unrealistically high or low values. These data sets were eliminated from consideration when compiling metrics, even when the acceleration data appeared valid, because the faulty pressure records prevented the estimation of Sensor Fish location within the stilling basin.
\end{abstract}

\subsubsection{Pressure Time Histories}

The first 30 seconds of a typical Sensor Fish pressure history is shown in Figure 3.1. This profile is interpreted as follows. First, there was an initial period of zero gage pressure as the Sensor Fish is initialized and the device is carried to the release pipe. After insertion into the release pipe, the pressure rises hydrostatically until the unit reaches the bottom of the pipe. In less than one second, the Sensor Fish arrives at the tainter gate and passes under it, where pressure rapidly returns to zero gage. As the Sensor Fish travels down the spillway face, the pressure is near zero gage as expected. At the foot of the spillway, the pressure record becomes complex when the unit enters the turbulent environment of the stilling basin.

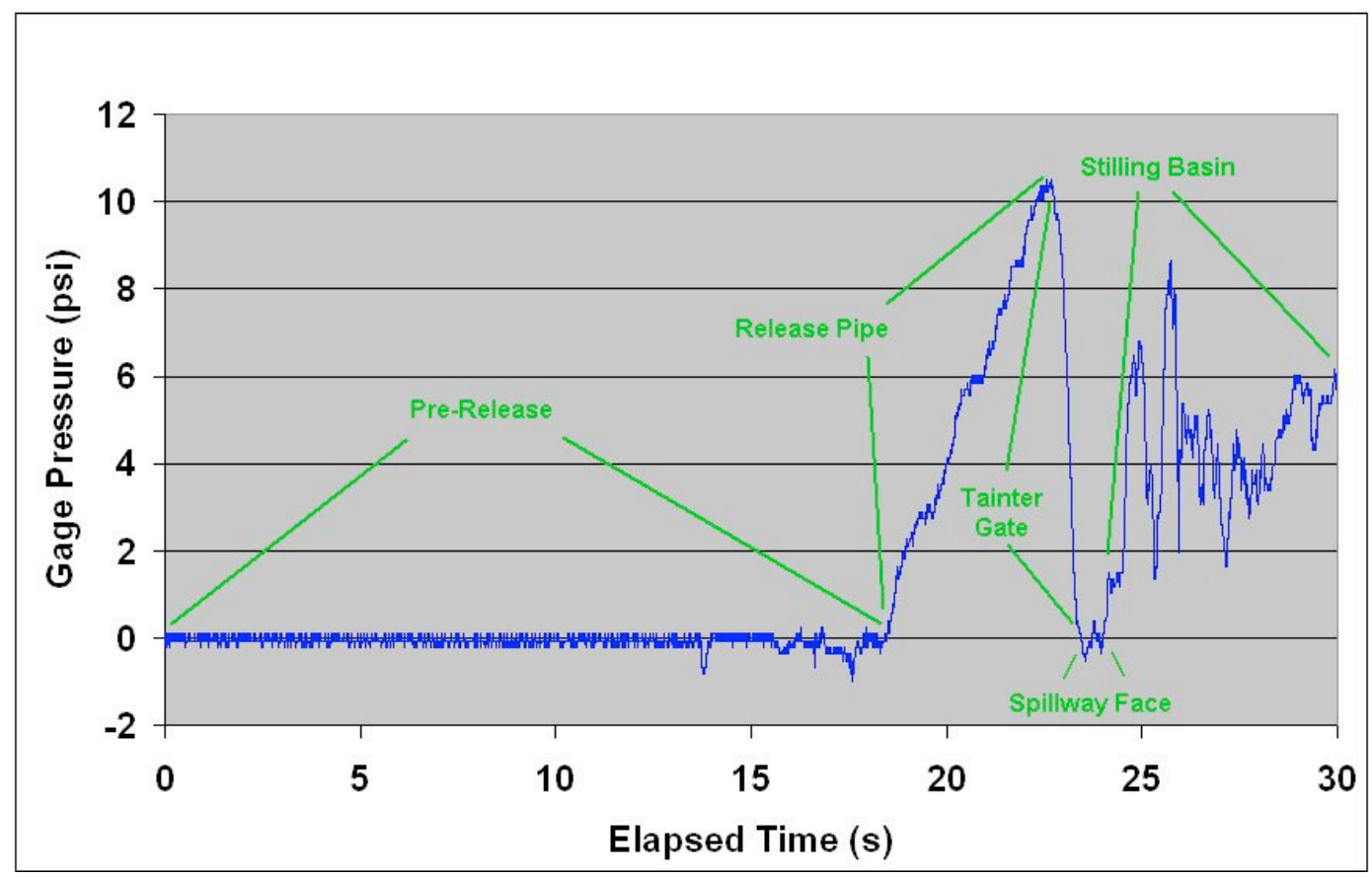

Figure 3.1. Features of a typical sensor fish pressure time history during a spillway passage release. 
Once in the stilling basin, the majority of pressure time histories from sensor fish exhibited the general patterns shown in Figure 3.2. For comparison of profiles, the time is set to zero at the pressure maximum under the tainter gate. After falling down the spillway face, the initial few seconds display the pressure increase at the foot of the spillway and the characteristic baffle block signature (as shown in Figure 2.10). The timing of these two events is very consistent among the deployments, with the baffle-block encounter occurring 3-4 seconds after tainter gate passage.

What happens to the pressure after the baffle blocks may be classified into four categories: immediate exit, delayed exit, recirculation, and other. Immediate and delayed exits are the most common. These patterns are shown in Figure 3.2, with sensor fish f203-sb2-p3-18-5 exhibiting an immediate exit and f208-sb2-p3-12-3 a delayed exit. Based on particle-track modeling (see Section 3.3), we believe that in the immediate exit, the sensor fish proceeds directly out of the stilling basin after passing the baffle blocks, resulting in the shortest possible residence time: about 5-7 seconds. In the delayed exit case, the sensor fish is caught up for several seconds in the highpressure zone caused by water slamming into the end sill before emerging from the stilling basin. This trajectory typically results in residence times of 8-12 seconds.

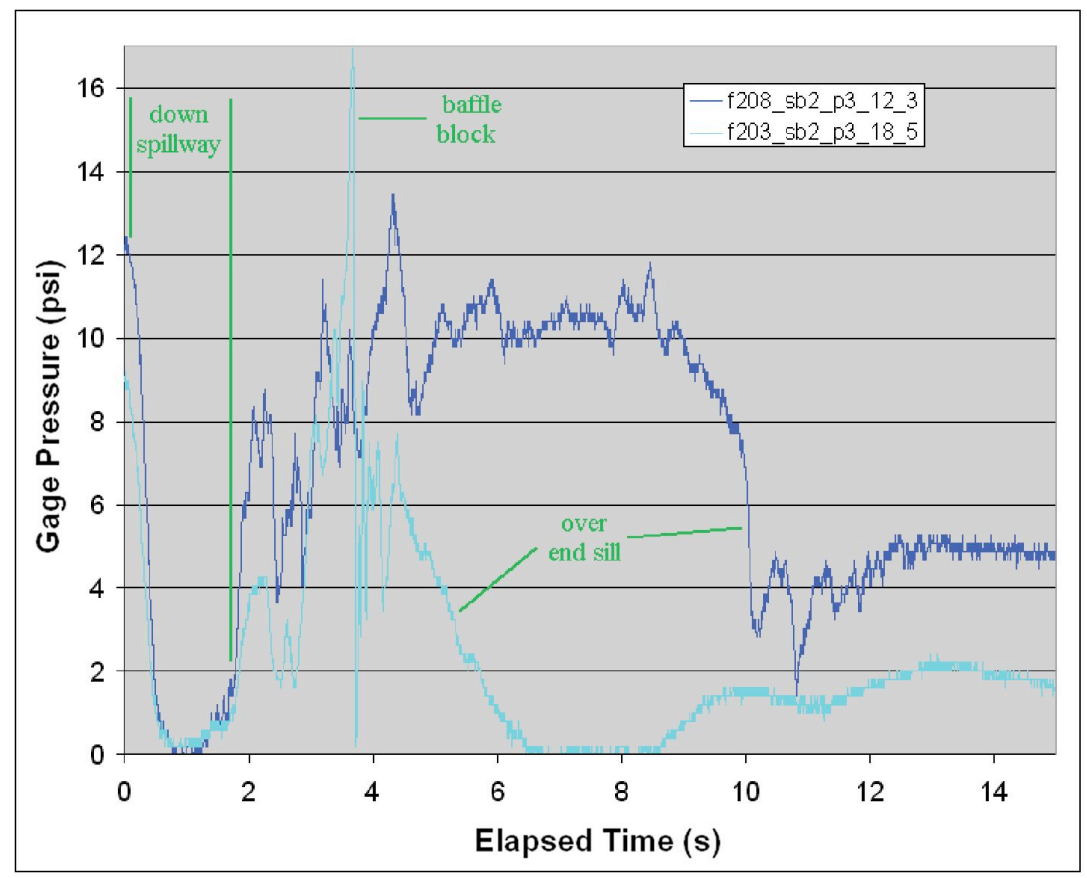

Figure 3.2. Common sensor fish pressure time histories for spillway passage releases.

Less common are profiles believed to result from recirculation within the stilling basin. The time histories display two or more repetitions of the baffle-block signature before exit from the stilling basin, as seen in Figure 3.3. Based, again, on particle tracking simulations, we contend that these sensor fish are repeatedly transported through the stilling basin by the large recirculation cell evident in the CFD models (see Figure 3.15). Sensor Fish caught in these recirculations can have dramatically increased residence times.

A small number of profiles do not fit into any of the other categories. These may result from more 


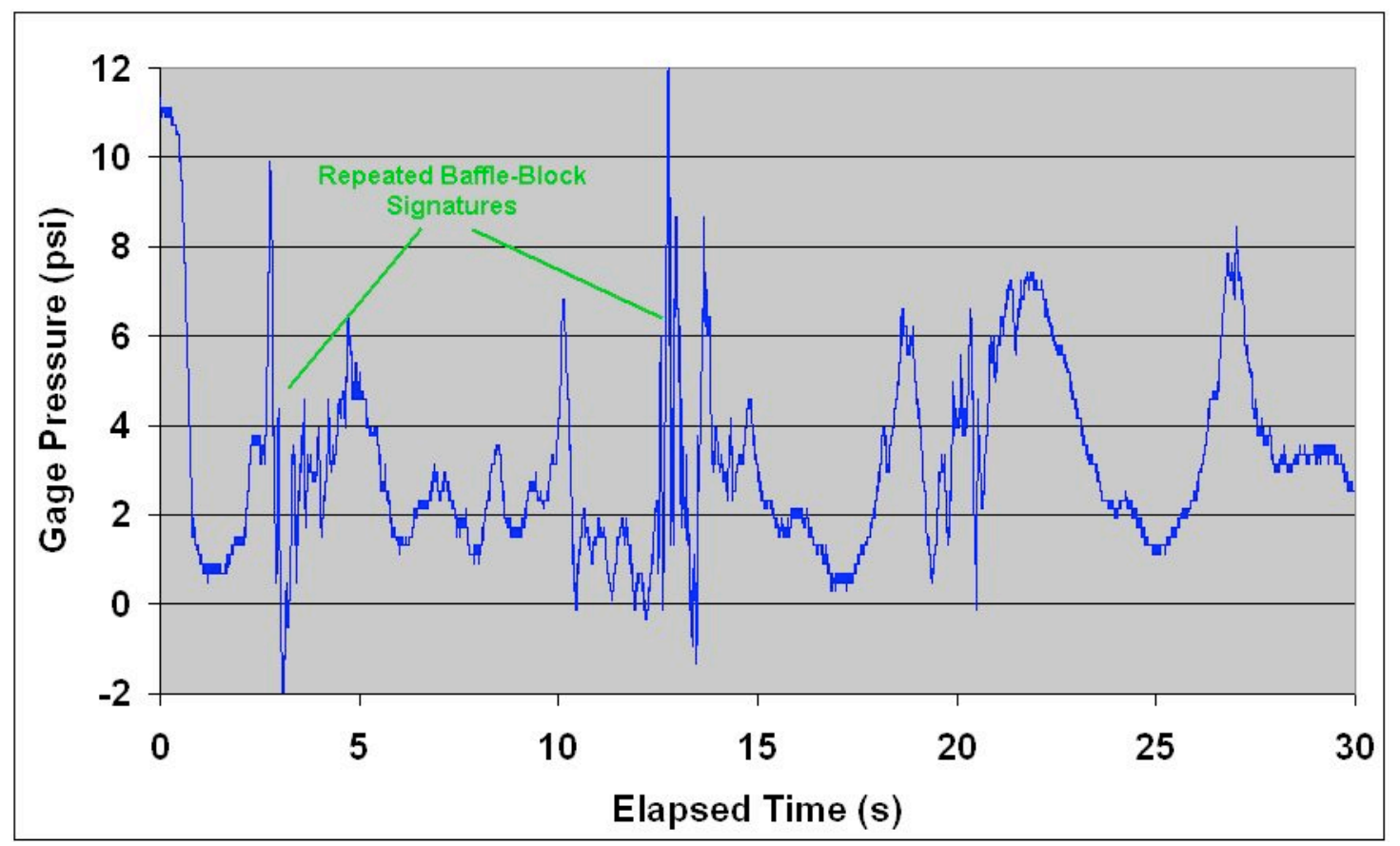

Figure 3.3. Sensor fish pressure record indicating recirculation in the stilling basin.

complex trajectories through the stilling basin, but their approximate paths can not be deduced from the available Sensor Fish data.

\subsubsection{Residence Time}

Based on pressure time histories, the residence time of sensor fish within the stilling basin for all treatments ranged from about 4 to over 100 seconds. The upper value was limited by the onboard data storage capacity. The values averaged about 18 seconds, but the most frequently occurring values, accounting for more than one-third of the releases, were between 6 and 10 seconds (Figure 3.4).

In general, residence time is inversely proportional to bay discharge rate (Figure 3.5). This is particularly evident in Bay 2. Higher discharge rates result in the spillway wall jet penetrating further downstream which appears to be more effective in flushing the sensor fish out of the stilling basin.

At any given discharge range, there was not any consistent tendency for one bay to have different residence times from other bays. Somewhat lower residence times were observed in Bays 2 and 6 under similar flow conditions after the installation of the training wall between Bays 6 and 7, though Bay 4 showed no appreciable change. No trends relating residence times to Sensor Fish release elevation (deep or shallow release pipes) or horizontal alignment (offset releases) were observed. 


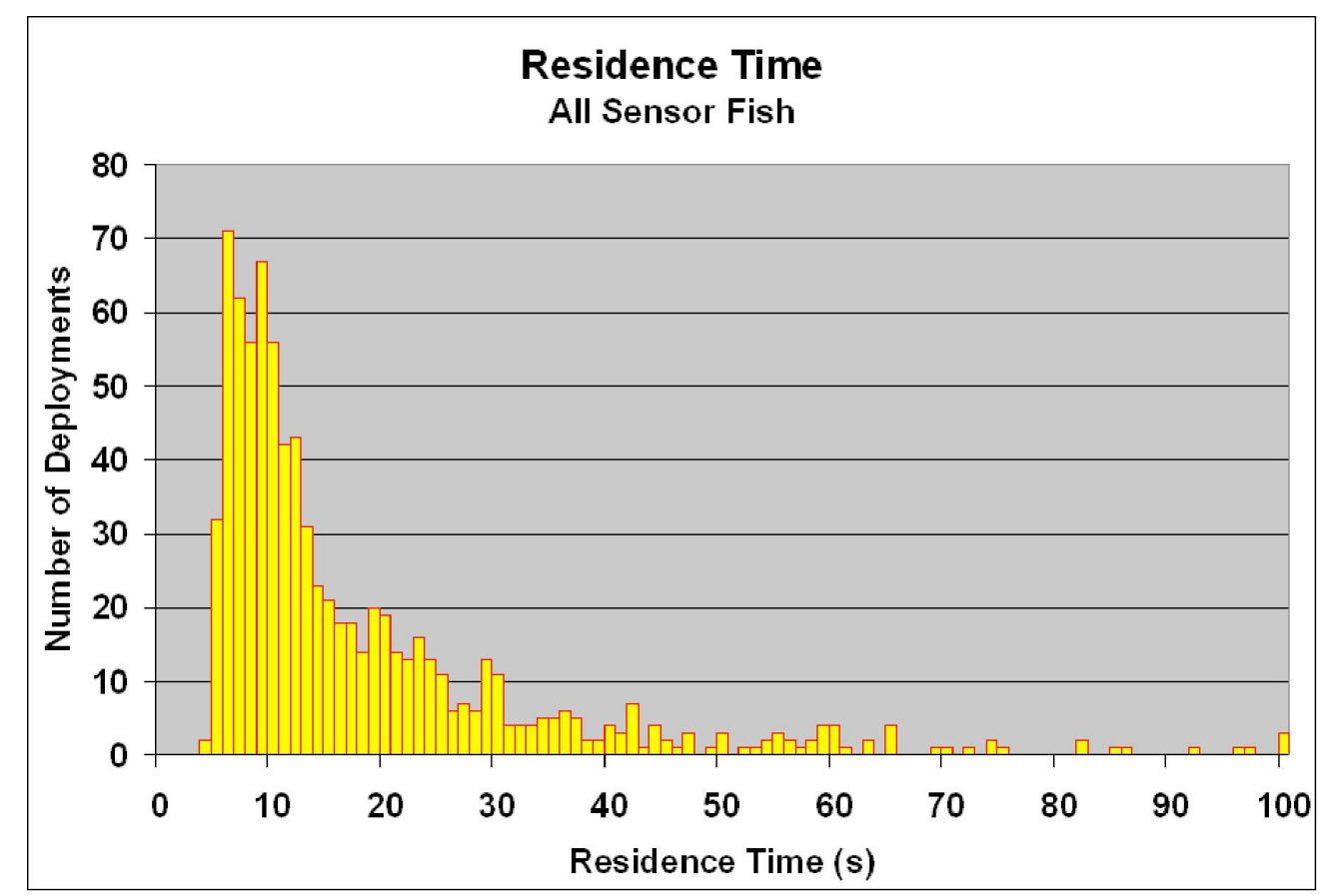

Figure 3.4. Histogram of sensor fish stilling basin residence time. All releases were pooled together.

\subsubsection{Collision Count}

The method used to obtain the collision count (CC) metric for sensor fish (see Section 2.5.1) depends on a minimum threshold value to establish a severe event such as a collision. In theory, this threshold should be set high enough to eliminate the possibility that accelerations due to low intensity collision and shear events would not be counted. The type of events in which we are interested in counting should have a high probability of injuring a fish. In live-fish studies at The Dalles, the injury rate (including mortalities) is between 5 and 10\%. Therefore, we expect that severe events of interest would not occur in much more than $10 \%$ of the sensor fish deployments, assuming all injuries are due to severe events. We can then adjust our threshold so that we obtain roughly one collision for every ten deployments. But since many of the treatments involved fewer than ten sensor fish deployments, we adjusted the threshold in order to achieve an average $30 \%$ collision rate. Since the magnitudes of the CC metric are binned using a set threshold only an analysis of relative values among treatments is possible.

Two different sensor fish models, with significantly different mass and thus acceleration response characteristics, were used during the period of this study. We computed a threshold value for each device separately. For the older, larger unit we used a threshold of $600 \mathrm{ft} / \mathrm{s}^{2}$; for the newer, smaller unit, we used $2200 \mathrm{ft} / \mathrm{s}^{2}$. This meant that the acceleration magnitude must change by at least this value within one sample interval of the sensor fish $(0.05 \mathrm{~s})$ in order for the acceleration spike to be considered as a collision. Moreover, the subsequent reading must have a lower magnitude in order to qualify the first reading as a collision acceleration spike.

In general, the largest collision counts occured at low and high discharge rates in Bays 2 and 4 


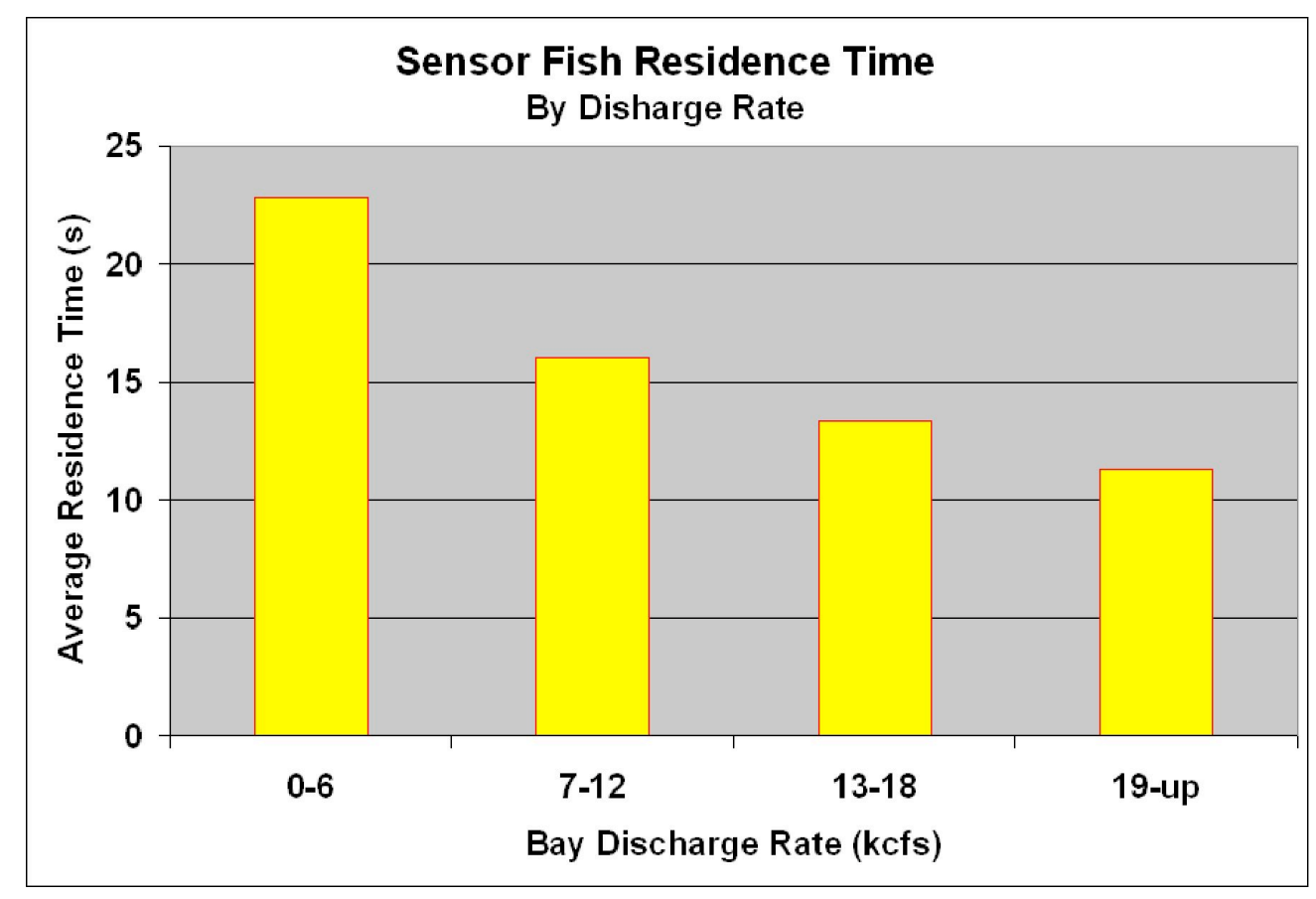

Figure 3.5. Average sensor fish residence time for different ranges of bay discharge.

(Figure 3.6). A possible explanation for this observation is that lower discharge rates have higher residence times, giving Sensor Fish a longer opportunity to collide with the structure. At larger discharge rates, the shorter residence times are counteracted by the greater probability of a severe collision due to higher water velocity. Bay 4 has slightly higher CC values than Bay 2 at all discharge rates.

A consistent relationship between CC and release elevation was not found, though the sample size for this analysis is very limited. Deeper (lower elevation) releases were hypothesized to have a greater chance of colliding with the bottom of the stilling basin, having begun closer to the concrete structure. With a water column thickness of only 2 to 10 feet on the spillway face and a turbulent boundary layer, it is unlikely that the vertical distribution at the release point upstream of the tainter gate can be maintained into the stilling basin. Indeed, particle tracking suggests a fair degree of vertical mixing in the turbulent boundary layer occurs by the time the flow reaches the stilling basin (see figure 3.14).

Horizontal alignment of releases did not appear to have a consistent effect on CC. Offset releases were conducted to determine if alignment of the baffle blocks faces or gaps influence the results. Evidence from CFD modeling suggests that central releases may preferentially result in passage between the baffle blocks, which may be more favorable for fish passage. Offset releases were designed to place the Sensor Fish more in line with the baffle block. But CFD modeling also indicates that the lateral trajectory of particles released in a spill bay is influenced by a number of factors, including discharge rate, operations of adjacent bays, and geometry of the bay. The limited sample size for offset-release data is insufficient to determine the influence of these confounding factors. 


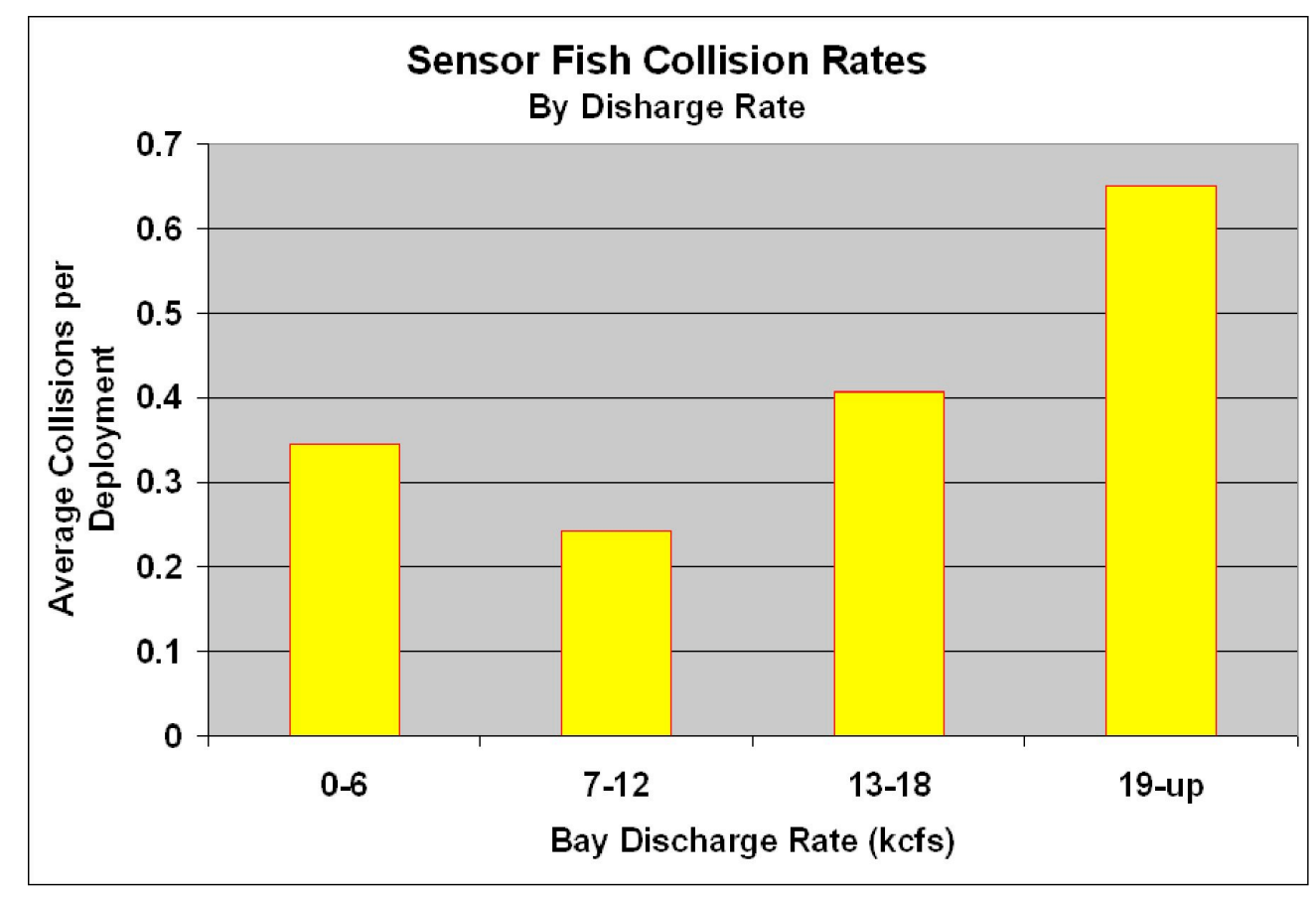

Figure 3.6. Sensor fish average collision rates as a function of bay discharge rate.

\section{3.2 Tainter Gate Approach Conditions Near Release Pipe Locations}

Two-dimensional CFD model results for the region upstream and just downstream of the tainter gates were used by fish biologists to assist in the placement of the release pipes. Velocity magnitudes from the CFD model were also used to estimate the forces acting on the pipes. The effect of increasing gate opening on the velocity distribution approaching the tainter gate is shown in Figure 3.7 for several representative discharges. As gate opening (and discharge) increase the high-velocity, rapid acceleration zone moves upstream and closer to the release pipe exits. The area where non-hydrostatic pressure conditions exist also increases with increasing gate opening.

The apparent entry location of sensors and presumably test fish is generally higher than target injection locations when calculated using the local absolute pressure measured by the sensor fish. In most cases, the length of injection pipes and their placement is done carefully enough to ensure location of the pipe terminus at the design elevation. One reason for this difference in elevation is that flow is accelerating as it approaches the gate opening and the pressure distribution is nonhydrostatic as illustrated by the CFD simulation in Figure 3.8. Calculated elevations from the pressure measured by the sensor fish will result in elevations that are higher than the actual elevation as the device approaches the gate opening. Figure 3.9 shows the distribution of this elevation difference using the CFD simulated pressure and then assuming hydrostatic conditions to compute an elevation. The elevation difference varies from nearly zero to about $3.5 \mathrm{ft}$ as discharge and release location change. Other factors that could cause further localized reductions in pressure include 3-D effects of the piers on flow acceleration (the CFD results are for a 2-D slice) and the wake effect of the injection pipes. The pipes are generally 4 to 6 inches in diameter, large enough to create a wake of a scale similar to the fish and sensor fish. In addition to possible local pressure reduction, turbulent conditions in the wake may cause the injection water discharged from the 
1 pipe, which carries test fish or sensors, to be deflected as it enters the injection pipe wake. The 2 apparent differences between target and actual flow entry elevations may not be an issue for many 3 spill studies where relative comparisons in biological results of spill passage between spill bays is 4 of interest, as long as the target elevations are not different between spillbays. However, it is not 5 at all clear that these differences should be ignored when the results of separate spill studies are 6 compared or when the response of fish to passage conditions following flow field entry at a specific 7 location is of concern. 

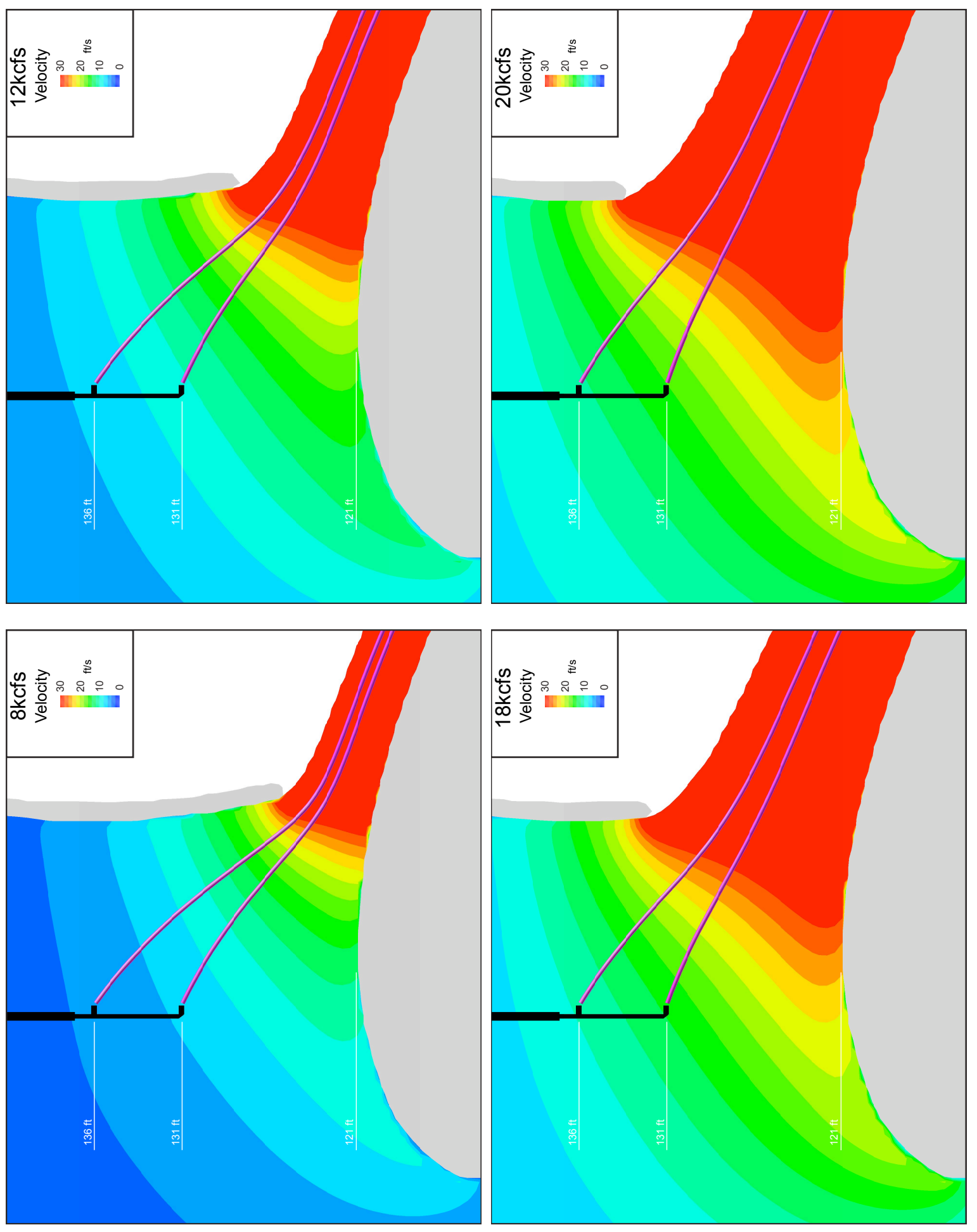

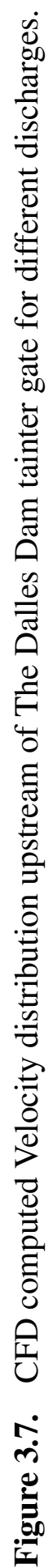




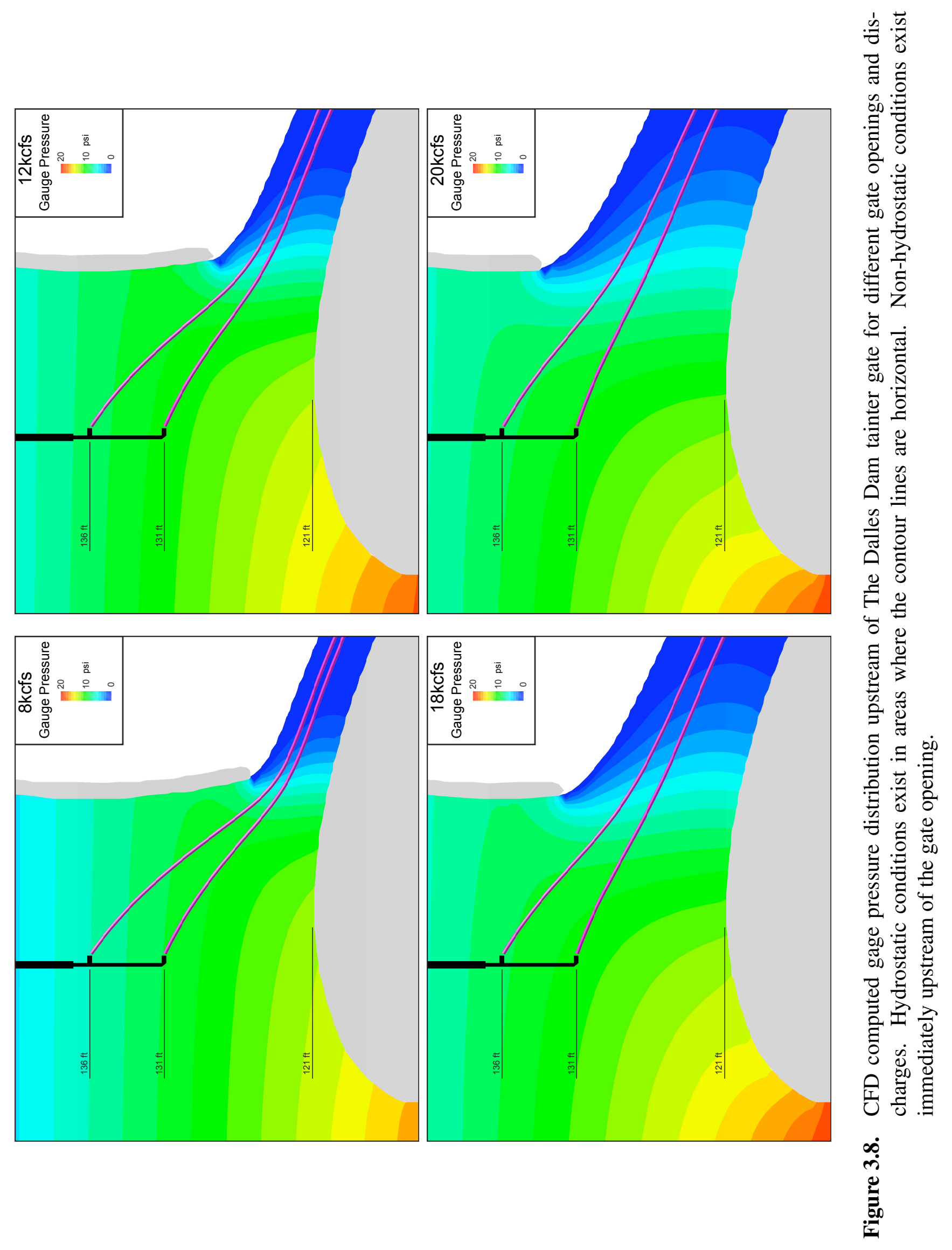



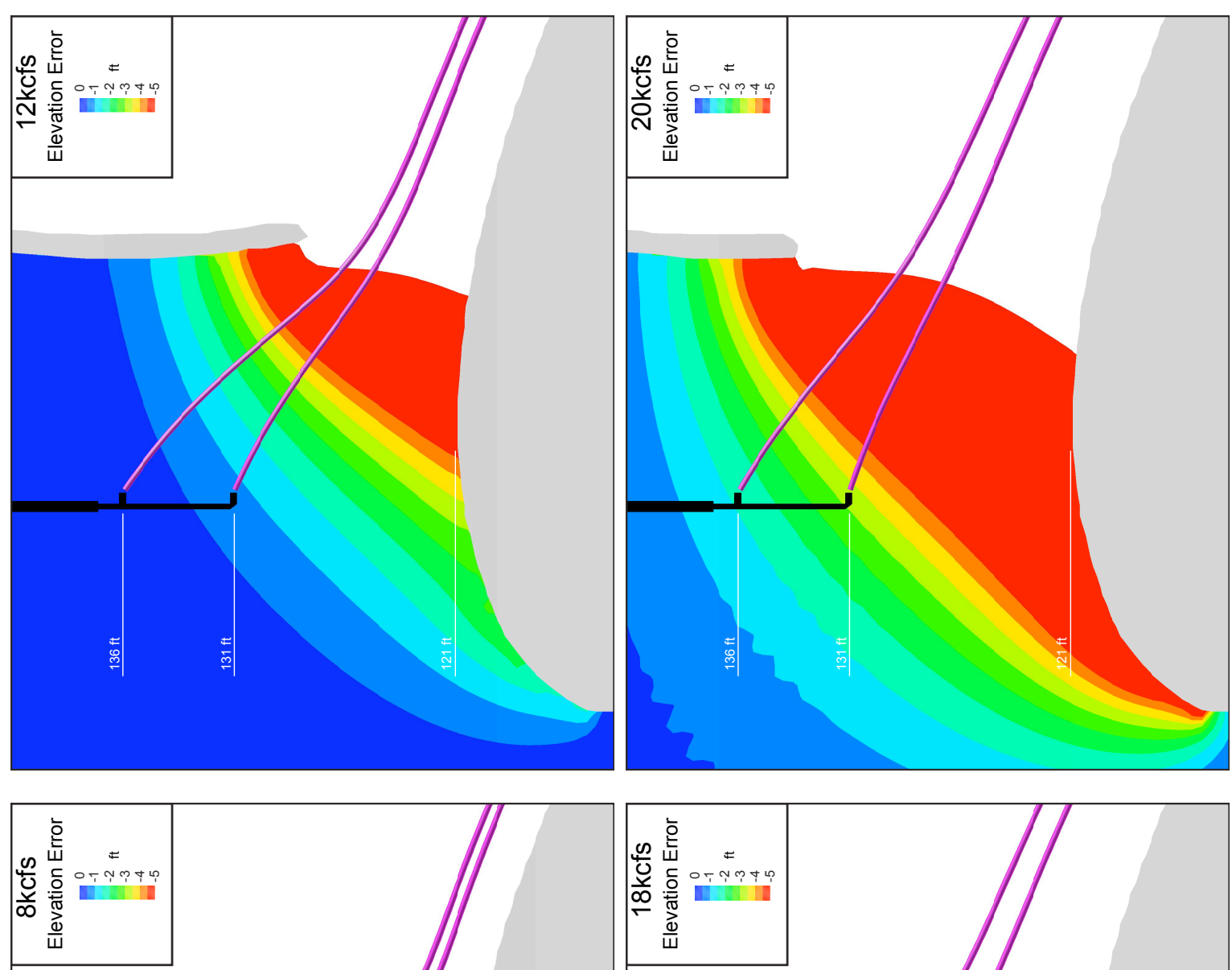

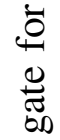

苂

$\frac{0}{2}$

$\stackrel{g}{E}$

$\stackrel{5}{0}$

:

$\frac{0}{2}$

芑

흥

.ำ

亘

ธี

0
0
0
0
0
0
0

哭

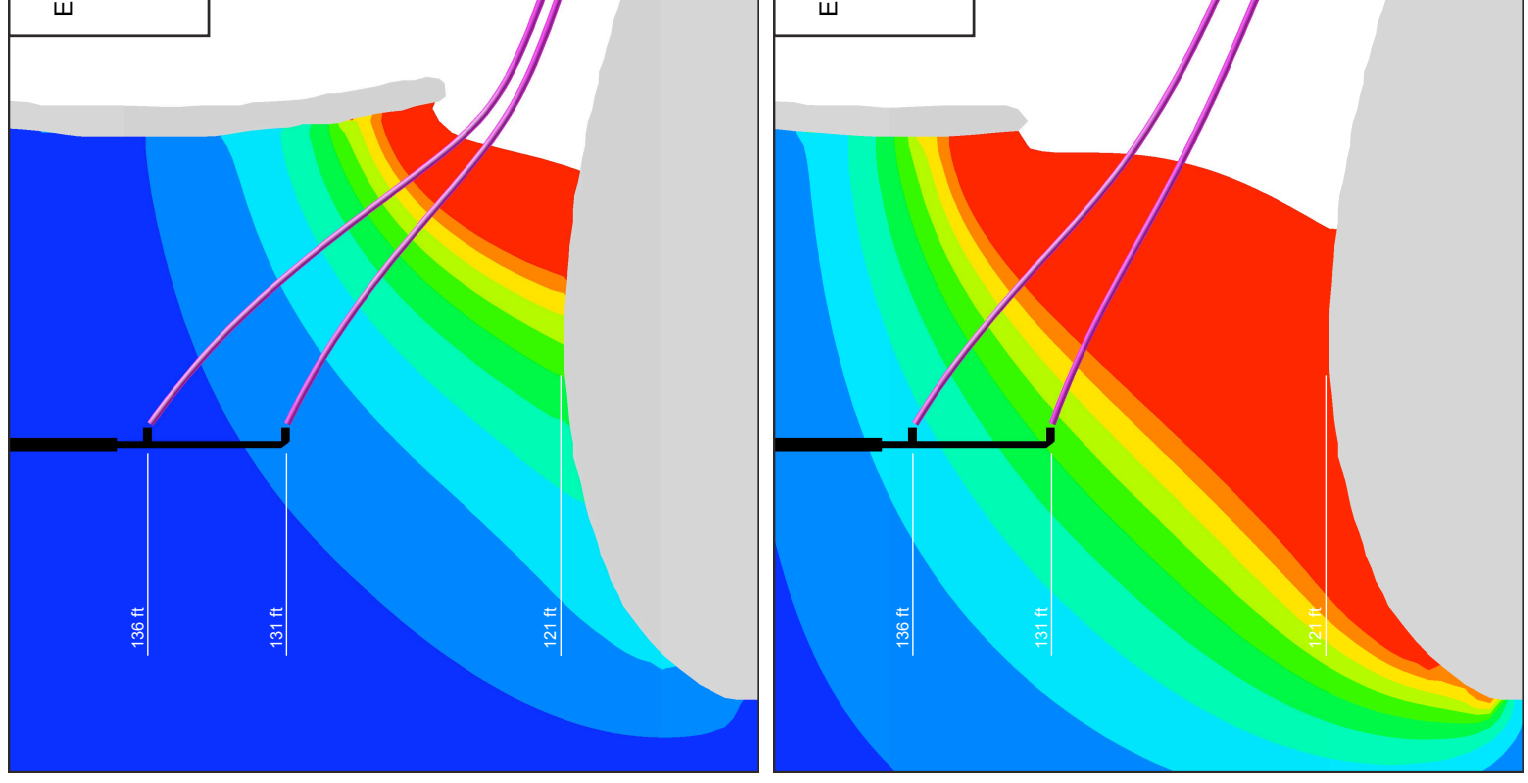

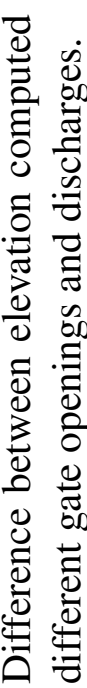

مे 


\subsection{Lagrangian Particle Tracking}

We performed the Lagrangian particle tracking analysis for 12 spillway operational scenarios for which we had CFD model results. The scenarios represented spill bay discharges from 3 to $21 \mathrm{kcfs}$ and a tailwater elevation range from 76.5 to $81 \mathrm{ft}$. Spill patterns varied from single- to 19-bay operation. Appendix A summarizes these model runs.

The available CFD runs were generated to represent field conditions for a number of live-fish and Sensor Fish passage studies conducted at the prototype. Note that many of the result comparisons discussed in this report involve cases with several independent variables, often preventing us from attributing differences in metrics to specific operational conditions. For instance, in examining the relationship between discharge rate in Bay 4 to residence time, we used field test conditions with a range of flows in Bay 4, but flows in adjacent bays were not necessarily held constant, nor were tailwater elevations.

The LPT analysis procedure consists of defining particle seed locations, computing the paths taken by the particles released from these locations, compiling statistics for the trajectories, and comparing the statistics amongst the test scenarios to identify features of interest. We specified particle release locations on a grid of 50 locations (Figure 3.10) half-way down the spillway face of each tested bay. The locations were laterally distributed across the bay two feet apart and extending to within one foot of each spill bay side. This lateral distribution was formed into two layers, shallow and deep. The shallow and deep release points were located within $25 \%$ of the water-column depth from the top and bottom of the flow, respectively. Since the water depth on the spillway face varied with bay discharge rate, the elevations of the release points depended on the spill.

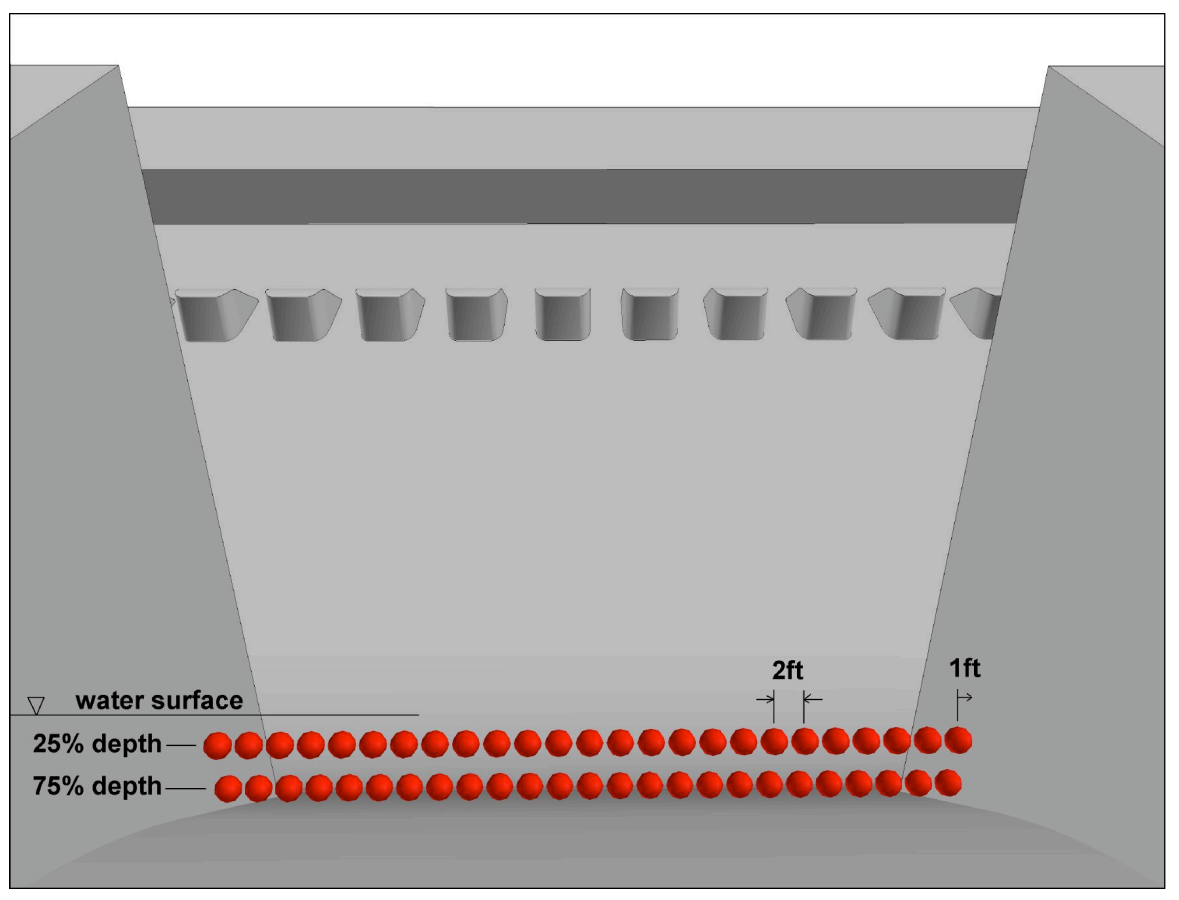

Figure 3.10. Particle release locations. 
We determined the total number of particle to release as follows. Since particles released in this study are subject to random diffusive effects based on the computed turbulence in the model, tracks of particles released from the same location within the model domain almost never coincide. Therefore, more than one particle needed to be released from each location to capture the variation in paths that occurs. We addressed the question of how many particles to release by examining the convergence of the computed metrics as we increased the number of sample particles. Figure 3.11 shows an example of how two metrics fluctuate as the number of sample particles increases. Both metrics converge within $10 \%$ of their final values when the sample size is about 3,500. We concluded that 10,000 particles would provide a representative sample of the track variations to provide stable metrics. To obtain our 10,000 particle sample, each of the 50 locations was seeded with 200 particles.

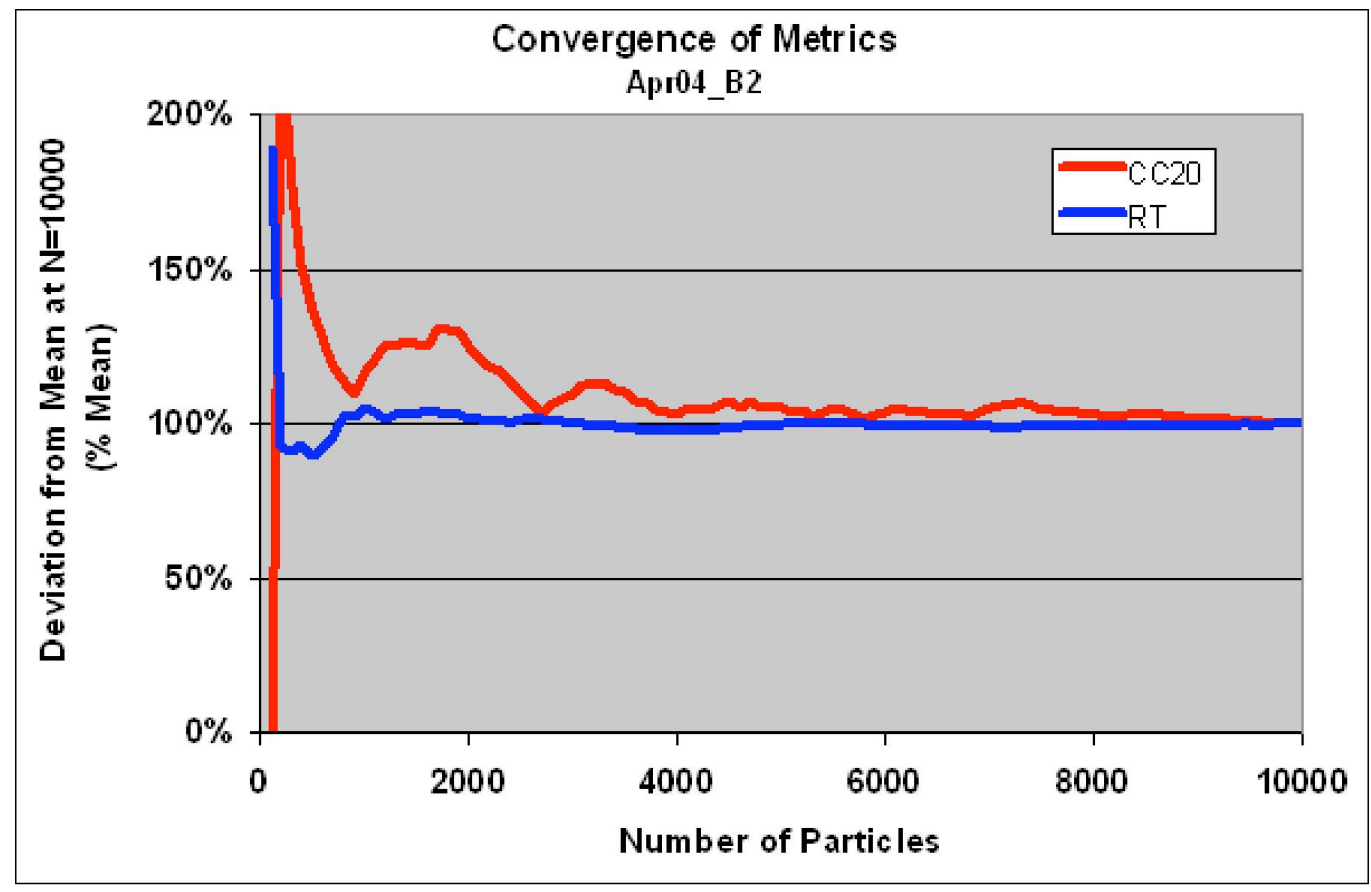

Figure 3.11. Relationship between computed metrics and number of particles.

The Lagrangian particles were spheres, $4 \mathrm{~cm}$ in diameter and with density equal to water. The particles were given a random diffusive component, described in Section 2.3.2, to simulate turbulence at scales smaller than those resolved by the CFD model.

\subsubsection{Trajectories}

Particle trajectories through the stilling basin exhibit a variety of patterns. These are not discernable when looking at all 10,000 tracks per bay that constitute a particle run (Figure 3.12), but may be investigated by examining individual tracks or through animation of the particles. The majority of particles take one of three general types of paths through the stilling basin: direct, single recirculation, and multiple recirculations (Figure 3.13).

The most common path is the direct path. Particles enter the stilling basin near the floor and 


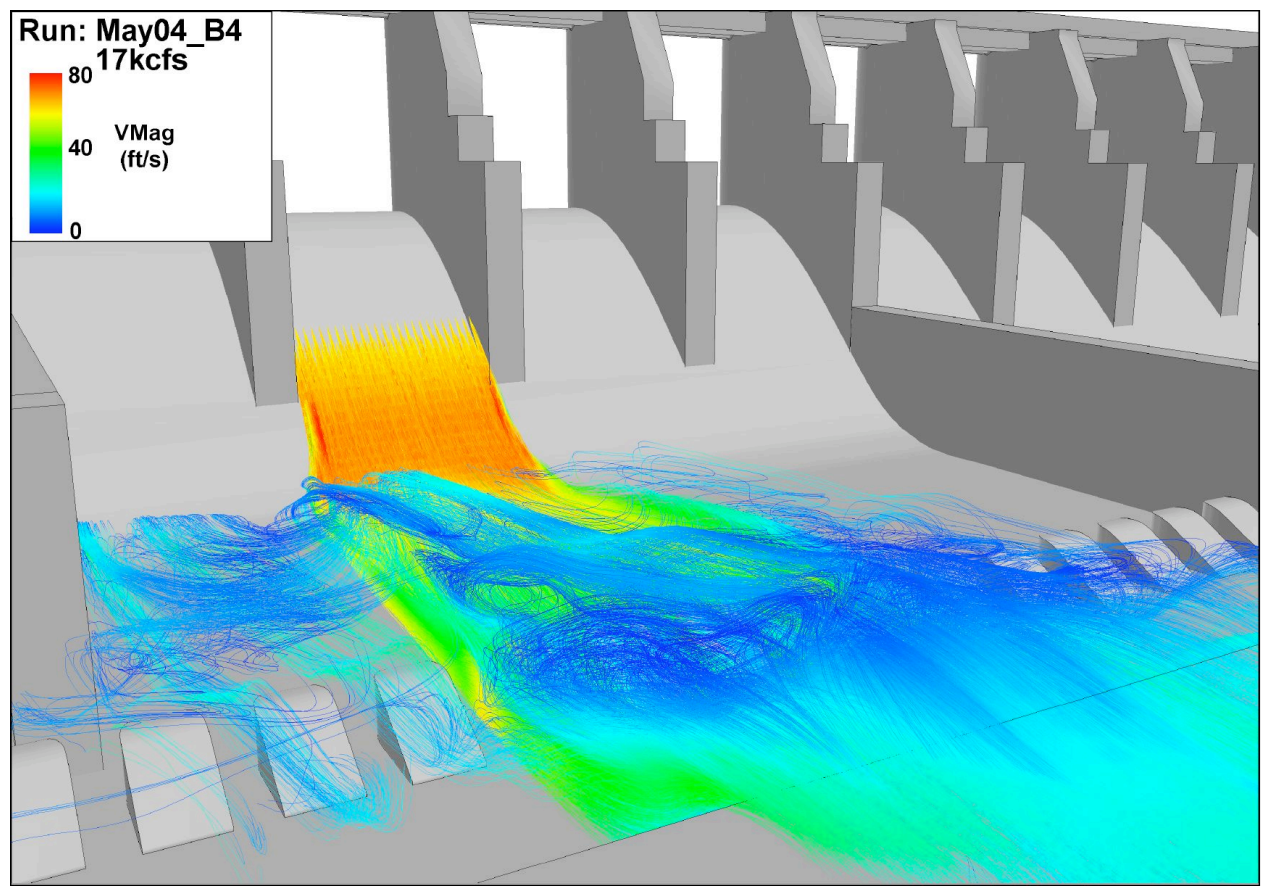

Figure 3.12. Particle tracks in Bay 4 at $17 \mathrm{kcfs}$ with the spillway in place between Bays 6 and 7 .

remain in the lower 10ft of the water column until they reach the baffle blocks (Figure 3.14). Then, they either collide with the blocks, or bypass them on the side. In either case, their paths are disrupted by the baffle blocks and they become more dispersed. Finally, the vertical flow generated by the end sill sends most particles out of the stilling basin.

Particles recirculate when they are caught up in the backflow in the upper 10ft, or so, of the water column between the foot of the spillway face and the end sill (Figure 3.15). This backflow is observed in all scenarios analyzed. Most often, the large-scale, non-uniform velocity generated at the baffle blocks causes the rise of the particle into the recirculation zone. Recirculation tends to be more prevalent at the lower discharge conditions that were simulated. Particle dispersion is higher at the edges of the bays (Figure 3.16 and Figure 3.17) increasing recirculation of particles in those locations.

Another phenomenon observed with recirculating particles is a lateral flow to the north end of the spillway. This was observed at the prototype and at the 1:80 ERDC physical model, particularly at the southern end of the spill pattern. Particle tracking also shows the presence of the lateral flow in the simulated flow fields (Figure 3.18). The concern that this lateral flow increases the time spent by fish in the stilling basin, thus raising the chance of injury, was one of the reasons for installing a training wall between Bay 6 and 7 in 2004. Observation of particle tracks in Bay 4 with and without the wall show a significant reduction in preferential transport towards Bay 3 (Figure 3.19). 


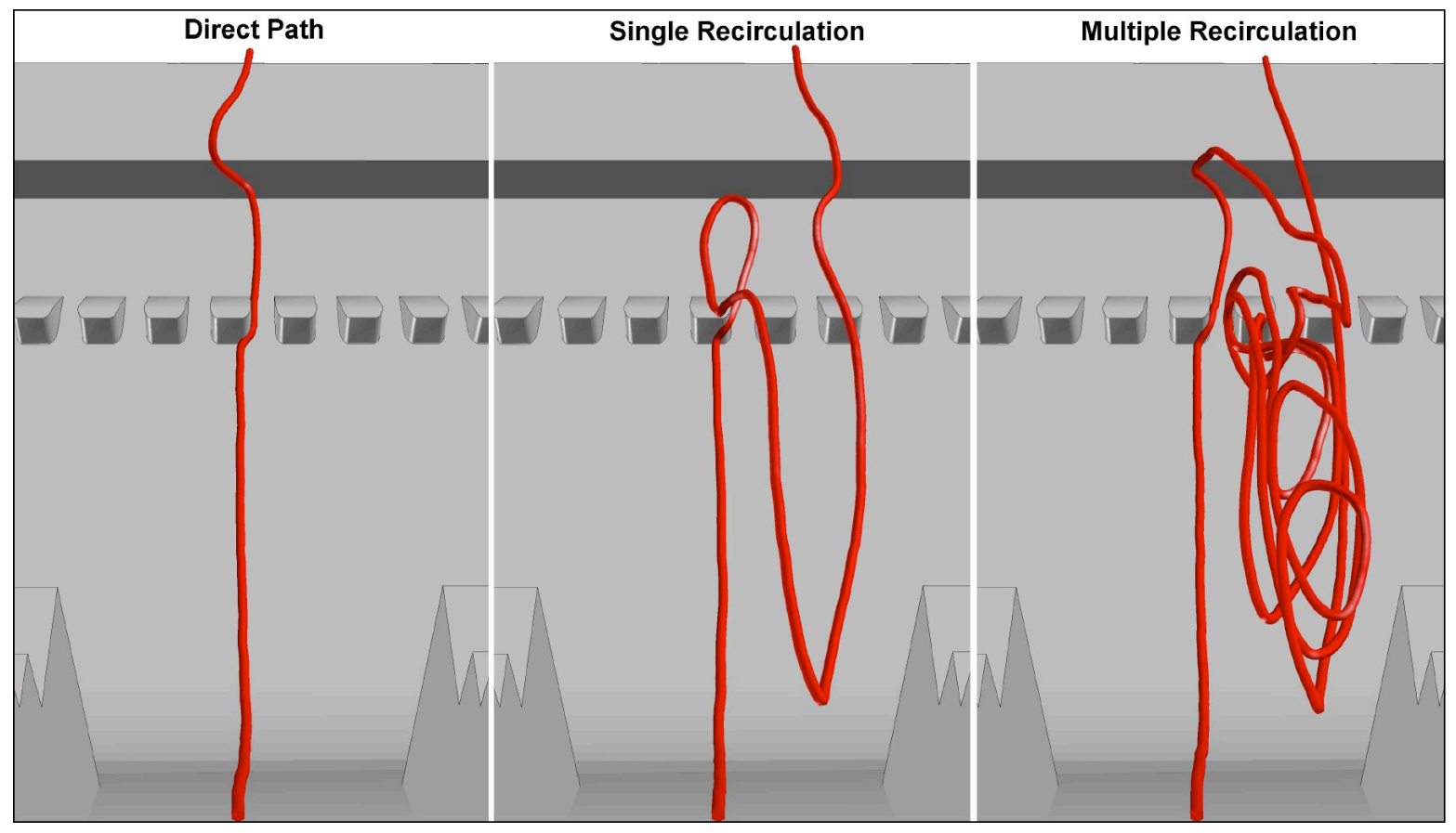

Figure 3.13. Common particle trajectories through the stilling basin. 


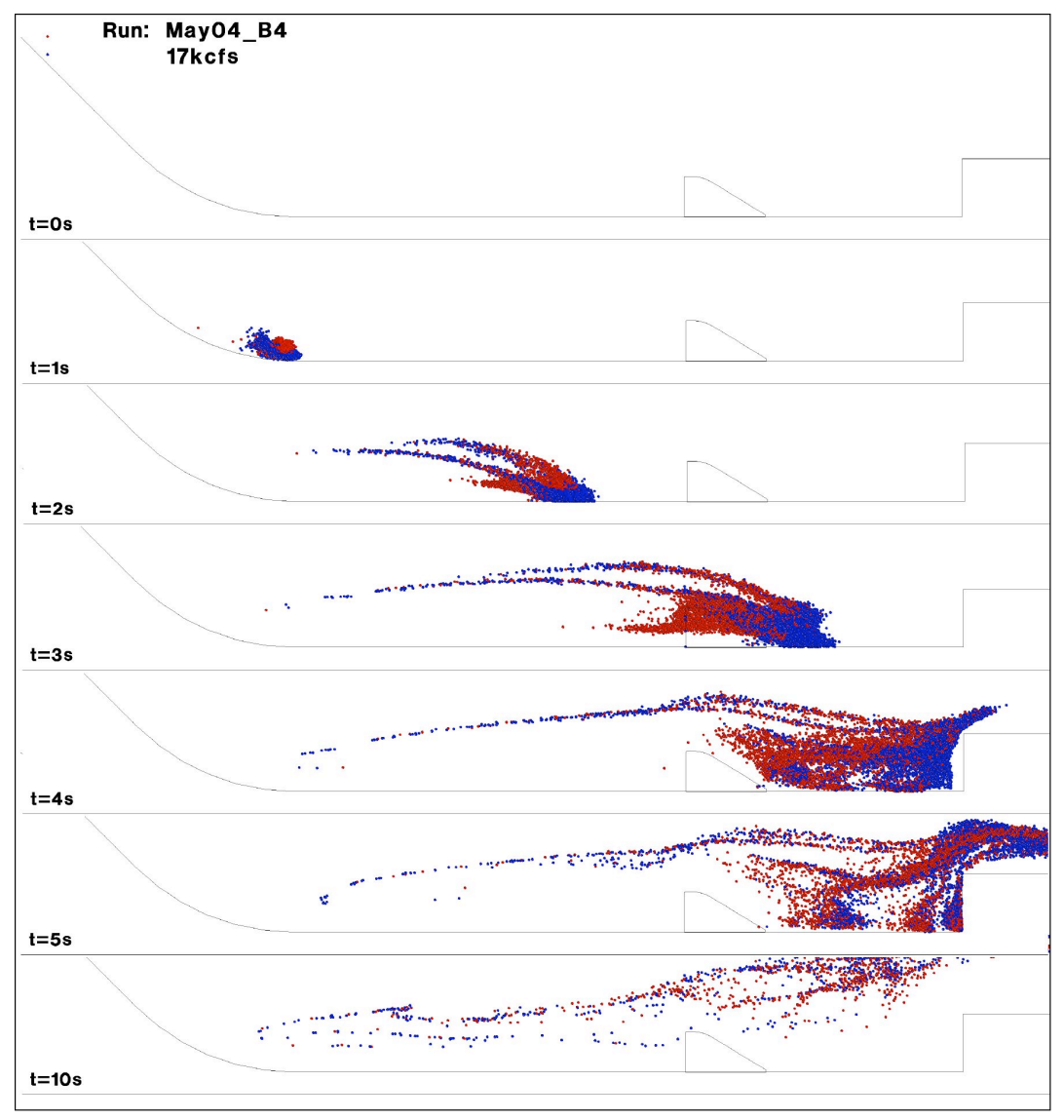

Figure 3.14. Side view of particle distributions at different times in Bay 4 at $17 \mathrm{kcfs}$. Red and blue particles were released at the higher and lower spillway face elevations, respectively.

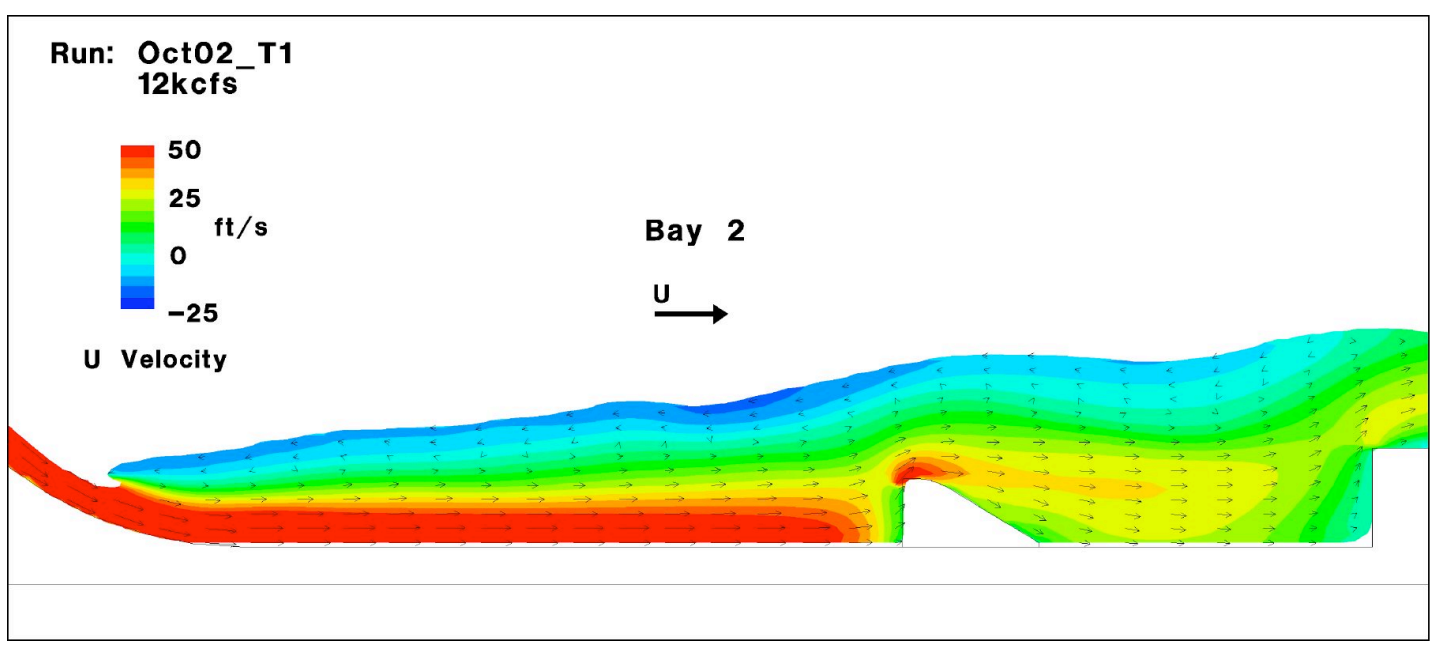

Figure 3.15. Recirculation zone in upper section of flow of Bay 2 at 12 Kcfs. 


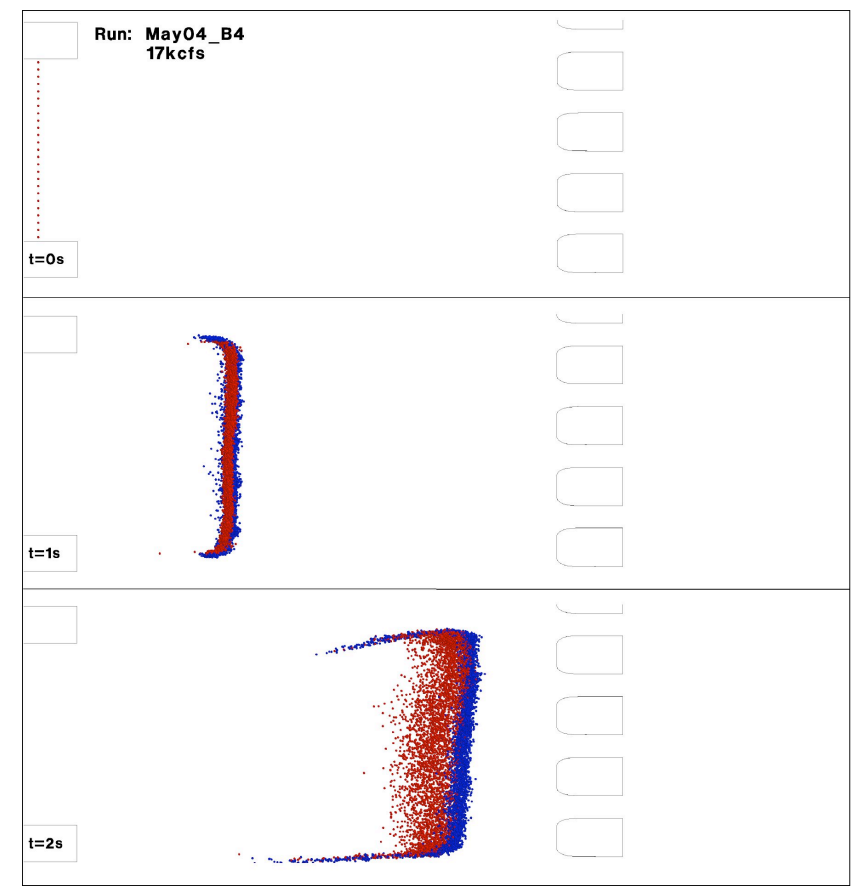

Figure 3.16. Plan view of particles shown in Figure 3.14 from time $=0$ to $2 \mathrm{~s}$.

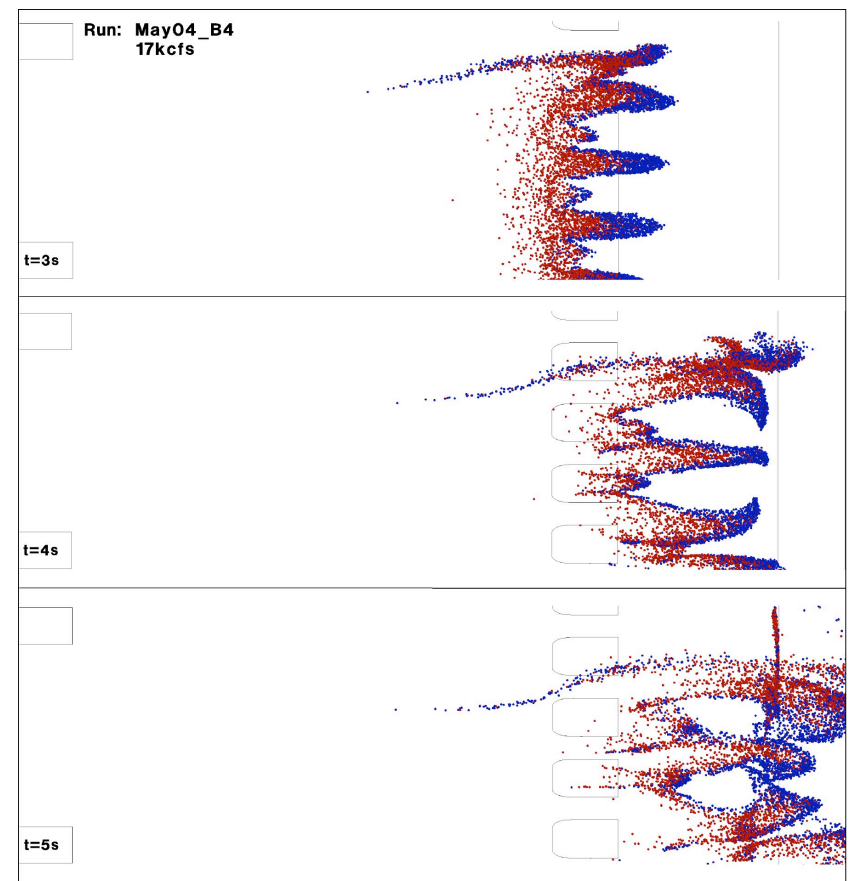

Figure 3.17. Plan view of particles shown in Figure 3.14 from time $=3$ to $5 \mathrm{~s}$. 


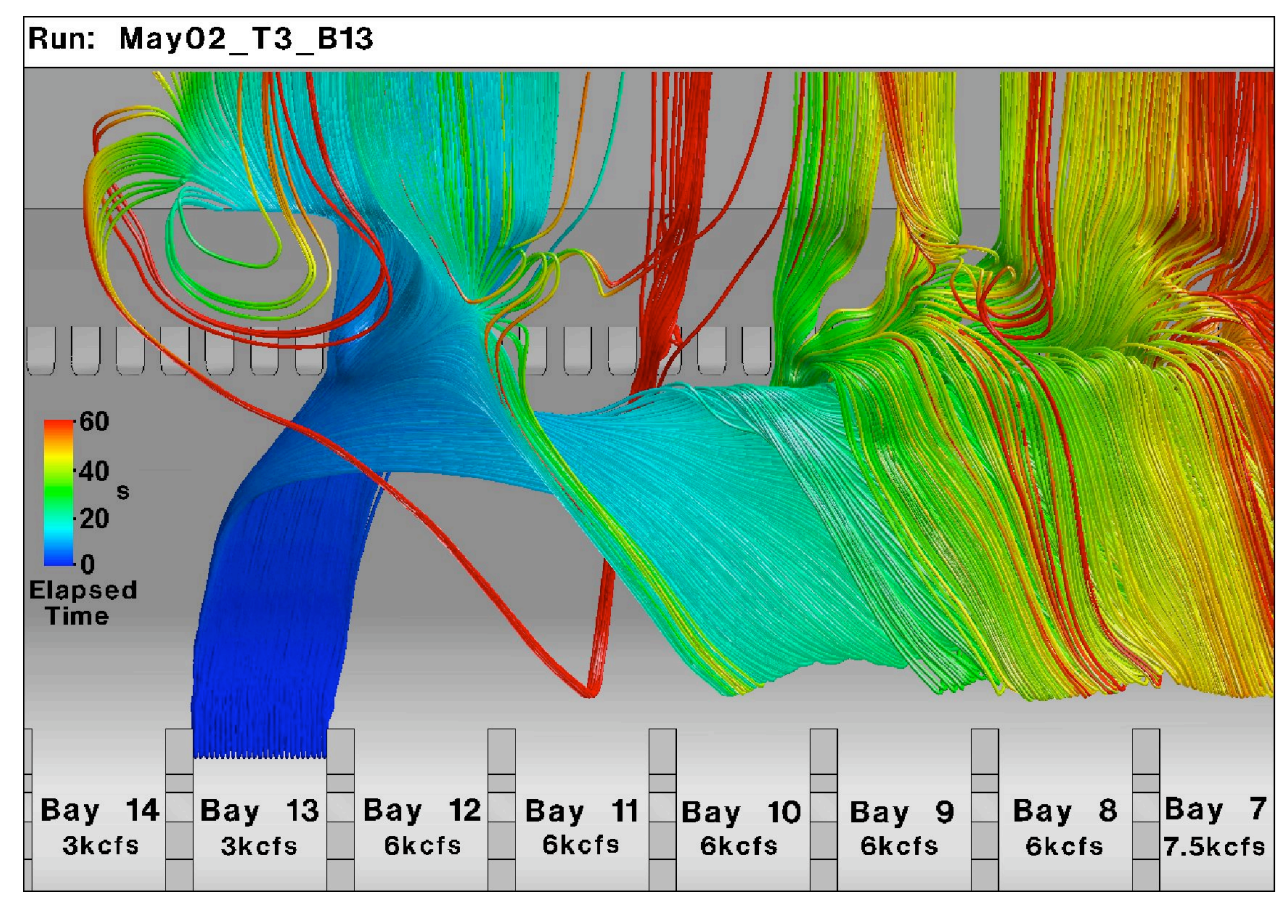

Figure 3.18. Particles released from Bay 13 caught in lateral flow.

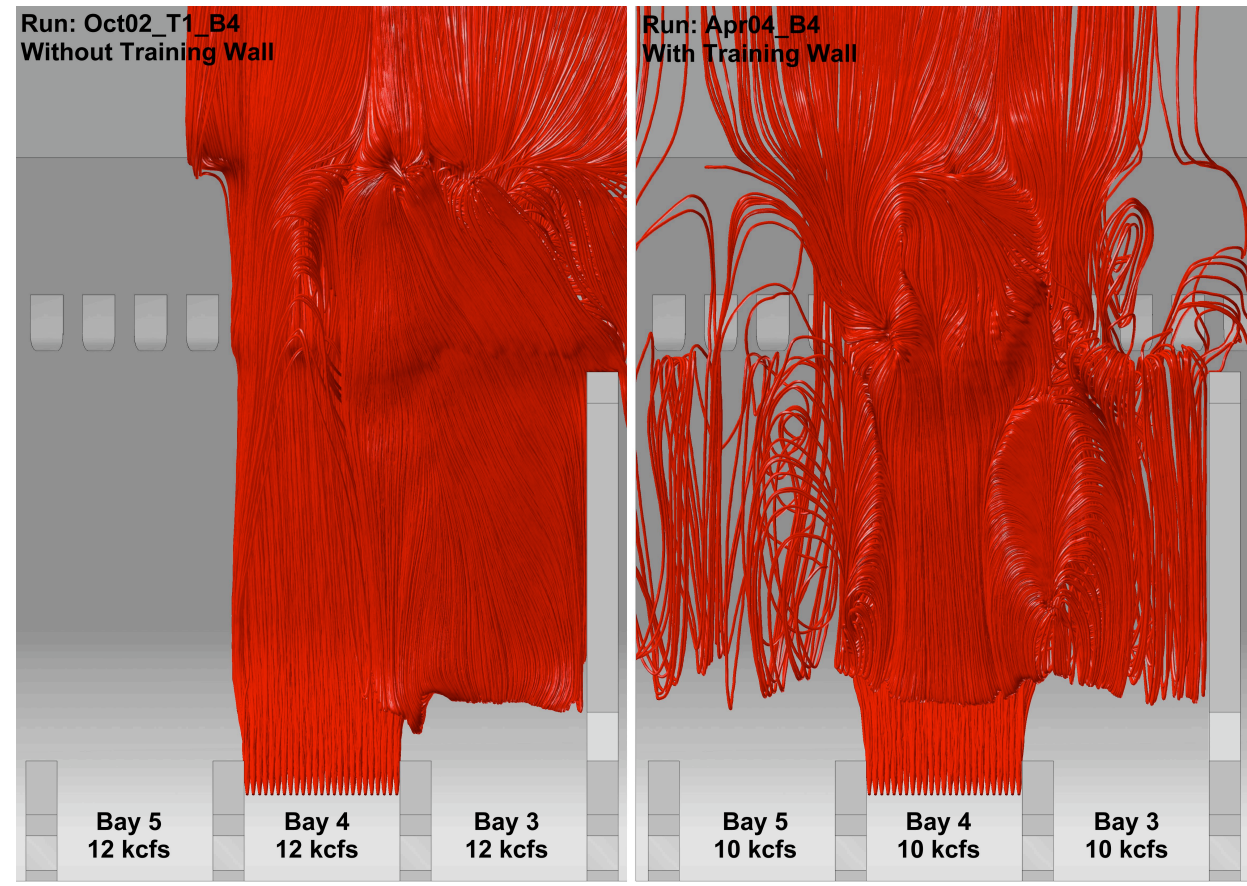

Figure 3.19. Particle tracks in Bay 4 without and with the Bay $6 / 7$ training wall. 


\subsubsection{Collision Locations}

Particles released in the spillway frequently strike the solid surfaces of the stilling basin. Figure 3.20 shows a typical distribution of collision locations in the stilling basin, with impact points colored and sized by strike velocity normal to the wall. While impacts occur on the spillway face and stilling-basin floor, the vast majority of strikes occur on the upstream faces of baffle blocks and, to a lesser degree, on the vertical step of the end sill. The highest intensity strikes almost always occur on the baffle blocks. Figure 3.21 shows typical trajectories of a particle stream striking a baffle block.

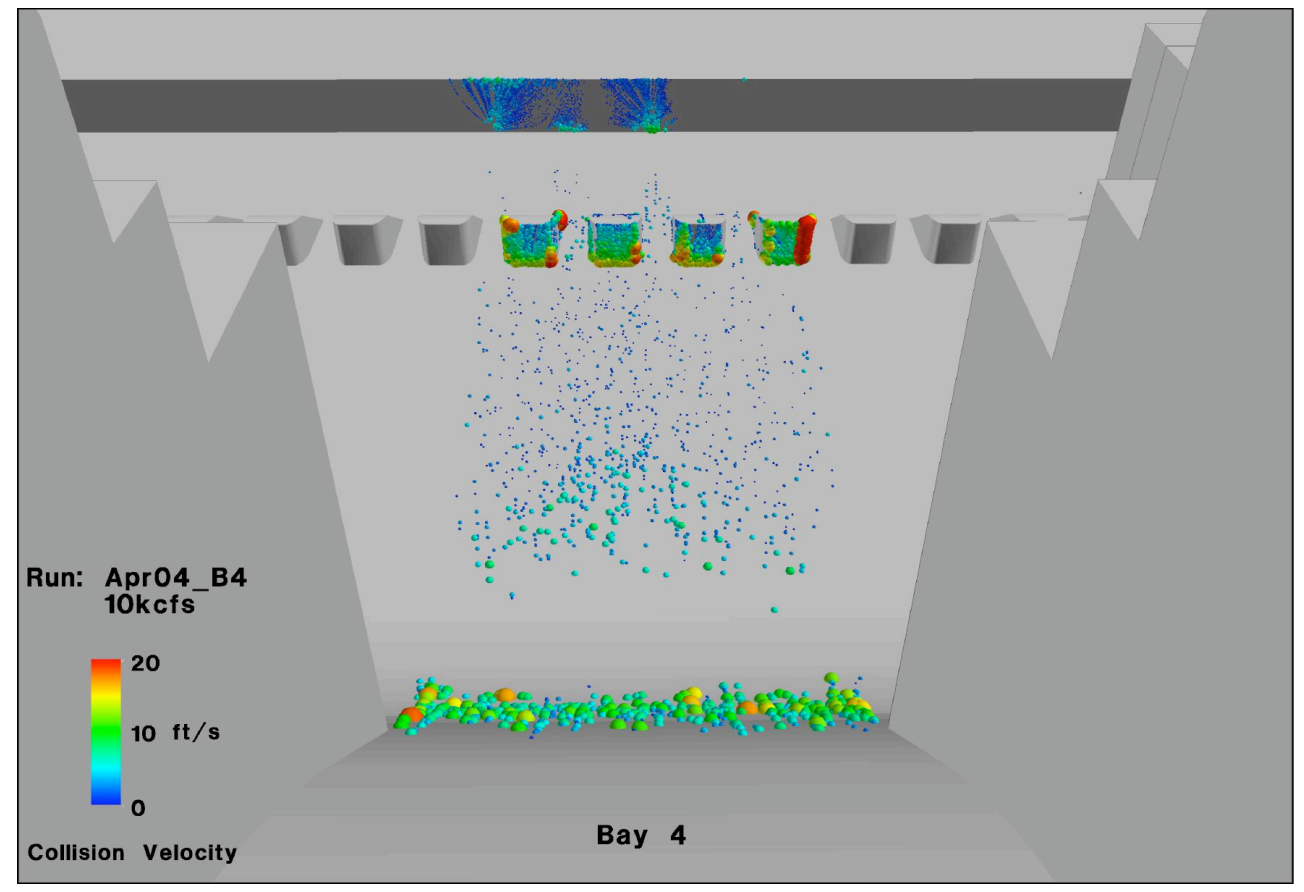

Figure 3.20. Particle wall collisions colored and sized by impact velocity in Bay 4 at 10kcfs.

Average strike velocity tends to increase with bay discharge rate. Figure 3.22 shows the CC20 metric (average count of collisions that are greater than $20 \mathrm{ft} / \mathrm{s}$ ) over a range of flow rates. Typical strike velocities for a test condition had a median between 2 and $3 \mathrm{ft} / \mathrm{s}$ with maximum values over $40 \mathrm{ft} / \mathrm{s}$ (Figure 3.23). Many of the lower-intensity strikes, particularly on the stilling basin floor, are grazing impacts with a low velocity magnitude normal to the surface. Frequently, such grazing collisions have large velocities tangent to the surface which could result in scraping injuries to fish.

\subsubsection{Residence Times}

Stilling-basin residence time is the elapsed time, in seconds, that a particle spends between the foot of the spillway ogee and ten feet beyond the end-sill step. Higher residence times are hypothesized to increase the chances of fish injury by extending the duration of exposure to the hostile environment of the stilling basin. Average residence times are affected by the magnitude of the downstream component of flow velocity and the length of the path taken by the particle. Higher discharge tends to create faster exit velocities and more-direct paths through the stilling basin. 


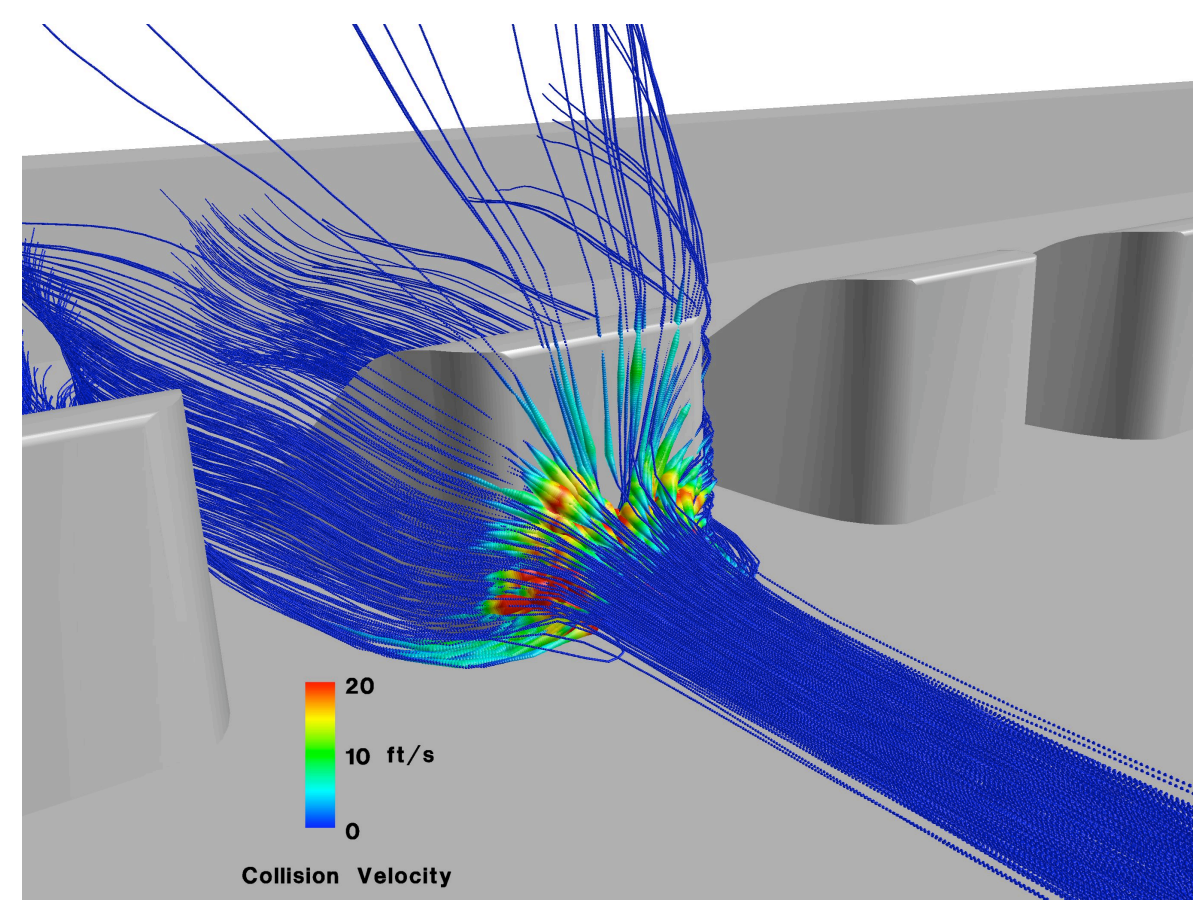

Figure 3.21. Trajectories of particle colliding with baffle block.

1 These combine to reduce residence time as flow rate increases (Figure 3.24).

2 Most particles travel in a relatively direct path through the stilling basin. Residence time increases 3 significantly when a particle takes a recirculatory path through the basin. The distribution of res4 idence times within a set of particle tracks reflects the prevalence of recirculatory paths. A his5 togram of residence times for a typical set of paths (Figure 3.25) has a primary peak associated with direct passage routes followed by a series of smaller values that represent discrete types of recirculatory paths. 


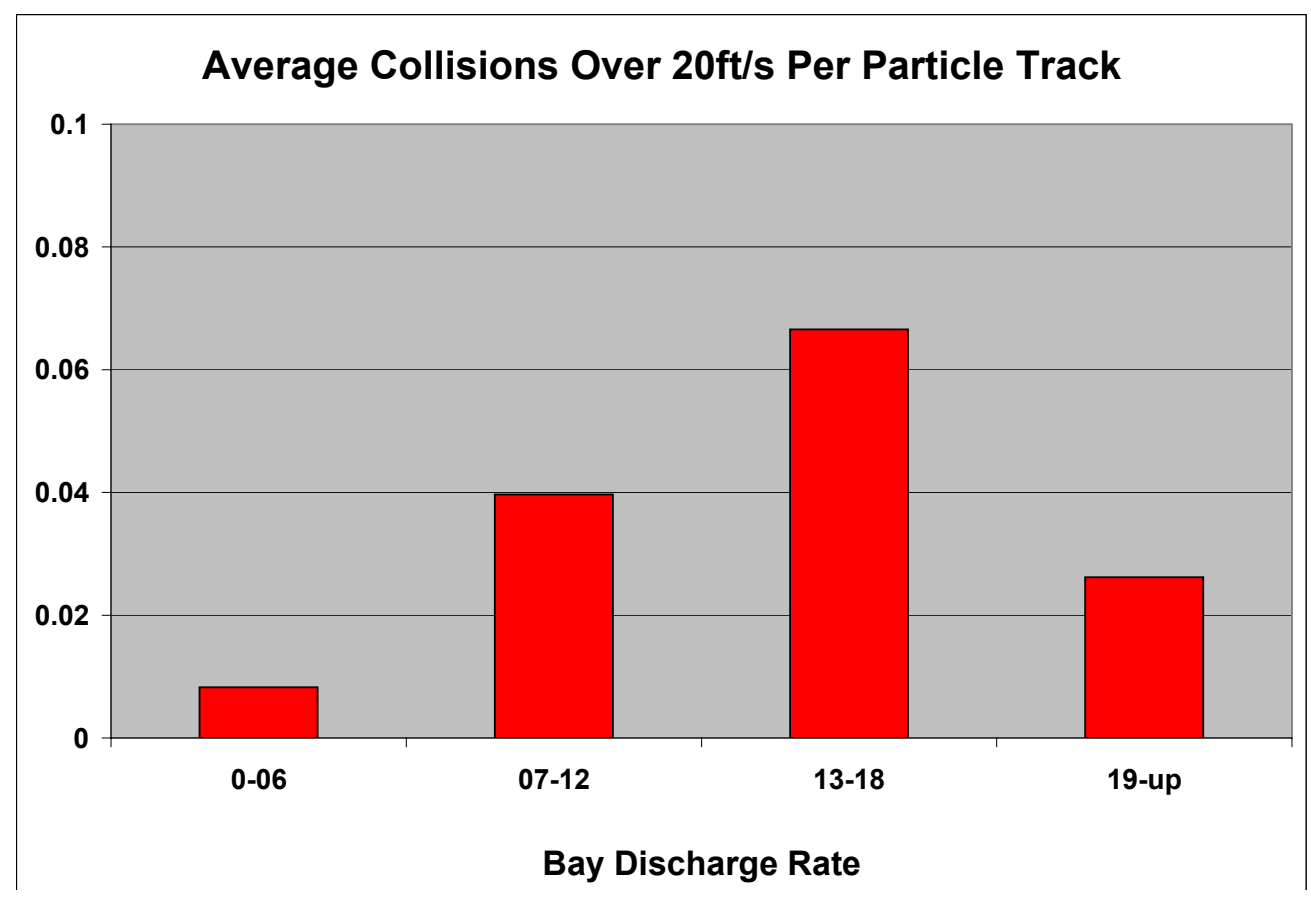

Figure 3.22. Collision count as function of bay discharge rate.

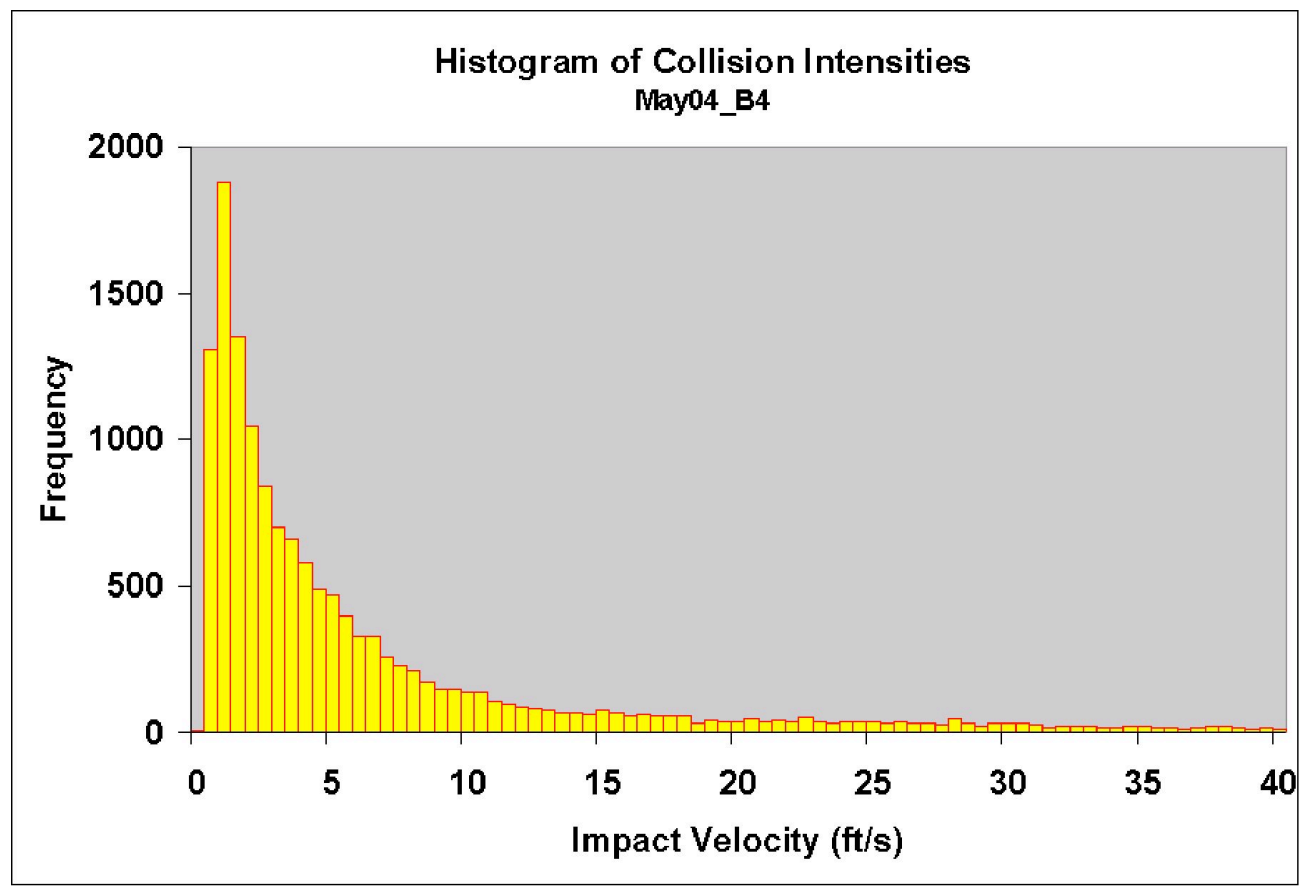

Figure 3.23. Distribution of collision intensities in Bay 4 at 17kcfs. 


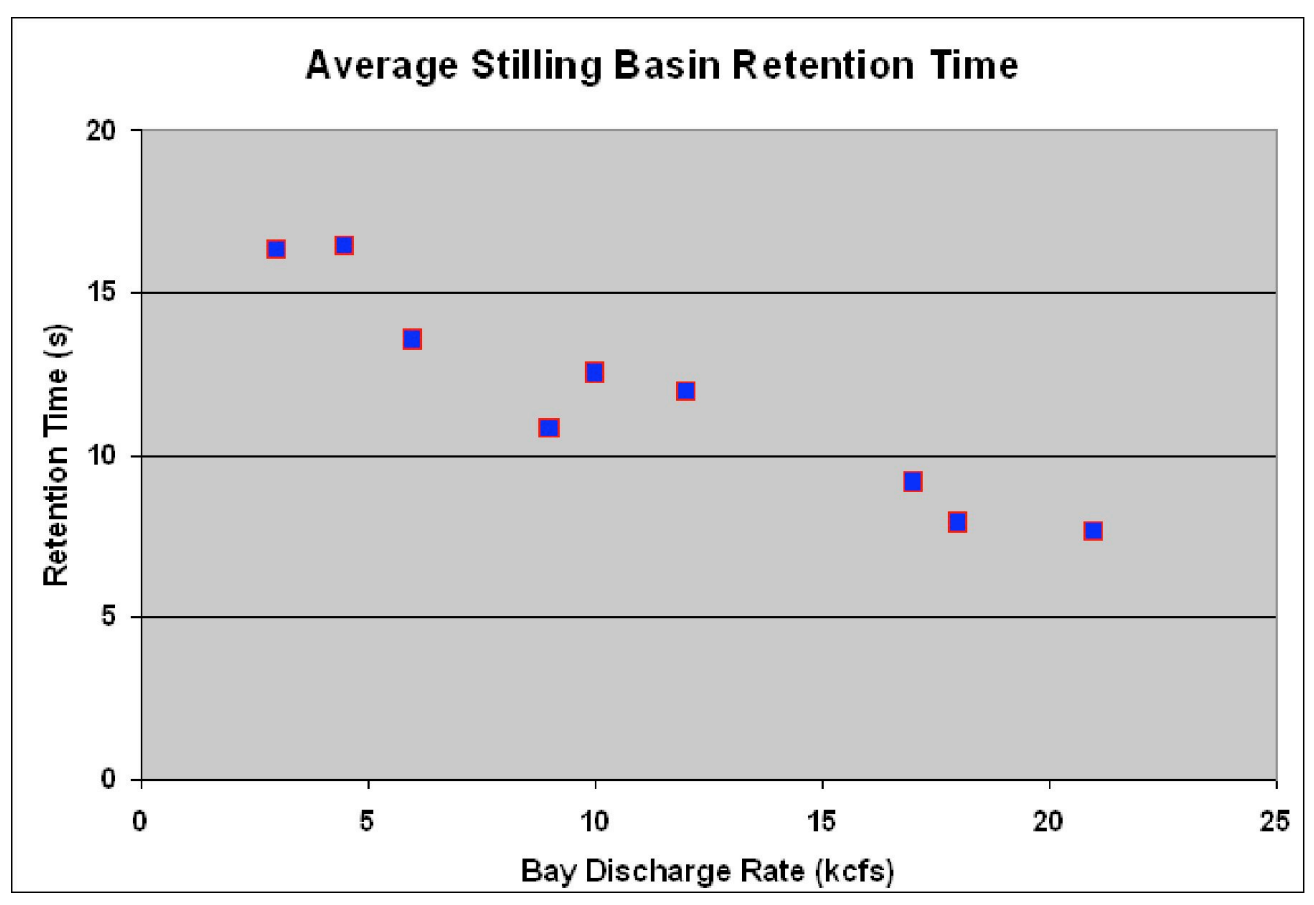

Figure 3.24. Residence time as a function of bay discharge rate.

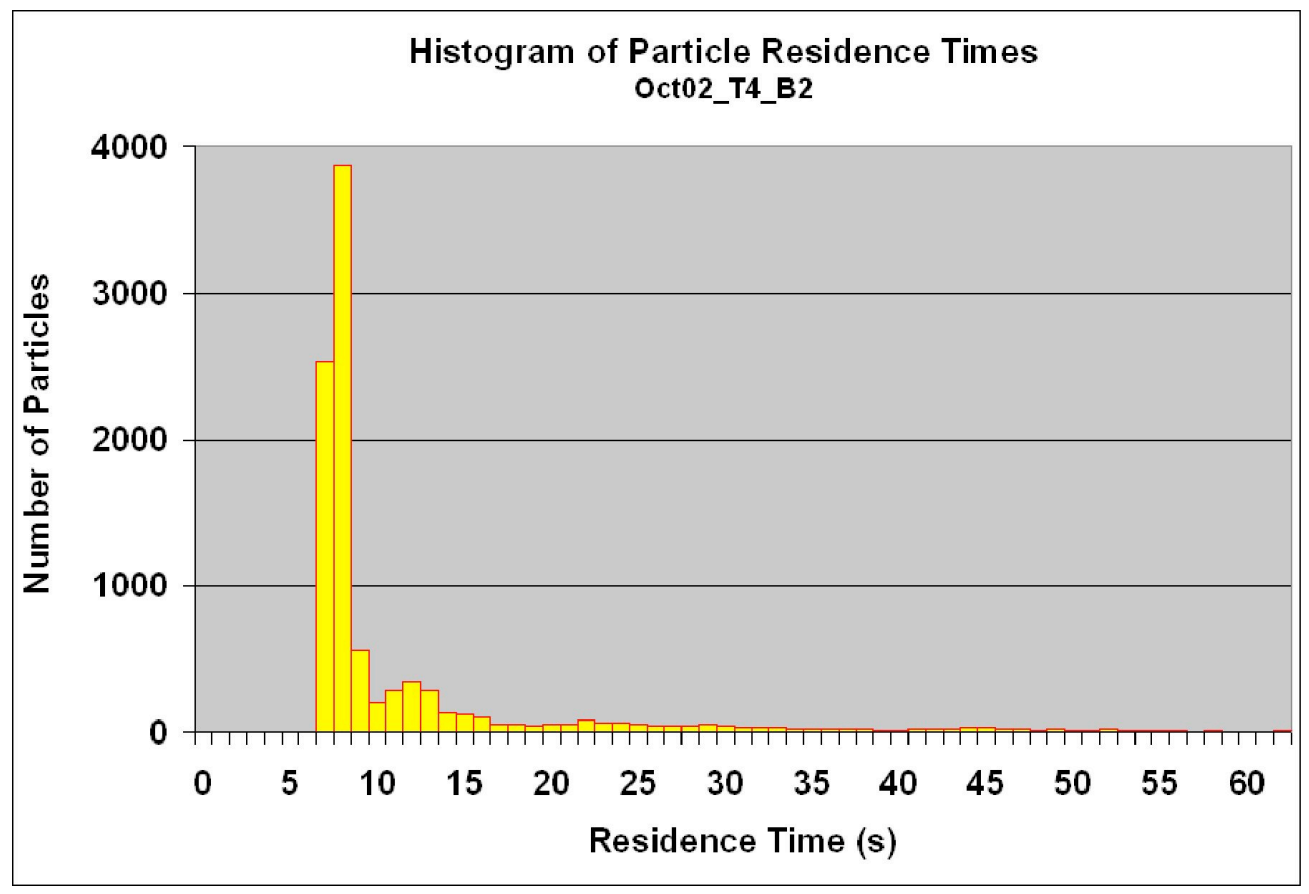

Figure 3.25. Distribution of residence times in Bay 2 at $4 \mathrm{Kcfs}$. 


\subsubsection{Release Location}

For most analyses, we aggregated the particle statistics from all of the 50 discrete release locations to compute average metrics for the bay. But to determine the effect of release location, we computed separate metrics for each release site.

Release location influences particle metrics. The collision metric, in particular, varies significantly across the width of the spill bay with peak values occurring at intervals corresponding to the baffle blocks (Figure 3.26). Although the high CC20 values correspond to baffle-block collisions, slight lateral components of the flow tend to offset the alignment (Figure 3.27) so that peak values do not necessarily line up with particles released directly in front of the baffle blocks.

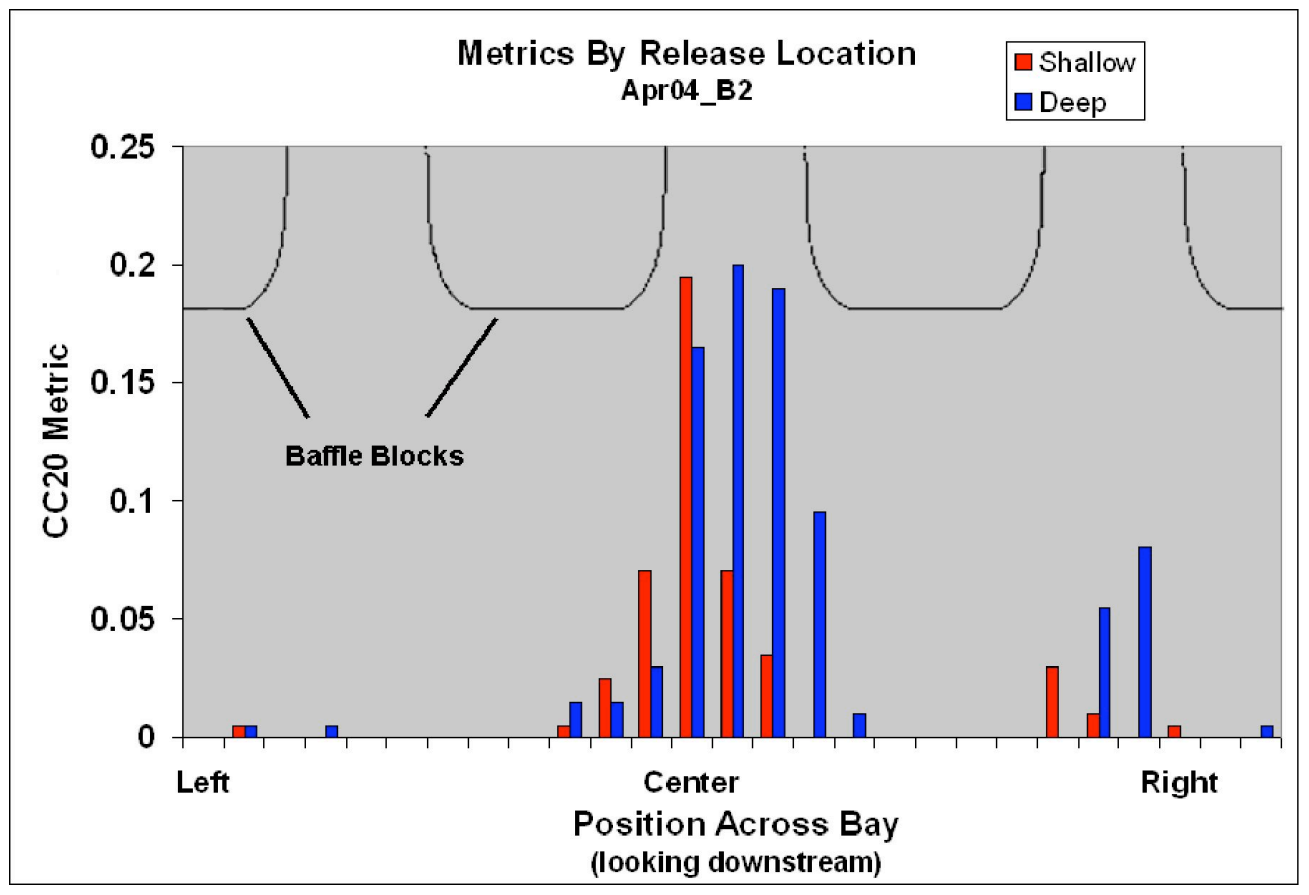

Figure 3.26. Collision count metric distribution by release location in Bay 2 at $12 \mathrm{Kcfs}$.

The residence time metric is also affected by particle release location. Figure 3.28 shows that particles released near the sides of Bay 2 have significantly higher residence times, due the their interaction with the flow separation generated by the end of the pier extensions (Figure 3.29). This situation does not occur in Bay 4 (Figure 3.30), where there are no pier extensions. However, this Bay 4 case does illustrate the sensitivity of release location on residence time. A lateral shift of just four feet in release position can make the difference between a residence time of $9 \mathrm{~s}$ and one of $47 \mathrm{~s}$ (Figure 3.31). 


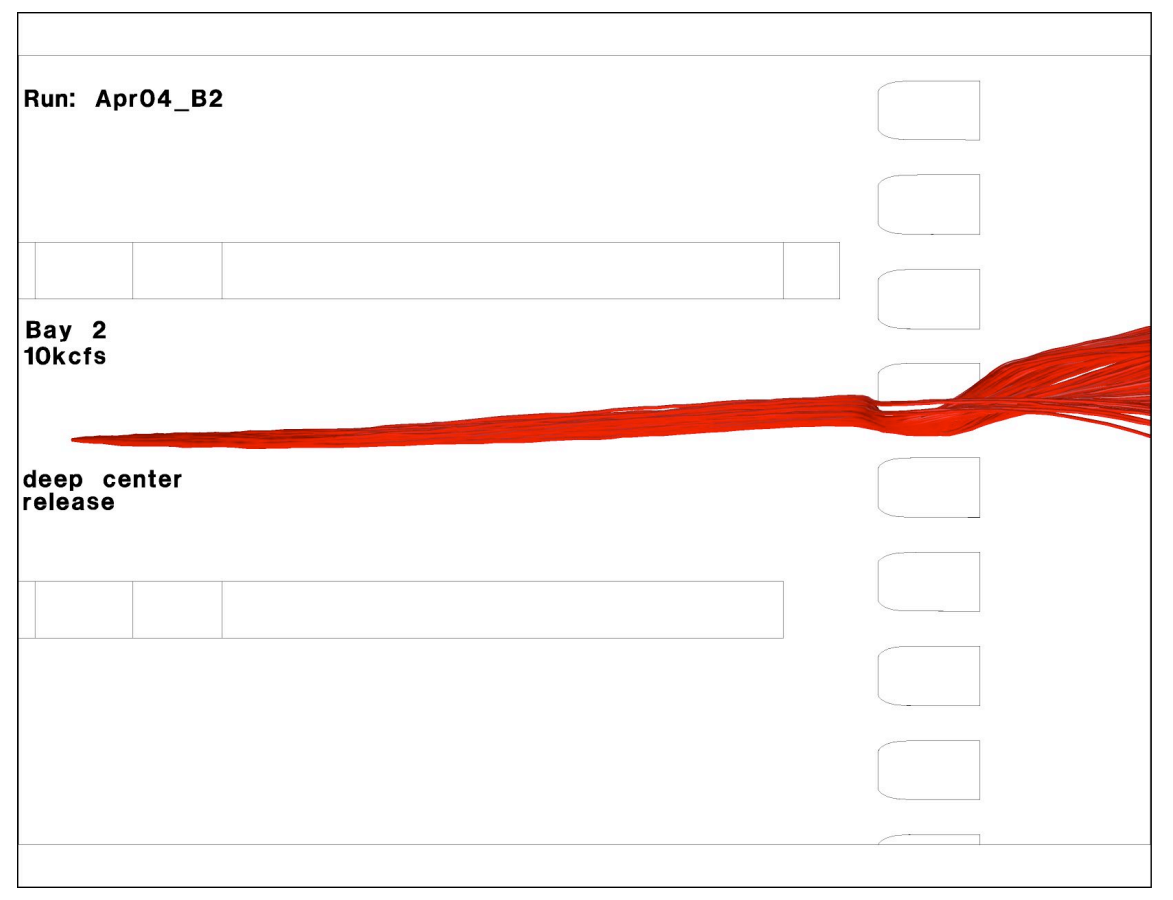

Figure 3.27. Lateral flow offsets particles released at center of Bay 2.

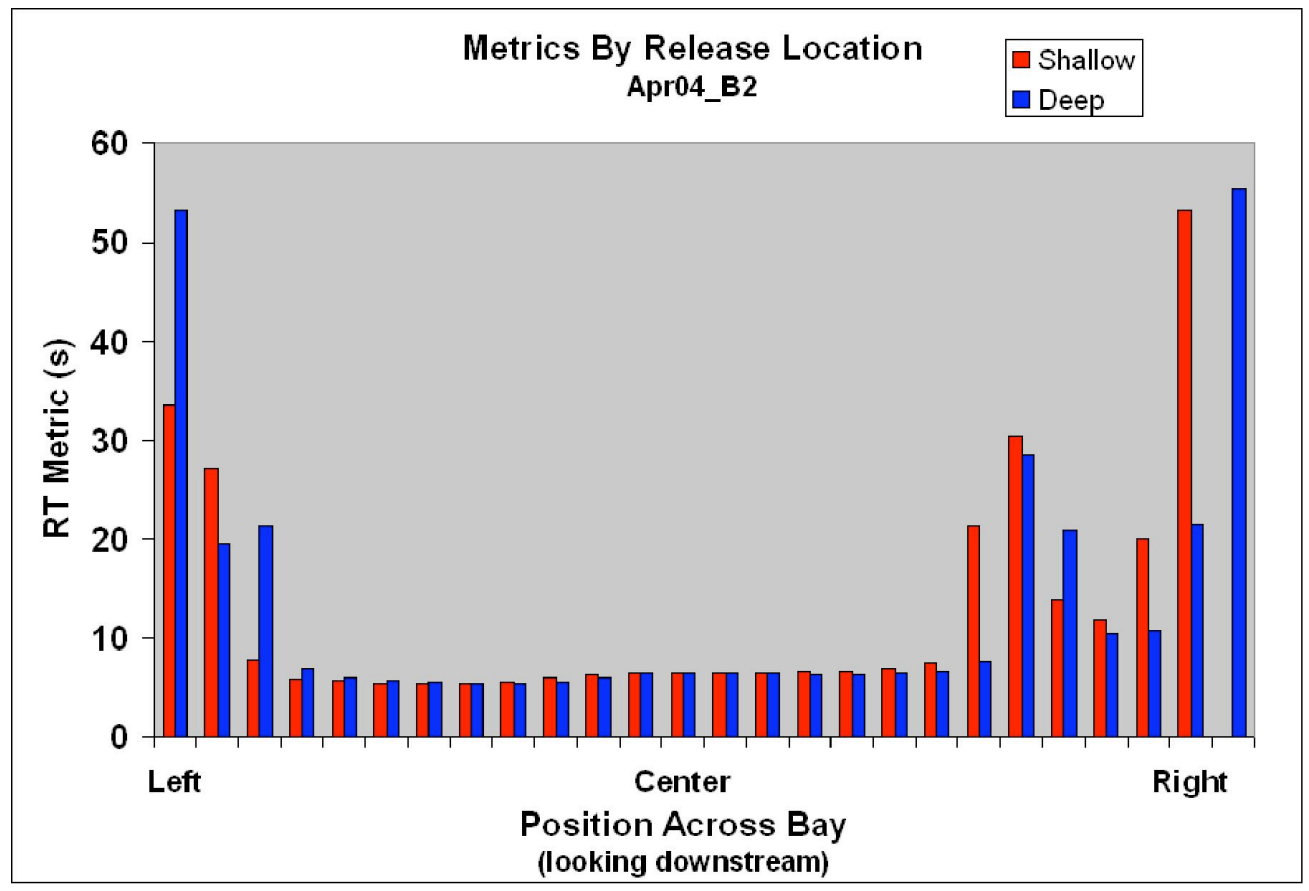

Figure 3.28. Residence time in Bay 2 at $10 \mathrm{Kcfs}$ as a function of release location across the spillway face. 


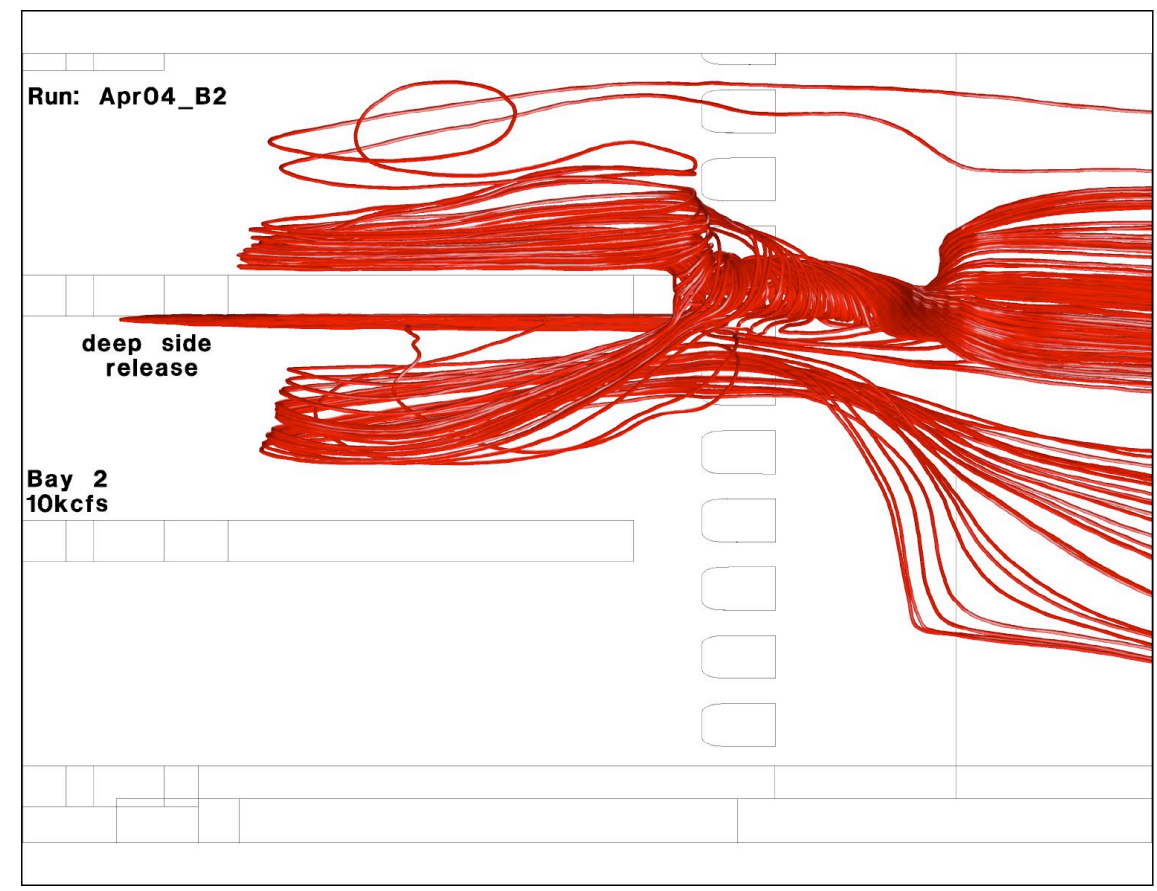

Figure 3.29. Interaction with flow separation area behind pier extension leads to longer residence times.

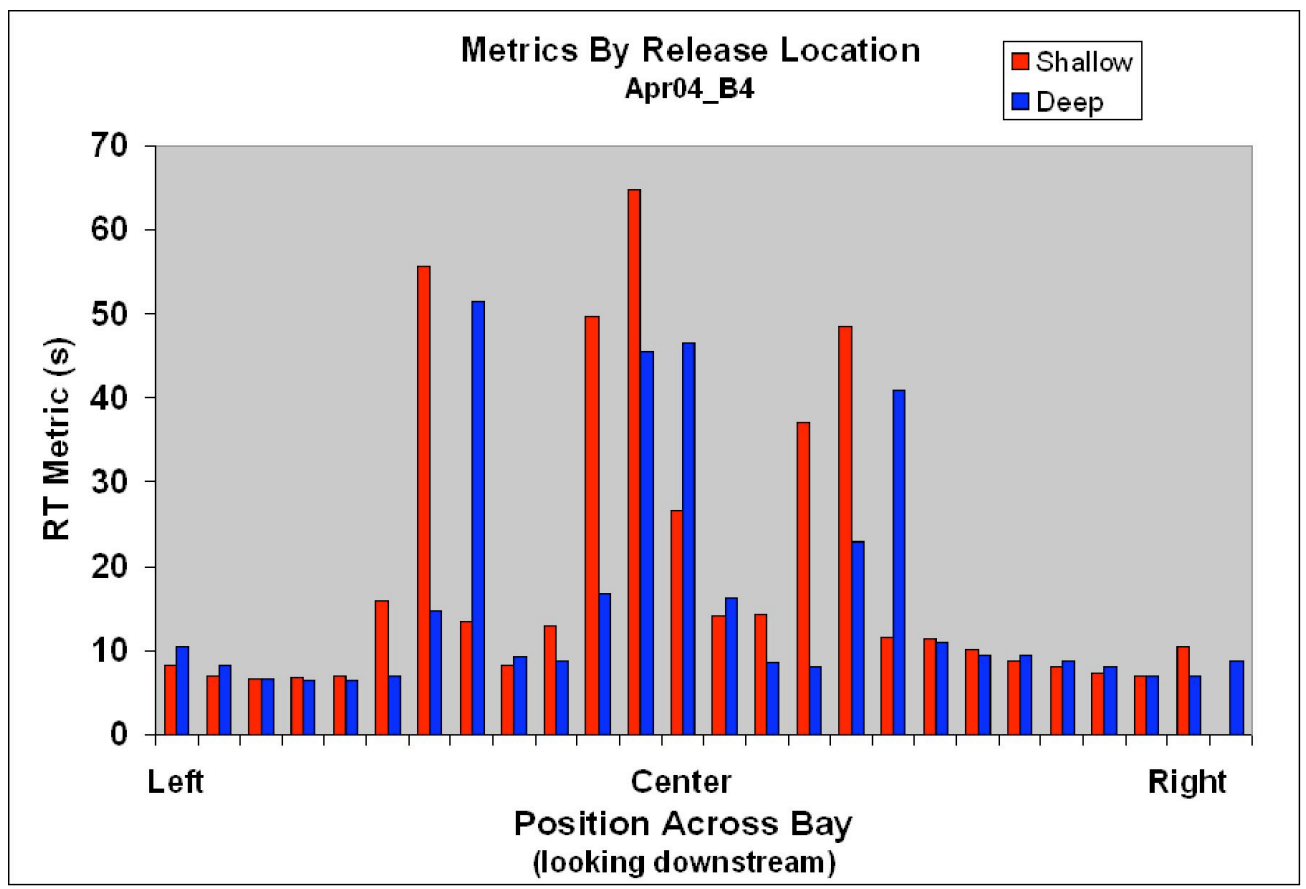

Figure 3.30. Residence time in Bay 4 at $10 \mathrm{Kcfs}$. 


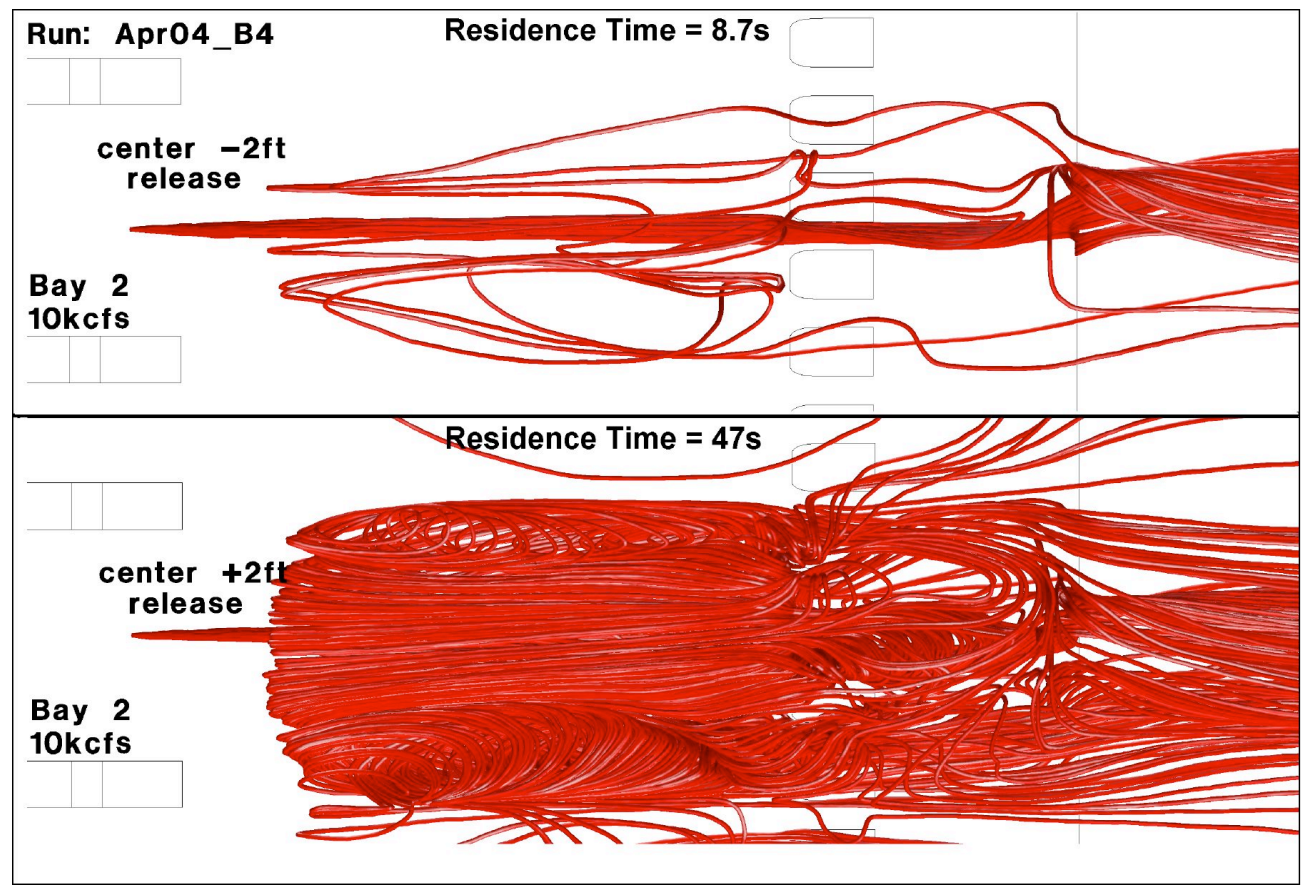

Figure 3.31. Effect on residence time of $4 \mathrm{ft}$ lateral shift in release location in Bay 2 . 
1 We analyzed the effect of release depth on particle metrics. We expected that particles released 2 deeper would suffer more scraping along the stilling basin floor and be less likely to get caught up in the recirculating flow higher in the water column. Therefore, we expected deep-release particles to have higher total collision counts (CC) and lower residence times (RT). The particle track data does not confirm these expectations. Metrics from deep and shallow releases are very similar among the bays and discharge rates tested (Figures 3.32 and 3.33).

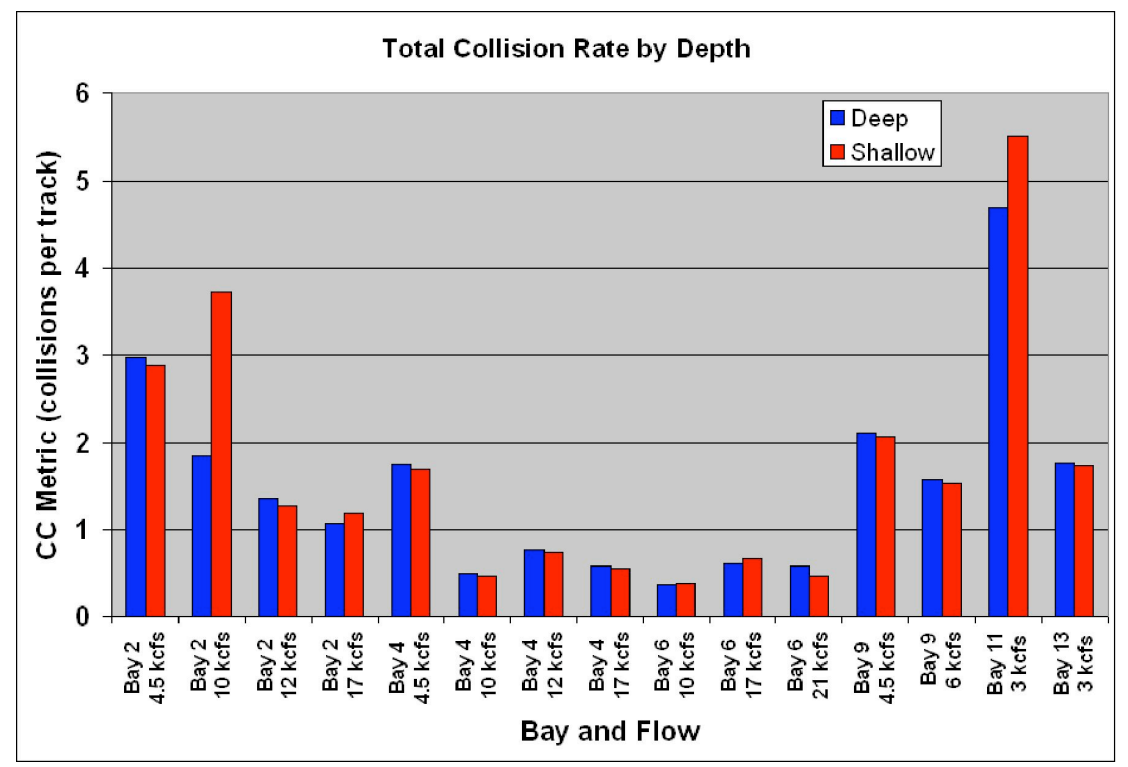

Figure 3.32. Relationship between total collision count rate and release depth.

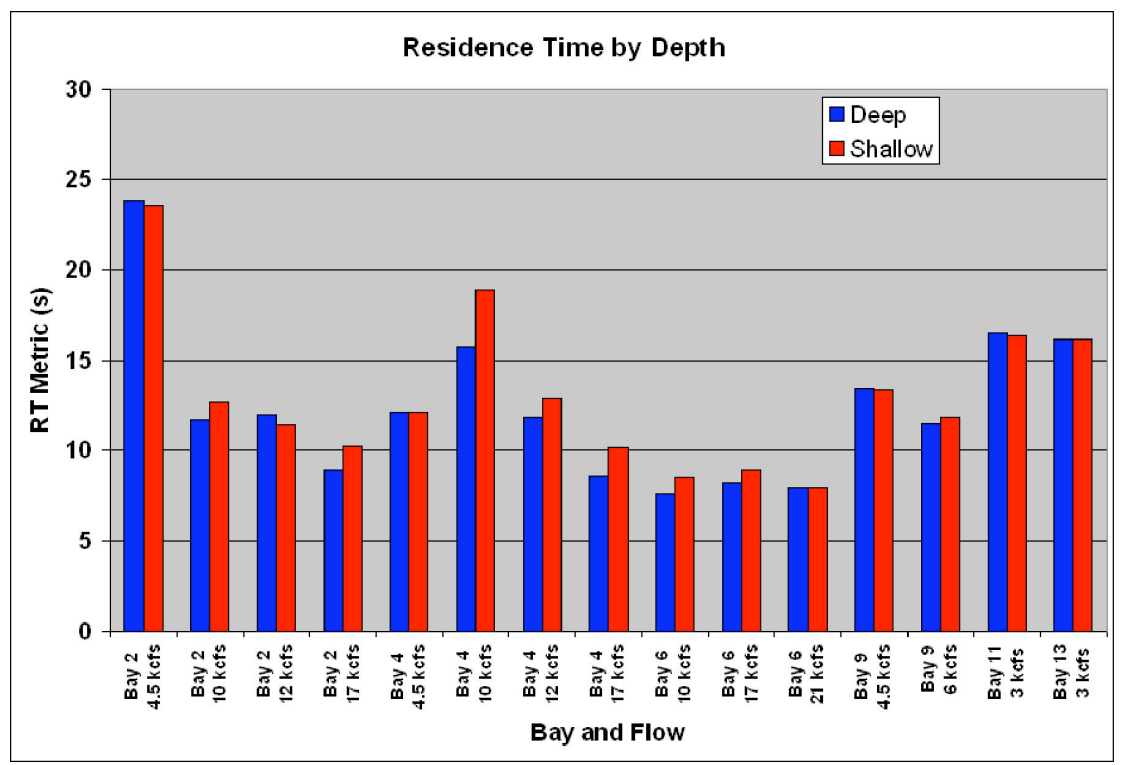

Figure 3.33. Relationship between residence time and release depth. 


\section{1}

\subsubsection{Baffle Block Removal}

Particle tracking and CFD were also used to evaluate possible spillway modifications. We ran particles through a spillway model with four baffle blocks removed from in front of Bay 2. We then compared the results to a model with identical operational conditions but with the baffle blocks present. Figure 3.34 contrasts the flow profiles of models with and without baffle blocks. Removal of baffle blocks results in a thickening and extension of the flow jet near the floor of the stilling basin and creates a substantial rise in the water surface elevation above the end-sill step. Figure 3.35 shows particle collisions in Bay 2 at a discharge of $21 \mathrm{Kcfs}$ without baffle blocks. There are many more collisions now occurring on the end sill wall when the baffle blocks are removed.

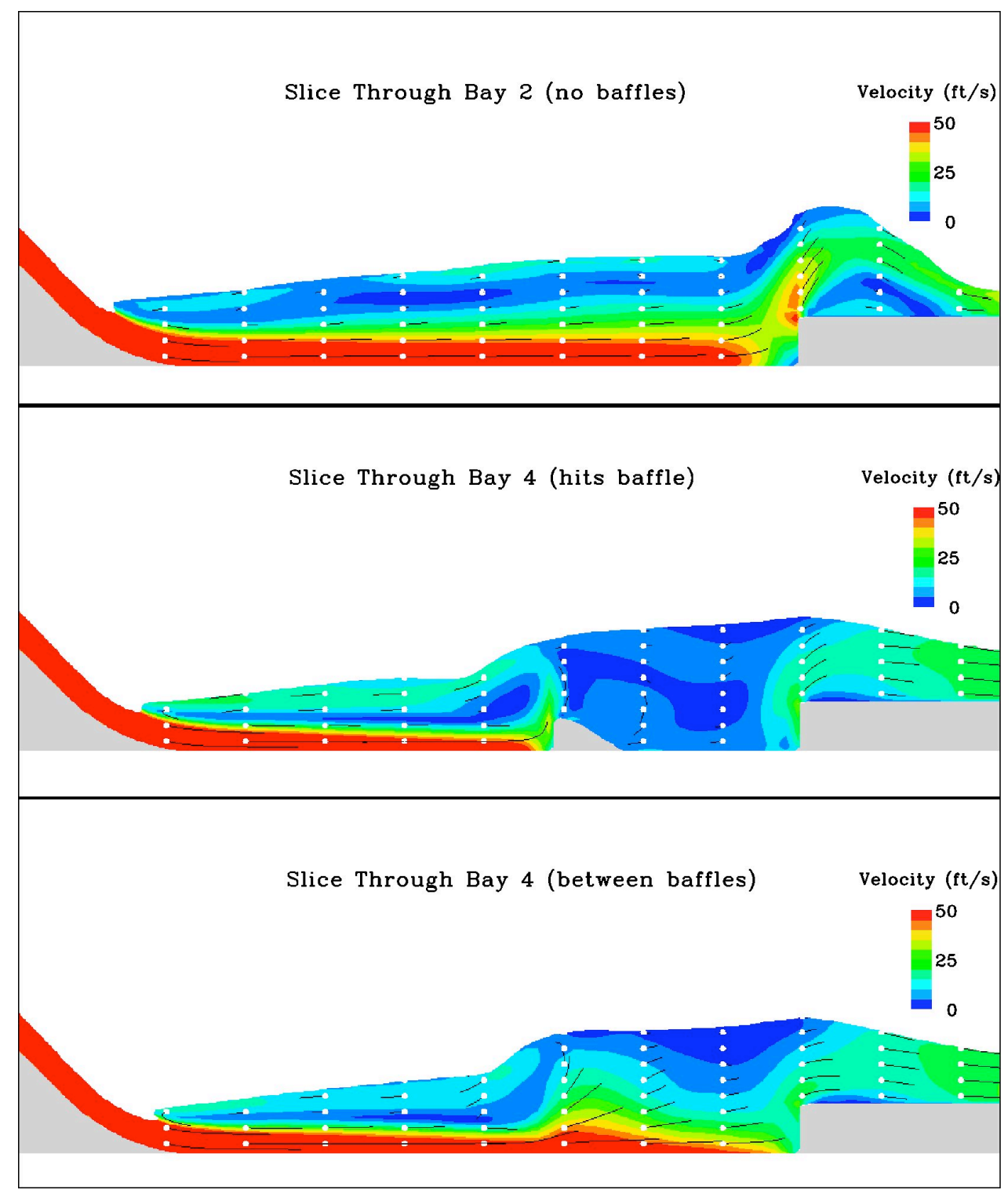

Figure 3.34. Effects of removing baffle blocks in front of Bay 2 . 


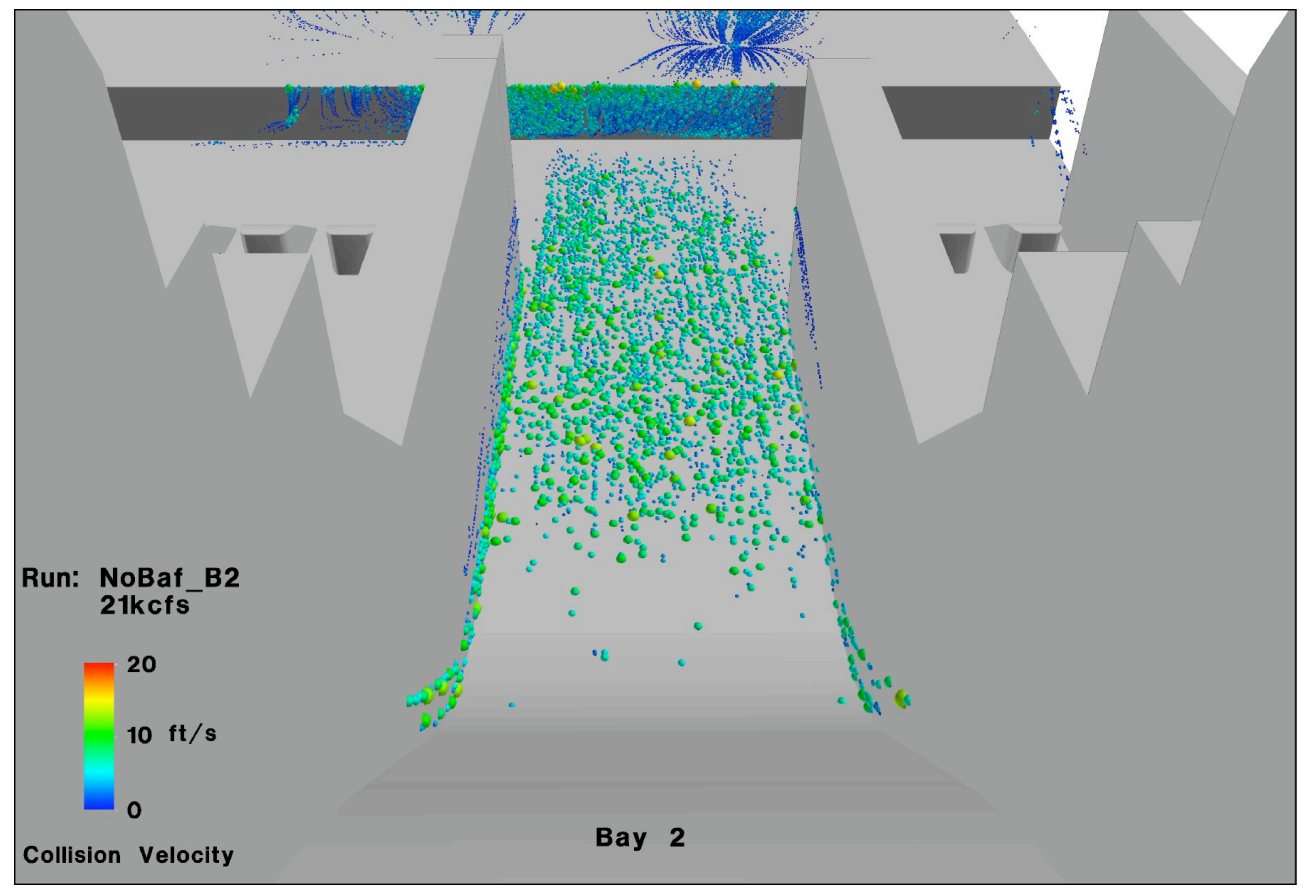

Figure 3.35. Particle wall collisions colored and sized by collision velocity in Bay 2 at 21 Kcfs with no baffle blocks. 


\subsubsection{Inertial Versus Fluid Particles}

Because the particles used in this study have mass and exhibit diffusive behavior, their paths differ from the streamlines that are normally used to show flow patterns in CFD model results. Particles with mass are subject to intertia. The turbulent diffusion component causes particles that start from a single point location to spread apart with time. These effects can be seen in Figure 3.36, which compares the tracks of massless, non-diffusive particles with inertial particles used in this study.

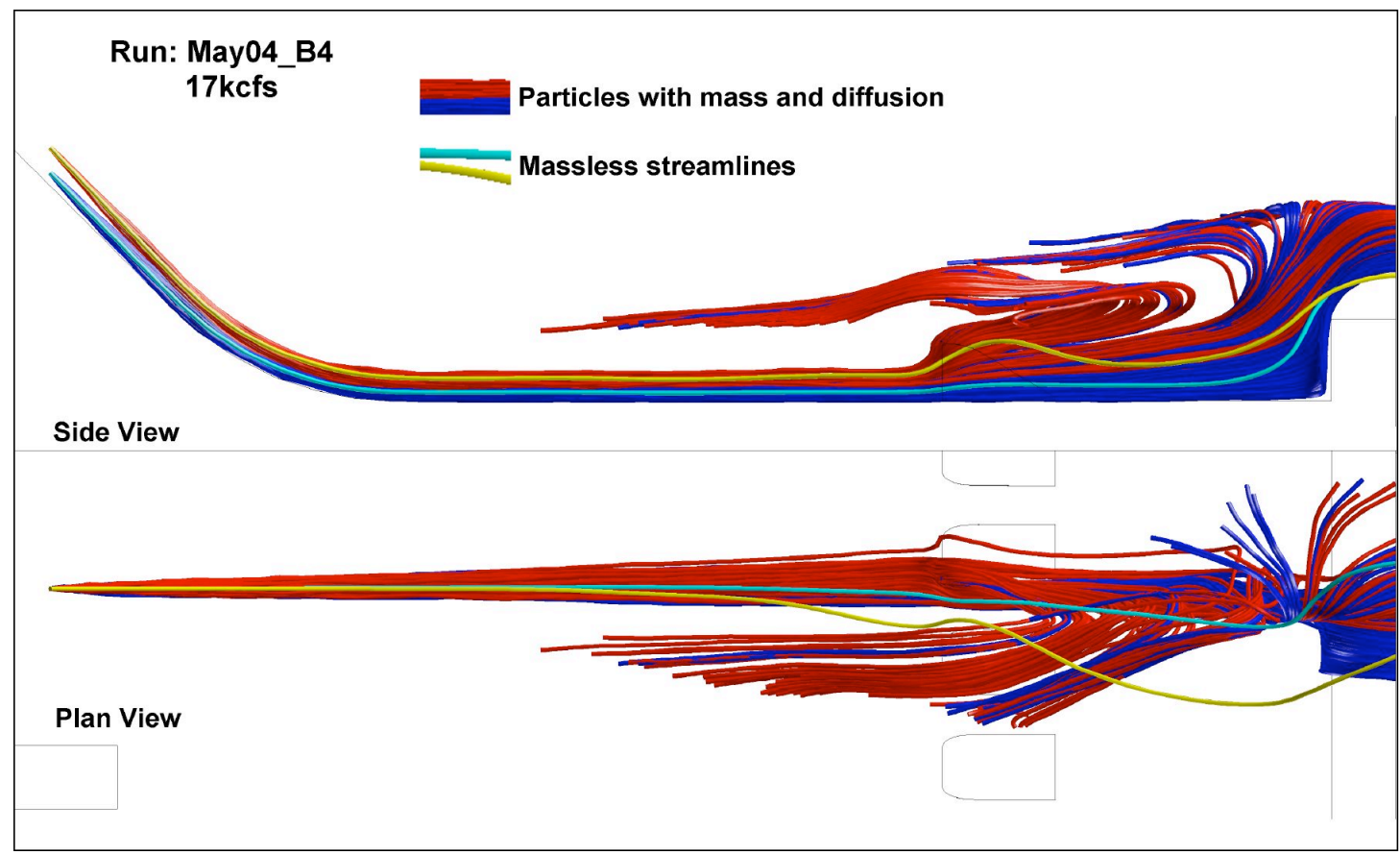

Figure 3.36. Comparison of streamlines to inertial particles used in this study.

While both sets of particles are released from the same points on the spillway, their trajectories differ in several important aspects. First, as the particles travel down the spillway face, the streamlines do not spread apart, but rather follow a path roughly in the middle of the mass of diffusing particles. Upon reaching the curve at foot of the spillway face, the streamlines remain equidistant from the floor, whereas the particles, affected by centripetal acceleration, are pressed a foot or two closer to the floor. As the paths move over the horizontal surface of the stilling basin, the shallowreleased streamline responds to a slight lateral flow that, in this scenario, is not present just a few feet lower. The result is that the streamlines largely bypass the baffle blocks, while the particles with mass hit them straight on. After the baffle blocks, some of the particles that hit the middle of the block are lifted into the region of backflow and follow a recirculating path within the stilling basin.

\subsection{Comparison of Live Fish Test, Sensor Fish, and Particle Tracking Results}

In this section we compare the results from the live fish balloon tag survival tests, Sensor Fish data, and inertial particle tracking simulations for tests conducted in 2003 and 2004. The results 
are broken down for specific treatment release locations (vertical and horizontal) and discharge. These years were selected because they have comprehensive live fish data, use the same Sensor Fish device, and included different release locations in the field test treatments. In 2004 the spillwall between bays 6 and 7 was in place. Note that the live fish and Sensor Fish releases were conducted concurrently. Further details and results are presented in tabular form in Appendix A.

Live fish 48-hour survival and clean fish (fish having no passage-related maladies) estimates from Normandeau Associates $(2004,2005)$ are shown in Figure 3.37. Live fish and Sensor Fish were released at various vertical and horizontal locations in bays 2 and 4 . Live fish were hand-tossed into the vortex that formed upstream of bay 6 . The vertical locations were at deep (10 ft above the ogee crest) and shallow ( $15 \mathrm{ft}$ above the ogee crest) release points. The deep release elevation is closer to the face of the spillway structure. Horizontal release locations were in the middle of the bay (mid-bay) and approximately $8 \mathrm{ft}$ south of the centerline (offset). The offset location was selected based on streamlines from the CFD simulations that showed a path that intersected a baffle block. Sample sizes ranged from 100 to 241 fish for the bay 2 and 4 treatments; vortex sample sizes were 39 and 149 fish for the 12 and $17 \mathrm{Kcfs}$ treatments, respectively.

In general, the live fish data do not show a consistent effect of vertical or horizontal release location. For example, fish released nearer the concrete at the mid-deep had a higher survival rate than those released from the offset-deep location in Spring 2003, bay 2 at $20 \mathrm{Kcfs}$. This result is not consistent with the hypothesis that fish released nearer to the concrete structure would have lower survival rates. Clean fish results showed a similar lack of consistent effects of release location except for the deep release for 2003 bay 2 at $20 \mathrm{Kcfs}$. Survival for vortex released fish was much lower for $17 \mathrm{Kcfs}$ compared to $12 \mathrm{Kcfs}$ in the Spring 2004 tests. Survivals showed a trend to be higher for "mid-range" discharge conditions of 12 and $17 \mathrm{Kcfs}$ as compared to 9 and $20 \mathrm{Kcfs}$ conditions. Also note that the error bars in Figure 3.37 overlap in the majority of test treatments.

Sensor Fish retention time (RT) and average collisions per deployment (CC) for 2003 and 2004 are shown in Figure 3.38. Release locations were the same as those used for the live fish. Sample sizes ranged from 12 to 24 for releases in bays 2 and 4; vortex releases had sample sizes of 4 and 11 for the 12 and $17 \mathrm{Kcfs}$ treatments, respectively. Retention time showed no clear trends with release depth and horizontal location. For bay 2 releases there is a trend of decreasing retention time with increasing discharge (from about 15 to 7 seconds). There is no clear correspondence between retention time and survival as shown for example in the 2003 bay 2 at $20 \mathrm{Kcfs}$ results where the offset-deep release shows the lowest survival, but the Sensor Fish retention time for the same location is not markedly different from the release locations. Average collisions per deployment varied widely over the treatment conditions and showed no consistent relationship with the live fish survival estimates. In some cases, the deep releases in 2003 show higher collision rates compared to the shallow releases. No such trend is evident in 2004. This wide variability is to be expected given the combination of a very turbulent environment, infrequent collisions events, and the small sample size per individual treatment.

Retention time and average collisions per deployment (CC20 metric) were also computed for the Lagrangian particles that were tracked through CFD simulations of a subset of the 2003 and 2004 field test operational conditions. Only particles released at locations corresponding to those of the live fish and Sensor Fish are included in the calculation of the metrics. As was the case with the Sensor Fish metrics, there was not a consistent relationship between live fish survival statistics 
1 and the particle tracking derived metrics. An exception was at the offset-deep release location for 22003 Bay 2 at $20 \mathrm{Kcfs}$ were the CC20 particle track metric and the Sensor Fish CC metric had the

3 highest values for 2003 conditions and these corresponded to the lowest live fish survival estimate. 

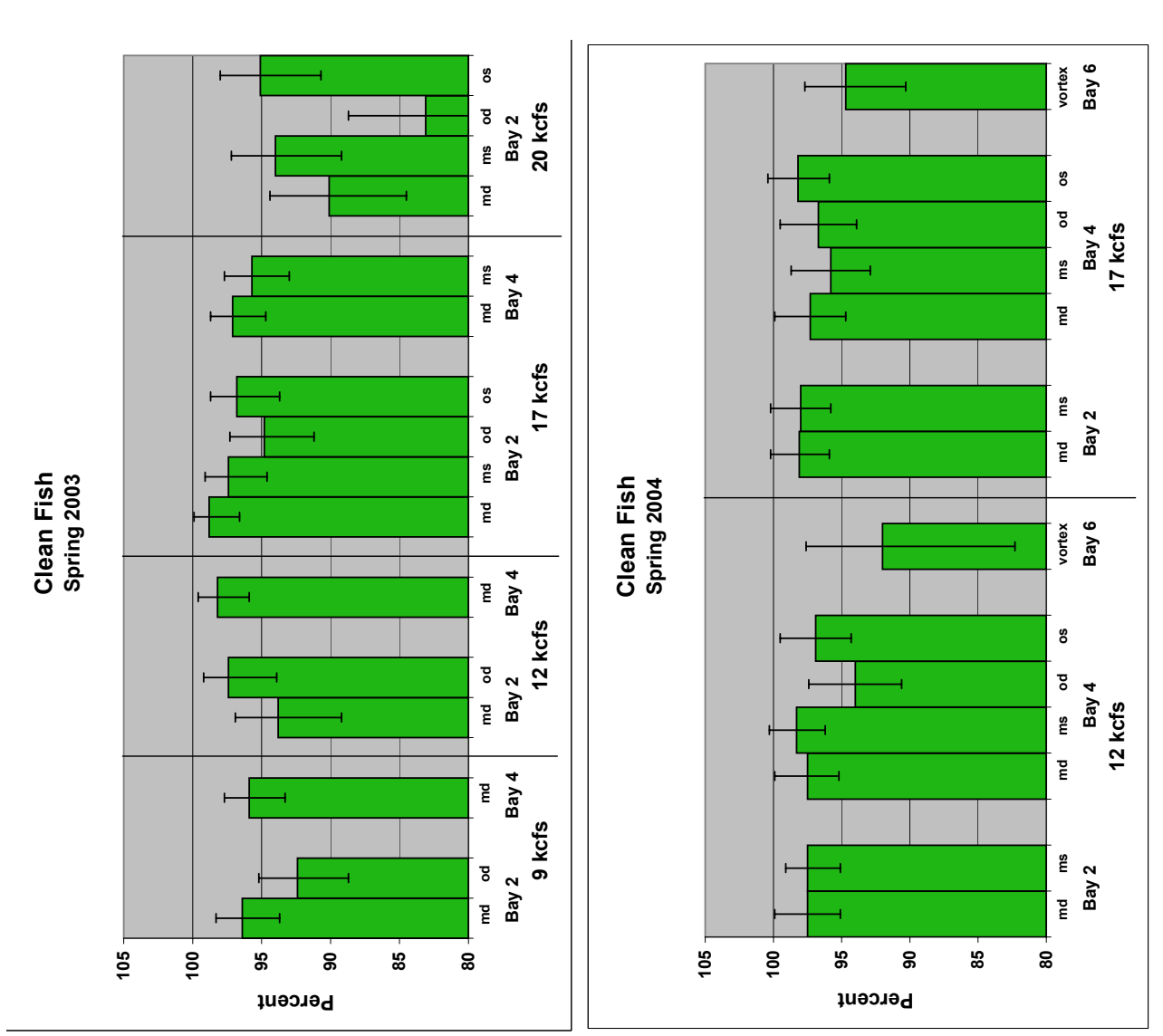

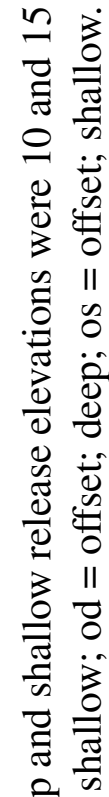

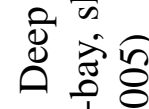

ஓ्ष

ปี ఓ సิ

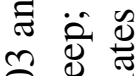

$\delta$ ช
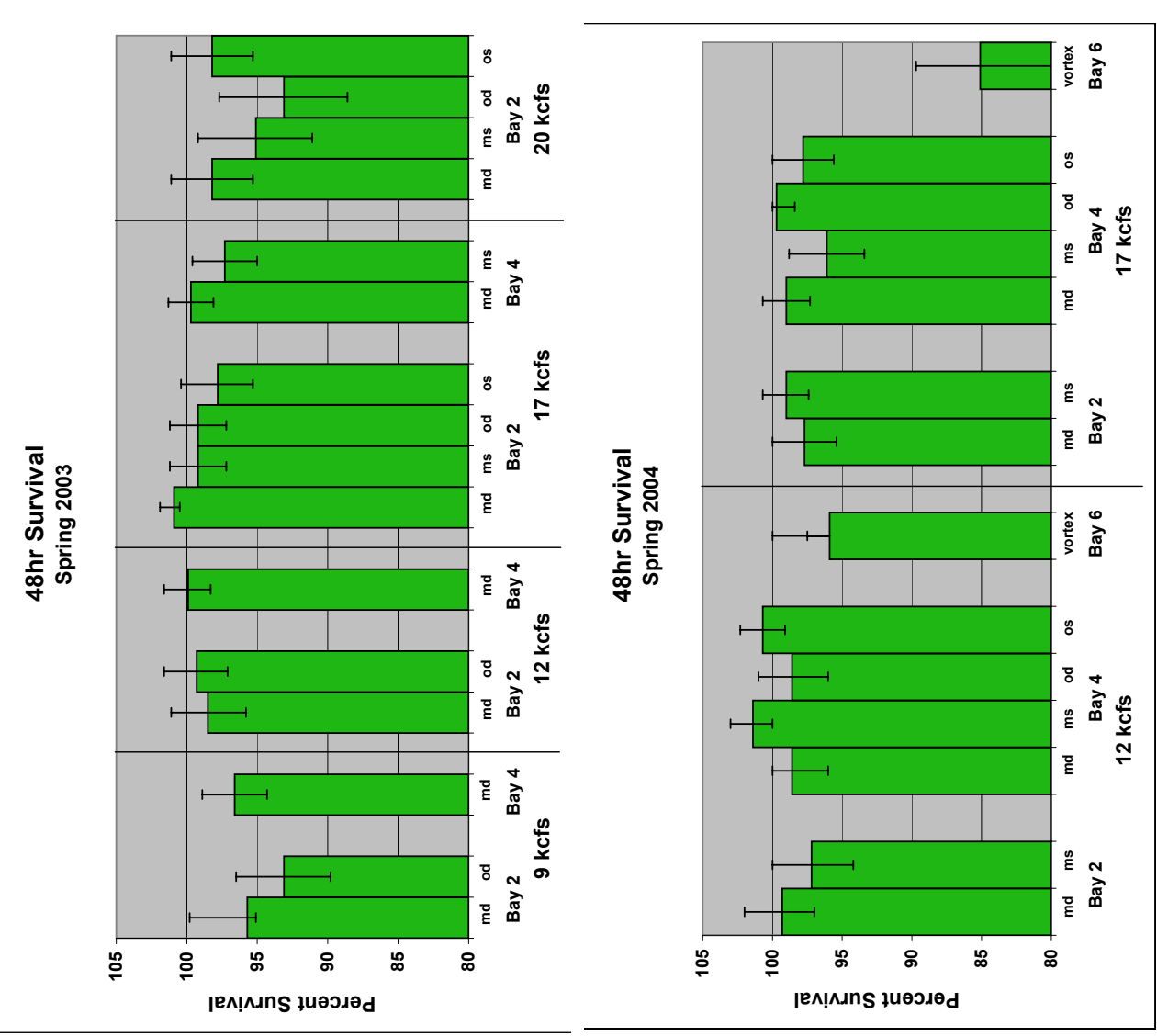

กิ

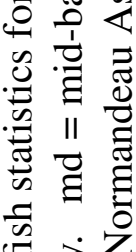

党

宓

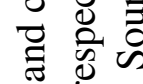

芯芯

.

ڤ

定

泀

:

กั่ 

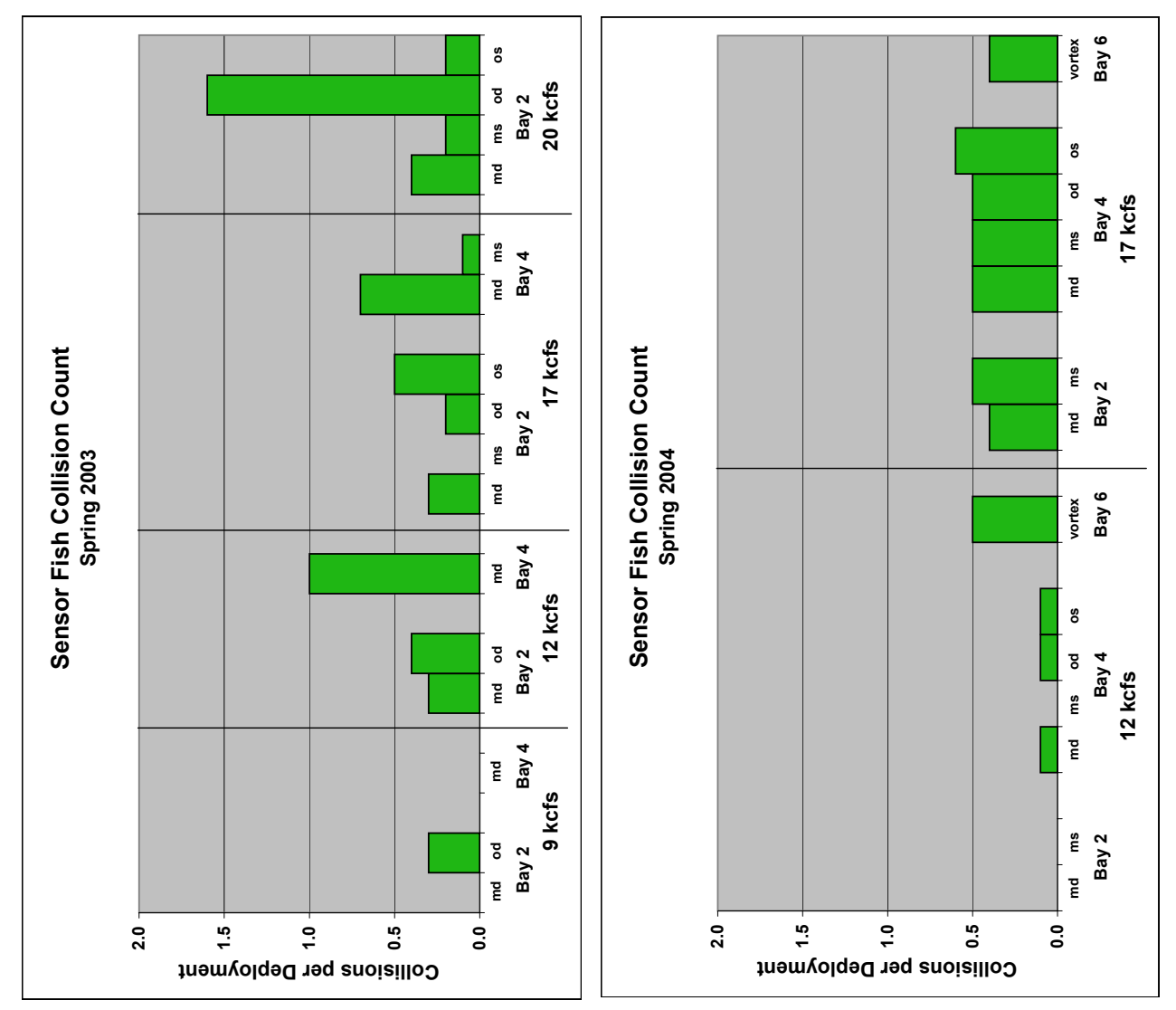

ষ্

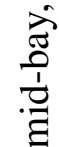

름

ঠัণ

๖ำ

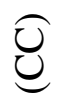
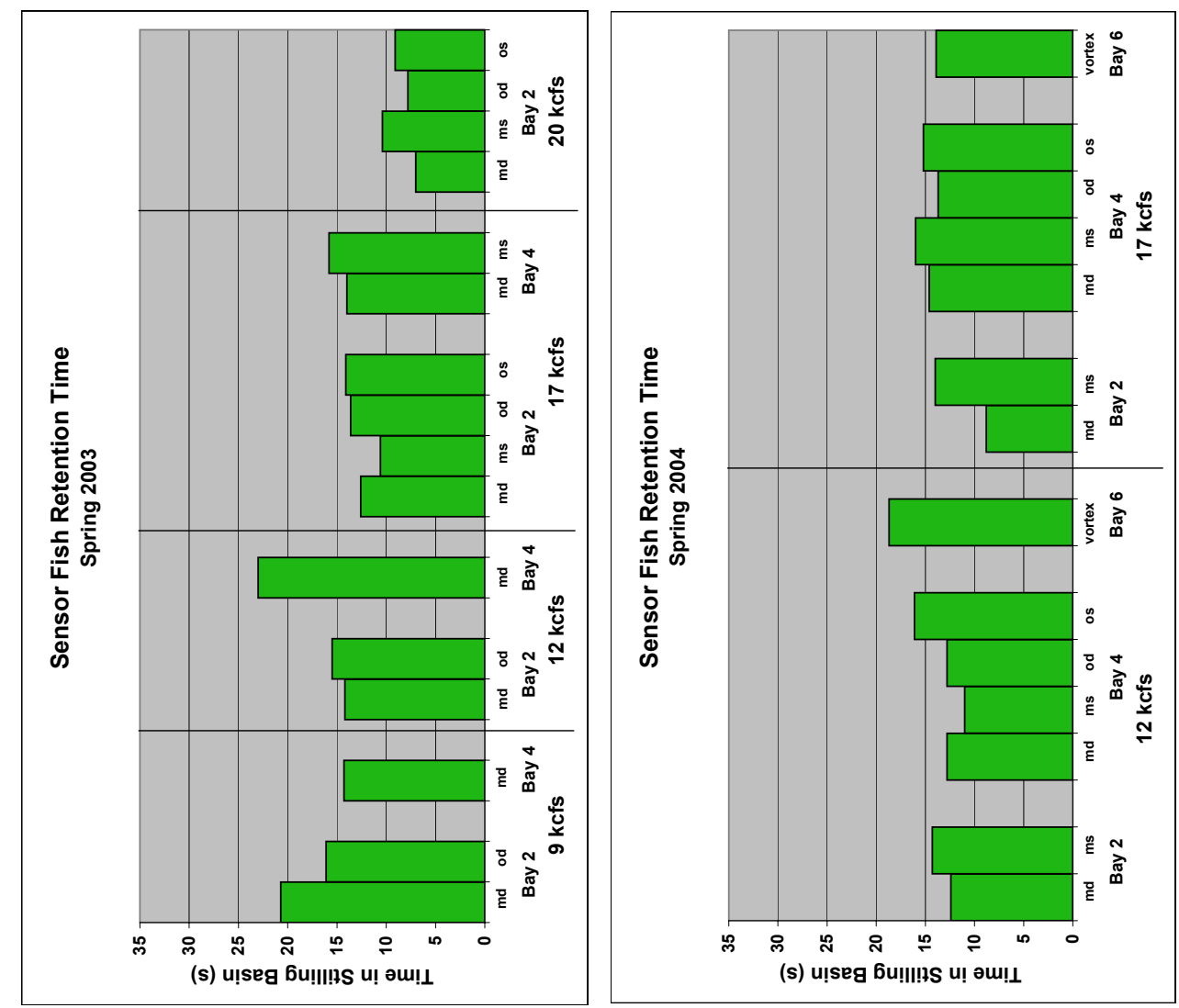

몽

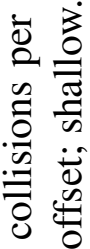

of II

త్ర

है

등

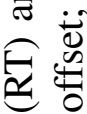

号

总亭

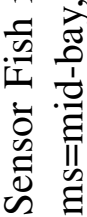

๓๐ 

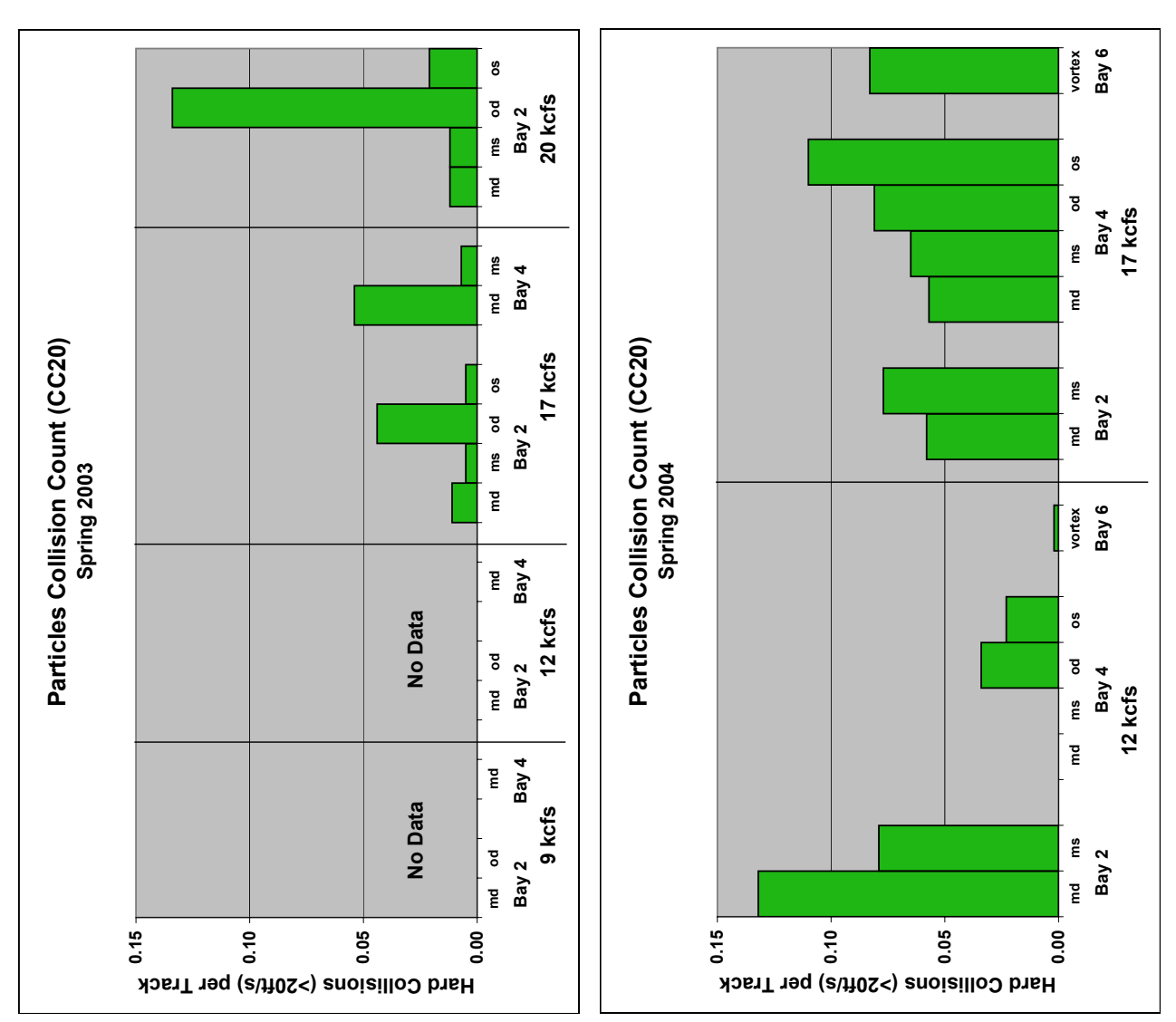

II
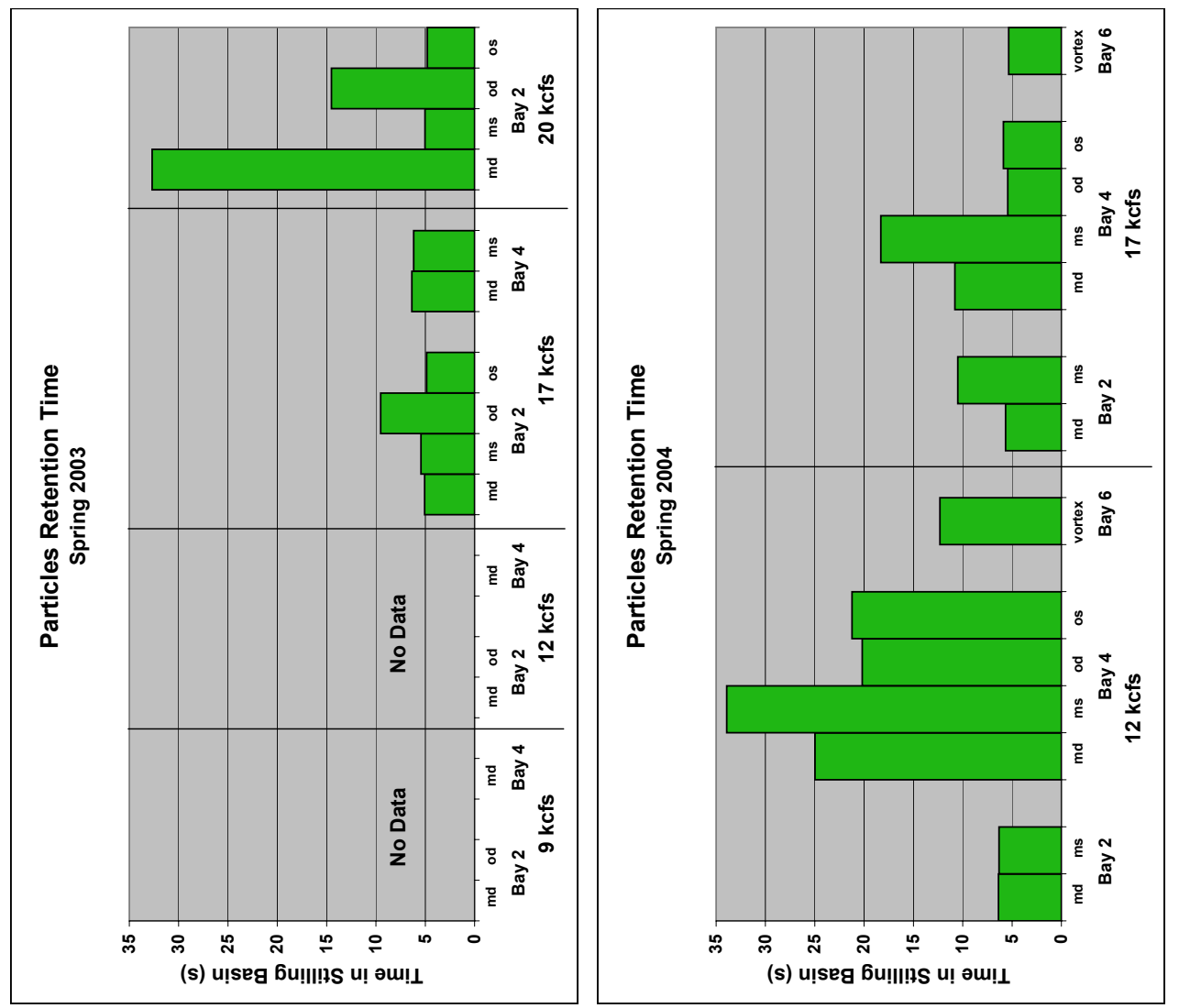

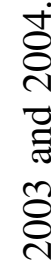

으

ชิ

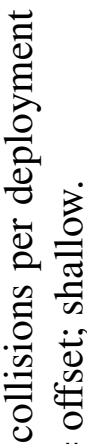

บ II

ป 0

d

80

苛节

들 1

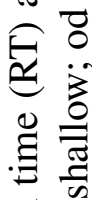

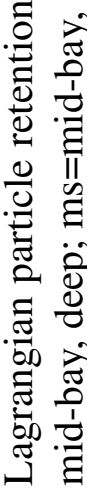

लें 


\subsection{Conclusions and Recommendations}

In this study, the spill-passage environment at The Dalles Dam in 2001-2004 was characterized using an integrated approach that used the Sensor Fish device, unsteady computational fluid dynamics (CFD) modeling, and Lagrangian tracking of particles with inertia.

\subsection{Conclusions}

The results of the study led to the following methods development and conclusions:

- The use of unsteady CFD and Lagrangian tracking of particles with inertia was found to be a means of quantifying stilling basin flow-realted characteristics using the retention time and collision count metrics. The methodology developed herein has since been applied in other studies by Carlson et al. (2006) and Rakowski et al. (2006).

- A relational database system (using Microsoft Access) was designed and partially implemented to facilitate the analysis of the large amount of Sensor Fish, CFD-based Lagrangian particle-tracking, and live fish data. The database was found to be an efficient means for accessing and analyzing the data from disparate sources.

- Particles with mass (inertia) follow different paths through the stilling basin compared to massless particles (as represented by streamlines in steady flow). Therefore, it is important to use inertial particles to when computing metrics such as retention time and collision count.

- Median stilling basin retention time ranged from 6 to 10 seconds, but did exceed 100 seconds in some cases. Retention time decreased with increasing spillway discharge. This trend was consistent between the Sensor Fish and particles.

- Sensor Fish and particles both showed that construction of the spillwall between bays 6 and 7 reduced the lateral flow component (towards the North) in the stilling basin.

- The majority of particles pass directly through the stilling basin with no recirculation.

- Particle tracking showed that the majority of high-intensity collisions occurred on baffle blocks.

- Even for particles that did not collide with the baffle blocks, many showed rapid pressure changes that could be harmful to fish.

- In a simulation with the baffle blocks removed, many more collisions occurred the face of the endsill as compared to the existing conditions with baffle blocks in place.

- The incidence of Sensor Fish collisions is higher at low (4 Kcfs) and high (20 Kcfs) discharges and lower at moderate (10-15 Kcfs) discharges when the data are pooled by discharge across all treatments. Live fish also tended to have higher survival at moderate discharge. However, no consistent trends were observed when the data were compared for 
individual treatments (release bay, release depth/offset, and discharge). The greater variability in collisions per deployment may be due to the small number of Sensor Fish released (about 15 samples) in an specific treatment.

- Particles showed that severe collision counts were maximum at moderate discharge (13 to 18 Kcfs) when the data were pooled by discharge. This trend was the inverse of that observed in the live fish and sensor fish data. When individual treatments were considered, confounding trends in particle severe collision counts were observed.

- Vertical release location (shallow or deep) did not have a consistent affect on live fish survival, Sensor Fish collision count, and particle collision count.

- Particle metrics showed a strong influence of horizontal release location on retention time and collision count. This effect was not observed in the Sensor Fish or live fish data, but only two horizontal locations were used in the field tests.

\subsection{Recommendations}

The following are our recommendations for future work:

- The prototype relational database system implemented in this work is specific to The Dalles Dam spillway studies. The functionality of this database can be expanded to be used in assessments of fish passage conditions at turbines, spillways and bypass facilities for other hydroelectric projects. In addition to overall survival estimates, the database should contain live fish injury mechanism classifications that are consistent with laboratory investigations of fish injury.

- A Sensor Fish statistical study design and data analysis methodology should be developed that can be used to estimate necessary sample sizes to meet a specified precision level in analysis metrics such as collision count. The methodology should also include presentation of standard error or confidence limits for each analysis metric using bootstrapping techniques. The sample size will be a function of the hydraulic environment (structures and turbulence) and study objectives. For example, studies of stilling basins and turbines may have different sample size requirements.

- Laboratory tests with Sensor Fish and live fish collisions are needed to determine the relationship between sensor collision intensity and live fish injury rates. This information is needed to assess the relative impact intensities of the detected collisions in order to distinguish between harmless and potentially injurious strikes. The tests should be representative of collision mechanisms for different hydraulic structures such as baffle blocks, deflectors, and turbine blades. Results from studies at Lower Monumental Dam (Carlson et al. 2006) show that most all significant events on the spillway face are due to collisions and not shear events.

- The use of more advanced turbulence models in the CFD simulation and additional refinement of turbulent flow representation near solid surfaces should be investigated. The turbu- 
lence simulated by the CFD code is an important component of the particle tracking method. In this study, spherical particles were used. A more realistic representation of the Sensor Fish could be simulated using cylindrical particles. A newer version of the particle tracking code has this feature and could be used in future studies.

- The overall methodology using Sensor Fish, CFD, particle tracking, and the database system developed in this study could be used to perform a synthesis of spillway passage studies conducted at different Columbia and Snake River Dams. The effects of different spillway elevation profiles and configurations with and without baffle blocks, flow deflectors, and RSWs (removable spillway weirs) could be analyzed. 



\subsection{References}

Abernethy CS, BG Amidan, and GF Cada. 2001. Laboratory Studies of the Effects of Pressure and Dissolved Gas Supersaturation on Turbine-Passed FIsh. PNNL-13470, Pacfic Northwest National Laboratory, Richalnd, WA.

BHL. 1964. Spillway and Stilling Basin for The Dalles Dam Columbia River, Oregon and Washington, Hydraulic Model Investigation. 55-1, Bonneville Hydraulic Laboratory, , US Army Engineer District, Portland.

Brickman D and PC Smith. 2002. "Lagrangian Stoachastic Modeling in Coastal Oceanography." Journal of Atmospheric and Oceanic Technology 19:83-99.

Carlson TJ and JP Duncan. 2003. Evolution of the sensor fish device for measuring physical conditions in severe hydraulic environments. DOE/ID-11079, Prepared for US DOE, Idaho Operations Office, Pacific Northwest National Laboratory, Richland, WA.

Carlson TJ, JP Duncan, and TL Gilbride. 2003. "The Sensor Fish: Measuring Fish Passage in Severe Hydraulic Conditions." Hydro Review 22:62-69.

Carlson TJ, JP Duncan, MC Richmond, JA Serkowski, and Z Deng. 2006. Characterization of Spillway Passage Conditions at Lower Monumental Dam, Snake River, Washington, 2005. PNWD-3662, Battelle Pacific Northwest Division, Richland, WA.

Cook CB, MC Richmond, and JA Serkowski. 2006. The Dalles Dam, Columbia River: Spillway Improvement CFD Study - Draft Report. PNNL-14768, Pacific Northwest National Laboratory, Richland, WA.

Deng Z, GR Guensch, CA McKinstry, RP Mueller, DD Dauble, and MC Richmond. 2005. "Evaluation of Fish Injury Mechanisms During Exposure to Turbulent Shear Flow." Can. J. Fisheries and Aquatic Sci. 62:1513-1522.

Deng Z, MC Richmond, CS Simmons, and TJ Carlson. 2004. Six-Degree-of-Freedom Sensor Fish Design: Governing Equations and Motion Modeling. PNNL-14779, Pacific Northwest National Laboratory, Richland, WA.

Dimou KN and EE Adams. 1990. "2-D Particle Tracking Model for Estuary Mixing." Estuarine and Coastal Modeling, Spaulding ML, ed., pp. 472-481. American Society of Civil Engineers, New York, New York.

Gondret P, M Lance, and L Petit. 2002. "Bouncing Motion of Spherical Particles in Fluids." Physics of Fluids 14(2):643-652.

Neitzel DA, DD Dauble, GF Cada, MC Richmond, GR Guensch, RP Mueller, CS Abernethy, and BG Amidan. 2004. "Survival Estimates for Juvenile Fish Subjected to a Laboratory-Generated Shear Environment." Trans. Amer. Fish. Soc. 133:447-454.

Normandeau Associates I. 2004. Direct Effects of Differential Spill Volumes on Mortlatity and Injury Rates of Juvenile Salmonids at The Dalles Dam Spillway, Columbia River in Fall 2002 and Spring 2003. Report to the US Army Corps of Engineers, Portland District, Portland, OR. 
Normandeau Associates I. 2005. Evaluation of the Training Wall on Fish Condition at The Dalles Dam Spillway, Columbia River, 2004. Report to the US Army Corps of Engineers, Portland District, Portland, OR.

4 Ploskey G, T Poe, A Giorgi, and G Johnson. 2001. Synthesis of Radio Telemetry, Hydroacoustic, and Survival Studies of Juvenile Salmon at The Dalles Dam (1982 - 2000). Pacific Northwest

6 National Laboratory, Richland, WA.

7 Rakowski CL, WA Perkins, MC Richmond, and JA Serkowski. 2006. Simulation of Tailrace

8 Egress at The Dalles Dam to Evaluate Proposed Spillwall Configurations. PNNL-16309, Pacific

9 Northwest National Laboratory, Richland, WA.

10 Turnpenny AWH, MH Davis, JM Fleming, and JK Davies. 1992. Experimental Studies Relat11 ing to the Passage of Fish adn Shrimps through Tidal Power Turbines. National Power Fawley,

USACE. 2000. Water Resources Development in Oregon 2000. US Army Corps of Engineers, 14 Portland, Oregon. 
Appendix A

Summary Tables 



\section{Appendix A - Summary Tables}

Tables included herein summarize the treatment conditions and metrics calculations for live fish, sensor fish, and Lagrangian particle tracking (LPT) for passage studies at The Dalles Spillway between 2001 and 2004. Table columns are described below.

\begin{tabular}{|c|c|}
\hline Study & Season and year of passage study. \\
\hline Condition & $\begin{array}{l}\text { Name for operational condition within a study. An operational condi- } \\
\text { tion consists of a relatively steady spill pattern as defined by the next } \\
14 \text { columns, which indicate individual spillbay discharge rates in kcfs. } \\
\text { Discharge rates usually fluctuated somewhat about the values presented. } \\
\text { Tailwater elevation was also variable, ranging between about } 75 \text { and } 82 \\
\text { ft above MSL. }\end{array}$ \\
\hline \multirow[t]{3}{*}{ Release } & $\begin{array}{l}\text { The spill bay, discharge rate in Kcfs, and release pipe Location of the } \\
\text { test treatment. Release locations were } 10 \mathrm{ft} \text { upstream of the tainter gate } \\
\text { for live and sensor fish, and halfway down the spillway face for parti- } \\
\text { cles. }\end{array}$ \\
\hline & $\begin{array}{l}\text { Releases could also be shallow or deep. Though actual values varied, } \\
\text { deep releases were typically } 10 \mathrm{ft} \text { above the ogee surface ( } 5 \mathrm{ft} \text { in Spring } \\
2001 \text { and 2002) and shallow releases about } 5 \mathrm{ft} \text { above the deep. }\end{array}$ \\
\hline & $\begin{array}{l}\text { Lateral positions were: mid - middle of bay; off - offset about } 8 \mathrm{ft} \text { to } \\
\text { the south of the middle, and vortex - released from the surface into the } \\
\text { vortex at the south edge of Bay } 6 \text {, upstream of the tainter gate. }\end{array}$ \\
\hline Live Fish & $\begin{array}{l}\text { Statistics reported for live fish studies are: Number of fish released; } \\
\text { Percent of released fish that sustained a non-fatal malady, such as a } \\
\text { bruise, cut, scrape, or loss of equilibrium; Percent of released fish that } \\
\text { wee either recovered dead, or died during the } 48 \mathrm{hr} \text { holding period }\end{array}$ \\
\hline Sensor Fish & $\begin{array}{l}\text { Statistics reported for sensor fish studies are: Number of sensor fish } \\
\text { deployed; Number of deployed units with usable data; Average number } \\
\text { of collisions per deployment; Average residence time in seconds }\end{array}$ \\
\hline CFD Particles & $\begin{array}{l}\text { Statistics reported for LPT studies are: Average number of collisions } \\
\text { per track; Average number of collisions per track exceeding an intensity } \\
\text { of } 20 \mathrm{ft} / \mathrm{s} \text {; Average residence time in seconds; Average acceleration }\end{array}$ \\
\hline
\end{tabular}




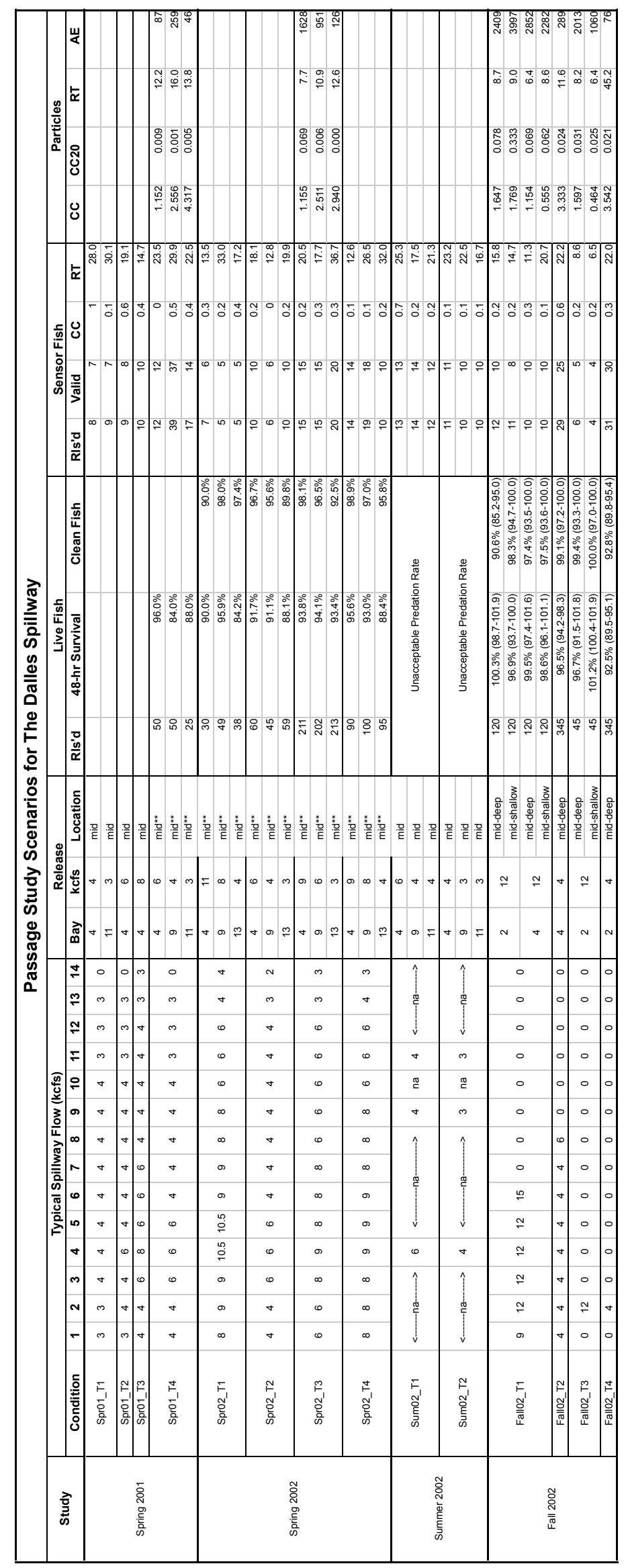




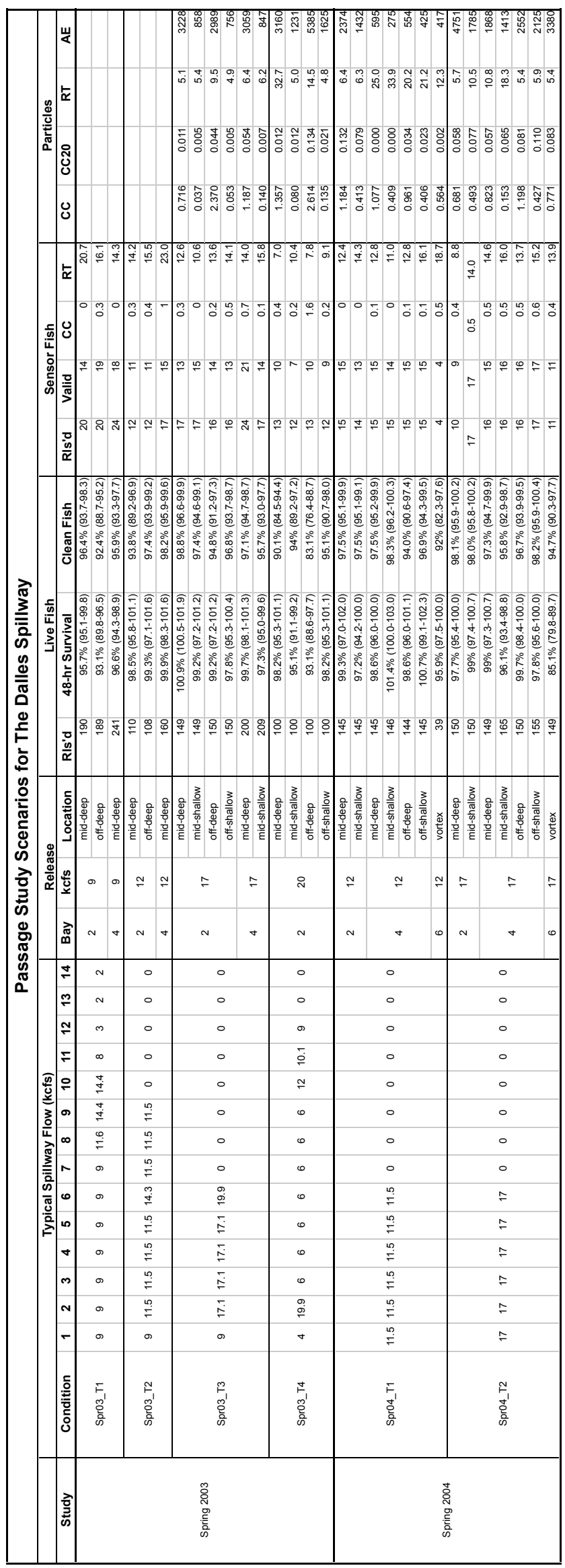



Appendix B

Geometry for The Dalles Tailrace CFD Models 



\section{Appendix B - Geometry for The Dalles Tailrace CFD Models}

A single electronic representation of The Dalles Dam and surrounding bathymetry and topography was created to define geometric boundaries for the CFD models. Development of this geometry model involved two distinct methods: one for creating the engineered structures and another for creating the land elevation surface. Both techniques produced computer files in stereolithographic (STL) format, a standard 3D modeling format. CFD models use the STL to establish boundaries in the mesh creation process.

\section{B.1 Bathymetry and dam structure}

Engineered structures include the spillway, powerhouse, non-overflow dam, existing ice-and-trash outfall, and several proposed relocated outfall chutes. Engineering drawings and other documents obtained from the U.S. Army Corps of Engineers (USACE) were used to create three-dimensional representations of these structures (Table B.1). These structures were initially modeled using three-dimensional computer aided design (CAD) software using a spillway oriented horizontal coordinate system in English units, which can be directly converted to Oregon North State Plane units by applying the following transformation: 1) rotate $126.5^{\circ}$ clockwise about the vertical axis, and 2) add 1,837,668.96 and 710,923.24 to the easting and northing coordinates, respectively. This was done to facilitate simulation of the spillway using Flow-3D. The vertical datum was mean sea level (NGVD29).

Table B.1. Document sources for TDA structures

\begin{tabular}{|l|ll|}
\hline \multicolumn{1}{|c|}{ Structure } & \multicolumn{2}{|c|}{ Document } \\
\hline Spillway & USACE drawings: & DDD-1-4-1/1 \\
& & DDD-1-4-2/1 \\
& & DDD-1-4-4/1 \\
& & DDD-1-4-8-9i \\
\hline Powerhouse & USACE drawings: & DDP-1-0-0/2 \\
& & DDP-1-0-0/7 \\
& & DDP-8-0-0/7 \\
\hline Non-Spill Dam & USACE drawings: & DDD-1-4-3.1/1 \\
\hline Sluiceway & USACE drawings: & DDD-1-4-3.1/25 \\
& & DDD-1-4-3.1/29 \\
\hline Proposed outfalls & USACE spreadsheet: & OUTFALL-EXIT-Cond.xls \\
\hline
\end{tabular}

River bathymetry and shoreline topography were combined to create a single continuous land elevation surface. This surface was generated by interpolation from point elevations obtained from sources listed in Table B.2 and shown in Figure B.1.

All elevation datasets were first loaded into a geographic information system for spatial manipulation. In regions where datasets overlapped, one dataset was chosen to prevail to the exclusion of the others. For example, the detailed bathymetric data collected in September 1999 (PTS- 
Table B.2. Document sources for bathymetry data

\begin{tabular}{|l|l|l|}
\hline \multicolumn{1}{|c|}{ Dataset } & \multicolumn{1}{|c|}{ Source } & \multicolumn{1}{c|}{ Description } \\
\hline PTS-DEM & USGS & $\begin{array}{l}10 \text { meter digital elevation model used for } \\
\text { topography. }\end{array}$ \\
\hline PTS-MAY2000 & $\begin{array}{l}\text { USACE Arc- } \\
\text { Info cover: } \\
\text { addsurvey }\end{array}$ & $\begin{array}{l}\text { Additional points from the May 24, 2000 } \\
\text { hydrographic survey. }\end{array}$ \\
\hline PTS-99222FORE-TAIL & $\begin{array}{l}\text { USACE file: } \\
\text { 99222Dal- } \\
\text { points.dgn }\end{array}$ & $\begin{array}{l}\text { Detailed bathymetry survey conducted } \\
\text { in September 1999 by Minister-Glaeser } \\
\text { Surveying, Inc covering areas above } \\
\text { and below dam. Some anomalous points } \\
\text { removed. }\end{array}$ \\
\hline PTS-OUTFALL & $\begin{array}{l}\text { USACE file: } \\
\text { Hydro2001.dgn }\end{array}$ & $\begin{array}{l}\text { Detailed bathymetry survey covering the } \\
\text { plunge pool of the ice and trash sluiceway } \\
\text { outfall. }\end{array}$ \\
\hline PTS-FORE160 PTS-TAIL74 & $\begin{array}{l}\text { USGS } \\
\text { DOQQ }\end{array}$ & $\begin{array}{l}\text { Columbia River shoreline points devel- } \\
\text { oped from digital orthoquad image. }\end{array}$ \\
\hline PTS-JASCONT & PNNL & $\begin{array}{l}\text { Manually generated points to force inter- } \\
\text { polation near engineered structures and } \\
\text { where data were absent. }\end{array}$ \\
\hline PTS-2FTCONT & $\begin{array}{l}\text { USACE } \\
\text { file: Dalles- } \\
\text { 1999A.dwg }\end{array}$ & $\begin{array}{l}\text { Points extracted from 2-ft contour lines } \\
\text { used for island topography only. }\end{array}$ \\
\hline
\end{tabular}

99222FORE and PTS-99222TAIL) superseded overlapping points in the PTS-MAY2000 datasets. Similarly, the digital elevation model dataset (PTS-DEM) was not used when other datasets were available.

Three special datasets were created to improve surface interpolation. The PTS-TAIL74 and PTSFORE160 datasets represent the river shorelines at an elevation of $74 \mathrm{ft}$ and $160 \mathrm{ft}$, respectively. These points were obtained by digitizing the shoreline from a US Geological Survey aerial photograph set, where the forebay and tailrace elevations were known from historic records. Minor adjustments were made to the digitized points to accommodate surveyed information. These datasets were constructed to help smooth the interpolation where relatively dense bathymetric data adjoin more sparse topographic data.

A third dataset, PTS-JASCONT, was created to force the interpolated surface beneath engineered structures and also to smooth out areas in the lower tailrace where bathymetric data is absent. In the latter case, sparse PTS-MAY2000 data points collected in a meandering pattern across the river resulted in an interpolation with an unnaturally undulating channel bottom. To correct this sampling artifact, manually drawn contours were added to force the bathymetry to align in the direction of the river channel. Points extracted from these contours were added to the PTS-JASCONT dataset. 


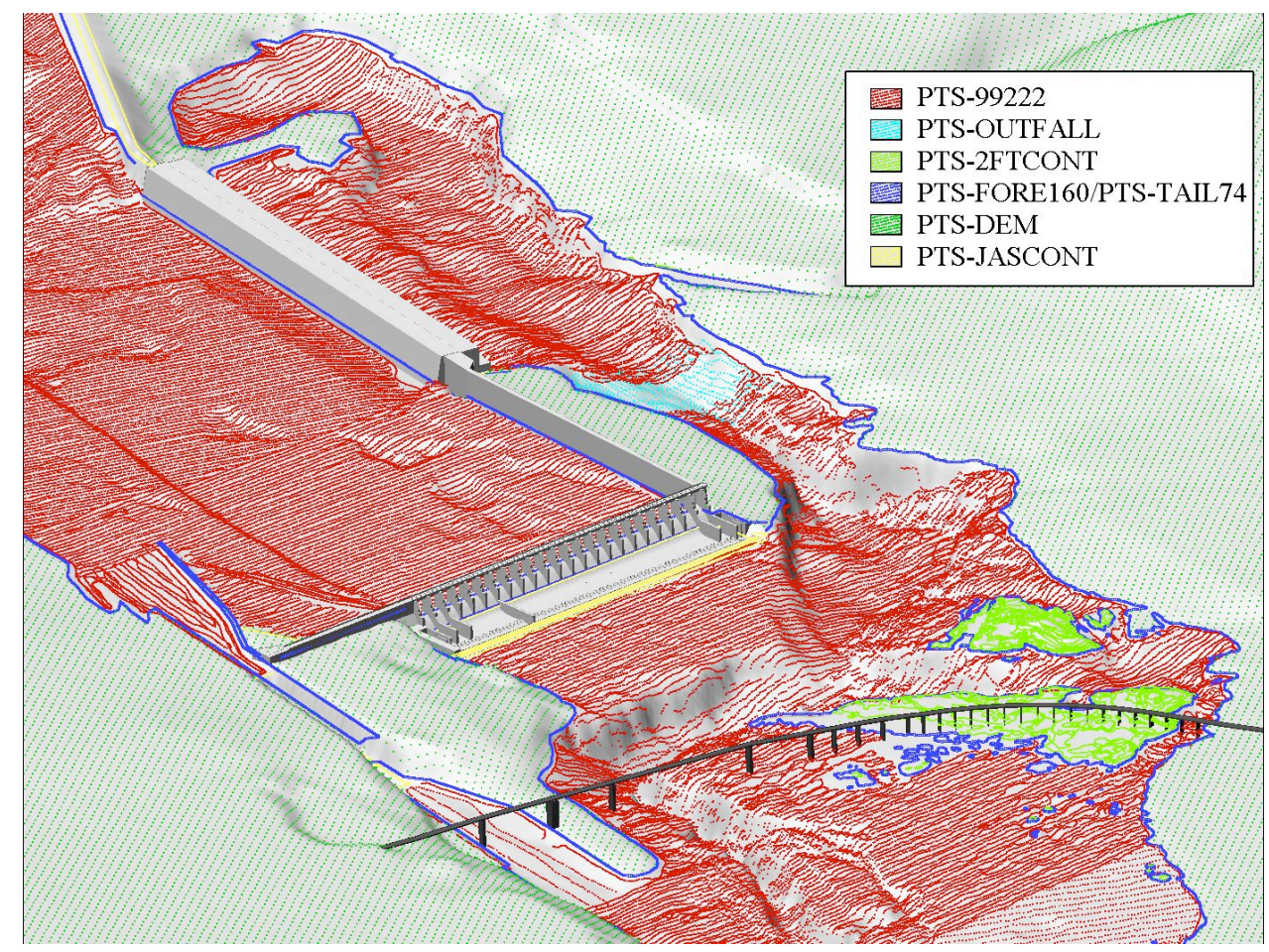

Figure B.1. Spatial distribution of point elevation data.

The engineered structure models were then combined with the topographic grid for visual examination. Unintended gaps between the topographic and engineered structures required minor adjustments to prevent simulated fluid from passing through these gaps. The topographic surface was also adjusted to prevent unintended blockage (overlap) of engineered structures. These problems were corrected by iteratively modifying the PTS-JASCONT dataset.

The topographic surface was inspected for unnatural features that resulted from dataset errors. One such feature was discovered in the narrow channel at the lower end of the powerhouse tailrace, just south of the spillway (see Figure B.2). This narrow fin extends halfway across the deepest part of the channel. Based on a reconnaissance survey, CENWP agreed to exclude the fin from the model. Several smaller anomalous features, involving only a few survey points, were also excluded from the model.

The completed datasets were exported in a format compatible with the CFD model (STL format) and could be combined with numerical representations of the engineered structures (see Figure B.3). The final extent of the STL domain included the entire tailrace downstream of the powerhouse. The STL continued downstream past the spillway and Highway 197 bridge for more than two miles. The CFD model interpolated the STL to the input specified domain limits for each simulation, so a larger STL extent allowed for expansions of the model domain without a need to recreate the underlying STL. 


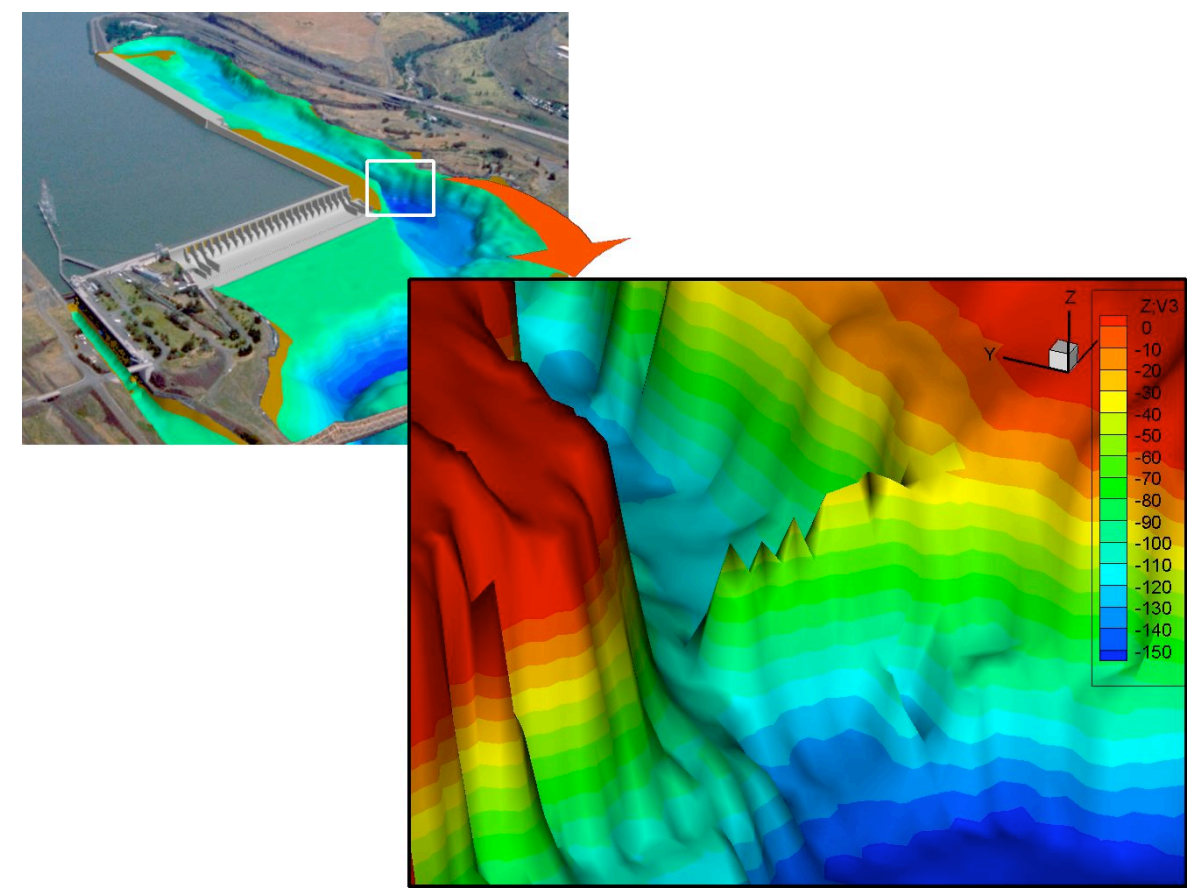

Figure B.2. Anomalous bathymetry features between the powerhouse and tailrace bathymetry

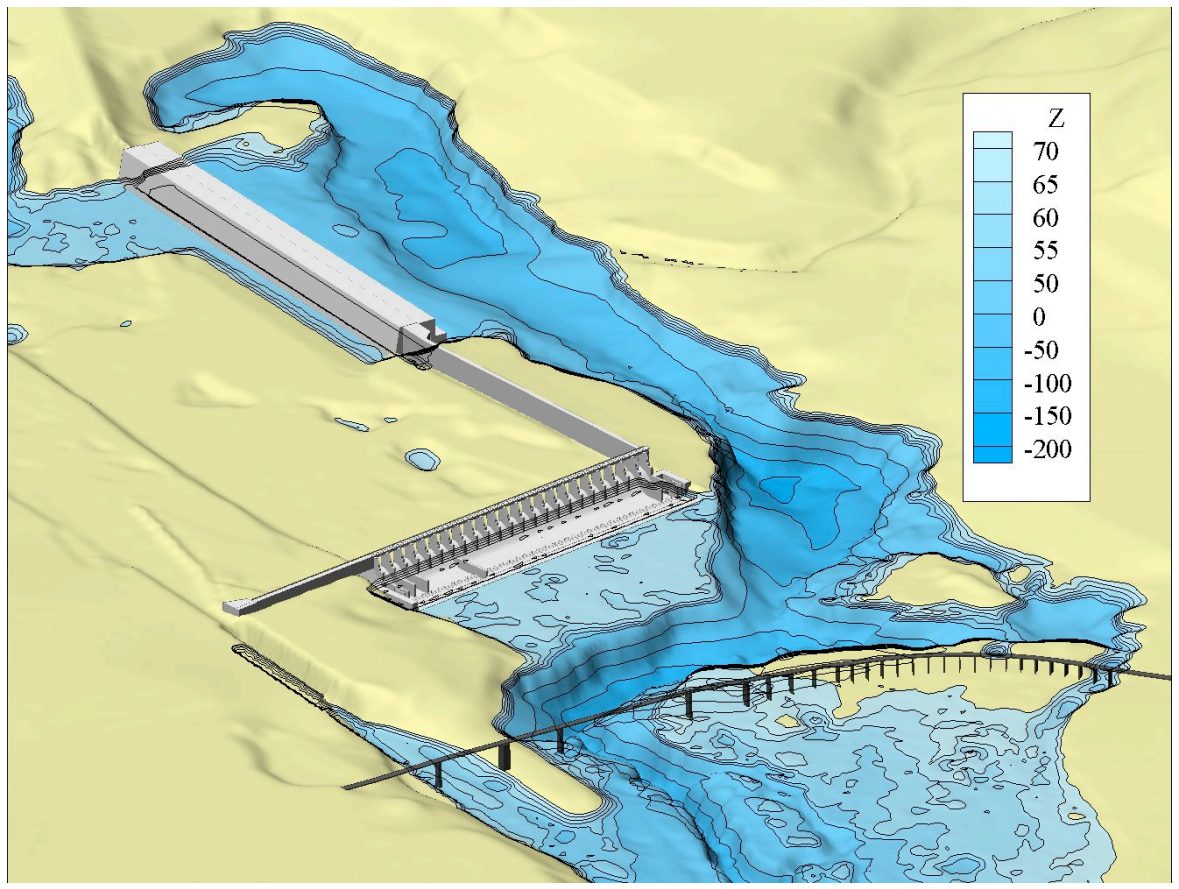

Figure B.3. Three-dimensional representation of the modeled bathymetry and engineering structures. Bathymetry has been shaded by elevation. 


\section{Appendix C}

\section{CFD Model}





\section{Appendix C - CFD Model}

\section{C.1 Model selection}

Prior to the start of this project, several computational fluid dynamics (CFD) models were considered to simulate The Dalles spillway and stilling basin. The necessary requirements of these models were 1) that they numerically solve the three-dimensional Navier-Stokes equations without using the hydrostatic approximation and 2) were capable of simulating flow conditions in the transient stilling basin. PNNL reviewed several of the CFD models presented in Freitas (1995) that had subsequently incorporated free-surface modeling by 2001 (see Cook and Richmond (2001)). At the time the PNNL report was published, Flow-3D was found to produce superior results in highly turbulent zones with large amounts of free-surface breakup (i.e. "frothy" areas). Based upon these findings, Flow-3D was selected as the CFD model best suited to simulate The Dalles stilling basin.

Flow-3D is a commercial software package that is supported though Flow Science, Inc. The model has a large user base and has been previously tested under a wide range of applications. Several recent applications to problems with similarities to the The Dalles stilling basin include Bradford (2000), Bombardelli et al. (2001), and Savage and Johnson (2001).

\section{C.2 Model formulation}

Flow-3D uses the finite volume method to discretized the Reynolds-averaged Navier-Stokes (RANS) equations. The physical domain to be simulated must be decomposed into Cartesian or Cylindrical blocks composed of variable-sized hexahedral cells. The domain can either be contained within a single block or several blocks, generally called "multi-blocks". If several blocks are used, each block must either be completely contained within a larger block ("nested") or be adjacent to another block and/or a domain boundary.

For each cell, average values for the fluid variables (pressure, velocity, turbulent kinetic energy, dissipation rate of turbulent kinetic energy) are computed at discrete times using a staggered grid technique (FSI 2003). The staggered grid technique places all dependent variables at the center of each cell except for velocities, which are located at cell faces. Most terms in the equations are evaluated explicitly using the current time-level values of the location variables. Although this explicit procedure is generally efficient and well suited for free-surface wave propagation, it requires that the time-step size be limited to maintain numerical stability requirements. Time steps for most of The Dalles simulations were on the order of 0.001 seconds.

The general numerical formulation of Flow-3D has a formal accuracy that is first order with respect to both time and space increments. Second order accurate methods are also available in the model. However those methods require increased computational time and can have more stringent conditions to maintain stability. Unless otherwise noted however, the simulations were performed using the first order accurate formulation.

Free-surface movement is computed using an Eulerian approach that involves tracking fluid movement into and out of stationary cells. This method was first developed by Hirt and Nichols (1981) 
and is commonly referred to as the volume-of-fluid (VOF) method. The VOF method implemented in Flow-3D applies a free-surface boundary condition, and for The Dalles application involves the computation of only a single fluid (i.e. cells are either filled with solid, fluid, or void).

The governing equations for the conservation of mass (C.1) and momentum (C.2) for incompressible flow, using the VOF methodology, are:

$$
\begin{gathered}
\frac{\partial}{\partial x}\left(u A_{x}\right)+\frac{\partial}{\partial y}\left(v A_{y}\right)+\frac{\partial}{\partial z}\left(w A_{z}\right)=0 \\
\frac{\partial u}{\partial t}+\frac{1}{V_{F}}\left(u A_{x} \frac{\partial u}{\partial x}+v A_{y} \frac{\partial u}{\partial y}+w A_{z} \frac{\partial u}{\partial z}\right)=-\frac{1}{\rho} \frac{\partial P}{\partial x}+F_{x} \\
\frac{\partial v}{\partial t}+\frac{1}{V_{F}}\left(u A_{x} \frac{\partial v}{\partial x}+v A_{y} \frac{\partial v}{\partial y}+w A_{z} \frac{\partial v}{\partial z}\right)=-\frac{1}{\rho} \frac{\partial P}{\partial y}+F_{y} \\
\frac{\partial w}{\partial t}+\frac{1}{V_{F}}\left(u A_{x} \frac{\partial w}{\partial x}+v A_{y} \frac{\partial w}{\partial y}+w A_{z} \frac{\partial w}{\partial z}\right)=-\frac{1}{\rho} \frac{\partial P}{\partial z}+G_{z}+F_{z}
\end{gathered}
$$

where $V_{F}$ represents the fractional volume open to flow, $\rho$ represents the fluid density, and the velocity components $(u, v, w)$ are in the coordinate directions $(x, y, z)$, respectively. $A_{x}$ represents the fractional area open to flow in the $x$ direction, while $A_{y}$ and $A_{z}$ represent similar area fractions in the other two directions. Likewise, $P$ represents the pressure, $G_{z}$ represents the gravitational acceleration (the $\mathrm{Z}$ axis is defined as upward in The Dalles model), and $\left(F_{x}, F_{y}, F_{z}\right)$ represent the viscous accelerations.

The governing equations are not complete without the specification of an equation of state, which relates fluid density to pressure, temperature, dissolved solids concentrations, etc. Flow-3D allows density to be non-uniform over the domain, however for The Dalles simulations density was specified as a uniform constant (isothermal, incompressible fluid with a uniform dissolved solids concentration).

The viscous accelerations are defined in the model using an eddy viscosity approach to the so called Reynolds stress terms. This results in the following suite of equations:

$$
\begin{gathered}
F_{x}=-\frac{1}{\rho V_{F}}\left(\frac{\partial}{\partial x}\left(A_{x} \tau_{x x}\right)+\frac{\partial}{\partial y}\left(A_{y} \tau_{x y}\right)+\frac{\partial}{\partial z}\left(A_{z} \tau_{x z}\right)\right) \\
F_{y}=-\frac{1}{\rho V_{F}}\left(\frac{\partial}{\partial x}\left(A_{x} \tau_{y x}\right)+\frac{\partial}{\partial y}\left(A_{y} \tau_{y y}\right)+\frac{\partial}{\partial z}\left(A_{z} \tau_{y z}\right)\right) \\
F_{z}=-\frac{1}{\rho V_{F}}\left(\frac{\partial}{\partial x}\left(A_{x} \tau_{z x}\right)+\frac{\partial}{\partial y}\left(A_{y} \tau_{z y}\right)+\frac{\partial}{\partial z}\left(A_{z} \tau_{z z}\right)\right)
\end{gathered}
$$


where the Reynolds stress tensor is calculated using:

$$
\begin{aligned}
\tau_{x x}=-2 \mu \frac{\partial u}{\partial x} \quad \tau_{y y} & =-2 \mu \frac{\partial v}{\partial y} \quad \tau_{z z}=-2 \mu \frac{\partial w}{\partial z} \\
\tau_{x y} & =\tau_{y x}=-\mu\left(\frac{\partial u}{\partial y}+\frac{\partial v}{\partial x}\right) \\
\tau_{x z} & =\tau_{z x}=-\mu\left(\frac{\partial u}{\partial z}+\frac{\partial w}{\partial x}\right) \\
\tau_{y z} & =\tau_{z y}=-\mu\left(\frac{\partial v}{\partial z}+\frac{\partial w}{\partial y}\right)
\end{aligned}
$$

The coefficient of dynamic viscosity, $\mu$, is assumed to be the sum of the molecular $(v)$ and turbulent kinematic viscosities $\left(\mathrm{v}_{t}\right)$ :

$$
\mu=\rho\left(v_{t}+v\right)
$$

Flow-3D has several models for calculating the turbulent viscosity: Prandlt mixing length, oneequation, two-equation $\kappa-\varepsilon$ and "Renormalization Group" (RNG) $\kappa-\varepsilon$, and Large Eddy Simulation (LES). Based upon prior experience with Flow-3D the RNG model was selected for all TDA simulations. Details on the RNG turbulence model can be found in Yakhot and Orszag (1986), Yakhot and Smith (1992) and Yakhot et al. (1992).

\section{C.3 Model bathymetry and dam structure}

The domain for the CFD model of The Dalles tailrace was constructed by using multiple sources of information. The information provided by these sources can be broken down into two categories: a) description of general engineered structures and b) description of the above and below water surface topography.

Engineered structures include the spillway, powerhouse, non-overflow dam, existing ice-and-trash outfall, and several proposed relocated outfall chutes. Engineering drawings and other documents obtained from the U.S. Army Corps of Engineers (USACE) were used to create three-dimensional representations of these structures. The data sources and processing methods are discussed in more detail in Appendix B.

River bathymetry and shoreline topography were combined to create a single continuous land elevation surface. The completed datasets were exported in a format compatible with the CFD model (STL format) and could be combined with numerical representations of the engineered structures (see Figure C.1). The final extent of the STL domain included the entire tailrace downstream of the powerhouse. The STL continued downstream past the spillway and Highway 197 bridge for more than two miles. The CFD model interpolated the STL to the input specified domain limits for each simulation, so a larger STL extent allowed for expansions of the model domain without a need to recreate the underlying STL. 


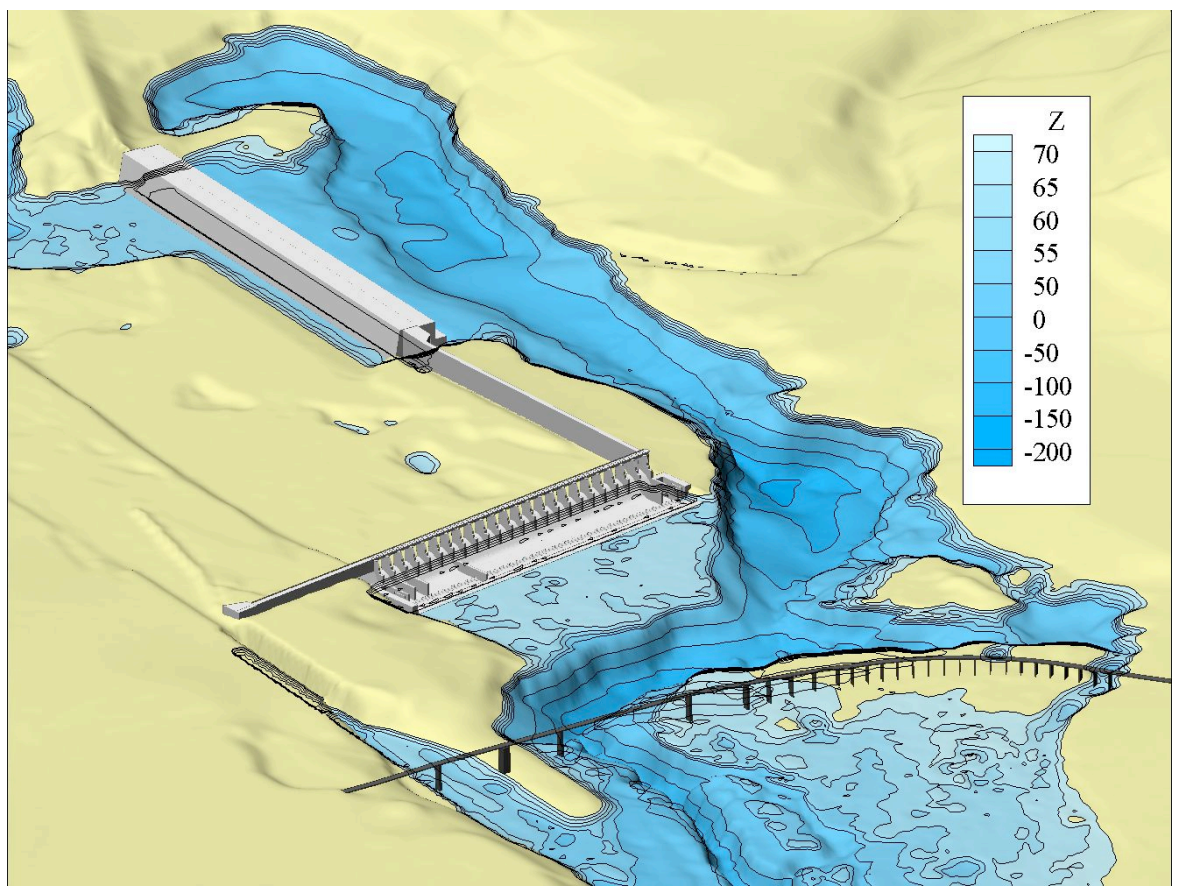

Figure C.1. Three-dimensional representation of the modeled bathymetry and engineering structures. Bathymetry has been shaded by elevation. 


\section{C.4 CFD Model Domains}

Simulations discussed in this section of the report differ only by the geographic extent of the CFD model domain. The same underlying dam structure and bathymetry (i.e. STL files) were used for all simulations. The separating factor between simulations discussed in this section is the overall extent of the modeled domain. As a general rule the maximum number of grid cells that can be simulated by Flow-3D on available desktop computers with 4Gb of RAM is approximately 7 million cells. Therefore, as the size of the domain increased, the mean cell spacing decreased. Multi-block techniques allow for cell refinement in areas of interest, but the general principle still holds true. As a consequence, the reduced domain simulations generally provided greater detail in the stilling basin and around the baffle blocks, while the bank-to-bank CFD models provided coarser information over a larger tailrace extent.

The reduced domain simulations discussed in this section span anywhere from one to 19 spillway bays. The reasons behind selecting one of the four reduced domain meshes depended upon the necessary grid size for the problem at hand and the length of time required for the simulation to warm-up and reach a dynamic equilibrium.

\section{C.4.1 One and Two Bay Spillway Simulations}

The 1- and 2-bay CFD domains are shown in Figures C.2 and C.3. Since The Dalles spillway bays are identical, except for those adjoining spillwalls or course, these CFD domains could represent any bay. These CFD domains are analogous to the sectional physical models, and the 2-bay domain model was always operated with a uniform flow discharging from all bays. It should be noted that the 2-bay model actually involves three bays; two half bays on either side of one full bay.

The upstream limit of the 1- and 2-bay domains began $50 \mathrm{ft}$ downstream of the spillway crest (i.e., dam axis). The upstream boundary condition for these models was determined by performing numerous two-dimensional tainter gate simulations and applying the CENWP rating curve with a forebay elevation at $160 \mathrm{ft}$ (see Table C.1). It was noted that over a wide range of gate openings that spillway jet velocities a set distance downstream from the gate were approximately constant. At $50 \mathrm{ft}$ downstream of the crest, the average velocities were $\mathrm{u}=41.4 \mathrm{ft} / \mathrm{s}$ and $\mathrm{w}=-40.8 \mathrm{ft} / \mathrm{s}$, where $\mathrm{u}$ is the longitudinal/downstream velocity component and $\mathrm{w}$ is the vertical component (positive upwards). Between a discharge of 4 and $18 \mathrm{kcfs}$, $\mathrm{u}$ and $\mathrm{w}$ varied by a maximum of $7 \%$ (max deviation from the mean was $2.8 \mathrm{ft} / \mathrm{s}$ in $\mathrm{u}$ and $2.5 \mathrm{ft} / \mathrm{s}$ in $\mathrm{w}$ ). The impacts of this simplifying assumption was considered negligible after taking into consideration the accuracy of the spillway rating curve and the lack of air entrained by the CFD model as the water flows down the spillway face.

The domain of the models extended a hundred feet or more downstream of the end wall. The 1and 2-bay models terminated $350 \mathrm{ft}$ from the spillway crest (approximately $100 \mathrm{ft}$ downstream of the end sill) and this domain was applied only for cases with small discharges (e.g. gate opening of $5 \mathrm{ft}$ or less) (see Figure C.2). The downstream boundary was extended by an additional $100 \mathrm{ft}$ when large discharges were simulated to capture the hydraulic jump that would occur at the end sill (see Figure C.3). For either domain length, the downstream boundary for the 1- and 2-bay 
models was a set fluid height (i.e. pressure boundary).

The lateral side boundaries for the 1- and 2-bay models were defined as symmetry conditions, which forces the velocity vectors to flow parallel to the boundary (i.e. zero normal component). The bottom domain boundary was the STL obstacle, which is equivalent to a wall boundary and a law-of-the-wall type profile was assigned. The resulting shear stresses were computed using a $\frac{1}{7}^{\text {th }}$ power-law approximation to the logarithmic expression. The top domain boundary was set to atmospheric pressure with zero fluid fraction, implying that the boundary should be dry.

Twenty-seven simulations were performed using either the 1- or 2-bay models. Nine of the 1bay models involved testing deflectors, and will be discussed later in this report. All simulation results, including a graphical distillation of the each simulation, can be found in the appendices.

opening discharge
\begin{tabular}{|c|c|}
\hline 0.0 & - \\
\hline 0.5 & 711 \\
\hline 1.0 & 1,464 \\
\hline 1.5 & 2,215 \\
\hline 2.0 & 2,969 \\
\hline 2.5 & 3,720 \\
\hline 3.0 & 4,475 \\
\hline 3.5 & 5,223 \\
\hline 4.0 & 5,970 \\
\hline 4.5 & 6,725 \\
\hline 5.0 & 7,469 \\
\hline 5.5 & 8,210 \\
\hline 6.0 & 8,962 \\
\hline 6.5 & 9,700 \\
\hline 7.0 & 10,450 \\
\hline
\end{tabular}

opening discharge
\begin{tabular}{|c|r|}
\hline 7.5 & 11,183 \\
\hline 8.0 & 11,913 \\
\hline 8.5 & 12,658 \\
\hline 9.0 & 13,402 \\
\hline 9.5 & 14,145 \\
\hline 10.0 & 14,864 \\
\hline 10.5 & 15,580 \\
\hline 11.0 & 16,316 \\
\hline 11.5 & 17,050 \\
\hline 12.0 & 17,782 \\
\hline 12.5 & 18,484 \\
\hline 13.0 & 19,211 \\
\hline 13.5 & 19,935 \\
\hline 14.0 & 20,633 \\
\hline 14.5 & 21,357 \\
\hline
\end{tabular}

opening discharge
\begin{tabular}{|l|l|}
\hline 15.0 & 22,077 \\
\hline 15.5 & 22,761 \\
\hline 16.0 & 23,508 \\
\hline 16.5 & 24,219 \\
\hline 17.0 & 24,891 \\
\hline 17.5 & 25,631 \\
\hline 18.0 & 26,370 \\
\hline 18.5 & 27,029 \\
\hline 19.0 & 27,722 \\
\hline 19.5 & 28,412 \\
\hline 20.0 & 29,056 \\
\hline 20.5 & 29,780 \\
\hline 21.0 & 30,501 \\
\hline 21.5 & 31,131 \\
\hline 22.0 & 31,801 \\
\hline
\end{tabular}

opening discharge
\begin{tabular}{|l|r|}
\hline 22.5 & 32,420 \\
\hline 23.0 & 33,175 \\
\hline 23.5 & 33,880 \\
\hline 24.0 & 34,485 \\
\hline 24.5 & 35,184 \\
\hline 25.0 & 35,778 \\
\hline 25.5 & 36,469 \\
\hline 26.0 & 37,156 \\
\hline 26.5 & 37,735 \\
\hline 27.0 & 38,468 \\
\hline 27.5 & 39,036 \\
\hline 28.0 & 39,707 \\
\hline 28.5 & 40,263 \\
\hline 29.0 & 40,926 \\
\hline 29.5 & 41,586 \\
\hline
\end{tabular}

\begin{tabular}{|c|c|}
\hline 30.0 & 42,124 \\
\hline 30.5 & 42,834 \\
\hline 31.0 & 43,361 \\
\hline Full Open & 46,199 \\
\hline
\end{tabular}

Table C.1. CENWP Rating Curve for TDA at Forebay Elevation $160 \mathrm{ft}$. Single bay tainter gate opening in feet and the corresponding discharge values are in cfs. 


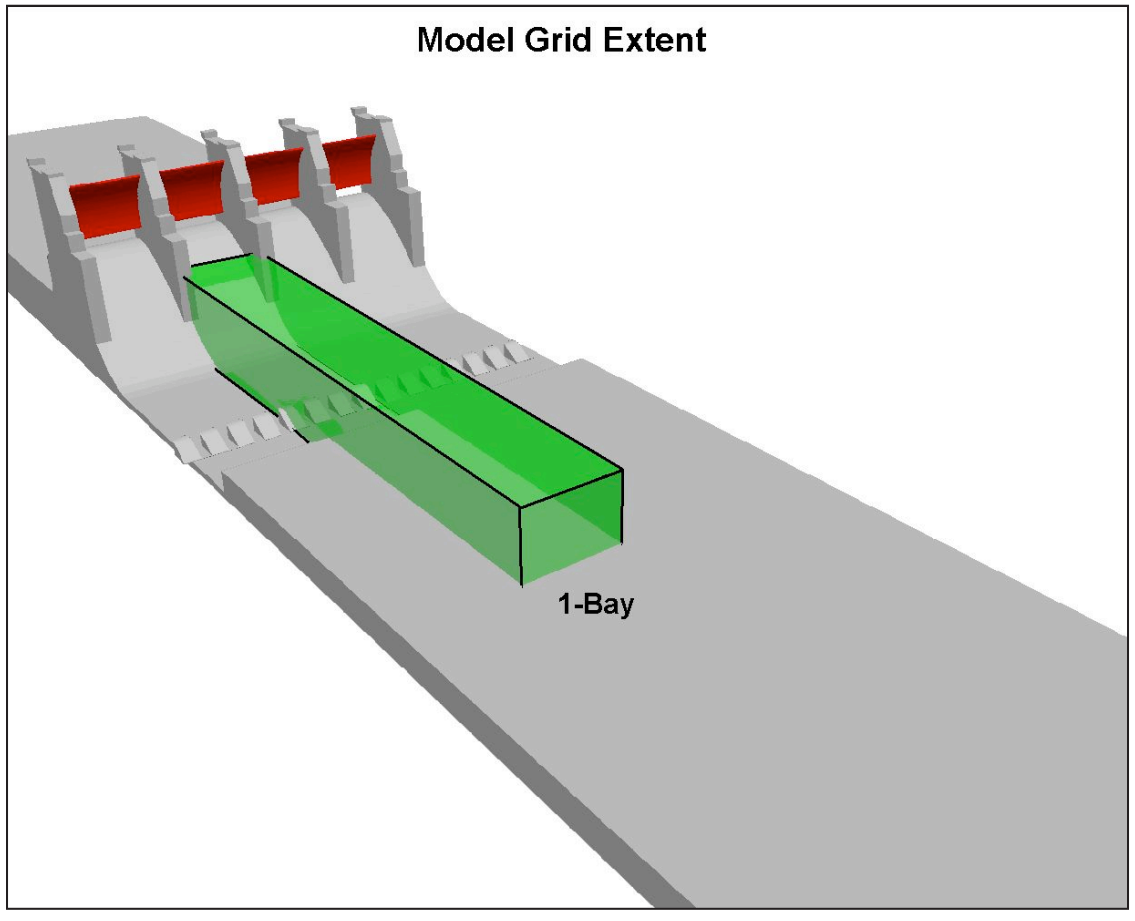

Figure C.2. Extent of the one-bay spillbay domain.

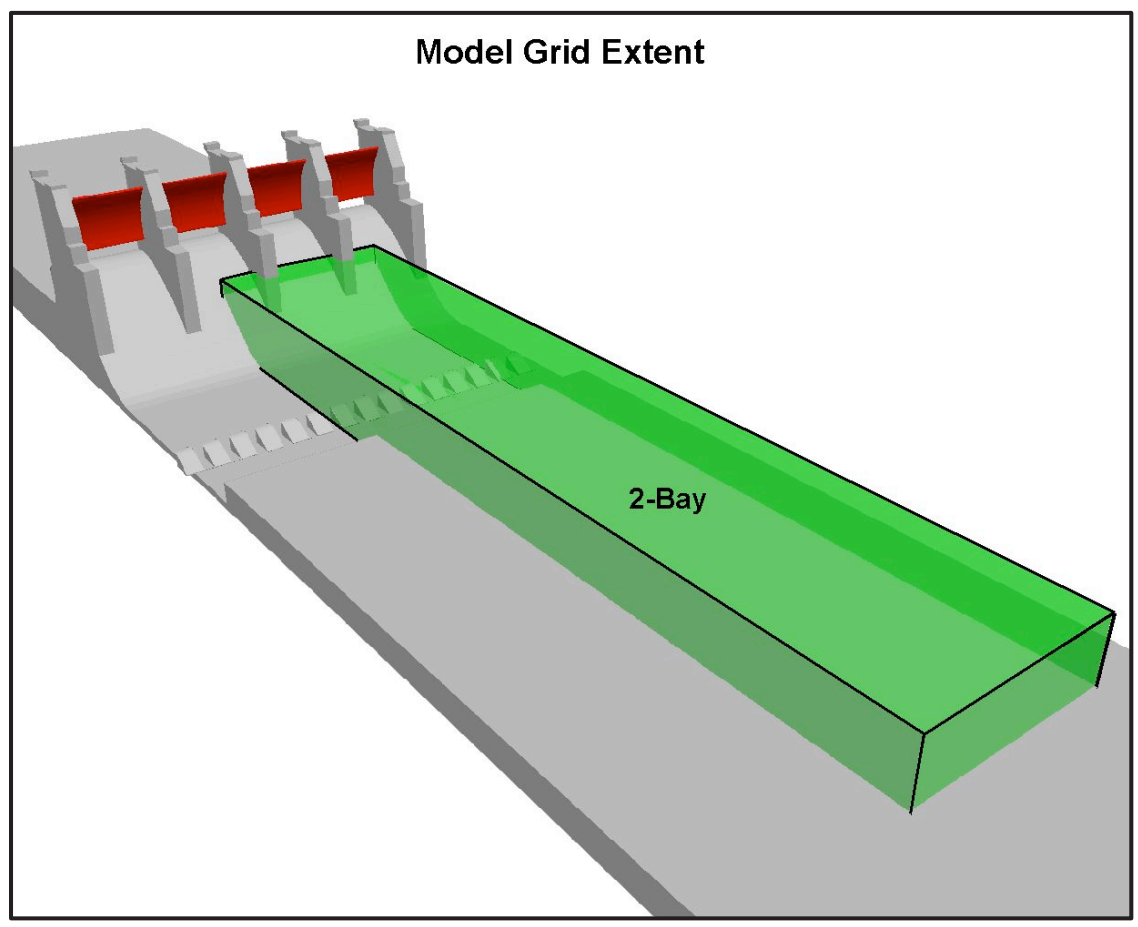

Figure C.3. Extent of the two-bay spillway domain. 


\section{C.4.2 Twelve, Fifteen, and Nineteen Bay Spillway Simulations}

The 12-, 15-, and 19-bay spillway models incorporated a much larger portion of the stilling basin. Because multiple bays were simulated, the model was able to capture laterally entrained flow that enters along the south (river left) boundary of the domain as illustrated with arrows in Figures C.4 and C.5. This phenomenon has been observed in the prototype, and is driven primarily by changes in water surface elevation in the stilling basin downstream of each spilling bay. The depressed water surface elevation induces lateral flow (i.e. flow parallel to the dam face) to occur in front of the non-spilling bays adjacent to the spilling bays. This phenomenon is shown by the direction of the short particle tracks downstream of any non-spilling bays (bays 14-19) and the first spilling bays (bays 12 through and 14) in Figure C.6.

To capture this phenomenon in the numerical model, a side velocity boundary was applied based upon the full spillway tailrace CFD model results. Although both the magnitude and direction of the lateral flow was observed to change along the boundary, the flow could be approximated over most discharge conditions simulated with the 12- and 19-bay models with $\mathrm{u}=-1.0 \mathrm{ft} / \mathrm{s}$ and $\mathrm{v}=-3.0$ $\mathrm{ft} / \mathrm{s}$, where $\mathrm{u}$ is the longitudinal velocity (negative upstream) and $\mathrm{v}$ is the lateral velocity (negative northward or into the domain). The 15-bay model improved slightly upon this approximation by varying the lateral flow. From upstream (nearest spillway - block 4) to downstream (block 1) the boundary velocities were: 50 to $153 \mathrm{ft}$ from crest $\mathrm{u}=-0.5 \mathrm{ft} / \mathrm{s} \mathrm{v}=-1.0 \mathrm{ft} / \mathrm{s} ; 153$ to $365 \mathrm{ft}$ from crest $\mathrm{u}=-0.5 \mathrm{ft} / \mathrm{s}$ and $\mathrm{v}=-2.0 \mathrm{ft} / \mathrm{s} ; 365$ to $500 \mathrm{ft}$ from crest $\mathrm{u}=-0.5 \mathrm{ft} / \mathrm{s}$ and $\mathrm{v}=-3.0 \mathrm{ft} / \mathrm{s} ; 500$ to $850 \mathrm{ft}$ from crest $\mathrm{u}=0.0 \mathrm{v}=-3.5 \mathrm{ft} / \mathrm{s}$.

The remaining domain boundaries for the 12-, 15-, and 19-bay models were identical to the 1- and 2-bay models. Internal boundaries between blocks in the 15-bay model were specified as "mesh block" boundaries and required no additional information (see FSI (2003) for details). 


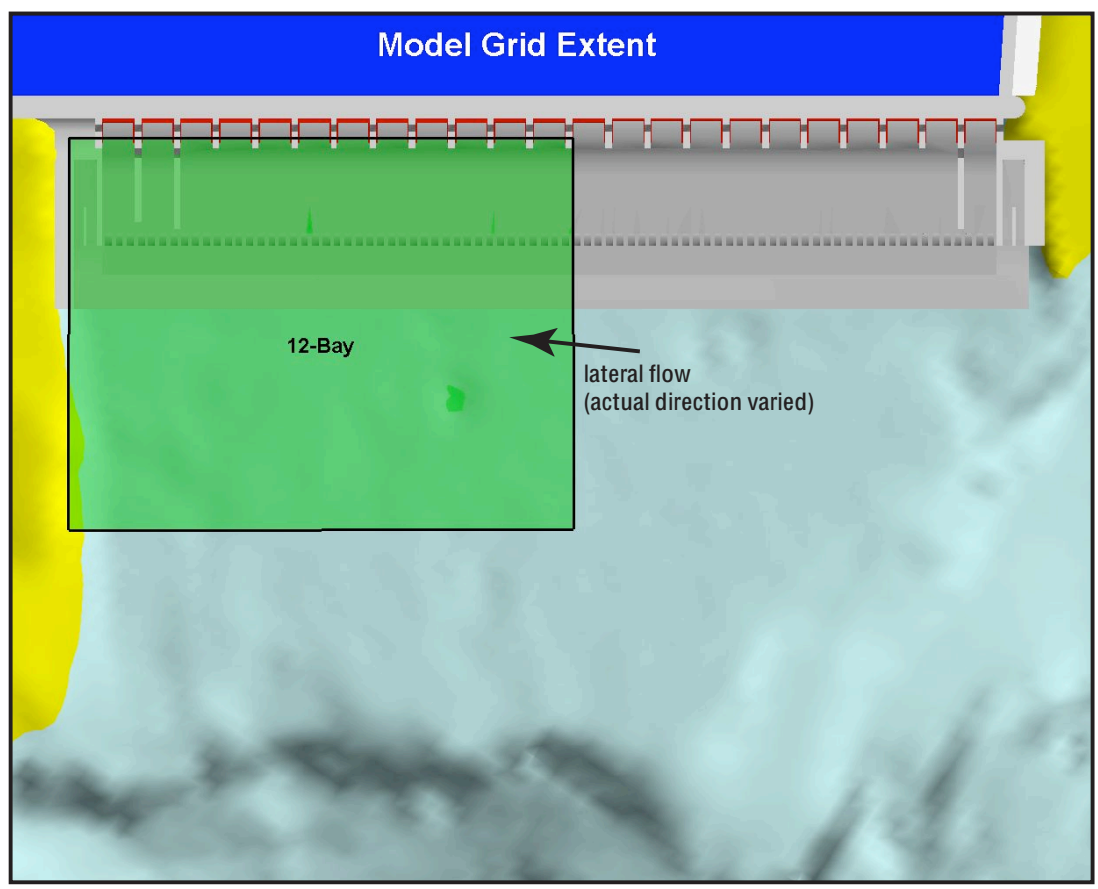

Figure C.4. Plan view of the 12-bay spillway domain (green rectangle). Gray represents the spillway, light blue represents the bathymetry (note the deep trough is partially visible at the bottom of the figure), tainter gates are shown in red, dry land has been shaded in gold, and dark blue represents the forebay (not simulated)

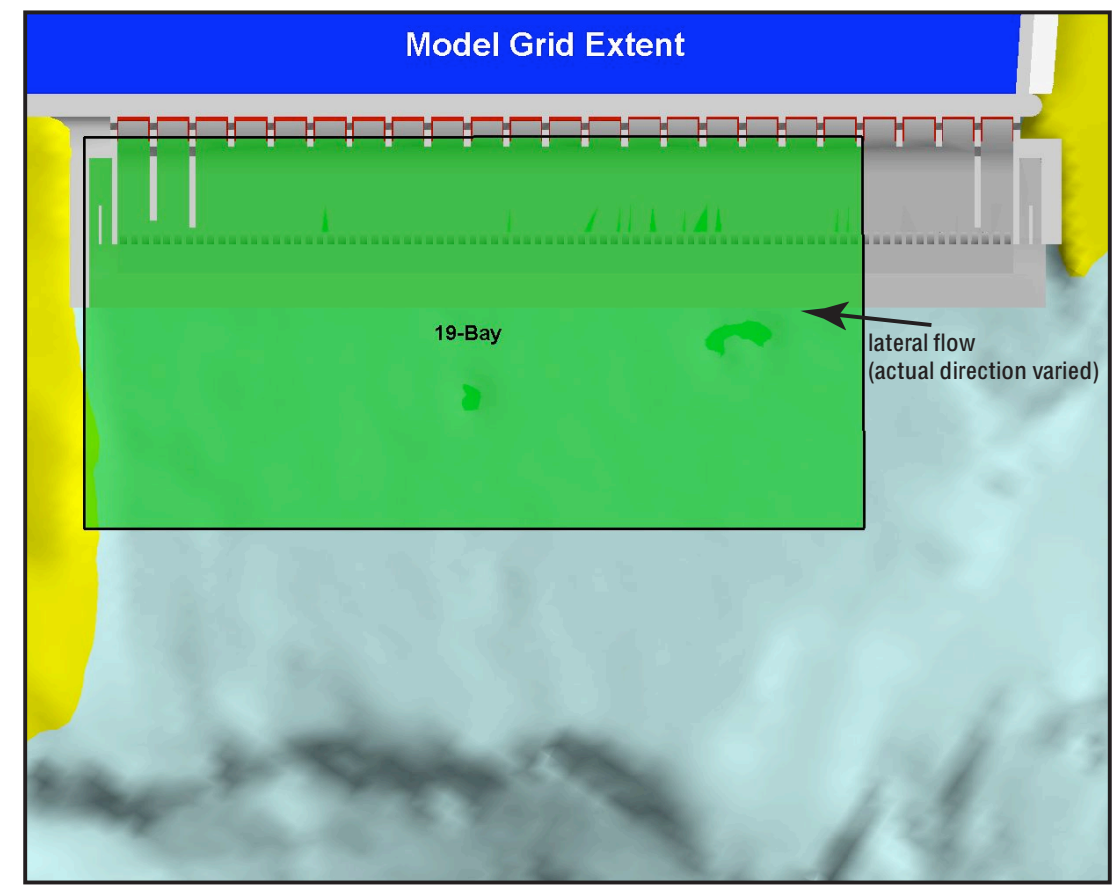

Figure C.5. Plan view of the 19-bay spillway domain (see previous figure caption for description of shading). 


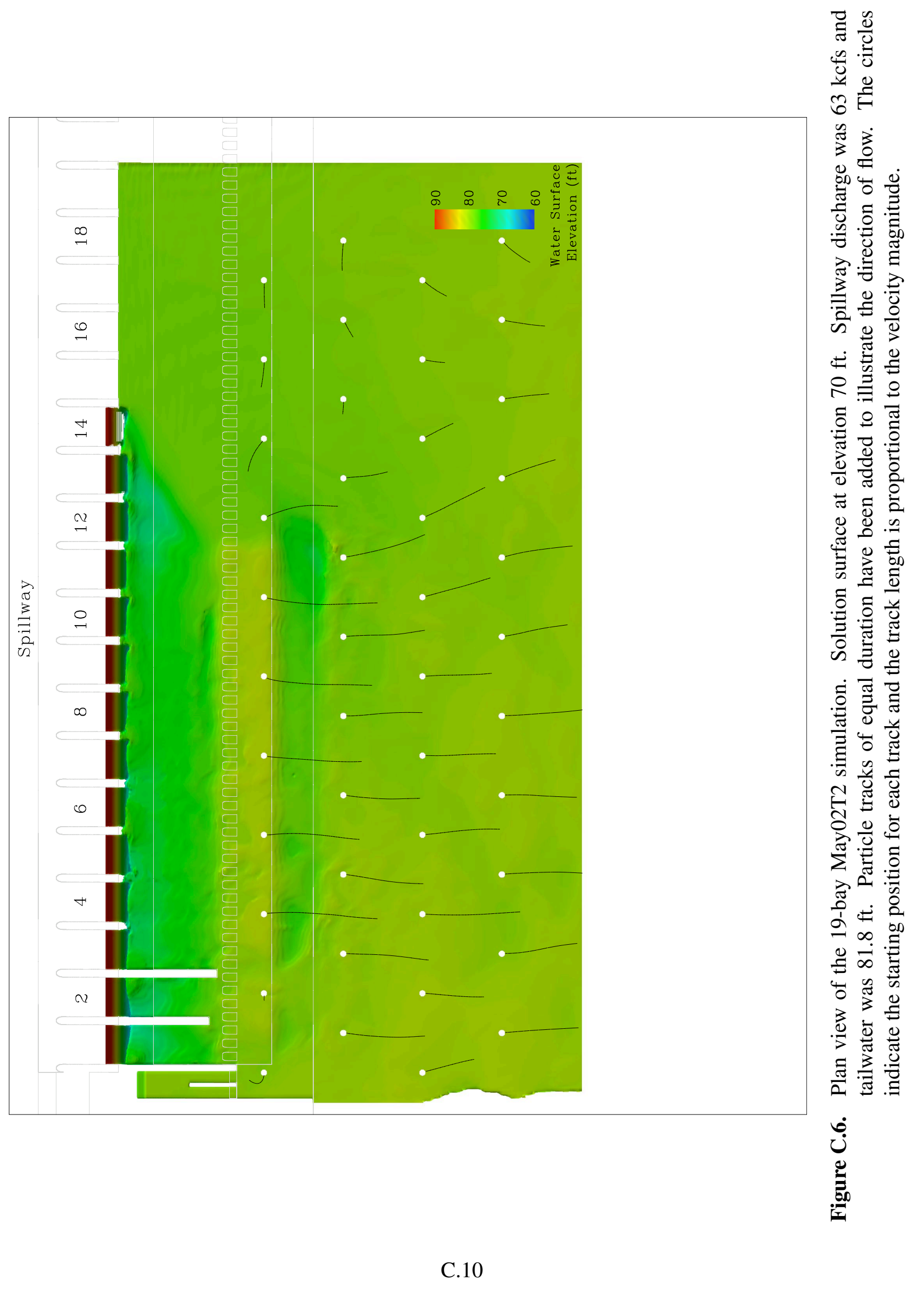




\section{C.5 References}

Bombardelli FA, CW Hirt, and MH Garcia. 2001. "Discussion on 'Computations of Curved Free Surface Water Flow on Spiral Concentrators'.” Journal of Hydraulic Engineering 127(7).

Bradford SF. 2000. "Numerical Simulation of Surf Zone Dynamics.” Journal of Waterway, Port, Coastal, and Ocean Engineering 126(1).

Cook CB and MC Richmond. 2001. Simulation of Tailrace Hydrodynamics Using Computational Fluid Dynamics Models. PNNL-13467, Pacific Northwest National Laboratory, Richland, WA.

Freitas CJ. 1995. "Perspective: Selected Benchmarks from Commercial CFD Codes.” Journal of Fluids Engineering 117:208-218.

FSI. 2003. Flow3-D User's Manual. Flow Science, Inc., Sante Fe, NM.

Hirt CW and BW Nichols. 1981. "Volume of Fluid (VOF) Method for the Dynamics of Free Boundaries." Journal of Computational Physics 39:201-255.

Savage BM and MC Johnson. 2001. "Flow over Ogee Spillway: Physical and Numerical Model Case Study." Journal of Hydraulic Engineering 127(8).

Yakhot V and SA Orszag. 1986. "Renormalization Group Analysis of Turbulence. I. Basic Theory." J. Scientific Computing 1:1-51.

Yakhot V, SA Orszag, S Thangam, TB Gatski, and CG Speziale. 1992. "Development of turbulence models for shear flows by a double expansion technique." Phys. Fluids A4(7):1510-1520.

Yakhot V and LM Smith. 1992. "The Renormalization Group, the e-Expansion and Derivation of Turbulence Models.” J. Scientific Computing 7:35-61. 

Appendix D

CFD Model Validation 



\section{Appendix D - CFD Model Validation}

\section{D.1 Simulating the 1:36 scale sectional model}

The Bonneville Hydraulic Laboratory, US Army Corps of Engineers, constructed a 1:36 scale sectional model of The Dalles Dam spillway before the prototype was constructed in the mid-1950s. This physical model was used for a wide variety of engineering design tests, including determining the discharge capacities of the final design spillway crest, minimum limits for excavation in the stilling basin, and other information pertinent to design of the spillway. Data preserved in the Bonneville Hydraulics Laboratory report germane to this study are pressures on the baffle blocks and end sill measured by means of piezometers installed in the model and connected to a manometer board. Prototype flow rates through the physical model ranged from a total river discharge of $100 \mathrm{kcfs}$ to a maximum flood discharge of 2,290 kcfs.

Memorandum Report 1-7 (BHL (1952)) and the summary Technical Report No 55-1 (BHL (1964)) describe the model tests and present summaries of the collected data. Figures Figures D.1 through D.7 have been duplicated from these reports to describe the various piezometer locations. All reported piezometer values were rounded in the reports to the nearest foot of water. Neither report discussed the typical range of water variation in the manometer board measurements nor the accuracy of the reported pressure measurements.

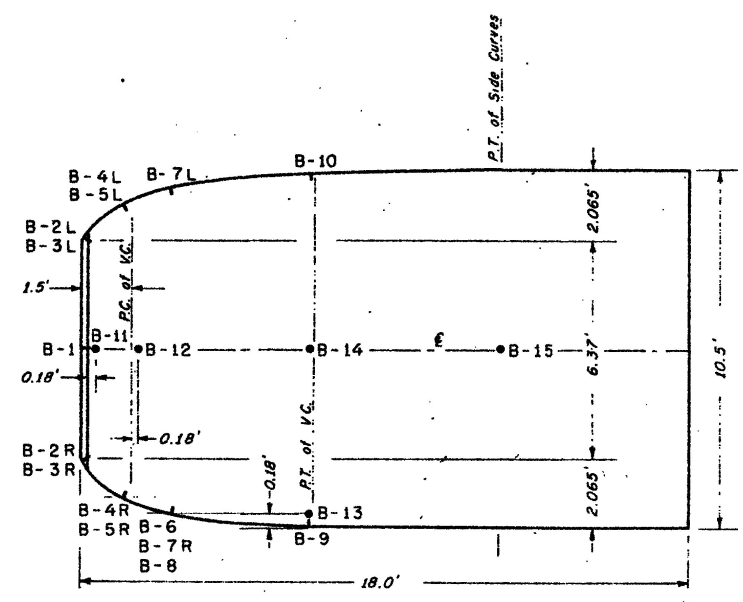

Figure D.1. Plan view of the instrumented 1:36 scale baffle block with piezometer locations. Dimensions are in prototype units of feet, and the B prefix signifies piezometers were located on the baffle block. Source: BHL (1952)

Two of the 1:36 scale physical model tests using the final (as built) spillway design were replicated using the numerical CFD model Flow-3D. It should be noted that the physical model released flows uniformly from all three spillway bays. Because of the lateral symmetry in hydraulic conditions, piezometers in the stilling basin were placed (approximately) along the center line of the physical model (note: because of the size and spacing of the baffle blocks, the centerline of the model was approximately inline with piezometers B-2L and B-3L instead of B-1). To minimize computational effort, the CFD model also took advantage of this symmetry about the model centerline, and 
only the center spillway bay was simulated. As with the physical model, the CFD model domain and boundary inputs were reduced to 1:36 scale for the simulation, and then scaled back to prototype equivalents at the end of the simulation. Both test conditions used identical finite volume cell sizes and input parameters. Table D.1 summarizes the simulation parameters.

Table D.1. Model parameters for the 1:36 model simulations

\begin{tabular}{ll}
\hline \hline Finite volume grid mesh & $\begin{array}{l}\text { Uniform size of } 0.0278 \mathrm{ft} \text { in all dimensions. } \\
\text { At prototype scale, this grid size spacing is } \\
\text { approximate } 1 \mathrm{ft} .\end{array}$ \\
Model width extent & $\begin{array}{l}\text { One bay plus end piers } \\
\text { Turbulence model }\end{array}$ \\
Upstream boundary & $\begin{array}{l}\text { Specified velocity at approximately half-way } \\
\text { down the spillway face }\end{array}$ \\
Downstream boundary & Tailrace water surface elevation \\
\hline \hline
\end{tabular}

The first of the two test conditions were: discharge of $5000 \mathrm{kcfs}$ per bay, forebay pool elevation at $160 \mathrm{ft}$, and tailwater elevation at $76.8 \mathrm{ft}$. These conditions are identified in the 1:36 phyical model report as the 200,000 cfs river discharge and 100,000 cfs spillway discharge test case.

A sketch of the physical model flow pattern for this discharge condition is shown in Figure D.4. A comparable slice from the CFD model is shown in Figure D.5. Both the profiles of water surface elevation and water velocity magnitudes over the end shelf are similar between the two figures. Both models show a distinct shear layer (zone of small magnitude between two layers going in different directions) between the end of the spillway face and the baffle block. The location and extent of the shear layer is approximately the same between the two model results.

Pressures computed by the CFD model were sampled at locations corresponding to the piezometer locations in the physical model. The results generated by both models are shown for the baffle block (Figure D.6) and for the end sill/downstream shelf (Figure D.7). The average bias in pressure between the CFD and physical model data were $-0.1 \mathrm{ft}$ over the baffle block and $-0.2 \mathrm{ft}$ over the end sill/shelf. It should be noted that these errors were computed at prototype scale; however, both the CFD and physical model results were computed at 1:36 scale. Mean average error (MAE) and root-mean-square (RMS) errors were $0.4 \mathrm{ft}$ and $0.5 \mathrm{ft}$, respectively. A difference of 0.5 feet at prototype scale is $0.014 \mathrm{ft}$ at 1:36 scale. Although the Memorandum Report does not comment on expected instrument error or measurement accuracy, differences in pressure on the order $0.5 \mathrm{ft}$ are expected to be within the accuracy of the measurement device.

The second of the two test conditions were: discharge of 20,000 kcfs per bay, forebay pool elevation at $160 \mathrm{ft}$, and tailwater elevation at $94.0 \mathrm{ft}$. These conditions are identified in the 1:36 physical model report as the $600,000 \mathrm{cfs}$ river discharge and 400,000 cfs spillway discharge test case.

A sketch of the physical model results for the second discharge condition in shown in Figure D.8, 
and the CFD model result slice is shown in Figure D.9. Both the profile of water surface elevation and water velocity magnitude over the end shelf are similar between the two figures. As with the $5 \mathrm{kcfs}$ simulation, the location and extent of the shear layer appear to be of approximately the same size and extent. Also, just downstream of the stilling basin and near the end sill wall, a small back roller was drawn in the sketch. The same hydraulic phenomenon was identified by the CFD model, and can be seen as the low velocity (blue) zone just past the leading edge of the end sill. The increase in velocity magnitude as the flows exit the stilling basin (accelerating from approximately $10 \mathrm{ft} / \mathrm{s}$ to upwards of $14 \mathrm{ft} / \mathrm{s}$ ) shown in the physical model was also captured by the CFD model, as can be seen by noting the shift in colors from green (10 ft/s) to yellows (15 ft/s) along the end shelf.

Pressures computed by the CFD model were sampled at locations corresponding to the piezometer locations in the physical model. The results generated by both models are shown for the baffle block (Figure D.10) and for the end sill/downstream shelf (Figure D.11). The average bias in pressure between the CFD and physical model data was $2.7 \mathrm{ft}$ over the baffle block. Although the bias is much larger for the baffle block zone at $20 \mathrm{kcfs}$ than for the $5 \mathrm{kcfs}$ test, we feel the results are reasonable considering the turbulent fluctuations occurring around the baffle block at this relatively large discharge. Perhaps more important than the absolute pressure magnitudes are the general rise and fall trends in pressure at the various piezometer locations, which were captured correctly by the CFD model. Therefore, although CFD computed pressures are higher than the physical model values, the overall trends in pressure fluctuation near the baffle block are similar. Downstream of the baffle block and near the end shelf, pressure values computed by the CFD model fall back inline with those reported by the physical model. CFD model pressure bias in this zone is, on average, only $0.4 \mathrm{ft} / \mathrm{s}$ and the MAE and RMS errors are $0.9 \mathrm{ft}$ and $1.0 \mathrm{ft}$, respectively. 


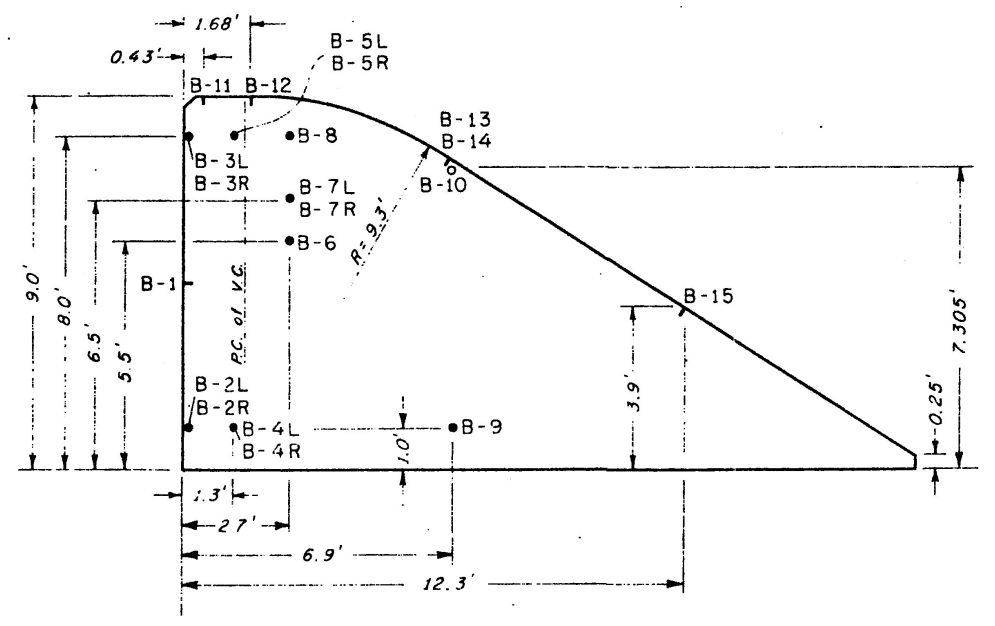

Figure D.2. Side view of the instrumented 1:36 scale baffle block with piezometer locations. Dimensions are in prototype units of feet, and the B prefix signifies piezometers were located on the baffle block. Source: BHL (1952)

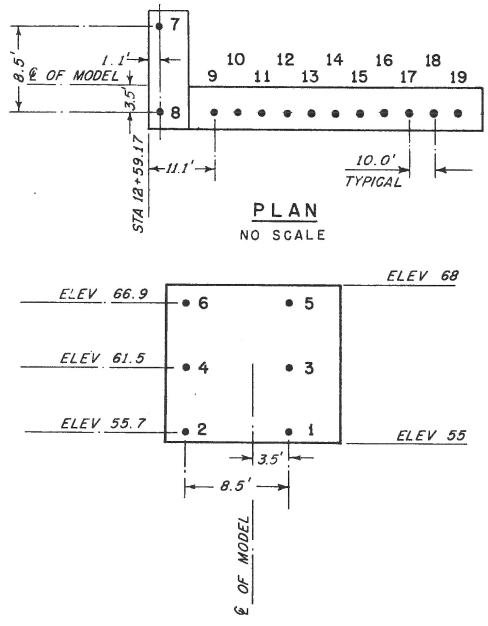

Figure D.3. Upstream elevation view (left; at Station 12+59.17) of the end sill piezometers and plan view (right) of the elevation $68 \mathrm{ft}$ shelf piezometers located downstream of the stilling basin. Piezometers E-8 through E-19 are inline and directly downstream of test baffle block, and piezometer E-19 is located the farthest downstream from the spillway. Dimensions are in prototype units of feet. Piezometer numbers are shown without the prefix "E" in the figure, which denotes end sill/shelf. Source: BHL (1952) 


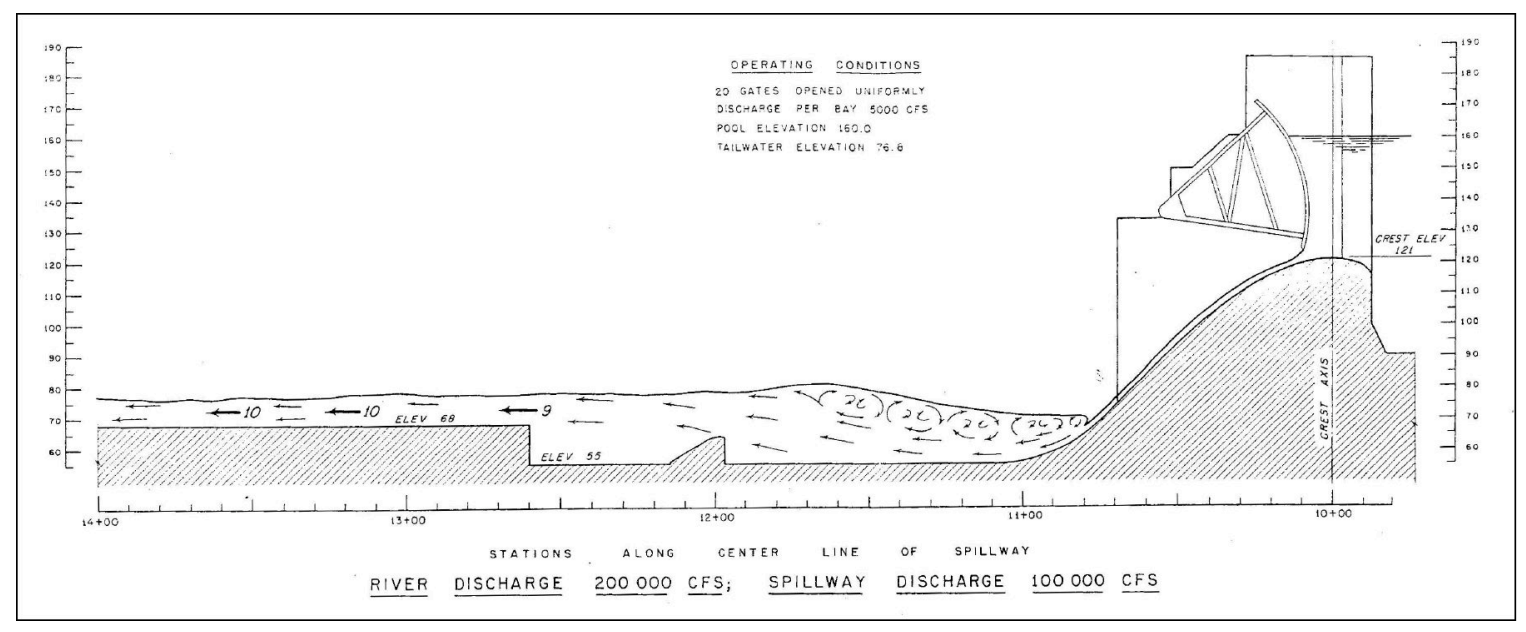

Figure D.4. Sketch of water surface elevation and velocity vectors from the $5 \mathrm{kcfs}$ per bay physical model simulation. Source: BHL (1964)

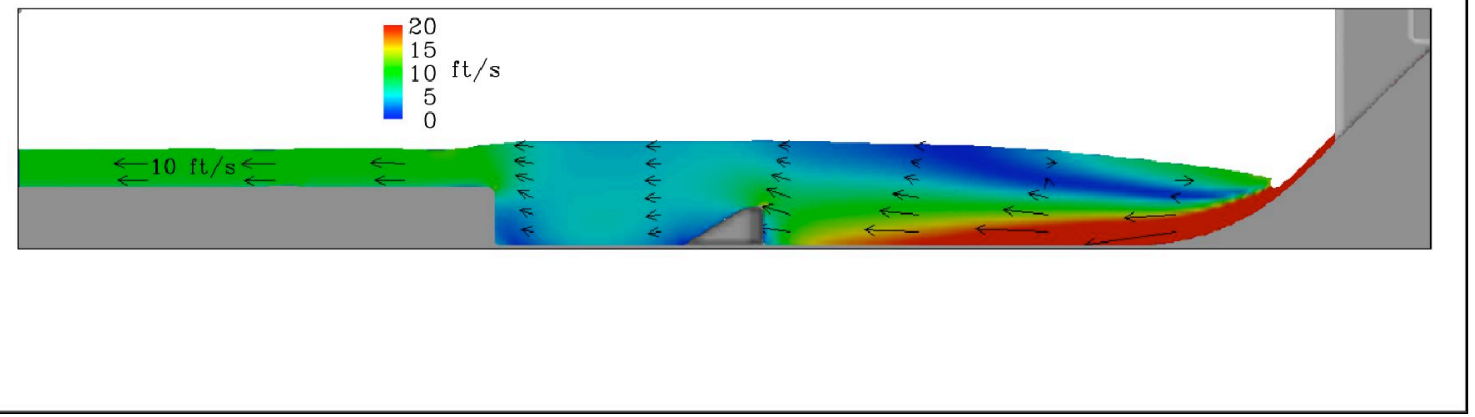

Figure D.5. Velocity magnitude shaded cross section generated by the CFD model for the $5 \mathrm{kcfs}$ simulation. The cross section passes through the model centerline baffle.

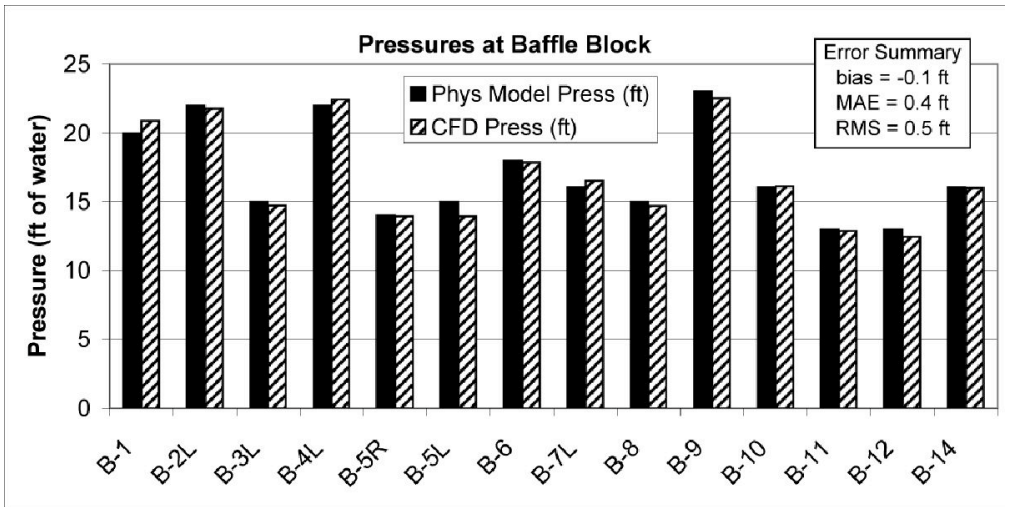

Figure D.6. Comparison of physical model versus CFD model pressures around the baffle block 


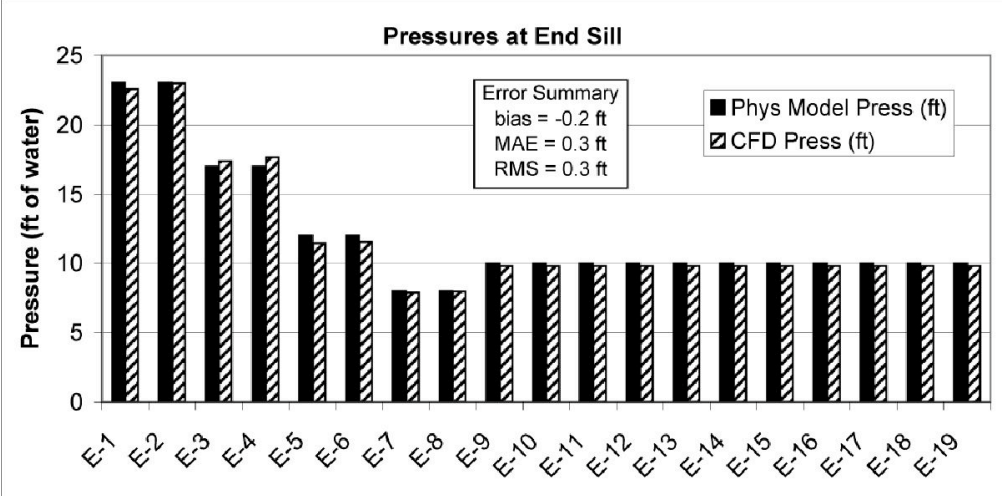

Figure D.7. Comparison of physical model versus CFD model pressures around the end sill

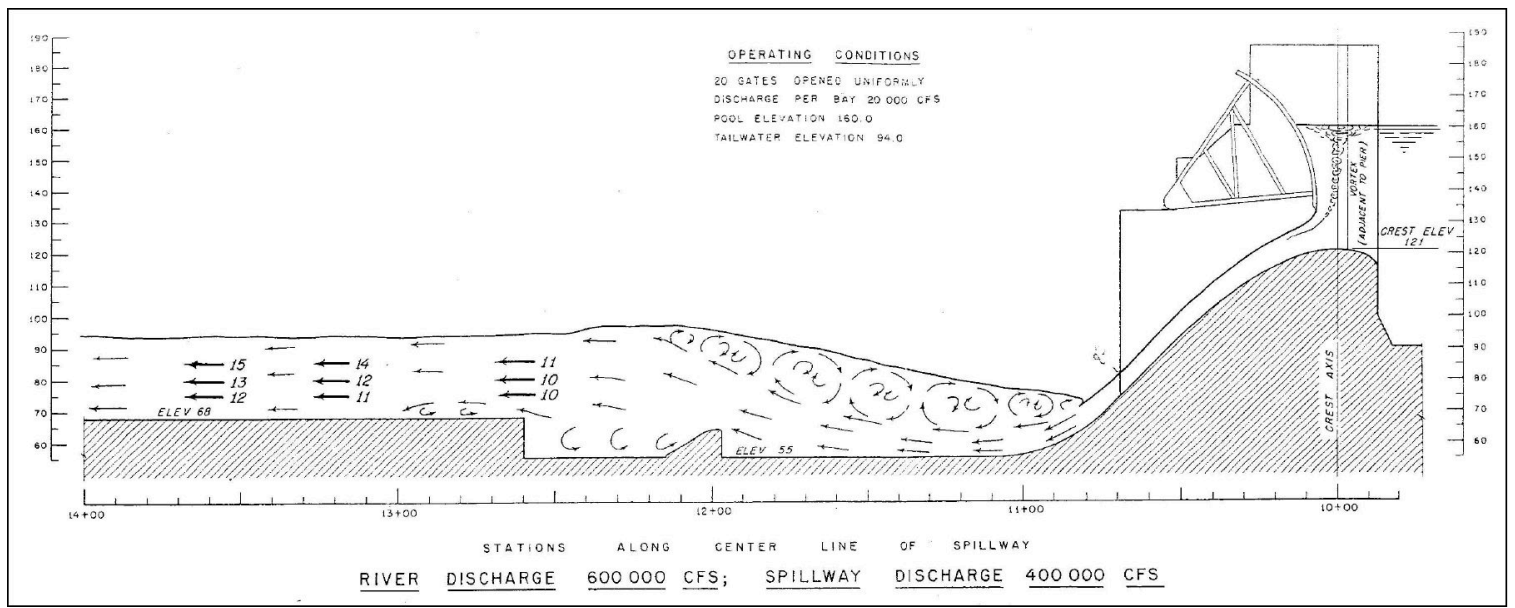

Figure D.8. Sketch of water surface elevation and velocity vectors from the $20 \mathrm{kcfs}$ per bay physical model simulation. Source: BHL (1964)

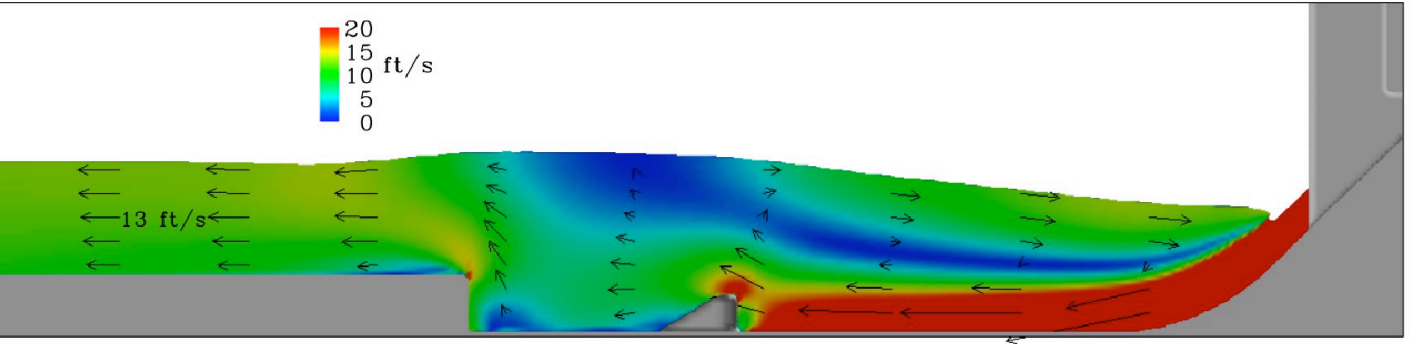

Figure D.9. Velocity magnitude shaded cross section generated by the CFD model for the 20 kcfs simulation. The cross section passes through the model centerline baffle. 


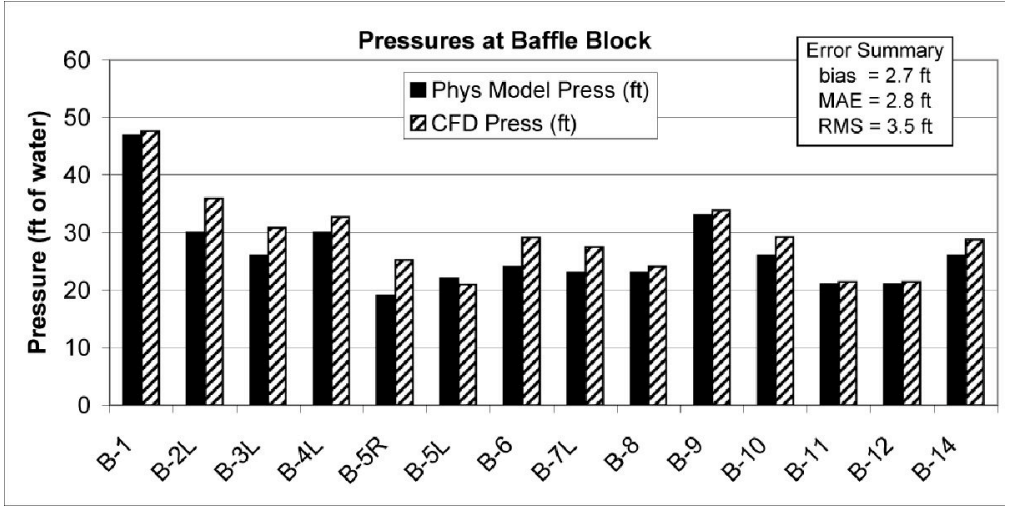

Figure D.10. Comparison of physical model versus CFD model pressures around the baffle block

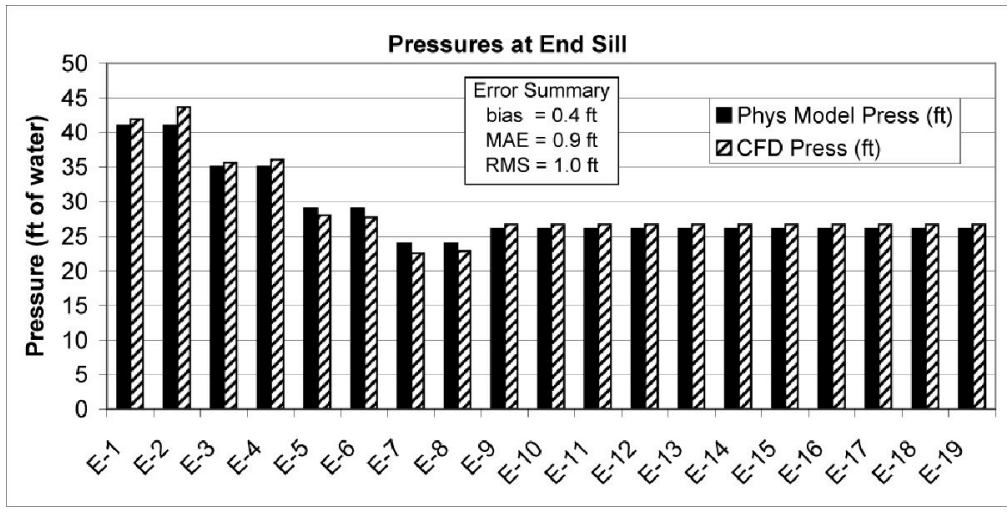

Figure D.11. Comparison of physical model versus CFD model pressures around the end sill 


\section{D.2 Simulating the 1:40 scale sectional model}

A 1:40 scale sectional physical model of The Dalles Spillway (see Figure D.12) was constructed at the Engineer Research and Development Center (ERDC), USACE Preslan and Wilhelms (2001). Conditions in this physical model were then recreated using Flow-3D (see Figure D.13). Water velocity data were collected in the physical model at the set locations shown in Figure D.14.

Since the 3.5 bays of the physical model were symmetric, it was assumed that flow patterns would also be symmetric from one bay to the next (although ERDC is confirming this assumption by collecting additional data in the flume). Therefore, to decrease the "wall-clock" time required for each simulation, the CFD model only simulated a single center bay (see the gray rectangular section in Figure D.14).

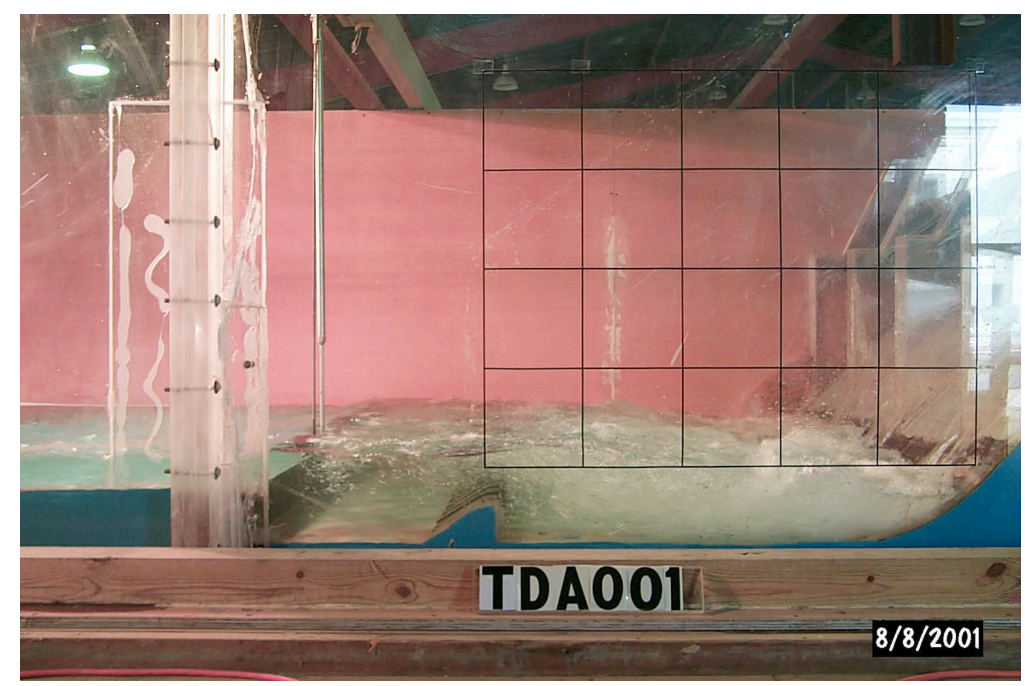

Figure D.12. 1:40 scale physical model of The Dalles Spillway at ERDC.

Comparisons were performed between the ERDC Dalles metrics feasibility study data (Preslan and Wilhelms 2001) and CFD results for the "no deflector with baffle test case". Results were compared at four locations: $7 \mathrm{ft}$ in front of the baffles, $9 \mathrm{ft}$ in front of the end sill, $51 \mathrm{ft}$ past the end sill, and $111 \mathrm{ft}$ past the end sill. For this test case, the CFD model was set up with the following boundary conditions (note: the CFD model, like the physical model, was actually at 1:40 scale, however all results have been scaled up to prototype using Froude number similarity): forebay was set at $160 \mathrm{ft}$, radial gates were opened $3 \mathrm{ft}$, the tailwater was set at $78 \mathrm{ft}$, and the flow rate was set at $5850 \mathrm{cfs}$. The flow rate set in the CFD model was derived by integrating the physical model vertical velocity profile at $370 \mathrm{ft}$.

Graphical and numerical comparisons of horizontal velocity component results are presented in Figure D.15 and Tables D.2. Water velocity magnitude differences, compared at four locations both within and downstream of the stilling basin, were minor with 73\% (6/22) of the CFD measurements falling within one standard deviation of the physical model mean value.

At $190 \mathrm{ft}, \mathrm{CFD}$ and physical model profiles roughly agree in shape, although the CFD model profile 


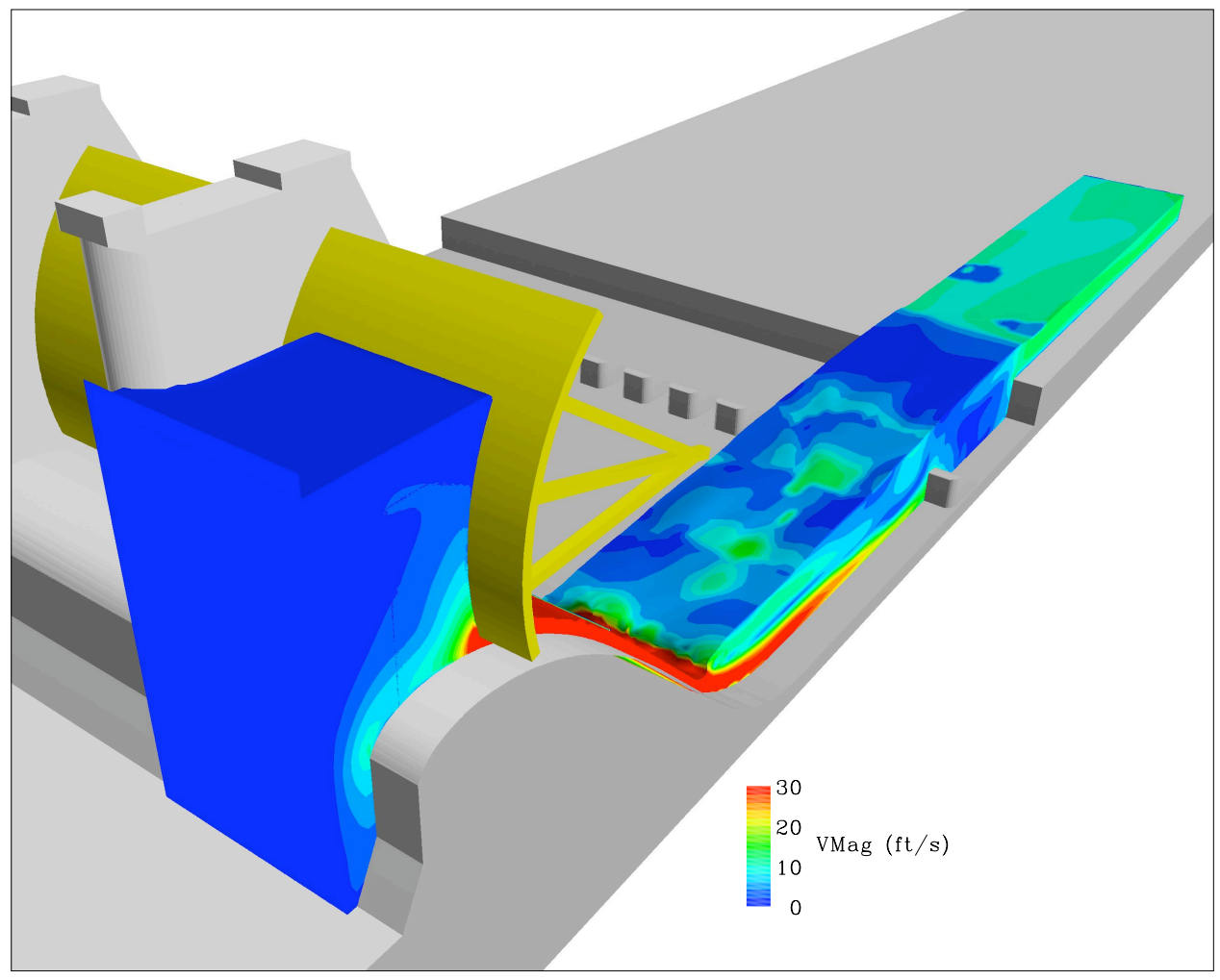

Figure D.13. 3-D perspective of the CFD 1:40 scale numerical flume.

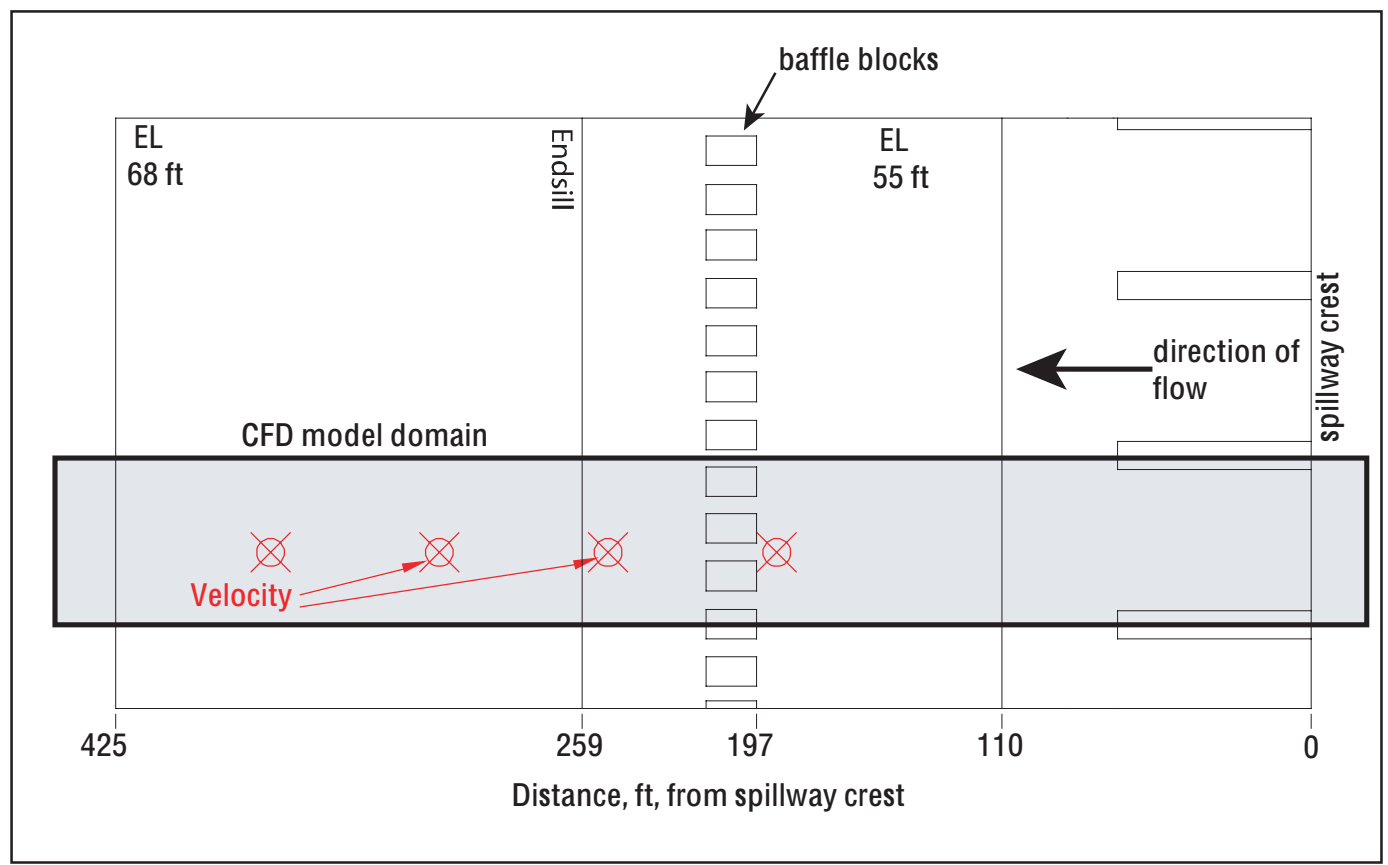

Figure D.14. Plan view of the physical model flume and measurement sites. CFD model domain was simplified to a single bay (shown in gray). Both model domains extend farther into the forebay and tailrace than shown. 
appears to be slightly less than the physical model means. The CFD model results all fall within one standard deviation, so differences may be due to the transient nature of the flow field (both the physical and CFD models). Differences would also result if the flow rates or gate openings between the physical and CFD models were different.

At 310 and $370 \mathrm{ft}$ the velocity distribution observed in the physical model displays a more uniform trend over the depth than the CFD model. The largest differences between the CFD and physical model lie at $370 \mathrm{ft}$. The bottom reading at these locations is at elevation $68.5 \mathrm{ft}$, or $0.5 \mathrm{ft}$ off the bottom. At 1:40 scale, $0.5 \mathrm{ft}$ is less than $1 / 6^{\text {th }}$ of an inch. Differences between the two models this close to the bottom may be due to a number of factors including: boundary layer influences caused by the velocity probe in the physical model, insufficient grid refinement in the CFD model, and/or turbulence and boundary wall functions used to approximate the boundary layer in the CFD model. If the errors are due to the CFD model's approximation of the boundary layer, this impact will be diminished when the CFD model is applied at prototype scale due to (a) reduced size of the boundary layer relative to the overall water column thickness and (b) the Reynolds number is higher in the prototype, which also diminishes the influence of the boundary layer on the overall water column. 

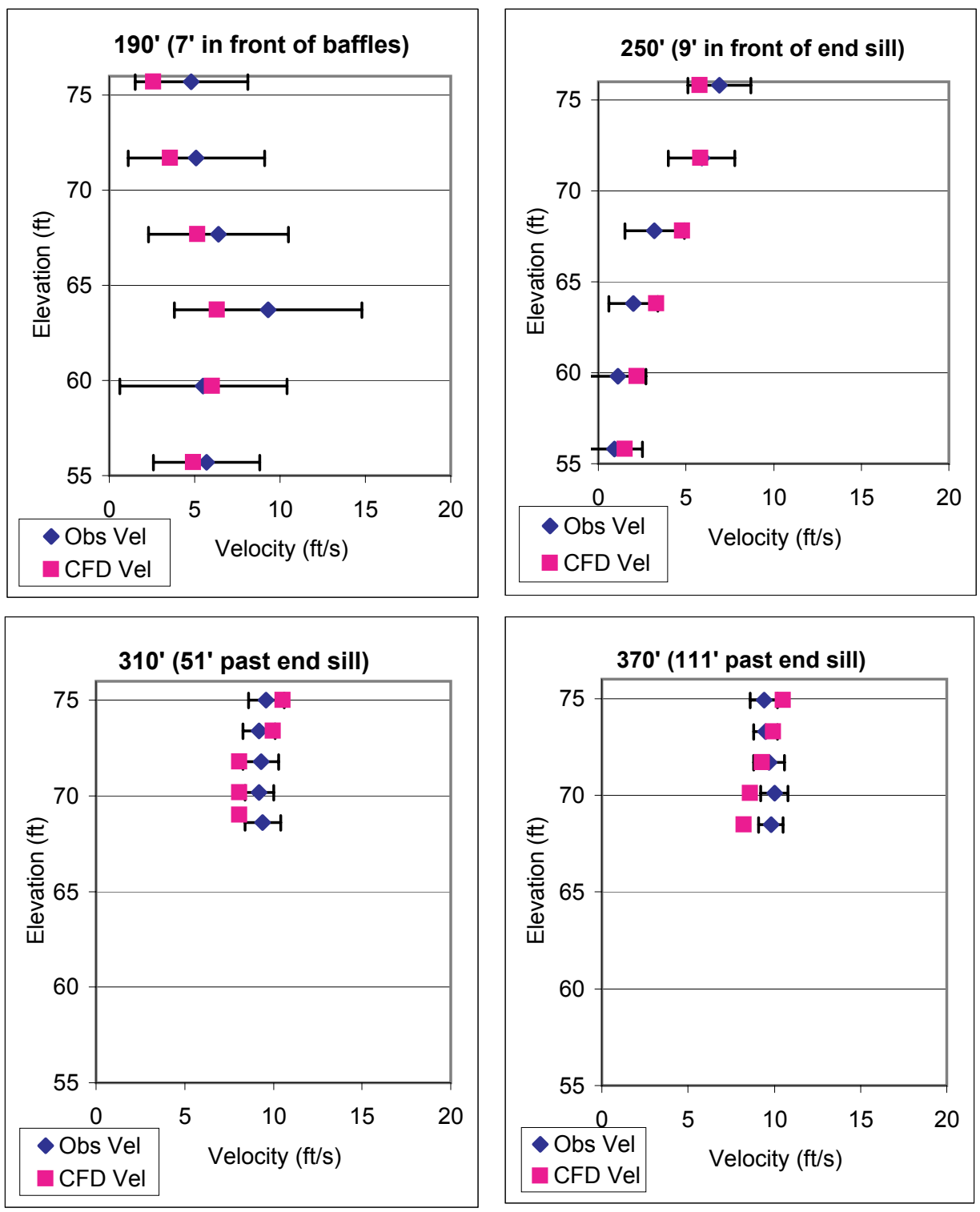

Figure D.15. Horizontal velocity component comparison between the 1:40 scale physical model and CFD model. Observed mean data have been plotted with blue squares with bars representing one standard deviation from the mean. 
Table D.2. Comparison of horizontal velocity data for the 1:40 scale TDA model.

\begin{tabular}{|c|c|c|c|}
\hline \multicolumn{4}{|c|}{ At 190' (7' in front of baffles) } \\
\hline Elevation & Obs Vel & Obs $\sigma$ & CFD Vel \\
\hline 55.7 & 5.7 & 3.1 & 4.9 \\
59.7 & 5.5 & 4.9 & 6.0 \\
63.7 & 9.3 & 5.5 & 6.3 \\
67.7 & 6.4 & 4.1 & 5.2 \\
71.7 & 5.1 & 4.0 & 3.6 \\
75.7 & 4.8 & 3.3 & 2.6 \\
\hline
\end{tabular}

\begin{tabular}{|c|c|c|c|}
\hline \multicolumn{4}{|c|}{ At 250' (9' in front of end sill) } \\
\hline Elevation & Obs Vel & Obs $\sigma$ & CFD Vel \\
\hline 55.8 & 0.9 & 1.6 & 1.5 \\
59.8 & 1.1 & 1.6 & 2.2 \\
63.8 & 2.0 & 1.4 & 3.3 \\
67.8 & 3.2 & 1.7 & 4.8 \\
71.8 & 5.9 & 1.9 & 5.8 \\
75.8 & 6.9 & 1.8 & 5.8 \\
\hline
\end{tabular}

\begin{tabular}{|c|c|c|c|}
\hline \multicolumn{4}{|c|}{ At 310'(51'downstream of end sill) } \\
\hline Elevation & Obs Vel & Obs $\sigma$ & CFD Vel \\
\hline 68.6 & 9.4 & 1.0 & 8.1 \\
70.2 & 9.2 & 0.8 & 8.1 \\
71.8 & 9.3 & 1.0 & 8.1 \\
73.4 & 9.2 & 0.9 & 10.0 \\
75.0 & 9.6 & 1.0 & 10.5 \\
\hline
\end{tabular}

\begin{tabular}{|c|c|c|c|}
\hline \multicolumn{4}{|c|}{ At 370' (111' downstream of end sill) } \\
\hline Elevation & Obs Vel & Obs $\sigma$ & CFD Vel \\
\hline 68.5 & 9.8 & 0.7 & 8.2 \\
70.1 & 10.0 & 0.8 & 8.6 \\
71.7 & 9.7 & 0.9 & 9.3 \\
73.3 & 9.5 & 0.7 & 9.9 \\
74.9 & 9.4 & 0.8 & 10.5 \\
\hline
\end{tabular}

\section{D.3 Tainter Gate Simulations}

A CFD model of a single TDA spillway bay was constructed to compute the velocity field upstream and immediately downstream of the tainter gates along the spillway face. Spillway face velocities were later used to determine upstream boundary conditions for the multiple-bay and bank-to-bank CFD simulations. CFD results upstream of the tainter gates were also later used by fish biologists to determine placement of live and sensor fish release pipes (see Section 3.2) and optimum aiming orientations for hydroacoustic instruments.

To reduce the computational effort required to operate the CFD model, the model domain was reduced to a single 2-D plane that passes through the centerline of a spillway bay. This approximation is appropriate for understanding hydraulic phenomenon in close proximity to the tainter gate centerline, however differences between the CFD model and prototype would be expected near the piers at each side of the tainter gate. Several 3-D phenomena occur near these piers, including vortices, which will not be captured by this 2-D model. Air-core vortices have been observed upstream of the tainter gates for some operational conditions. In addition, far upstream of the gate there will be a lateral component to the approach flow, the strength of which depends upon powerhouse and spillway conditions. If results far upstream of the gate are required, a 3D model (Rakowski et al. 2006) of the forebay which incorporates these lateral flows should be applied because these conditions are not represented by the 2-D model.

Water velocities were measured data upstream of a open tainter gate at The Dalles using a Sontek 
acoustic Doppler velocimeter (ADV) ${ }^{(\mathrm{a})}$ Cables were strung along Lines A and B (see Figure D.16), which were then used to lower an ADV to different depths. At each of these depths, the ADV collected multiple individual velocity readings that were later averaged into ensemble means to form a validation dataset for a 2-D Flow-3D model of The Dalles spillway.

The CFD model domain extended approximately $100 \mathrm{ft}$ upstream of the tainter gate. The gate was fixed at a set opening ( $1 \mathrm{ft}, 3 \mathrm{ft}$, or $5 \mathrm{ft}$ ) and a uniform upstream forebay elevation of $158.6 \mathrm{ft}$ was applied.

Measured versus simulated velocity magnitudes are compared in Figure D.17. Due to the harsh flow conditions (shedding vortices and high velocities) along Line B, the ADV was not stable at many of the depths along that line. Therefore, a complete velocity profile along the entire line was not collected. A partial data set, collected when the spillway gate was open $5 \mathrm{ft}$, was also compared to CFD model results (Figure D.17). Tables D.3 summarizes the error statistics comparing the measured and simulated velocity magnitudes. Mean absolute error (MAE) was less than $0.25 \mathrm{ft} / \mathrm{s}$ for all cases simulated. The simulated discharge, discharge from the CENWP rating curve ${ }^{(\mathrm{b})}$, and their difference is listed in Table D.4.

Table D.3. Summary of velocity magnitude error statistics for the tainter gate validation simulation cases.

\begin{tabular}{ccccc}
\hline \hline Gate Opening (ft) & Meas. Line & Bias (ft/s) & MAE (ft/s) & RMS (ft/s) \\
\hline 1 & A & 0.02 & 0.11 & 0.14 \\
3 & A & 0.06 & 0.15 & 0.25 \\
5 & A & 0.09 & 0.25 & 0.30 \\
5 & B & 0.04 & 0.19 & 0.25 \\
\hline \hline
\end{tabular}

Table D.4. Comparison of computed discharge and discharge obtained from CENWP rating curve.

\begin{tabular}{ccccc}
\hline \hline Forebay Elev. (ft) & Gate Opening (ft) & Simulated (cfs) & Rating Curve (cfs) & Difference \\
\hline 158.6 & 1 & 1621 & 1438 & $12 \%$ \\
158.6 & 3 & 4514 & 4394 & $2.7 \%$ \\
158.6 & 5 & 7434 & 7329 & $1.4 \%$ \\
\hline \hline
\end{tabular}

(a) M. A. Weiland, unpublished data.

(b) P. Williams, personal communication. 


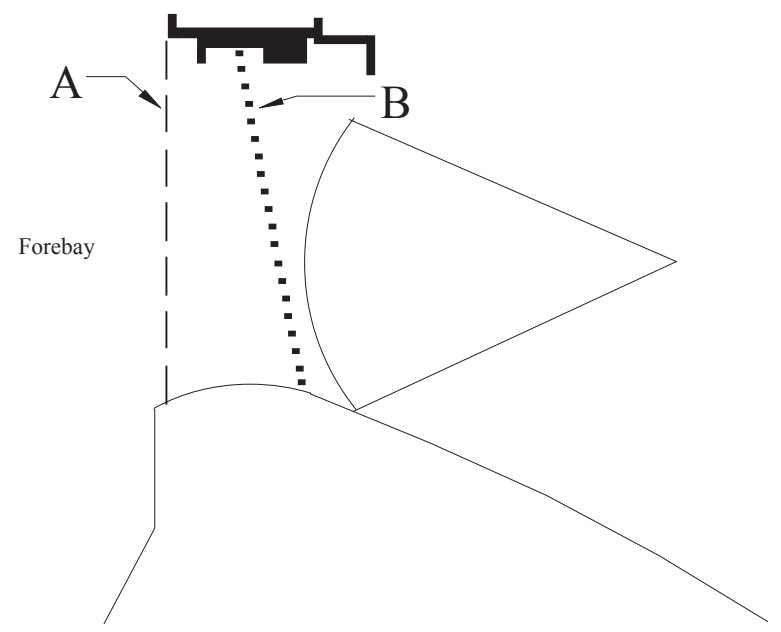

Figure D.16. Cross-sectional view of the spillway bay where ADV measurements were performed. Line A is near the pier nose and Line B is near midpoint of the bay at bridge deck to near the opening. 
Line A

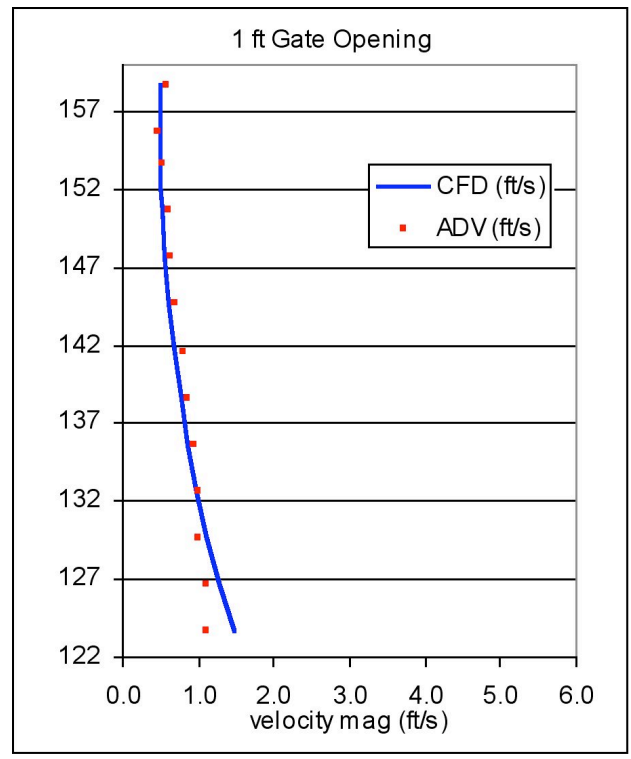

Line A

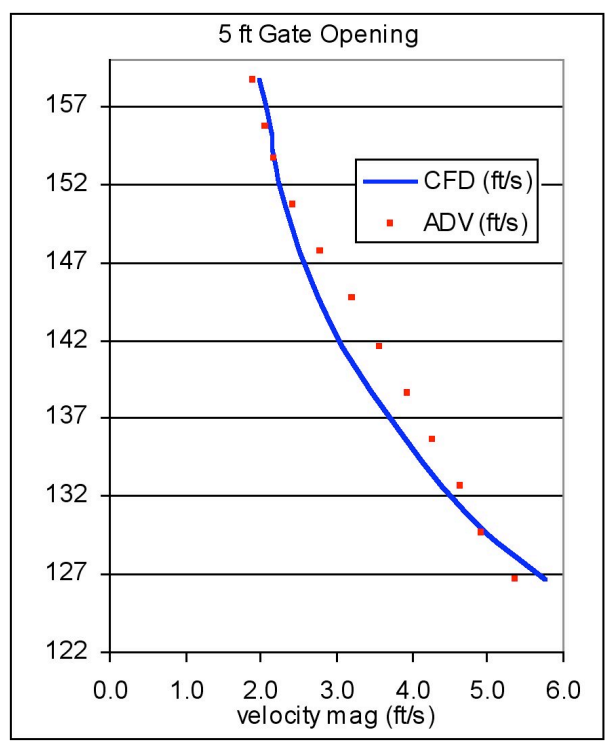

Line A

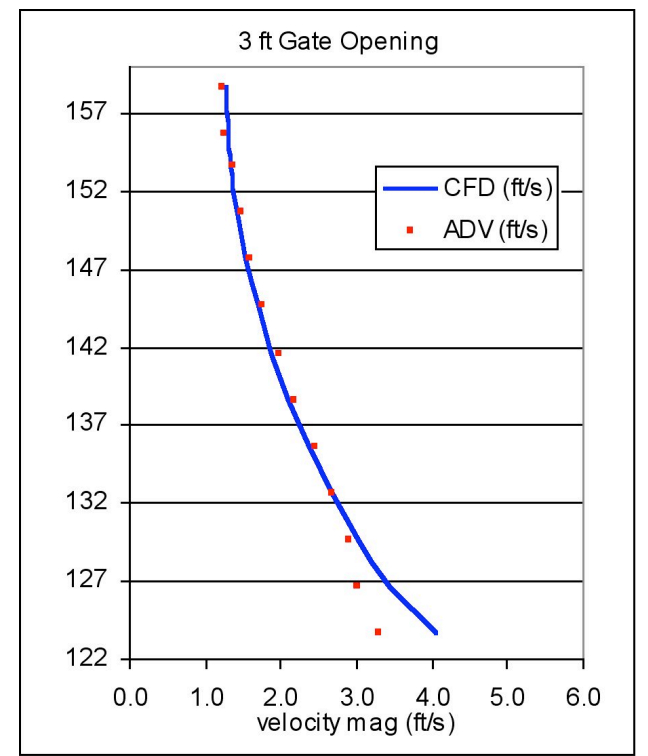

Line B

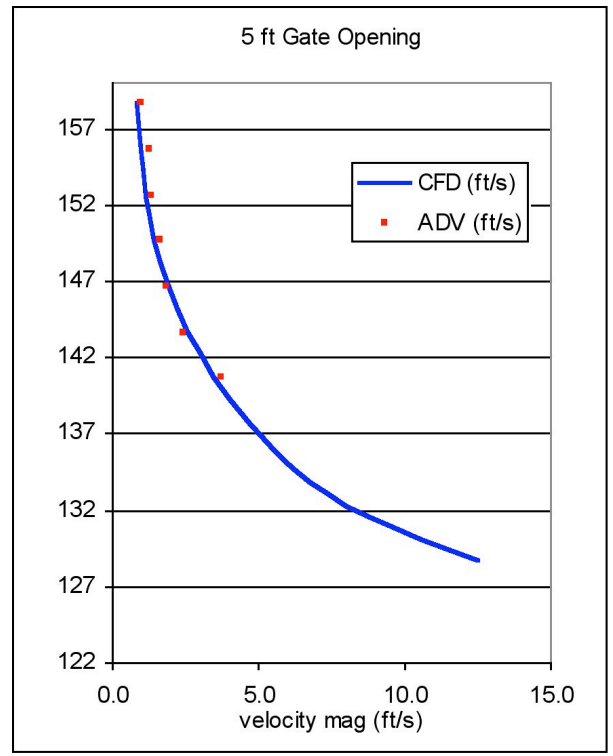

Figure D.17. Comparison of measured and computed velocity magnitude profiles upstream of a tainter gate at The Dalles. All profiles were measured along Line A (see Figure D.16) except for one partial profile along Line B at a $5 \mathrm{ft}$. gate opening. 


\section{D.4 References}

BHL. 1952. Spillway and Stilling Basin for The Dalles Dam Columbia River, Oregon and Washington. 1-6, Bonneville Hydraulic Laboratory, , US Army Engineer District, Portland.

BHL. 1964. Spillway and Stilling Basin for The Dalles Dam Columbia River, Oregon and Washington, Hydraulic Model Investigation. 55-1, Bonneville Hydraulic Laboratory, , US Army Engineer District, Portland.

Preslan W and S Wilhelms. 2001. Dalles, Metrics Feasibility Study Draft submitted to Portland District, USACE. ERDC, Vicksburg, MS.

Rakowski CL, MC Richmond, JA Serkowski, and GE Johnson. 2006. Forebay Computational Fluid Dynamics Modeling for The Dalles Dam to Support Behavior Guidance System Siting Studies. PNNL-15689, Pacific Northwest National Laboratory, Richland, WA. 